\title{
Therapeutics: Key to well being
}

Edited by

Tathagata Ray Chaudhuri

Adity Sarbajna

Sandeep Poddar

Amiya Bhaumik

\section{Published by :}

Lincoln Research and Publications Limited, Australia in collaboration with

Lincoln University College, Malaysia

www.lincolnrpl.org $\quad$ www.lucp.net 


\section{Therapeutics: Key to well being}

\section{Edited by}

Tathagata Ray Chaudhuri

Associate Professor, Department of Botany

Asutosh College, Kolkata, India

Adity Sarbajna

Assistant Professor, Department of Zoology

Surendranath College, Kolkata, India

Sandeep Poddar

Deputy Vice Chancellor (Research \& Innovation)

Lincoln University College, Malaysia

Amiya Bhaumik

President

Lincoln University College, Malaysia

Published by :

Lincoln Research and Publications Limited, Australia

in collaboration with

Lincoln University College, Malaysia 
Copyright (C2021

Lincoln Research and Publications Limited, Australia and Lincoln University College, Malaysia

All rights reserved

No part of this book can be reproduced or transmitted by any means, electronic or mechanical, including photocopying recording or by any information storage and retrieval system without prior written permission from the publisher.

Published on: $30^{\text {th }}$ November 2021

\section{Published by:}

Lincoln Research and Publications Limited

144A, Marsden Road

Ermington, Sydney

NSW 2115

Australia

Tel.: +61-411497511

E-mail: info@lincolnrpl.org

Web.: www.lincolnrpl.org

in collaboration with

\section{Lincoln University College}

Wisma Lincoln

No. 12-18, Off Jalan, Perbandaran SS 6/12

47301 Petaling Jaya

Selangor Darul Ehsan

Malaysia

Tel.: +603-7806 3478

Fax: +603-7806 3479

Toll Free: 1-300-880-111

E-mail: lucp@lincoln.edu.my

Web.: www.lucp.net

ISBN: $\quad 978-0-6488798-4-8$

elSBN 978-967-2819-01-1

doi:10.31674/book.2021.tkwb

Price: AUD 50 


\section{Editors}

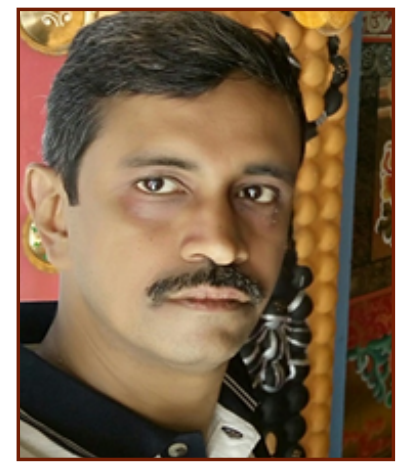

\section{Tathagata Ray Chaudhuri}

Associate Professor, Department of Botany

Asutosh College, Kolkata, India

Dr. Tathagata Ray Chaudhuri is presently Associate Professor, Department of Botany, Asutosh College, Kolkata. He completed his Ph.D. from Bose Institute Kolkata in Plant Biotechnology. He served as the Head of the Department of Botany and Environmental Science departments at Asutosh College and is presently Prof-in-Charge of Academic Affairs, Asutosh College. He has published several research papers in the areas of Plant Biotechnology and Molecular Plant Pathology.

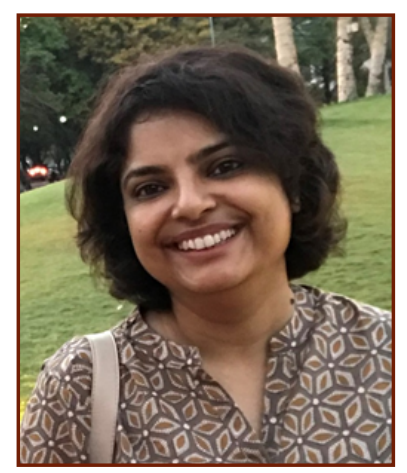

\section{Adity Sarbajna}

Assistant Professor, Department of Zoology

Surendranath College, Kolkata, India

Dr. Adity Sarbajna is an Assistant Professor in Department of Zoology, Surendranath College, Kolkata. She did her Ph.D. from University of Calcutta on Aquaculture and Fisheries. She is a passionate teacher with keen interest in research. She has received several awards in her academic career, authored and edited National as well as International publications and has completed a number of research projects funded by various departments under Government of West Bengal, India.

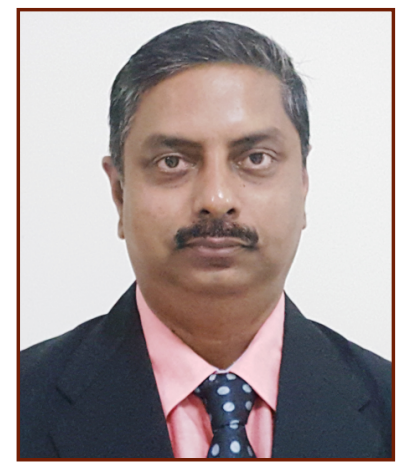

\section{Sandeep Poddar}

Deputy Vice Chancellor (Research \& Innovation)

Lincoln University College, Malaysia

Prof. Dr. Sandeep Poddar, presently the Deputy Vice Chancellor (Research \& Innovation) of Lincoln University College, Malaysia. He also served as Senior Research Director and Executive Editor(Publications), Lincoln University College, Adjunct Faculty (Honorary), Bharat Center Canada. He has graduated from University of Calcutta in 1993 with Honours in Zoology, he has obtained Post Graduate Diploma in Dietetics from All India Institute of Hygiene and Public Health 1995, Master of Science in Zoology with specialization in Biochemical Genetics from Dayalbagh Educational Institute 1998 with distinction. In addition to this he also obtained Master of Business Administration (MBA) from Lincoln University College in 2021. He has completed Ph.D. in Zoology from Vivekananda Institute of Medical Sciences on Cytotoxicity in 2004. After completing Ph.D. he pursued Post Doctoral Research in different projects on Hemoglobinopathies and Oral Cancer mutation. He is serving as reviewer of several International Journals. He has published several research papers, organized international conferences, and edited books in Malaysia, Australia and India. Dr. Sandeep is founder Assistant Secretary of Dr. Tarak Nath Podder Memorial Foundation, Kolkata, India.

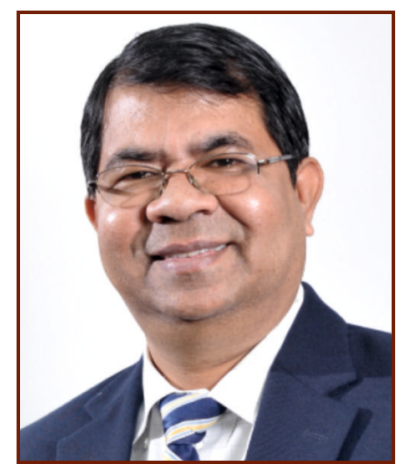

\section{Amiya Bhaumik \\ President \\ Lincoln University College, Malaysia}

Dr. Amiya Bhaumik is the Founder and Former Vice-Chancellor of Lincoln University College. He is purely from the field of education. Dr. Bhaumik is Executive Vice President of the International Education Consulting Group, St. Louis, USA since 1999. Dr. Amiya Bhaumik was Research Fellow of UNESCO, Paris. During this tenure, Dr. Bhaumik has traveled extensively to Europe, Africa, Asia and Latin America. He has served as Professor of Business Administration in University of Lucknow, India and in University of Malaya and many other places. Dr. Amiya Bhaumik is a very dynamic personality. He has authored numerous book chapters and has huge number of publication in many national and international journals. He has also edited several books. 

An Overview of the Properties and Pharmaceutical uses of Bioactive Compounds from Sesame (Sesamum indicum L.)

Aritrika Sinha, Abhishek Das, Rishita Chakraborty, Suranjana Sarkar

A Synoptic Review on the Pharmacological Properties of Ocimum sanctum L.

Sayantika Roy, Swadhin Murmu, Swagata Mondal, Sonali Ray

Investigational Treatment of Covid-19

Rudra Prasad Maiti, Abhik Kumar Manna, Ashish Ranjan, Lalita Das

The Story of Aspirin: - Journey from Willow to Wander Drug

Krishnendu Chatterjee, Tiasa Chatterjee, Apurba Biswas

Ethnomedicinal Uses in West Bengal, India

Pritha Manna, Nilufa Nasrin, Abontika Das, Jayanta Sikdar

Monoclonal Antibody in Cancer Therapy: Overview

Himadri Chakraborty, Mainak Mukherjee, Subhadra Roy

Review on Ruthenium (II) Anticancer Complexes: Challenges and Expectation

Rajdeep Chakraborty, Arijit Banerjee, Lalita Das

Investigating the Pathomechanisms of Diabetic Retinopathy: The Cost of Diabetes 



\section{Editorial}

Therapeutics are medications that are used to treat or prevent an illness. Drug therapy, medical gadgets, nutrition therapy, and stem-cell therapies are all examples of therapeutics. Therapeutics can be used in patients to treat the disease or its symptoms, as well as in preventative medicine and palliative care.

Tinospora cordifolia (Willd.) Miers is a well-known indigenous medicinal plant belonging to the family Menispermaceae. The herb is extensively used in traditional medicine for treatment of chronic fever related to dengue and malaria. It is also recommended as ayurvedic treatment to increase immunity and improve digestive ailments.

India, West Bengal has a sizable number of medicinal plants because of different weather conditions. West Bengal is one and only state in India where Darjeeling Himalayas are within the north and Sundarbans areas are in the south with meadowlands and uplands covering a vicinity with a variety of medicinal plants. The traditional system of public health care has been effectively used, over many years to treat illnesses in West Bengal. In tribal culture of West Bengal traditional medicine can be an awfully sound and reputed medical system. This 21 st century totally believes in modern medical system, but tribal peoples avoid allopathic and homeopathic medicine to cure their disease.

Sesame plant is used for numerous purposes. It is used in different culinary processes. It also has applications in pharmaceutical, industrial, and engineering industry. Different phytonutrients, some flavonoid phenolic antioxidants, several vitamins and dietary fibre which have medicinal properties. It has other proven medicinal benefits such as anti-inflammatory, anti-microbial, anti-hypertensive, antipyretic, anticancer and few additional properties. As a result, the sesame plant has a bright future in the medical arena, with the potential to improve and enhance the eminence of life of mankind.

The tremendous pharmacological activities and a wealth of available literature make Ocimum sanctum one of the most valuable herbs in the plant kingdom. The pharmaceutical activities of the herb results from the amalgamated and synergistic interactions of the different phytochemicals present. This widespread herb is easily available in India and other neighbouring countries, growing both in wild and cultivated forms. The extensive range of the properties of its chemical constituents makes it a potential entity for more detailed clinical research. More investigations will establish the prospects of using the plant and its active novel chemical constituents in a large scale in modern medicine.

Several Covid-19 medicines are being used un-licensed due to pandemic. For this reason, a long-term data was needed for a proper evaluation in their efficiency and safety. So, this review is about a detailed investigation of several possible treatment of covid-19, which can guide pharmacist and therapist in the time of pandemic.

The cheapest and most frequently used drug in medicine is Aspirin. In the wide range of pharmacological area, it is a non-steroidal anti-inflammatory drug, including antipyretic, analgesic, and antiplatelet assets. Aspirin has been long used as a beneficial analgesic and antipyretic. Even in historical times, salicylate-containing flora inclusive of the willow had been typically used to alleviate ache and fever.

Cisplatin or cis-diamminedichloridoplatinum (II) is one of the most successful and efficient chemotherapeutic drugs for the treatment of various types of malignancies, including bladder, testis, ovary, head and neck, lung cancer, germ cell tumors, lymphomas, sarcomas, and many others. Cisplatin molecules bind with DNA to form an adduct which finally transduces several signalling pathways, resulting in apoptosis and cell death. Unfortunately, neither cytotoxicity nor apoptosis are completely generated in cancer cells. Therefore, cisplatin may have a variety of side effects that limit its use and effectiveness.

The study of distinct cultural approaches to health, sickness, and illness, as well as the nature of local therapeutic systems, is known as ethnomedicine. Ethnomedicinal research are important for the discovery of novel crude medicines from indigenous medicinal plants that have been described. Ethnobotanical research is critical for the development of new medicines derived from plant species that are part of the world's indigenous heritage. Medicinal herbs are frequently utilised as cosmetics, 
flavours, oils, bitters, spices, sweeteners, pesticides, and death agents to assist relieve human misery. Monoclonal antibodies are immune system proteins that are manufactured in a laboratory. Antibodies are proteins that are produced naturally by the body that assist the immune system in recognising and destroying disease-causing organisms such as bacteria and viruses. Monoclonal antibody medicines are cancer treatments that use body's germ-fighting immune system to combat disease.

Therefore, therapeutic effect refers to the response to any therapy whose outcomes are deemed useful or favourable. This is true whether the outcome was anticipated, unanticipated, or even unintended. Consequently, therapeutics is used in patients with active disease - to treat the disease itself or its signs and symptoms - in preventive medicine, or as palliative care.

The editors would like to thank all the authors for their contribution in such varied topics that will help to create awareness about therapeutics for serving and caring for the patient in a comprehensive manner, preventing disease as well as managing specific problems. The editors are also thankful to the Principal, Surendranath College, Kolkata, India, Management of Lincoln University College, Malaysia and Lincoln Research \& Publishing Limited, Australia for giving them the necessary permission to publish this book. We are also thankful to Department of Biotechnology, Government of India for providing the financial assistance. This book provides knowledge about different medicine that deals specifically with the treatment of disease and the art and science of healing. The researchers here deal with varied topics of therapeutics accordingly, to refer to the use of drugs and the method of their administration in the treatment of disease.

Tathagata Ray Chaudhuri

Adity Sarbajna

Sandeep Poddar

Amiya Bhaumik 


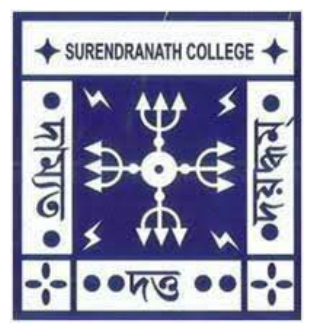

\title{
Surendranath College
}

24/2, Mahatma Gandhi Road, Kolkata - 700 009, India

Phone: (033) 2350 2864, 2354 3876, Fax: (033) 23502864

E-mail: snlcollege@gmail.com, Web.: www.snlawcollege.ac.in

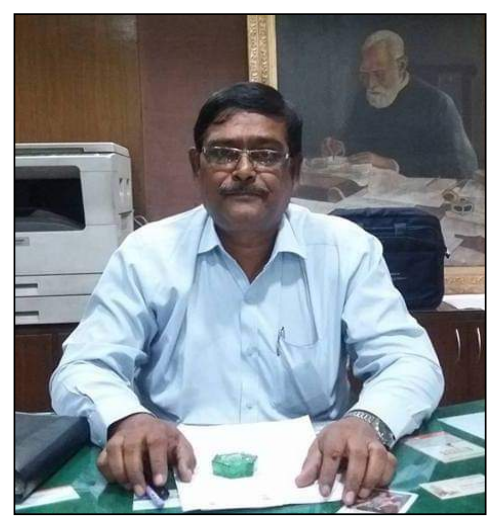

\author{
Dr. Indranil Kar \\ M.Sc., Ph.D. \\ Principal \\ Surendranath College \\ Kolkata, India
}

\section{FOREWORD}

It is my great pleasure to introduce this book titled as "Therapeutics: Key to well being," a collection of review articles written by the undergraduate students of the four DBT STAR departments of Surendranath College, Kolkata, covering a wide range of contemporary themes on current advances in various areas of therapeutics, under able mentorship of their faculty members as mentors.

The volume consists of twelve chapters and pursues specific objectives while complementing the existing literature on different areas of therapeutic sciences. It explores the scope of future developement in various related emerging fields and analyses the challenges in doing so. I extend special thanks and underline my deepest appreciation to the publisher for publishing this issue, Department of Biotechnology, Government of India for providing the financial assistance and all the editors of this book for their real hard work and sincere effort in bringing out this wonderful volume.

While I hope this collection will have particular appeal to all the new young readers in this field, I am confident that the volume will raise interest among our regular readership of scholars and practitioners elsewhere as well, thanks to the relevance and diversity of contributions compiled here in this volume.

Happy reading to all!

Dr. Indranil Kar

Principal

Surendranath College

Kolkata, India 



\title{
Medicinal Properties of Tinospora cordifolia (Willd.) Miers: A Review
}

\author{
Trina Bhattacharya, Riya Mondal, Rubia Khatoon, Rumi Kundu, Dipasree Roychowdhury* \\ Department of Botany, Surendranath College, Kolkata, India \\ *Corresponding Author's Email: dipasree.roychowdhury@yahoo.com
}

\begin{abstract}
Tinospora cordifolia (Willd.) Miers is a well-known indigenous medicinal plant belonging to the family Menispermaceae. The plant is commonly known as 'Giloy' or 'Guduchi' in India and is extensively found in the tropical regions of the country. The roots, stems, and leaves of this indigenous plant have been used in different herbal medicine formulations for ages, including in the treatment of jaundice, diabetes, heart disease, different types of arthritis, urinary tract infections, and as an antiseptic, to name a few. The herb is extensively used in traditional medicine for treatment of chronic fever related to dengue and malaria. It is also recommended in ayurveda to increase immunity and improve digestive ailments. In the last three decades, pre-clinical research has provided tremendous evidence of a varied range of the claimed pharmacological properties in animal models and in vitro studies, namely, hypo-glycaemic activity, anti-pyretic activity, anti-microbial activity, hepato-protective activity, neuro-protective and neuro-regenerative properties, etc. This review is aimed at an up to date compilation of the recent advancements in the field of pharmacological research in Tinospora cordifolia.
\end{abstract}

Keywords: Tinospora cordifolia, Giloy, Guduchi, Medicinal Value, Pharmacological Properties

\section{INTRODUCTION}

Tinospora cordifolia (Willd.) Miers (Family-Menispermaceae; Synonym-Menispermum cordifolium Willd.) is a large deciduous climbing shrub, native to the tropical areas of India, Sri Lanka, Myanmar, and other parts of South-East Asia, as well as in Africa (The Plant List, 2013). In India, it is distributed throughout the tropical regions, extending from Assam and West Bengal in the east to Maharashtra in the west, from Delhi in the north to Kerala and Karnataka in the south. T. cordifolia is one of the wellknown traditional medicinal plants extensively used in the treatment of various diseases in Ayurveda, Unani, and Siddha medicine from ancient times. T. cordifolia is commonly known as' Guduchi 'in Marathi,' Giloy'/Giloi'/'Gilai' in Hindi, 'Gulancha' in Bengali, 'Galo' in Guajarati, 'Geloi' and' Amarlata 'in Assamese,' Guluchi 'in Oriya,' Gilo 'in Punjabi,' Tinospora' in English, etc. In traditional medicine, the plant extracts have been used in the treatment of dysplasia, jaundice, urinary tract infection, diabetes, heart diseases, rheumatoid arthritis, digestive diseases, and many more (Nadkarni \& Nadkarni,1976). The most important secondary metabolites of $T$. cordifolia responsible for its medicinal properties are: alkaloids like tinosporine, tinosporaside, magnoflorine, berberine, and coline; sterols like giloinsterol and -sitosterol, in addition to the most common glucoside, amritoside (Choudhary et al., 2013). This review is aimed at providing an up-to-date compilation status of the recent advances in research on various pharmacological properties of T. cordifolia.

\section{REVIEW LITERATURE}

\section{Pharmacological properties of Tinospora cordifolia}

In the last three decades, extensive research has provided proof of plethora of pharmacological properties of different parts of the plant (Figure 1). T. cordifolia is reported to have array of medicinal properties like- anti-diabetic (Stanely Mainzen Prince \& Menon,2000, 2003; Sonkamble \& Kamble, 2015; Chacko, 2018; Khanal et al., 2019; Vora et al., 2020), anti-pyretic (Pendse et al., 1977; Ashok et al., 2010; Hussain et al., 2015; Rakib et al., 2020), hepato-protective (Bishayi et al., 2002; Panchabhai 
et al., 2008; Rakib et al., 2020), cardio-protective (Rao et al., 2005; Sharma et al., 2011a; Priya et al., 2017; Begum et al., 2021), neuro-protective (Kosaraju et al., 2014; Sharma \& Kaur 2018; Birla et al., 2021), anti-allergic, anti-oxidant (Sharma \& Joshi, 2011; Praveen et al., 2012; Prasad \& Chauhan, 2019), anti- tumour (Jagetia, Nayak \& Vidyasagar, 1998; Jagetia \& Rao, 2006; Deepa et al., 2019; Palmieri et al., 2019), radio-protective (Goel et al., 2004; Sharma et al., 2011b; Patel et al., 2013) immuno-modulatory (Bishayi et al., 2002; Nageswari, Reddy \& Venkatappa, 2018), anti-ulcer (Sarma et al., 1995; Bairy et al., 2002; Kaur, Singh \& Kumar, 2014), anti-fertility (Gupta \& Sharma, 2003; Ittiavirah \& Rahman, 2013), anti-microbial (Jeyachandran, Xavier \& Anand, 2003; Mishra et al., 2014; Chowdhury, 2020), etc. Recently the plant gained attention due to reports of antiviral property against Covid-19 (Chowdhury, 2020).

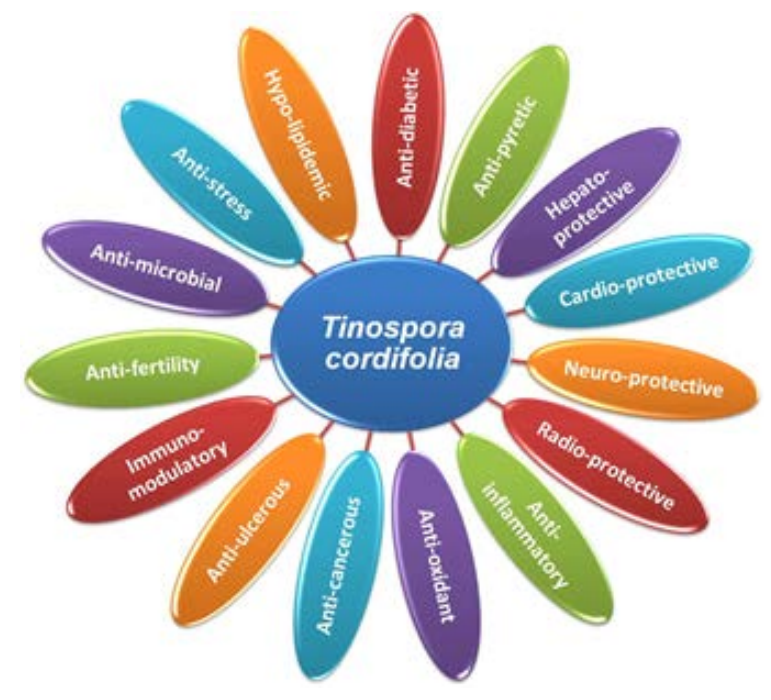

Figure 1: Pharmacological properties of Tinospora cordifolia (Willd.) Miers

\section{DISCUSSION}

\section{Anti-diabetic Activity:}

Tinospora cordifolia has been used in the treatment of diabetes since ancient times. Various pharmacological studies have proved the hypoglycaemic properties of the plant, especially in root extracts. The anti-hyperglycaemic effect of aqueous and alcoholic extracts as well as lyophilized powder of the plant has been reported to be effective in pre-clinical trials on drug-induced diabetic animals as well as cell cultures. Oral administration of alcoholic extracts of $T$. cordifolia roots is reported to significantly reduce blood glucose and urine glucose in alloxan-dependent diabetic rats (Stanely Mainzen Prince \& Menon, 2000, 2003). Aqueous solution of the plant extract significantly reduced blood glucose levels in Streptozotocin-induced diabetic rats as well (Chacko, 2018). Tinospora extract has been shown to have better hypoglycaemic activity when co-administered with other conventional drugs. Aqueous extract of T. cordifolia co-administered with drugs like metformin, sitagliptin, and glibenclamide has been reported to show better management of diabetes and its related co-morbidities in streptozotocin-induced diabetic rats compared to those administered individually (Vora et al., 2020). Further, the plant extract did not show any pharmacokinetic interaction with drugs administered. The phenolic compounds present in extracts of $T$. cordifolia are suggested to be responsible for the anti-diabetic effects which act by inhibiting alpha-amylase and beta-glucosidase activity (Sonkamble \& Kamble, 2015). Khanal et al., (2019) identified nine secondary metabolites of $T$. cordifolia involved in modulation of proteins related to diabetes, among which, tembetarine is suggested to be the most important one responsible for anti-diabetic properties. It works by modulating the majority of diabetic proteins, specifically modulating neuro-active ligand-receptor interactions (Khanal et al., 2019). 


\section{Anti-oxidant Activity:}

The antioxidant property of root extracts of $T$. cordifolia has been studied for a long time. Oral administration of aqueous root extracts of the plant has shown significant antioxidant properties against alloxan drug induced diabetes rats (Stanely Mainzen Prince \& Menon 1999, 2001; Stanely Mainzen Prince, Padmanabhan \& Menon, 2004). Both aqueous and alcoholic extracts of $T$. cordifolia cause a decrease in the levels of marker compounds related to lipid peroxidation, namely-plasma thiobarbituric acid reactive substances and -tocopherol, and thus are suggested to reduce oxidative stress (Stanely Mainzen Prince \& Menon, 1999; Stanely Mainzen Prince, Padmanabhan \& Menon, 2004). It simultaneously causes an increase in the levels of glutathione and vitamin $C$ in the test subjects, thus helping in combating free radicals (Stanely Mainzen Prince \& Menon 1999). 'Giloy' extracts (5g/kg body weight) are also reported to significantly increase the reduced catalase, glutathione, and superoxide dismutase activity in drug-induced diabetic rats (Stanely Mainzen Prince \& Menon, 2001; Stanely Mainzen Prince, Padmanabhan \& Menon, 2004). Some reports suggest extraction methods have a prominent impact on the antioxidant properties of the plant. Praveen et al. (2012) observed extracts of leaves of $T$. cordifolia to score the highest antioxidant activity compared to ethyl acetate, butanol and aqueous extracts. In another report, an ethanolic extract of $T$. cordifolia leaves showed promising free radical scavenging potency that was significantly superior to aqueous and methanolic extracts of the same (Sharma \& Joshi, 2011). This observation was supported recently by Prasad and Chauhan (2019), where the total phenolic content and antioxidant activity of ethanolic extracts from both stem and roots of $T$. cordiolia proved to be significantly higher than the other solvents tested. In this study, ethanolic stem extracts of the plant scored significantly better in both hydrogen peroxide scavenging (87\%) and hydroxyl free radical scavenging (91\%) activities (Prasad \& Chauhan, 2019).

\section{Anti-pyretic Activity:}

Giloy' is well known for its fever reducing or preventing properties in traditional medicines. Anti-pyretic activity of the plant extracts in animal models is being studied for more than three decades (Pendse et al., 1977; Leghari, Muzaffar \& Haq,1984; Ikram, Khattak \& Gilani,1987; Vedavathy \& Rao, 1991). Pendse et al., (1977) reported the antipyretic activity of aqueous stem extract of $T$. cordifolia in albino mice, while Leghari, Muzaffar and Haq (1984) and Ikram, Khattak and Gilani (1987) observed similar activity in Himalayan rabbits. Ethanolic extracts of the Tinospora cordifolia stem showed very effective in reducing fever in Yeast induced pyrexia in albino rats (Vedavathy \& Rao, 1991; Ashok et al., 2010). Aqueous- methanolic extract of the whole plant showed anti-pyretic effect in dose dependent manner in similar animal models (Hussain et al., 2015). In recent studies, methanolic extracts and its sub-fractions showed anti-pyretic activity in dose dependent manner and in silico studies suggested the probable mode of action for such activity to be modulated by the phytochemical, genkwanin in Tinospora crispa (Rakib et al., 2020).

\section{Anti-inflammatory Activity:}

Aqueous extracts of $T$. cordifolia showed significant anti-inflammatory and immuno-suppressive properties in albino rats and rabbits respectively (Pendse et al., 1977). Similar anti-inflammatory activity against carrageenan induced paw edema model in albino mice is reported for aqueous and aqueous methanolic extracts of T. cordifolia respectively (Patgiri et al., 2014; Hussain et al., 2015). Philip, Tom and Vasumathi (2018) elucidated the mechanism of anti-inflammatory potential of this plant at the molecular level. In this in vitro study, chloroform extracts of $T$. cordifolia significantly reduced up-regulation of pro-inflammatory biomarkers with minimum inhibition of cyclooxygenase-1 enzyme expression in the process, thus making the 'Giloy' an ideal plant for development of antiinflammatory drug in future (Philip, Tom \& Vasumathi, 2018).

\section{Hypo-lipidaemic Activity:}

Alternative therapy for the treatment of high blood cholesterol and other blood lipids has attracted much attention in recent days due to the increase in abnormal baseline lipid levels of adults worldwide in their 
30s. Of the different herbal drugs used traditionally for such treatment aimed at side-effect-free intervention for lipid reduction in the blood, the roots of 'Giloy' are noteworthy. Different pharmacological studies supported the hypolipidemic activity of the plant in pre-clinical studies. Stanely, Mainzen, Prince, Menon, and Gunasekaran (1998) discovered a hypolipidaemic effect in Tinospora cordifolia root aqueous extract. In the study, aqueous extracts of the roots administered (2.5-5 g/kg body weight) to alloxan-induced diabetic rats for 6 weeks showed a significant reduction in serum and tissue cholesterol, phospholipids, and free fatty acids in test subjects. The root extract at a dose of $5 \mathrm{~g} / \mathrm{kg}$ body weight showed the highest hypolipidaemic effect (Stanely Mainzen Prince, Menon \& Gunasekaran, 1998). Similar activity is also reported in alcoholic extracts of the Tinospora roots, where oral administration of the extracts for 6 weeks resulted in a reduction of lipids in serum and tissues in the treated animal subjects (Stanely Mainzen Prince \& Menon, 2003). In another study, administration of aqueous extract of $T$. cordifolia at a much lower dose, viz. $200 \mathrm{mg} / \mathrm{kg}$ body weight, decreased serum glucose, cholesterol, triglycerides, creatine kinase, and free fatty acids to a normal level when compared to that of a standard drug in diet-induced hyperlipidemic rats (Vetrivadivelan et al., 2012).

\section{Cardio-protective Activity:}

Tinospora cordifolia not only reduces blood and serum lipid levels, but also provides overall protection of the cardio-vascular system, as evident from reports on cardio-protective activity in different studies conducted with alcoholic and aqueous extracts of the plant in pre-clinical studies (Rao et al., 2005; Sharma et al., 2011a; Priya et al., 2017; Begum et al., 2021). The restoration of blood supply to the ischemic tissue frequently results in injury or cellular damage, which is known medically as ischemiareperfusion injury (IR-injury).Whole plant of T. cordifolia extracted with alcohol, showed a beneficial effect on partial reversion of IR-injury when pre-treated with the plant extract before inducing myocardial ischemia in rat models (Rao et al., 2005). Oxidative stress is suggested to be one of the major pathways responsible for IR-injury, and thus, anti-oxidants can play an important role in preventing cellular damage progression. As discussed earlier, T. cordifolia is rich in anti-oxidants, which is suggested to have contributed to the cardio-protective role of the plant against IR-injury (Rao et al., 2005).

In addition, Sharma et al. (2011a) reported similar cardio-protective activity of alcoholic extract of the whole plant of $T$. cordifolia in calcium chloride induced arrhythmia in rats. Methanolic stem extract of the medicinal plant showed a noticeable protective effect on cadmium-induced cardiotoxicity in male Wistar rats (Priya et al., 2017). A recent study with aqueous leaf extracts of $T$. cordifolia by Begum et al., (2021) showed similar cardio-protective potential of the plant leaf against cisplatin-induced cardiotoxicity in animal models.

\section{Hepato-protective Activity:}

The medicinal plant Tinospora cordifolia is used in various traditional healing systems worldwide including preventing damage to the liver due to various reasons. T. cordifolia extract protected the liver in carbon tetrachloride induced hepatic damage in rats. Administration of the plant extract $(100 \mathrm{mg} / \mathrm{Kg}$ body weight) significantly reduced biomarkers for liver damage like- reduction in levels of serum glutamate oxaloacetate transaminase (SGOT), serum glutamate pyruvate transminase (SGPT), alkaline phosphatase (ALP) and bilirubin in blood of test subjects. T. cordifolia extract also eliminated the immune-suppressive effects of carbon tetrachloride, suggesting Tinospora sp. to be a promising herb for development of protection against liver damage (Bishayi et al., 2002). Rakib et al., (2020) recently reported similar hepato-protective property by in silico approach in carbon tetrachloride induced animal model with crude organic extract and various sub-fractions of Tinospora crispa. 'Giloy' have also been reported to have protective property against anti-tubercular drug induced hepatic damage when administered alone or in combination with Phyllanthus emblica (Panchabhai et al., 2008).

\section{Neuro-protective Activity:}

Loss of dopaminergic neurons, the main source of dopamine in the mammalian central nervous 
system, is associated with Parkinson's disease, which is categorised as one of the most well-known neurological disorders in human beings. The majority of conventional drugs used in treatment have numerous unfavourable side effects. The ethno-medicinal plant, 'Giloy', has neuro-protective properties as revealed by various studies involving Parkinson's disease in animal models. Ethanolic extracts of Tinospora cordifolia showed significant protective function against 6-hydroxy dopamine induced Parkinson's disease in rat models by reducing accumulation of iron and protecting dopaminergic neurons (Kosaraju et al., 2014). The neuro-protective and neuro-regenerative capacity of the plant was also reported against glutamate-induced excito-toxicity in the in vitro study conducted by Sharma and Kaur (2018). In the study, comparative analysis of different extraction processes was also evaluated, suggesting butanol extract to be the most potent in neuro-protective activity in comparison to hexane, chloroform, and ethyl acetate extracts following fractionation of the aqueous extract of Tinospora cordifolia (Sharma \& Kaur, 2018). Birla et al., (2021) studied molecular mechanisms of the neuroprotective activity of the plant extract in a Rotenone intoxicated mouse model through a proteomics approach. The study demonstrated the therapeutic effect of the plant extract via regulation of multiple pathways, leading to the protection of dopaminergic neurons.

\section{Anti-microbial Activity:}

The antimicrobial activity of the indigenous medicinal plant 'Giloy' has been reported against a number of bacteria, both Gram positive and Gram negative, against fungi as well as against viruses, thus supporting the traditional use of the plant as an antiseptic agent. The plant's ethanolic extract has been shown to have significant antibacterial activity against Gram positive bacteria such as Staphylococcus aureus and Gram negative bacteria such as Escherichia coli, Proteus vulgaris, Enterobacter faecalis, Serratia marcesenses, and Salmonella typhi (Jeyachandran, Xavier, and Anand, 2003). Mishra et al. (2014) reported that hydro-methanolic extract of Tinospora cordifolia exhibits anti-microbial activity against Bacillus subtilis, Micrococcus luteus, Staphylococcus aureus, and Staphylococcus epidermidis, while ethanolic extracts of the plant show significant antibacterial property against $E$. coli as well. Methanolic extract of the root and stem of $T$. cordifolia exhibited anti-microbial activity against bacteria (viz. E. coli and B. subtilis) as well as fungi (viz. Aspergilus niger and Candida sp.), indicating a wide range of antimicrobial activity (Prasad \& Chauhan, 2019). Berberine, a phytochemical constituent of $T$. cordifolia, has been found to have the potential for regulation of a key protein function, thus controlling viral replication in Covid-19 disease progression in in silico studies (Chowdhury, 2020). This finding further extends the use of 'Giloy' as natural medicine for its antimicrobial properties.

\section{Anti-cancerous Activity:}

Decades of research on Tinospora sp. suggests that the plant has anti-cancer potential. Extracts of T. cordifolia are reported to exhibit significant anti-proliferative properties in pre-clinical trials with animal models (Jagetia, Nayak \& Vidyasagar, 1998; Jagetia \& Rao, 2006; Deepa et al., 2019; Palmieri et al., 2019). Jagetia, Nayak, \& Vidyasagar (1998) reported the ability of "Giloy" extracts to effectively kill HeLa cells in vitro in a dose-dependent manner. Interestingly, the plant extract was equal to or more efficient than the common chemotherapeutic drug, doxorubicin. The ability of $T$. cordifolia to kill HeLa cells, which is comparable to cancerous cell lines in many ways, opened the avenue for future studies on anti-proliferative properties of the plant.

Ehrlic Ascites Carcinoma (EAC) is a spontaneous breast cancer in mice and one of the most common models for pre-clinical studies on anti-tumour drugs and cancer progression. Test subjects transplanted with EAC showed dose dependent response to $T$. cordifolia extracts (dichloromethane extract) for tumour-free survival with optimal activity at $50 \mathrm{mg} / \mathrm{kg}$ body weight in mice (Jagetia \& Rao, 2006). Intervention with an optimal dose of 'Giloy' extract increased the life span of the mice from 19 days (control group) to 90 days (test subjects) in survivors (100\%). The mode of action for tumour free survival is suggested to be due to the cytotoxic effect of the plant extracts on the tumour cells via a decrease in glutathione concentration and an increase in lipid peroxidation (Jagetia \& Rao, 2006).

Deepa et al. (2019) suggested in a recent systematic review of T. cordifolia as a potent anti-cancerous 
plant based on more than 300 published works that berbarine and its analogue palmatine alkaloids are some of the most important phytochemicals present in the plant responsible for its anti-cancerous properties.According to a study on human colon cancer cell lines, the purified alkaloid berberine from $T$. cordifolia works on cancer cells by specifically targeting more than 30 genes involved in cancer cell proliferation and differentiation (Palmieri et al., 2019).Berberine is also known to have a cytotoxic effect on cancer cells by promoting apoptosis without any side effects.

\section{Radio-protective Activity:}

Pre-clinical trials show a promising future for the medicinal plant Tinospora cordifolia in preventing radiation injury. Gamma irradiation in male mice models results in decrease in body weight and $100 \%$ mortality. Administration of stem extracts of $T$. cordifolia before irradiation with gamma rays showed impressive protection as evident from different parameters, including, nearly $76 \%$ survival rate, prevention of weight loss, increase in spleen colony forming unit, etc. Administration of the plant extract even restored total lymphocyte count after 2 weeks of exposure in the test subjects (Goel et al., 2004). Sharma et al., (2011b) also reported similar radio-protective function of $T$. cordifolia extracts, administered orally 30 minutes before gamma radiation in male mice. The test subjects showed $100 \%$ survival rate with significant increase in body weight, tissue weight and other related parameters compared to control sets (receiving gamma radiation without administration of 'Giloy' extract before exposure). Furthermore, the experimental animals pre-treated with the plant extract showed amelioration of increased lipid peroxidase and decreased glutathione concentration due to irradiation in testes (Sharma et al., 2011b). Radio-protective and cyto-protective activities of the plant extract containing cordifolioside $A$ are also noted in mice when administered through peritoneum 15 days prior to gamma ray irradiation (Patel et al., 2013).

\section{Anti-ulcerous Activity:}

The pharmacological affectivity of Tinospora cordifolia against ulcer is reported since many years supporting its use in Ayurveda for treatment of ulcer. Sarma et al. (1995) reported anti-ulcer property of the ethanolic extracts of T. cordifolia roots against stress induced ulcer. The protective activity of the plant extract was even comparable with the anti-ulcer drug diazepam. Similar anti-ulcer activity was observed with alcoholic extracts from whole plant of T. cordifolia in different drug induced ulcer models in addition to stress-induced ulcers (Bairy et al., 2002). Moreover, in this study, the ulcer-protective efficiency of the plant extract was comparable to common anti-ulcer drugs famotidine and misoprostol in drug induced ulcer models. Pyrolic ligation induced ulcer is another common model for study of antiulcer drugs, where accumulation of gastric acid leads to ulcer formation in the stomach. $T$. cordifolia extracts showed impressive anti-ulcer property against Pyrolic ligation induced ulcer and ethanol induced ulcer rat models with reduced ulcer index, gastric volume and gastric acidity (Kaur, Singh \& Kumar, 2014).

\section{Anti-fertility Activity:}

Traditional and ethno-medicine recommends the plant 'Giloy' for its anti-fertility properties, however, there are limited number of reports supporting the traditional claim. Of the few reports available, Gupta and Sharma (2003) observed oral administration of T. cordifolia stem extracts caused significant reduction in testicular weight, weight of seminal vesicle and ventral prostate, more than $70 \%$ decrease in spermatids and reduction in serum testosterone levels in male rats. Similar results were observed in male Albino Wistar rats fed with aqueous extracts of the plant $(100 \mathrm{mg} / \mathrm{kg}$ body weight) for 2 months suggesting spermicidal and anti-androgenic activity of $T$. cordifolia stem (Ittiavirah \& Rahman, 2013). These preliminary studies suggested contraceptive effect of the plant 'Giloy', however, more studies regarding mode of action, dosage and active principals taking part in the activity must be investigated in future, to assure safe usage of the plant.

\section{Anti-stress Activity:}

In the Ayurvedic system, "Giloy" is often recommended for its rejuvenating and adaptogenic properties. 
Stress causes havoc in the human physiological system in addition to prominent deterioration of mental health. Herbal safe anti-stress adaptogens help in combating depression, improving cognitive power and memory. Research shows anti-oxidants combat oxidative stress, a major outcome of mental stress discussed above, Tinospora cordifolia is rich in anti-oxidant properties. Sarma et al. (1996) reported the anti-stress activity of ethanolic extracts of the plant administered at $100 \mathrm{mg}$ per $\mathrm{kg}$ of body weight in a pre-clinical trial, and the results were comparable with those of the common anti-depressant drug diazepam. The probable mode of action for the plant to act against depression is suggested to work by either increasing the levels of amines, namely, norepinephrine, serotonin and dopamine or inhibiting degradation of the same (Mutalik \& Mutalik, 2011). Preliminary clinical trials also showed significant improvement in patients with mental stress in combination with yoga, even comparable to diazepam (Biswas, Saha \& Maity, 2015). However, the limited number of studies in this field calls for further research on the dosage of the herb, mechanism of action, as well as interactions with other drugs, to be recognised in modern medicine.

\section{Immuno-modulatory Activity:}

Aqueous and ethanolic extracts of $T$. cordifolia stem are reported to modulate the immune-suppressive activity of cyclophosphamide, a common medicine used in chemotherapy and to suppress immunity (Manjrekar, Jolly \& Narayanan, 2000). The alcoholic extracts also inhibited drug-induced anemia, however, the aqueous extract was suggested to be more potent in immune-modulation compared to the ethanolic extract of the plant (Manjrekar, Jolly \& Narayanan, 2000). Similar results were observed in rats treated with calcium chloride, where administration of $T$. cordifolia extracts inhibited the immunosuppressive effect of calcium chloride (Bishayi et al., 2002). Stem and leaf extracts of the plant also ameliorated the immuno-suppressive effects of azidothymidine (a common drug used in treatment of AIDS) in pre-clinical trials (Nageswari, Reddy \& Venkatappa, 2018).

The immuno-modulatory function of $T$. cordifolia is suggested to be due to the synergistic action of multiple bioactive compounds, of which cordifolioside $A$ and syringin are already known to have immuno-modulatory properties (Sharma et al., 2012). Additionally, 5 more immuno-modulatory active compounds have been identified for the plant, showing a significant increase in phagocytosis and nitric oxide concentration, as well as increased production of ROS (Sharma et al., 2012).

\section{CONCLUSION}

Tinospora cordifolia ('Giloy'), an indigenous medicinal plant of India, is well known in traditional herbal medicine for its plethora of medicinal properties. The plant is very commonly found in the dry deciduous forests of tropical India and is employed in the treatment of fevers, diabetes, heart diseases, and in the prevention of kidney and liver damage, to name a few. This review focused on the recent advances in research elucidating the pharmacological properties of the plant $T$. cordifolia. The traditional use of the 'Giloy' plant in the treatment of diabetes is well supported by the different studies performed, mainly due to the presence of various compounds inhibiting the $\alpha$-amylase and $\beta$-glucosidase enzymes enzymes. Tembetarine, an important secondary metabolite responsible for the plant's .anti-diabetic properties, and is thought to work by modulating diabetes-related proteins. An important traditional use of 'Giloy' to treat high fever is well supported by the pre-clinical studies in T. codifolia as well as in silico studies in $T$. crispa. The plants score well in anti-oxidant properties and thus also have impressive anti-inflammatory and anti-cancerous activities, as evident from the observations in animal models.

Multiple studies have shown its hepato-protective, cardio-protective, immuno-modulatory, neuroprotective, and anti-microbial properties, validating its use in the treatment of jaundice, heart diseases, and against neuro-degenerative diseases like Parkinson's disease. The plant scores well in antimicrobial activity against a wide range of microbes, including bacteria, fungi, and viruses. A recent study on the anti-viral properties of active phytochemicals present in Tinospora cordifolia against viral replication of Covid-19 opened a new avenue for research and development of a much needed herbal drug against the pandemic causing virus. A few reports are available supporting the anti-fertility 
activities of the plant, which need to be elucidated further for the safe administration of "Giloy" in the treatment of various diseases.

\section{ACKNOWLEDGMENT}

We express our sincere thanks to the Department of Biotechnology, Government of India, for the funding from the DBT-STAR College Grant, under which this review project was conducted. The authors are also grateful to the Principal and the DBT-STAR Coordinator, Surendranath College, for their support and encouragement in implementation of this review project.

\section{REFERENCES}

Ashok, B. K., Ravishankar, B., Prajapati, P. K., \& Bhat, S. D. (2010). Antipyretic activity of Guduchi Ghrita formulations in albino rats. Ayu, 31(3), 367.

Bairy, K. L., Roopa, K., Malini, S., \& Rao, C. M. (2002). Protective effect of Tinospora cordifolia on experimentally induced gastric ulcers in rats. Journal of Natural Remedies, 2(1), 49-53.

Begum, N., Shivakumar, P., Reddy, A. G., Ramya, B., \& Anil, B. (2021). Cardio protective actions of Tinospora cordifolia and vitamin $\mathrm{C}$ against experimental toxicity due to Cisplatin. The Pharma Innovation Journal, 10(3): 235-242

Birla, H., Keswani, C., Singh, S. S., Zahra, W., Dilnashin, H., Rathore, A. S., ... \& Singh, S. P. (2021). Unraveling the neuroprotective effect of Tinospora cordifolia in Parkinsonian mouse model through proteomics Approach. DOI: https://doi.org/10.21203/rs.3.rs-151144/v2

Bishayi, B., Roychowdhury, S., Ghosh, S., \& Sengupta, M. (2002). Hepatoprotective and immunomodulatory properties of Tinospora cordifolia in $\mathrm{CCl} 4$ intoxicated mature albino rats. The Journal of Toxicological Sciences, 27(3), 139-146.

Biswas, P., Saha, A., \& Maity, L. N. (2015). Antistress activity of Tinospora cordifolia with application of yoga. International Journal of Ayurvedic Medicine, 6(3), 220-224.

Chacko, M. (2018). A Study on the Hypoglycaemic Effect of Tinospora Cordifolia in Albino Rats. Journal of Evolution of Medical and Dental Sciences, 7(23), 2782-2789.

Choudhary, N., Siddiqui, M. B., Azmat, S., \& Khatoon, S. (2013). Tinospora cordifolia: ethnobotany, phytopharmacology and phytochemistry aspects. International Journal of Pharmaceutical Sciences and Research, 4(3), 891.

Chowdhury, P. (2020). In silico investigation of phytoconstituents from Indian medicinal herb 'Tinospora cordifolia (giloy)'against SARS-CoV-2 (COVID-19) by molecular dynamics approach. Journal of Biomolecular Structure and Dynamics, 1-18.

Deepa, B., Babaji, H. V., Hosmani, J. V., Alamir, A. W. H., Mushtaq, S., Raj, A. T., \& Patil, S. (2019). Effect of Tinospora cordifolia-derived phytocomponents on cancer: a systematic review. Applied Sciences, 9(23), 5147.

Goel, H. C., Prasad, J., Singh, S., Sagar, R. K., Agrawala, P. K., Bala, M., ... \& Dogra, R. (2004). Radioprotective potential of an herbal extract of Tinospora cordifolia. Journal of Radiation Research, 45(1), 61-68.

Gupta, R. S., \& Sharma, A. (2003). Antifertility effect of Tinospora cordifolia (Willd.) stem extract in male rats. Indian Journal of Experimental Biology,41:885-9.

Hussain, L., Akash, M. S., Ain, N. U., Rehman, K., \& Ibrahim, M. (2015). The analgesic, antiinflammatory and anti-pyretic activities of Tinospora cordifolia. Advances in Clinical and Experimental Medicine, 24(6), 957-964. 
Ikram, M., Khattak, S. G., \& Gilani, S. N. (1987). Antipyretic studies on some indigenous Pakistani medicinal plants: II. Journal of Ethnopharmacology, 19(2), 185-192.

Ittiavirah, S. P., \& Rahman, P. H. (2013). Evaluation of spermicidal and antiandrogenic activities of aqueous extract of Tinospora cordifolia (Willd.) stem. African Journal of Pharmacy and Pharmacology, 7(34), 2392-2396.

Jagetia, G. C., \& Rao, S. K. (2006). Evaluation of the antineoplastic activity of guduchi (Tinospora cordifolia) in Ehrlich ascites carcinoma bearing mice. Biological and Pharmaceutical Bulletin, 29(3), 460-466.

Jagetia, G. C., Nayak, V., \& Vidyasagar, M. S. (1998). Evaluation of the antineoplastic activity of guduchi (Tinospora cordifolia) in cultured HeLa cells. Cancer Letters, 127(1-2), 71-82.

Jeyachandran, R., Xavier, T. F., \& Anand, S. P. (2003). Antibacterial activity of stem extracts of Tinospora cordifolia (Willd) Hook. $f$ \& Thomson. Ancient Science of Life, 23(1), 40.

Kaur, M., Singh, A., \& Kumar, B. (2014). Comparative antidiarrheal and antiulcer effect of the aqueous and ethanolic stem bark extracts of Tinospora cordifolia in rats. Journal of Advanced Pharmaceutical Technology \& Research, 5(3), 122.

Khanal, P., Patil, B. M., Mandar, B. K., Dey, Y. N., \& Duyu, T. (2019). Network pharmacology-based assessment to elucidate the molecular mechanism of anti-diabetic action of Tinospora cordifolia. Clinical Phytoscience, 5(1), 1-9.

Kosaraju, J., Chinni, S., Roy, P. D., Kannan, E., Antony, A. S., \& Kumar, M. S. (2014). Neuroprotective effect of Tinospora cordifolia ethanol extract on 6-hydroxy dopamine induced Parkinsonism. Indian Journal of Pharmacology, 46(2), 176.

Leghari, M. Y., Muzaffar, N. A., \& Haq, I. U. (1984). Pharmacological testing of antipyretic activity of Tinospora cordifolia. J Pharm Univ, 3, 31-41.

Manjrekar, P. N., Jolly, C. I., \& Narayanan, S. (2000). Comparative studies of the immunomodulatory activity of Tinospora cordifolia and Tinospora sinensis. Fitoterapia, 71(3), 254-257.

Mishra, P., Jamdar, P., Desai, S., Patel, D., \& Meshram, D. (2014). Phytochemical analysis and assessment of in vitro antibacterial activity of Tinospora cordifolia. International Journal of Current Microbiology and Applied Sciences, 3(3), 224-234.

Mutalik, M., \& Mutalik, M. (2011). Tinospora cordifolia: Role in depression, cognition and memory. Australian Journal of Medical Herbalism, 23(4), 168-173.

Nadkarni, K., \& Nadkarni, A. K. (1976). Indian Materia Medica, Popular Prakashan Pvt. Ltd., Bombay, 1 , 799.

Nageswari, G., Reddy, A. H., \& Venkatappa, B. (2018). Evaluation of immunomodulatory effect of Tinospora cordifolia leaf and stem on zidovudine induced immunotoxicity. Evaluation, 5(3), 1-5.

Palmieri, A., Scapoli, L., lapichino, A., Mercolini, L., Mandrone, M., Poli, F., ... \& Martinelli, M. (2019). Berberine and Tinospora cordifolia exert a potential anticancer effect on colon cancer cells by acting on specific pathways. International Journal of Immunopathology and Pharmacology, 33, 2058738419855567.

Panchabhai, T. S., Ambarkhane, S. V., Joshi, A. S., Samant, B. D., \& Rege, N. N. (2008). Protective effect of Tinospora cordifolia, Phyllanthus emblica and their combination against antitubercular drugs induced hepatic damage: an experimental study. Phytotherapy Research: An International Journal Devoted to Pharmacological and Toxicological Evaluation of Natural Product Derivatives, 22(5), 646650. 
Patel, A., Bigoniya, P., Singh, C. S., \& Patel, N. S. (2013). Radioprotective and cytoprotective activity of Tinospora cordifolia stem enriched extract containing cordifolioside-A. Indian Journal of Pharmacology, 45(3), 237.

Patgiri, B., Umretia, B. L., Vaishnav, P. U., Prajapati, P. K., Shukla, V. J., \& Ravishankar, B. (2014). Antiinflammatory activity of Guduchi Ghana (aqueous extract of Tinospora Cordifolia Miers.). Ayu, 35(1), 108.

Pendse, V. K., Dadhich, A. P., Mathur, P. N., Bal, M. S., \& Madan, B. R. (1977). Antiinflammatory, immunosuppressive and some related pharmacological actions of the water extract of Neem Giloe (Tinospora cordifolia): A preliminary report. Indian Journal of Pharmacology, 9(3), 221.

Philip, S., Tom, G., \& Vasumathi, A. V. (2018). Evaluation of the anti-inflammatory activity of Tinospora cordifolia (Willd.) Miers chloroform extract-a preclinical study. Journal of Pharmacy and Pharmacology, 70(8), 1113-1125.

Prasad, B., \& Chauhan, A. (2019). Anti-Oxidant and antimicrobial studies of Tinospora cordifolia (Guduchi/Giloy) stems and roots under in-vitro condition. Int. J. Adv. Microbiol. Health. Res, 3(1), 110.

Praveen, N., Thiruvengadam, M., Kim, H. J., Kumar, J. P., \& Chung, I. M. (2012). Antioxidant activity of Tinospora cordifolia leaf extracts through non-enzymatic method. Journal of Medicinal Plants Research, 6(33), 4790-479.

Priya, L. B., Baskaran, R., Elangovan, P., Dhivya, V., Huang, C. Y., \& Padma, V. V. (2017). Tinospora cordifolia extract attenuates cadmium-induced biochemical and histological alterations in the heart of male Wistar rats. Biomedicine \& Pharmacotherapy, 87, 280-287.

Rakib, A., Ahmed, S., Islam, M. A., Haye, A., Uddin, S. N., Uddin, M. M. N., ... \& Emran, T. B. (2020). Antipyretic and hepatoprotective potential of Tinospora crispa and investigation of possible lead compounds through in silico approaches. Food Science \& Nutrition, 8(1), 547-556.

Rao, P. R., Kumar, V. K., Viswanath, R. K., \& Subbaraju, G. V. (2005). Cardioprotective activity of alcoholic extract of Tinospora cordifolia in ischemia-reperfusion induced myocardial infarction in rats. Biological and Pharmaceutical Bulletin, 28(12), 2319-2322.

Sarma, D. N. K., Khosa, R. L., Chansauria, J. P. N., \& Sahai, M. (1995). Antiulcer activity of Tinospora cordifolia Miers and Centella asiatica Linn extracts. Phytotherapy Research, 9(8), 589-590.

Sharma, A. K., Kishore, K., Sharma, D., Srinivasan, B. P., Agarwal, S. S., Sharma, A., ... \& Jatav, V. S. (2011a). Cardioprotective activity of alcoholic extract of Tinospora cordifolia (Willd.) Miers in calcium chloride-induced cardiac arrhythmia in rats. Journal of Biomedical Research, 25(4), 280-286.

Sharma, A., \& Kaur, G. (2018). Tinospora cordifolia as a potential neuroregenerative candidate against glutamate induced excitotoxicity: an in vitro perspective. BMC Complementary and Alternative Medicine, 18(1), 1-17.

Sharma, M., \& Joshi, S. (2011). Comparison of anti-oxidant activity of Andrographis paniculata and Tinospora cordifolia leaves. J Curr Chem Pharm Sc, 1, 1-8.

Sharma, P., Parmar, J., Verma, P., \& Goyal, P. K. (2011b). Radiation-induced testicular injury and its amelioration by Tinospora cordifolia (an Indian medicinal plant) extract. Evidence-Based Complementary and Alternative Medicine, 2011.

Sharma, U., Bala, M., Kumar, N., Singh, B., Munshi, R. K., \& Bhalerao, S. (2012). Immunomodulatory active compounds from Tinospora cordifolia. Journal of Ethnopharmacology, 141(3), 918-926.

Sonkamble, V. V., \& Kamble, L. H. (2015). Antidiabetic potential and identification of phytochemicals from Tinospora cordifolia. American Journal of Phytomedicine and Clinical Therapeutics, 3(1), 097- 
110.

Stanely Mainzen Prince, P., \& Menon, V. P. (1999). Antioxidant activity of Tinospora cordifolia roots in experimental diabetes. Journal of Ethnopharmacology, 65(3), 277-281.

Stanely Mainzen Prince, P., \& Menon, V. P. (2000). Hypoglycaemic and other related actions of Tinospora cordifolia roots in alloxan-induced diabetic rats. Journal of Ethnopharmacology, 70(1), 9-15.

Stanely Mainzen Prince, P., \& Menon, V. P. (2001). Antioxidant action of Tinospora cordifolia root extract in alloxan diabetic rats. Phytotherapy Research: An International Journal Devoted to Pharmacological and Toxicological Evaluation of Natural Product Derivatives, 15(3), 213-218.

Stanely Mainzen Prince, P., \& Menon, V. P. (2003). Hypoglycaemic and hypolipidaemic action of alcohol extract of Tinospora cordifolia roots in chemical induced diabetes in rats. Phytotherapy Research: An International Journal Devoted to Pharmacological and Toxicological Evaluation of Natural Product Derivatives, 17(4), 410-413.https://doi.org/10.1002/PTR.1130

Stanely Mainzen Prince, P., Menon, V. P., \& Gunasekaran, G. (1998). Hypolipidaemic action of Tinospora cordifolia roots in alloxan diabetic rats. Journal of Ethnopharmacology, 64(1), 53-57.

Stanely Mainzen Prince, P., Padmanabhan, M., \& Menon, V. P. (2004). Restoration of antioxidant defence by ethanolic Tinospora cordifolia root extract in alloxan-induced diabetic liver and kidney. Phytotherapy Research: An International Journal Devoted to Pharmacological and Toxicological Evaluation of Natural Product Derivatives, 18(9), 785-787.

The Plant List (2013) (2013). The plant list. http://www.theplantlist.org

Vedavathy, S., \& Rao, K. N. (1991). Antipyretic activity of six indigenous medicinal plants of Tirumala Hills, Andhra Pradesh, India. Journal of Ethnopharmacology, 33(1-2), 193-196.

Vetrivadivelan, K., Venkateswaran, K. V., Selvasubramanian, S., \& Sesh, P. S. L. (2012). Antihyperlipidemic effect of Tinospora cordifolia extract in streptozotocin induced diabetic rats. International Journal of Pharmaceutical Sciences and Research, 3(5), 1423.

Vora, A., Varghese, A., Kachwala, Y., Laddha, A. P., Bhaskar, M., Akhtar, J., \& Yadav, P. (2020). Pharmacokinetic and pharmacodynamic interactions of Tinospora cordifolia aqueous extract and hypoglycemic drugs in streptozotocin-induced diabetes in rats. Pharmacognosy Magazine, 16(68), 47. 


\title{
Some Traditional Medicinal Plants of West Bengal: A Short Review
}

\author{
Anamika Biswas, A K Obaidulla Azmi, Amit Saha* \\ Department of Botany, Surendranath College, Kolkata, India \\ *Corresponding Author's Email: ammico02@yahoo.co.in
}

\begin{abstract}
In India, West Bengal has a sizable number of medicinal plants which is because of different weather conditions. West Bengal is that the one and only state in India where Darjeeling Himalayas are within the north and Sundarbans areas at the south with meadowlands and uplands covering a vicinity with a variety of medicinal plants. A medicinal plant is any plant in which one or more than one of its body parts hold materials that are used for remedial motives. Medicinal stuffs are extracted from many different parts of a plant like leaves, seeds, fruits, flowers, barks, roots and many more. More than half of the medicinal plants have been used in rehabilitating bloating, constipation, diarrhea, nausea, vomiting, dermal problems like swelling, burning, itching and irritants etc. As medicinal plants get improved empirical and commercial attentiveness, there is an increasing demand on the uncultivated plant inhabitants from which almost all traditional medicinal plants are yielded. But there are some considerable important zones at cultivation of medicinal plants in West Bengal like impoverished equipment, scarcity of profitable materials, economic situation and bewildering cultivation etc. for better yielding. Besides that, ongoing increase in human population is one among the starting points for rethinking about cultivation and medicinal administration of our state, as our economy system and sustenance of societies primarily depend on forests' gifts. In future, this review work will enrich the ethnomedicine branch of Botany and provide new information about various uses of medicinal plants.
\end{abstract}

Keywords: Tribal Communities; Ethnomedicine; Medicinal Plants; West Bengal

\section{INTRODUCTION}

We all know that the entire mankind has been directly dependent on the flora since the distant past. In addition to food, clothing and shelter uses of innumerable medicinal plants by man are specially mentioned in most ancient scriptures of all civilizations. In the prehistoric age of India, Maharshi Charaka was considered as father of Ayurveda as a large number of medicinal plants and their uses is mentioned in his famous book, "Charaka Sanhita". About $70 \%$ of Indian population inhabits in rural areas and many of them reside in the vicinity of forest (Datta et al., 2014). They also use various plant parts as food, medicines and in many other purposes for their daily livelihood (Kala et al., 2006). Use of plants as a source of medication has been a onetime and important practice of the health care system in India since ancient times (Mondal et al., 2015). Several studies on them have been executed in some parts of India, over the last few decades. The tribal groups use those medicines which are mostly collected from plant sources. Through this review, the different types of medicinal plants and their uses in various districts of West Bengal have been highlighted. This state has a vast number of medicinal plants especially in tribal areas due to its changeable climatic conditions. West Bengal possesses about 850 species of medicinal plants. In the year of 2007, MoEF (Ministry of Environment \& Forests, now as Ministry of Environment, Forest and Climate Change) and FRLHT (Foundation for Revitalization of Local Health Traditions) together with State Forest Department of West Bengal conducted a CAMP (Conservation Assessment and Management Prioritization) workshop and they released a list of forty six medicinal plant species for further plant-conservation (Mukherjee, 2018). More than half of the population of various developed countries have unanimously agreed on the accessibility, non-somnolent and anesthetized use of medicinal plants. But there are some major discussed areas at cultivation of medicinal plants in West Bengal like impoverished infrastructure, 
deficiency of higher-ranking materials, economic circumstances and bewildering cultivation etc. A large number of medicinal plants used in Murshidabad, Nadia, Hooghly, Burdwan and North Bengal have been reviewed. Hence, there is a need to document all the uses of various medicinal plants for further research works and disease treatment (Mistry, 2015).

\section{LITERATURE REVIEW}

\section{Traditional Medicinal Plants of West Bengal}

Traditional medicine is one in every of the popular terms of cognitive content in our society. The indigenous or traditional knowledge comprises of an unlimited assemblage of information regarding the uses of plants material for health motives. All the plants which are specially mentioned in the Table 1 are used as medicine in various parts of West Bengal. These are used predominantly by regional people and also the plant or plant parts are easily available in the local markets or village markets. This review work indicates the requirements of preservation of medicinal plants and explores the long run prospect of research on this matter.

Table 1: List of some Traditional Medicinal Plants in West Bengal

\begin{tabular}{|c|c|c|c|c|c|}
\hline $\begin{array}{l}\text { Sl. } \\
\text { No. }\end{array}$ & Local Name & Scientific Name & Family & Plant Parts & Medicinal Uses \\
\hline 1. & Grit Kumari & Aloe vera & Xanthorrhoeaceae & Leaves,pulp & Burns, wounds, inflammations. \\
\hline 2. & Neem & Azadirachta indica & Meliaceae & Leaves, bark & Preventmalaria,skin infection etc. \\
\hline 3. & Tulsi & Ocimum sanctum & Lamiaceae & Leaves & Treat common cold, asthma, fever. \\
\hline 4. & Amrul & Oxalis corniculata & Oxalidaceae & $\begin{array}{l}\text { Whole } \\
\text { plant }\end{array}$ & Used for spinal-muscular stiffness. \\
\hline 5. & Gulancha & Tinospora cordifolia & Menispermaceae & Stem & Stemboiled-water control blood sugar. \\
\hline 6. & Basak & Justicia adhatoda & Acanthaceae & Leaves & Leaf boiled water prevent cough. \\
\hline 7. & Thankuni & Centella asiatica & Apiaceae & Leaves & $\begin{array}{l}\text { Prevent chronic dysentery and blood } \\
\text { stool. }\end{array}$ \\
\hline 8. & Helencha & Enydra fluctuans & Asteraceae & Leaves & Purify blood and prevent weakness. \\
\hline 9. & Kalmegh & Andrographis paniculata & Acanthaceae & Leaves & $\begin{array}{l}\text { Leaves' paste soup prevent worm, } \\
\text { fever, cough, chronic diseases. }\end{array}$ \\
\hline 10. & Karola & Momordica charantia & Cucurbitaceae & $\begin{array}{l}\text { Leaves, } \\
\text { fruit }\end{array}$ & $\begin{array}{c}\text { Leaves and fruit juice prevent diabetes, } \\
\text { allergy etc. }\end{array}$ \\
\hline 11. & Kulekhara & Hygrophila auriculata & Acanthaceae & Leaves & $\begin{array}{l}\text { Leaves' juice increases hemoglobin and } \\
\text { it is used in treatment of anemia. }\end{array}$ \\
\hline 12. & Lajjabati & Mimosa pudica & Mimosaceae & Root & Used to prevent leucorrhea. \\
\hline 13. & Chirota & Swertia chiratia & Gentianaceae & $\begin{array}{l}\text { Whole } \\
\text { plant }\end{array}$ & Prevent liver problems. \\
\hline 14. & Ashok & Saraca asoca & Detarioideae & Bark & Used in menstrual problems. \\
\hline 15. & Futki & Melastoma malabathricum & Melastomataceae & Leaves & Prevent burnt issues. \\
\hline 16. & Nagmoni & Dracaena bulbifera & Asparagaceae & Leaves & $\begin{array}{l}\text { Leaves' paste prevents insect bite } \\
\text { wounds. }\end{array}$ \\
\hline 17. & Bel & Aegle marmelos & Rutaceae & Fruit, seed & $\begin{array}{c}\text { Fruit and seed prevent stomach } \\
\text { problems. }\end{array}$ \\
\hline 18. & Gadhal Pata & Paederia scandens & Rubiaceae & Leaves & $\begin{array}{l}\text { Leaves' paste prevent leucorrhea and } \\
\text { extract used to treat night blindness. }\end{array}$ \\
\hline 19. & Dhatura & Datura stramonium & Solanaceae & Seed & Seed used to treat dog bite wound. \\
\hline
\end{tabular}


Traditional Medicinal Plants of West Bengal

\begin{tabular}{|c|c|c|c|c|c|}
\hline 20. & Halud & Cucurma longa & Zingiberaceae & Rhizome & Used to prevent skin inflammations. \\
\hline 21. & Nishinda & Vitex negundo & Verbenaceae & Leaves & Leaves used to increase brain memory. \\
\hline 22. & Ada & Zingiber officinale & Zingiberaceae & Rhizome & $\begin{array}{l}\text { Used in digestion treatment and wound } \\
\text { pain relief. }\end{array}$ \\
\hline 23. & Dandakalash & Leucas plukenetii & Labiateae & Seed, Leaves & Seed paste gives relief from insect bites. \\
\hline 24. & Mithapata & Scoparia dulcis & Scrophulariaceae & Leaves & $\begin{array}{l}\text { Leaves' paste used to control } \\
\text { pneumonia. }\end{array}$ \\
\hline 25. & Tentul & Tamarindus indica & Fabaceae & Stem bark & Bark ass used to prevent wounds. \\
\hline 26. & Shatamuli & Asparagus racemosus & Liliaceae & Root, leaves & Hyper-acidity, peptic ulcer, aphrodisiac \\
\hline 27. & Nayantara & Catharanthus roseus & Apocynaceae & Roots, leaves & Prevent diabetes. \\
\hline 28. & Curry pata & Murraya koenigii & Rutaceae & $\begin{array}{l}\text { Bark, root, } \\
\text { leaves }\end{array}$ & Prevent stomachic problems. \\
\hline 29. & Shiuli & $\begin{array}{l}\text { Nyctanthes arbor- } \\
\text { tristis }\end{array}$ & Oleaceae & Leaves & Prevent inflammation. \\
\hline 30. & Kesutthe & Eclipta alba & Asteraceae & $\begin{array}{l}\text { Whole } \\
\text { plant }\end{array}$ & $\begin{array}{l}\text { Used in hepatitis treatment, an antidote } \\
\text { in scorpion sting. }\end{array}$ \\
\hline 31. & Bherenda & Ricinus communis & Euphorbiaceae & Leaves & Used in treatment of arthritis. \\
\hline 32. & Haritaki & Terminalia chebula & Combretaceae & Fruit, bark & $\begin{array}{c}\text { Used in dental care and chronic heart } \\
\text { diseases. }\end{array}$ \\
\hline 33. & Sajna & Moringa oleifera & Moringaceae & $\begin{array}{l}\text { Root, bark, } \\
\text { leaves, seed }\end{array}$ & Used as abortifacient. \\
\hline 34. & Methi & Trigonella foenum graecum & Papilionaceae & Leaves, seed & $\begin{array}{c}\text { Usedin antidiabetic, hypotensive } \\
\text { treatments. }\end{array}$ \\
\hline 35. & Bakul & Mimusops elengi & Sapotaceae & $\begin{array}{l}\text { Unripe } \\
\text { fruit }\end{array}$ & Used to treat loose teeth. \\
\hline 36. & Swetchandan & Santalum album & Santalaceae & Wood & Cure acne problems. \\
\hline 37. & Dhudhi & Euphorbia hirta & Euphorbiaceae & Leaves & Prevent urearelated problems. \\
\hline 38. & Kanchan & Bauhinia variegata & Caesalpiniaceae & Roots, leaves & Prevent diarrhea, piles, worms \\
\hline 39. & Bahera & Terminalia bellirica & Combretaceae & Fruit, bark & $\begin{array}{l}\text { Prevent bile-stimulant, anemia, and } \\
\text { bronchitis. }\end{array}$ \\
\hline 40. & Kolke & Tabernaemontana divaricata & Apocynaceae & Latex, flower & Preventdiabetes,inflammation. \\
\hline 41. & Jaba & Hibiscus rosa sinensis & Malvaceae & $\begin{array}{l}\text { Roots, } \\
\text { leaves, } \\
\text { Flower, }\end{array}$ & $\begin{array}{l}\text { Prevent fever, skin diseases, and } \\
\text { inflammations. }\end{array}$ \\
\hline 42. & Ashwagandha & Withania somnifera & Solanaceae & Root, leaves & $\begin{array}{l}\text { Extract used in sound sleep, joint pains, } \\
\text { inflammation, sexual impotency. }\end{array}$ \\
\hline 43. & Kakmachi & Solanum nigrum & Solanaceae & $\begin{array}{l}\text { Whole } \\
\text { plant }\end{array}$ & $\begin{array}{l}\text { Prevent swellings, flatulence, and } \\
\text { dyspepsia. }\end{array}$ \\
\hline 44. & Sati & Curcuma zedoaria & Zingiberaceae & Rhizomes & $\begin{array}{l}\text { Used as tonic, particularly prescribed to } \\
\text { ladies after childbirth. }\end{array}$ \\
\hline 45. & Dhoney & Coriandrum sativum & Apiaceae & Fruit & $\begin{array}{l}\text { Fruits used as digestive component and } \\
\text { ant vomiting agent. }\end{array}$ \\
\hline 46. & Genda & Tagetes erecta & Asteraceae & Leaves & $\begin{array}{l}\text { Leaves' juice applied on cuts, wounds to } \\
\text { stop bleeding. }\end{array}$ \\
\hline 47. & Puin sak & Basella alba & Basellaceae & Root & Root used to treat tuberculosis. \\
\hline 48. & Swarnalata & Cuscuta reflexa & Cuscutaceae & $\begin{array}{l}\text { Whole } \\
\text { plant }\end{array}$ & $\begin{array}{l}\text { Whole plant juice usedto treat } \\
\text { jaundice. }\end{array}$ \\
\hline
\end{tabular}




\begin{tabular}{|c|c|c|c|c|c|}
\hline 49. & Lankajoba & Malvaviscus arboreus & Malvaceae & Flower & Flower is used to treat stomach problem. \\
\hline 50. & $\begin{array}{l}\text { Barokuchichak phang } \\
\text { (Rava) }\end{array}$ & Angiopteris evecta & Marattiaceae & Rhizome & $\begin{array}{l}\text { Rhizome sap with talmishri } \\
\text { consumed to cure leucorrhea. }\end{array}$ \\
\hline 51. & Segoon & Tectona grandis & Verbenaceae & Leaves & $\begin{array}{l}\text { Leaf juice used to treat irregular } \\
\text { menstrual cycle. }\end{array}$ \\
\hline 52. & Harjora & Cissus quadrangularis & Vitaceae & Stem & $\begin{array}{l}\text { Stem extract is used to treat broken } \\
\text { bone. }\end{array}$ \\
\hline 53. & Astapata & Houttuynia cordata & Saururaceae & $\begin{array}{l}\text { Whole } \\
\text { plant }\end{array}$ & $\begin{array}{c}\text { Whole plant } \begin{array}{r}\text { used in stomach } \\
\text { problems. }\end{array} \\
\end{array}$ \\
\hline 54. & Dulaltulsi & $\begin{array}{l}\text { Ocimum } \\
\text { basilicum }\end{array}$ & Labiatae & Leaves & $\begin{array}{l}\text { Freshleaves' juice used as drops to } \\
\text { treat earache. }\end{array}$ \\
\hline 55. & Jongli dopati & Impatiens trilobata & Balsaminaceae & Root & Root used to treat migraine pain. \\
\hline 56. & Lalchita & Gomphrena globosa & Amaranthaceae & Leaves & Leaves are used to stop bleeding. \\
\hline 57. & Anaras & Ananas comosus & Bromeliaceae & Leaves & Leaf extract to kill worms. \\
\hline 58. & Piyara & Psidium guajava & Myrtaceae & Bark & Bark used to treat child dysentery \\
\hline 59. & Golmorich & Piper nigrum & Piperaceae & Seed & Seeds are used to treat cough and cold. \\
\hline 60. & Hatisur & Heliotropium indicum & Boraginaceae & Root & Root extract is used in eye treatment. \\
\hline 61. & Manasa & $\begin{array}{c}\text { Euphorbia } \\
\text { neriifolia }\end{array}$ & Euphorbiceae & $\begin{array}{l}\text { Leaves and } \\
\text { stem }\end{array}$ & $\begin{array}{l}\text { Leaves' paste used as kajal for eye } \\
\text { infection. }\end{array}$ \\
\hline 62. & Sarpagandha & Rauvolfia serpentina & Apocynaceae & $\begin{array}{l}\text { Root and } \\
\text { leaf }\end{array}$ & $\begin{array}{l}\text { Used to prevent blood pressure and } \\
\text { hypertension. }\end{array}$ \\
\hline 63. & Jastimadhu & Scoparia dulcis & Scrophulariaceae & Leaves & Prevent cough and cold. \\
\hline 64. & Assam lata & Chromolaena odorata & Asteraceae & Leaves & Used to treat cut wounds. \\
\hline 65. & Rosun & Allium sativum & Amaryllidaceae & Bulb & Used to treat body pain and cough. \\
\hline 66. & Bhuikamri & Merremia emarginata & Convolvulaceae & Leaf & Used for Chronic blood dysentery. \\
\hline 67. & Harjora & Cissus quadrangularis & Vitaceae & $\begin{array}{l}\text { Whole } \\
\text { plant }\end{array}$ & $\begin{array}{l}\text { Cured fracture wound and treat } \\
\text { constipation. }\end{array}$ \\
\hline 68. & Babla & Acacia nilotica & Mimosaceae & Latex, leaf & $\begin{array}{l}\text { Used for treat weakness and indigestion, } \\
\text { acidity. }\end{array}$ \\
\hline 69. & Man-kachu & Alocasia macrorrhiza & Araceae & Stem & Used to prevent piles. \\
\hline 70. & Arhar & Cajanus cajan & Papilionaceae & Leaf & Leaf juice prevent jaundice. \\
\hline 71. & Tala Kachu & Coccinia grandis & Cucurbitaceae & Leaf & Leaf oil prevent migraine pain. \\
\hline 72. & Karpoor & Cinnamomum camphora & Lauraceae & Oil & Prevent insect bite. \\
\hline 73. & Peyaj & Allium cepa & Liliaceae & Bulb & Used to treat conjunctivitis, insect bite. \\
\hline 74. & Vasaka & Adhatoda vasica & Acanthaceae & $\begin{array}{l}\text { Leaves, } \\
\text { flowers, fruits }\end{array}$ & Used to treat coughs. \\
\hline
\end{tabular}

(Source: Bose et al., 2015; Choudhury et al., 2013; Das and Ghosh 2017; Datta et al., 2014; Dey et al., 2010; Ghosh 2008; Mistry 2015; Mukherjee, 2018)

\section{DISCUSSION}

The traditional system of public health care has been effectively used for over many years to treat illnesses in West Bengal. In tribal culture of West Bengal traditional medicine can be an awfully confidential and reputed medical system. This $21^{\text {st }}$ century totally believes in modern medical system but tribal peoples avoid allopathic and homeopathic medicine to cure their disease. Their dearth of upto-date education and intense faith in natural efficiency are indirectly in command of this. Most of the standard knowledge of medicinal plants seems to be restricted to the elder people of any tribal area 
(Datta et al., 2014). Besides that, in every tribal culturethere is a special community called 'Vaidya', who are erudite about various medicinal plants and their uses. Details of the implementation of the plants for countless objectives arepassed along by way ofverbal communication only and these have been hypercritically exploited from them. (Choudhury et al., 2013).Most of the ethnobotanical studies confirmed that the leaves are the main portion of the plant utilized in the treatment of diseases (Mandal et al., 2020). But the various segments of plants can carry dissimilar vigorous elements in the plant. Hence, any part of the plant can be harmful when on the other hand, use of another portion of that same plant can be safe. The medicinal properties of these plant species have made an impressive contribution within the origin and evolution of the many traditional herbal therapies. These lore systems have begun to disappear with the passage of our time because of scarcity of written documents and comparatively low income in these traditions (Tripathi et al., 2013). Over past some years, the medicinal plants have retrieved an intensive acceptance in herbal medicine due to its minor after effect, compared to the allopathic medicines. The traditional medicinal practitioners prepare paste, powder, pills and solutions from one plant or mixture of plants for the villagers and hence, they are considered as doctor within the tribal areas (Mondal et al., 2015). Excess of plants have been used in rehabilitating bloating and excess gas, constipation, diarrhea, nausea and vomiting, abdominal pain, dermal problems like, swelling, burning, itching and irritants etc. But sometimes it has been observed that because of lack of well studies about the right methods of using medicinal plants, variety of individuals may die by countless side effects. So, during preparation of these medicines the traditional medicinal practitioners stay in their mind and take some proper precautions mind like amount of plants' parts used, dosage and solvent etc. The colossal assortments of these species from native environment are destroying vegetation too (Das \& Ghosh, 2017) and also according to the practitioners or vaidyas, the new young generations are minimalengross to pick up and make use of the traditional treatment for alleviating various types of health problems (Tripathi et al., 2013). Besides that, there are some pitfalls in cultivation and marketing of medicinal plants in province like absurd harvesting, less knowledge, infertile and unsuitable lands and many more. Therefore, developing the pre- and post-cultivation procedures including standard plant materials, irrigation, fertilizer, plant protection, employing fresh techniques to reinforce the assembly system, enlarging the effective planttissue culture system for profitable quality plant materials, inspiring the young generations such schemes are expected to help within the assembly of appreciable number of medicinal plants in West Bengal. The use of traditional medicinal plants would surely impact a notable mark on ethnomedicine branch of Botany similarly as in the commercial fields of West Bengal in future (Sarkar \& Kalyani, 2005).

\section{CONCLUSION}

Villages and tribal areas of West Bengal are an important source and also the secret treasure of traditional medicinal plants. Almost in every corner of the West Bengal plants are always used as medicine. Traditional practitioners are the foremost source of knowledge on medicinal plants and about their uses. This ethno medicinal learning are transferred from one generation to different generation. Medicinal use and knowledge about these plants are marked as many small racial groups. Era, social construct, proficiency of the locals was found to be remarkable points when the quality knowledge of herbal medicines was bothered. But due to this rejuvenation and loss of biodiversity in now every day, it has noticed a significant decrease within the ethnic knowledge, moreover within the traditional medicinal branch of Botany. Preservation of these traditional medicinal should lean utmost importance during this region to forestall the rapid loss of ethno botanical wealth. Apart from the seventy four traditional medicinal plants mentioned in the review there are also other ethno medicinal plants which are very useful and important for curing various ailments and future research works. Necessary steps should be taken to forestall the extinction of these highly medicinally important plants. For reducing the ecological diversity eradication a few expedients should be grasped like record of rare medicinal plants, proper coaching services to farmers and also the villagers who are engaged in cultivation of medicinal plants, establishment of herbal gardens in house land areas, inspiring the young generation about the medicinal plants etc. So, the probability of procreation and 
cultivation of the plant should be examined to grasp the aim of defendable development. Further research on these plants may end in the innovation of unique researches and studies and also it should come up with a brand-new perspective of supportable enlargement.

\section{ACKNOWLEDGEMENT}

The authors express their sincere thanks to Department of Biotechnology, Government of India for the funding from DBT-STAR College grant, under which this review project was conducted. We are also grateful to the Principal and the DBT-STAR Coordinator, Surendranath College, for their support and encouragement in implementing this review project at undergraduate level.

\section{REFERENCES}

Bose, D., Roy, J. G., Mahapatra, S. D., Datta, T., Mahapatra, S. D., \& Biswas, H. (2015). Medicinal plants used by tribals in Jalpaiguri district, West Bengal, India. J Med Plants Stud, 3(3), 15-21.

Choudhury, S., Rahaman, C. H., Mandal, S., \& Ghosh, A. (2013). Folk-lore knowledge on medicinal usage of the tribal belts of Birbhum district, West Bengal, India. International Journal of Botany and Research, 3(2), 2277-4815.

Das, D., \& Ghosh, P. (2017). Some important medicinal plants used widely in Southwest Bengal, India. International Journal of Engineering Science Invention, 6(6), 28-50.

Datta, T., Patra, A. K., \& Dastidar, S. G. (2014). Medicinal plants used by tribal population of Cooch Behar district, West Bengal, India-anethnobotanical survey. Asian Pacific Journal of Tropical Biomedicine, $4(1), 478-482$.

Dey, A., \& De, J. N. (2012). Ethnobotanical survey of Purulia district, West Bengal, India for medicinal plants used against gastrointestinal disorders. Journal of Ethnopharmacology, 143(1), 68-80.

Dey, S. K., Banerjee, D., Chattapadhyay, S., \& Karmakar, K. B. (2010). Antimicrobial activities of some medicinal plants of West Bengal. International Journal of Pharma and Bio Sciences, 1(3),1-10.

Ghosh, A. (2008). Ethnomedicinal plants used in West Rarh region of West Bengal. Natural Product Radiance, 7(5), 461-465.

Kala, C. P., Dhyani, P. P., \& Sajwan, B. S. (2006). Developing the medicinal plants sector in northern India: challenges and opportunities. Journal of Ethnobiology and Ethnomedicine, 2(1), 1-15.

Mandal, A., Saha, P., Begum, A., Saha, A., Chakraborty, B., Dutta, S., \& Roy, K. K. (2020).Ethnomedicinal plants used by the ethnic people living in fringe villages of Rasikbil of Cooch Behar district, West Bengal, India. Indian J. Sci. Technol, 13(16), 1676-1685.

Mistry, J. (2015). Traditional medicinal plants used by local people of Murshidabad district, West Bengal, India. World J Pharm Sci, 4(9),1225-34.

Mondal, K., Paul, A., \&Haque, S. (2015). Ethnobiological and traditional medicine practices in Burdwan district, West Bengal, India. Int J EthnobiolEthnomed, 19(1), 1-8.

Mukherjee, S. K. (2018). Some common medicinal plants for the welfare of the people of West Bengal, India. Dynamics in Biology, 1(1), 42-47.

Sarkar, R., \& Kalyani, N. (2005). Role of Indigenous Folk Medicinal Plants among the Tribal Communities inWest Bengal. Lokodarpan, 5(1), 116-121.

Tripathi, S., Ray, S., Mondal, A. K., \& Verma, N. K. (2013). Rare ethno medicinal plants of south West Bengal, India with their different medicinal uses: needs conservation. Int J Life Sci Biotech Pharm Res, 2(2), 2250-3137. 


\title{
An Overview of the Properties and Pharmaceutical uses of Bioactive Compounds from Sesame (Sesamum indicum L.)
}

\author{
Aritrika Sinha, Abhishek Das, Rishita Chakraborty, Suranjana Sarkar* \\ Department of Botany, Surendranath College, Kolkata, India \\ *Corresponding Author's Email: suranjana29@gmail.com
}

\begin{abstract}
Sesame (Sesamum indicum L., family Pedaliaceae) is undeniably a significant cash crop in the oilseed sector. It has multiple bioactive compounds such as phytosterols, tocopherol, homologues, lignans etc. which are good for health. Lignans are formed because of the oxidative coupling of hydroxyphenylpropane. Sesamin, sesamol, sesamolin, and sesaminol are the most important lignans in terms of medicinal and pharmacological properties. These lignans have been extensively researched and are considered to have multiple benefits. These benefits are its antioxidant, antiaging, anti-inflammatory, anti-diabetes and anti-cancer properties. These lignans have the potency to target modern chronic diseases, which can progress to clinical diseases. The most common type of long-lasting disease is rheumatic inflammatory disease. It disturbs the sustenance structures and different parts of the body and can progress to cancer. Tocopherols are a critical part of the human diet. Different tocopherol homologues are found in sesame seeds. These include a-tocopherols, $y$ tocopherols, and $\delta$-tocopherols. This crop is also a significant source of bioactive peptides, phytates, phytosterols and polyunsaturated fatty acids although the usability of these compounds are unclear. This chapter discusses the functional significance and medicinal utility of various bioactive constituents existing in sesame seeds.
\end{abstract}

Keywords: Sesame; Bioactive Components; Lignans; Sesamin; Phytosterols

\section{INTRODUCTION}

Sesame is a very important annual cash crop in the world. This oilseed crop is one of the world's oldest cultivated plants. From the ancient times sesame seeds are raised in tropical regions. Seeds of Sesamum indicum is used as a traditional health food in East Asia, and its oil is used in natural Indian and Chinese naturopathy medicine to boost energy and avoid ageing (Kumar \& Singh, 2015). The Pedaliaceae family contains approximately 16 genera and 60 species, with Sesamum being the most important genus group.

Quoting morphological and cytogenetic affinities between domesticated sesame and the wild south Indian S. mulayanum Nair., accompanied by several archaeological proofs of its cultivation in of the Indus Valley's Harappa area between 2250 and 1750 B.C. Bedigian (2003) validated that sesame was first domesticated in India. It is known as tiland raashi in Oriya and is known as tiland raashi in Gujarati and Bengali. It is known as tiland raashi in Hindi/Urdu. The term sesame derives from the early Egyptian semsent, Arabic simsim and Coptic semsem (Home Cooking, 1998).

Three main commercial products obtained from sesame are its seeds, seed-oil and meal. Sesame seeds are represented as a symbol of immortality in Hindu legends. Sesame seeds were one of the earliest crops to be used for edible oil production (Carvalho et al., 2001). Sesame is used as a component in various foods. When roasted, sesame seed has a nutty flavour. Bread, breadsticks, cookies, chocolate, and ice cream are all delicious when made with roasted natural sesame seed. Cakes with seeds are popular in Greece. Mechanically hulled sesame seed is used to make bakery and candies, as well as the creamy, sweet and wholesome tahini. Tahini is high in protein and an 
excellent source of energy. Sesame flour is a tasty, creamy, light brown powder made from sesame seeds. Sesame flour is high in protein especially rich in amino acids methionine and tryptophan. Sesame seeds have three times the calcium content of a comparable amount of milk (Home Cooking, 1998). India produces a wide variety of sesame varieties with varying grades, each unique to the region. Sesame seeds are harvested twice a year and are available all year. India was a dominant and one of the world's oldest sesame producers.
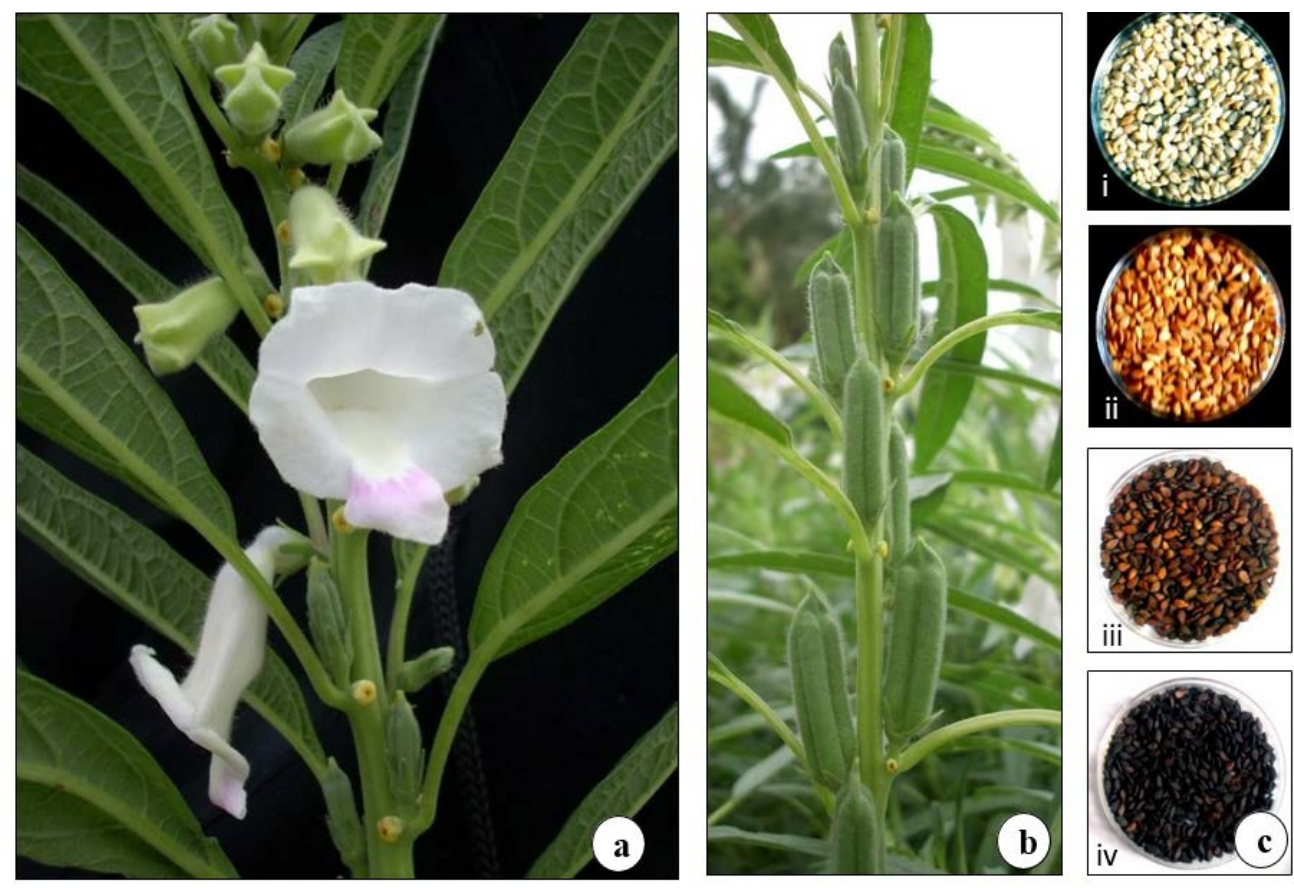

\section{Figure 1: a) Sesamum indicum twig with flowers b) Fruits of Sesame c) Seeds of Different Sesame Accessions - i. Swetha Til ii. Uma iii. Madhvi iv. TMV-4}

\section{LITERATURE REVIEW}

Sesame seeds have a $50-60 \%$ oil content and almost $85 \%$ poly unsaturated fatty acids (Latif \& Anwar, 2011). It has a strong resistance to oxidative rancidity and can be stored for an extended period of time (Abou-Gharbia, Shehata \& Shahidi, 2000; Yen \& Shyu, 1989). The active constituents of sesame oil have a variety of pharmacological properties, including decreasing blood lipids (Hirata et al., 1996) and arachidonic acid levels (Shimizu et al., 1991), reducing blood cholesterol levels (Hirata et al., 1996; Chen et al., 2005; Visavadiya \& Narasimhacharya, 2008), anti-inflammatory function (Utsunomiya et al., 2000; Hsu et al., 2005), anti-proliferative activity (Yokota et al., 2007), increasing the amount of hepatic fatty acid oxidation enzymes (Ashakumary et al., 1999), lower hypertention (Nakano et al., 2007) and shows neuroprotective effects against hypoxia or brain damage (Cheng et al., 2006). So far, sesame has been found to be the most efficient food for increasing the access of tocopherol among biological resources (Cooney et al., 2001; Jiang et al., 2001; Lemcke-Norojarvi et al., 2001). Sesame's utility as antiseptics and bactericides has increased because of these qualities.

Sesame is also high in lignans, which are a class of bioactive phenolic compounds that include sesamin, episesamin, sesamol, sesamolin, and -tocopherol (Jeng \& Hou, 2005). They are, however, most abundant in sesame seed and sesamin is the most abundant isomer (1520 6.8 mol/100 g) (Liu, Saarinen \& Thompson, 2006, Liang et al., 2015). Raw sesame oil contains $0.5-1.1$ percent sesamin and 0.2-0.6 percent sesamolin, which ensures to the oil's medicinal properties because these lignans are said to have high antioxidant properties (Kumar \& Singh, 2015). These lignans are responsible for sesame oil's superior oxidative stability and long shelf life. The majority of modern sesame research 
has centred on particularly the two major oil-soluble lignans, sesamin and sesamolin (Budowski \& Markley, 1951; Fukuda \& Nakata, 1999). Sesamin has been linked to a number of biochemical actions, which helps in the production of pro-inflammatory prostaglandins, provides protection against ethanol and carbon tetrachloride-induced liver damage, increases the absorption of -tocopherol, and has anticarcinogenic properties in animals. Although, the exact mechanism of some of these effects is unknown, it has been suggested that sesamin plays a proactive role and that sesamin's metabolites are responsible for the physiological consequences (Penalvo et al., 2005). Sesamin undergoes oxidative demethylenation of methylene dioxyphenyls in rat liver, resulting in catechol or methoxycatechol, which are significant antioxidant moieties as mentioned by Nakai and colleagues (2003). Sesamin also protects us against breast cancer type diseases (Penalvo et al., 2005; Liu, Saarinen \& Thompson, 2006). In rats, sesamin has been found to decrease blood pressure, lower serum lipids, and prevent cholesterol absorption and production. (Kumar \& Singh, 2015). Cephalin, a sesame seed phospholipid, has been shown to have hemostatic activity. Sesame oil has a wide range of medicinal and pharmacological uses. It has mild laxative, soothing, and demulcent properties. As a poultice, the seeds and fresh leaves can be used. Seeds have been shown to have antibacterial activity against Staphylococcus, Streptococcus and common skin fungi such as athlete's foot fungus. According to Sirato-Yasumoto et al., 2001, the oil possesses high density lipoprotein cholesterol (HDL) and lower low-density lipoprotein cholesterol (LDL). Lignans are abundant in refined sesame oil. In addition to antioxidants, sesame oil includes a high quantity of linoleate in triglyceride form, which inhibits the proliferation of malignant melanoma cells preferentially (Smith \& Salerno, 1992). As a viable alternative to diesel fuel, the focus has recently switched to the manufacturing of biodiesel from sesame seed oil. Ethnobotanical and therapeutic benefits of this commercially important, nutritionally dense oilseed should be studied for its improved utilisation.

\section{DISCUSSION}

\section{Pharmacological activity of sesame:}

\section{Anti-inflammatory and anti-pyretic activity}

The anti-inflammatory activity was determined by inhibiting paw edoema caused by carrageenan (an edematogenic substance) injection into the rat's right hind paw's sub-plantar area. Their findings confirmed anti-inflammatory action of sesamin and oil of sesame by preventing pleural exudate production and leucocyte migration (Patel, Murugananthan \& Gowda, 2012; Wu et al., 2019).

The antipyretic activity of the oil is equivalent to that of paracetamol. In one research, sesame oil taken as a dietary supplement was found to have analgesic, antipyretic, and anti-inflammatory properties in animal models (Saleem et al., 2011).

\section{Anti-microbial activity}

Sesame contains inherent antibacterial effects against a wide range of skin infections, including infection by Streptococcus, Staphylococcus and common skin fungi like athlete's foot. Streptococcus and other common cold germs are killed by it when gargled down the throat. It is beneficial to people who have psoriasis or dry skin. It functions as a natural UV protector. Sesame oil has the highest antimicrobial activity and is comparable to standard Kanamycin. It also has the highest zone of inhibition against Salmonella typhi. It was discovered that sesame oil has antibacterial activity against Streptococcus mutans, Lactobacilli acidophilus and total bacteria (Anand et al., 2008).

\section{Effects of sesamin on hypertension}

Several in vitro and in vivo studies demonstrate sesamin's antihypertensive effects. According to Li and colleagues' research, giving in monocrotaline-induced hypertensive rats, sesamin (50 mg and $100 \mathrm{mg}$ ) for four weeks decreases proper ventricular systolic blood pressure and mean pulmonary arterial pressure. (Li et al., 2015). Sesamin's antihypertensive properties have also been observed in humans. Use of $60 \mathrm{mg}$ sesamin containing for four weeks among middle-aged men and women who were mildly 
hypertensive showed reduction in both Systolic and diastolic blood pressure at the end of the trial on twelve subjects (Miyawaki et al., 2009). Epidemiological studies recommend that lowering blood pressure by $2-3 \mathrm{mmHg}$ can slow the progression of CVDs. As a result, little drop in systolic and diastolic blood pressure caused by sesamin may be sufficient enough to lower the risk of developing cardiovascular disease (Miyawaki et al., 2009). Sesamin's antihypertensive properties are also being studied in patients suffering from rheumatoid arthritis, who are at a higher risk of developing CVDs (Helli et al., 2016). Sesamin has also been investigated as a possible inhibitor of the arachidonic acid metabolite 20-hydroxyeicosatetraenoic acid (20HETE) (AA). The renin-angiotensin system (RAS) has been found to interact with 20-HETE and affect blood pressure control, potentially contributing to hypertension aetiology. (Hoopes et al., 2015).

\section{Sesame in lipid metabolism}

Due to its chemical composition, dietary consumption of sesame oil has a high potential for condition improvement by preventing postprandial lipemia or lipid oxidation. Even though several studies on the effect of sesamin on lipid metabolism are available, just a few studies that have used whole sesame oil as a diet are available (Chavali, Zhong \& Forse,1998). It appears to have lipid peroxidation as well as the lipid profile. It is clear that sesame, which is high in lignans, has a greater impact on serum triacylglycerol levels and hepatic fatty acid oxidation. As a result, eating lignan-rich sesame causes physiological functions that alters lipid metabolism in a possibly advantageous way. Sesamol has been demonstrated to help in oxidative stress management caused by lipopolysaccharides and to activate the phosphatidylinositol 3-kinase/Akt/endothelial nitric oxide synthase pathways (Ying et al., 2011) Sesame seed coat contains a lot of ethyl protocatechuate. It has antioxidant properties. In humans, it inhibits LDL oxidation. It is also used to keep foods with a high fat content fresh (Asghar, Majeed \& Akhtar, 2014).

\section{Wound healing properties}

At the injury site, free radicals are produced, which are identified to impede healing by damaging cell membranes, nucleotides, proteins and lipids. Quite a few antioxidants, such as curcumin and vitamin E, have been described to protect tissues from oxidation damage in this context. Antioxidants have been proven to aid in wound healing. Sesame oil has antioxidative action potential, which assists in the prevention of oxidation regarding harms and stimulate the remedial procedure (Fukuda et al., 1986; Pascoe et al., 1987). In experimentally induced rats, both seeds and oil of S. indicum enhance wound healing. Topically applied gel comprising sesame seeds or oil, or oral ingestion of seeds or oil, significantly increase breaking strength, wound contraction, and epithelialization period in incision, excision and burn wound models (Kiran \& Asad, 2008).

\section{Sesame in Atherosclerosis}

Sesame oil may effectively obstruct the creation of atherosclerosis lesion due to the harmonious interactions of fatty acid and non-saponifiable compositions (Bhaskaran et al., 2006). An altered type of sesamol (INV-403) is used to improve its characteristics and is being studied for its influence on atherosclerosis. INV-403 is a new modified lignan derivative that slows the development of atherosclerosis by modulating IKK2 and nuclear factor-B signalling. (Ying et al., 2011).

\section{Anti-cancer properties}

In vitro studies have revealed that sesame oil prevents the development of malignant melanoma cells and human colon cancer cell proliferation (Smith \& Salerno, 1992). Consuming sesame seeds raises plasma -tocopherol and boosts vitamin E activity, both of which have been linked to a reduced danger of cancer and heart disease. Sesame seed cephalin has blood clotting activity. Sesame fiber has traditionally been used as an anti-diabetic, anti-tumor, anti-ulcer, cancer preventive, cardio-protective and laxative. Sesame seed contains myristic acid, which has cancer-preventive effects (Chakraborthy, Sharma \& Kaushik, 2008). Anticancer properties of sesame are summarized in Table -1. 
Table 1: Anticancer Properties of Sesame Lignans

\begin{tabular}{|c|c|c|}
\hline Sesame lignans & $\begin{array}{c}\text { Types of Cancer controlled by sesame } \\
\text { lignans }\end{array}$ & Reference \\
\hline \multirow[t]{10}{*}{ Sesamin } & Chronic Myeloid Leukemia & Harikumar et al., 2010 \\
\hline & Myeloma & Harikumar et al., 2010 \\
\hline & Breast Cancer & $\begin{array}{l}\text { Yokota et al., 2007; Truan, Chen \& Thompson, } \\
\text { 2012; } \\
\text { Lee et al., 2011; Harikumar et al., 2010; } \\
\text { Akl et al., 2013 }\end{array}$ \\
\hline & Cervical Cancer & Dou et al., 2018 \\
\hline & Colon Carcinoma & Harikumar et al., 2010 \\
\hline & Human Hepatocellular Carcinoma & Deng et al., 2013 \\
\hline & Human Lung Adenocarcinoma & Harikumar et al., 2010 \\
\hline & Pancreatic Cancer & Harikumar et al., 2010 \\
\hline & Prostate Cancer & Jeng \& Hou, 2005; Harikumar et al., 2010 \\
\hline & Malignant Melanoma & Srisayam, Weerapreeyakul \& Kanokmedhakul, 2017 \\
\hline \multirow[t]{5}{*}{ Sesaminol } & Lymphoid Leukemia & Namiki, 2007; Miyahara et al., 2001 \\
\hline & Breast Cancer & Watanabe et al., 2017 \\
\hline & Colon Carcinoma & Watanabe et al., 2017 \\
\hline & Lung Adenocarcinoma & Watanabe et al., 2017 \\
\hline & Melanoma & Watanabe et al., 2017 \\
\hline \multirow[t]{12}{*}{ Sesamol } & Acute Myeloid Leukemia & Geetha et al., 2015 \\
\hline & Chronic Myeloid Leukemia & Fujimoto et al., 2010 \\
\hline & Lymphoid Leukemia & Miyahara et al., 2000 \\
\hline & Breast Cancer & Jacklin et al., 2003 \\
\hline & Colon Adenocarcinoma & Shimizu et al., 2014 \\
\hline & Colon Carcinoma & Khamphio, Barusrux \& Weerapreeyakul , 2016 \\
\hline & Human Hepatocellular Carcinoma & Liu et al., 2013; Liu et al., 2017 \\
\hline & Lung Adenocarcinoma & $\begin{array}{l}\text { Siriwarin \& Weerapreeyakul, 2016; Siriwarin et al., } \\
2018\end{array}$ \\
\hline & Human Malignant Melanoma & Srisayam, Weerapreeyakul \& Kanokmedhakul, 2017 \\
\hline & Mouse Melanoma & Kumar et al., 2011 \\
\hline & Two-Stage Mouse Skin Carcinogenesis & Kapadia et al., 2002 \\
\hline & Mouse Leydigtumor & Chen et al., 2011 \\
\hline \multirow[t]{3}{*}{ Sesamolin } & Burkitt's lymphoma & Kim \& Lee, 2015 \\
\hline & Prostate Cancer & Jeng \& Hou, 2005 \\
\hline & Human Malignant Melanoma & Srisayam, Weerapreeyakul \& Kanokmedhakul, 2017 \\
\hline
\end{tabular}




\section{Other Medicinal Uses}

Sesame oil is used to treat a variety of long-term illnesses like hepatitis, diabetes, and migraine as it has been established by the recent studies conducted by Ayurvedic physicians in Holland. These effects are supported by major migraine pathophysiological theories including the neural and sensitization theories. Tumor-suppressing properties are present in sesame flower extract (Bhaskaran et al., 2006). Sesame oil contains nutritious, demulcent, and moisturizing qualities and is utilized as an intramuscular solvent. It's also been known to be used as a laxative. The leaves contain a gummy substance that, when combined with water, produces a rich, tasteless mucilage that is used to treat infant-cholera, diarrhoea, dysentery, menstrual irregularities, poly-urea, stomach problems, cataract, boils, carbuncles, major burns, skin diseases, alopecia, and as a tonic (Morton, 1990). The unsaponified portion of plant-derived oil contains phytosterols. Phytosterols account for $66 \%$ of total sterols in sesame oil. They function as an anti-cholesteric substance. Because their structure is similar to oestrogen, they can be used in oral contraception (Asghar, Majeed \&Akhtar, 2014).

\section{Future research aspects}

It is preferable to choose sesame cultivars which are having high contents of sesamolin and sesamin as they have high benefits on human health. There are wide use of sesame seeds and products in India. However, it is still not fully known what the profiles of sesamin and sesamolin of these cultivars are. Hence, studies should be conducted on Indian sesame cultivars to determine their sesamin and sesamolin contents. Till date, there is no vivid information about the mineral distributions of sesame seeds. After the seed testa is removed, sesame seeds are usually considered for food uses. Hence, analysis of the dehulled sesame seed is also required. It is also unknown where minerals are found in embryonic tissue. Estimates of diversity in cultivated plants validate the conservation approaches and aid in the selection of initial material for breeding programs. Diversified crop measures have typically been limited to assessing genome polymorphism at the DNA level. Selected morphological characteristics have been detected sporadically, and therefore the content of important chemical components has been identified, but chemical phenotypes have not been extensively and methodically incorporated in diversity surveys. Therefore, to explain the association between metabolic and genome diversity, non-targeted metabolic profiling of sesame can be used.

\section{CONCLUSION}

Sesame plant is used for numerous purposes. It is used in different culinary processes. It also has applications in pharmaceutical, industrial, and engineering industry. Different phytonutrients, some flavonoid phenolic antioxidants, several vitamins and dietary fiber which have medicinal properties come from sesame. It has other proven medicinal benefits such as anti-inflammatory, anti-microbial, anti-hypertensive, anti-pyretic, anticancer and few additional properties. As a result, the sesame plant has a bright future in the medical arena, with the potential to improve and enhance the eminence of life of mankind.

\section{ACKNOWLEDGEMENTS}

The authors would like to acknowledge the Department of Biotechnology of the Government of India for sponsoring this review study under the DBT-Star College Grant. The authors would like to express their gratitude to the Principal, Surendranath College and the DBT-STAR Coordinator for their help and encouragement in implementing this review project.

\section{REFERENCES}

Abou-Gharbia, H. A., Shehata, A. A. Y., \& Shahidi, F. (2000). Effect of processing on oxidative stability and lipid classes of sesame oil. Food Research international, 33(5), 331-340.

Akl, M. R., Ayoub, N. M., Abuasal, B. S., Kaddoumi, A., \& Sylvester, P. W. (2013). Sesamin synergistically potentiates the anticancer effects of $\mathrm{Y}$-tocotrienol in mammary cancer cell lines. Fitoterapia, 84, 347- 
359.

Anand, T. D., Pothiraj, C., Gopinath, R. M., \& Kayalvizhi, B. (2008). Effect of oil-pulling on dental caries causing bacteria. African Journal of Microbiology Research, 2(3), 63-66.

Asghar, A., Majeed, M. N., \& Akhtar, M. N. (2014). A review on the utilization of sesame as functional food. American Journal of Food and Nutrition, 4(1), 21-34.

Ashakumary, L., Rouyer, I., Takahashi, Y., Ide, T., Fukuda, N., Aoyama, T., ... \& Sugano, M. (1999). Sesamin, a sesame lignan, is a potent inducer of hepatic fatty acid oxidation in the rat. Metabolism, 48(10), 1303-1313.

Bedigian, D. (2003). Sesame in Africa: origin and dispersals. Food, Fuel and Fields: Progress in African Archaeobotany. Cologne: Heinrich Bert Institute, 17-36.

Bhaskaran, S., Santanam, N., Penumetcha, M., \& Parthasarathy, S. (2006). Inhibition of atherosclerosis in low-density lipoprotein receptor-negative mice by sesame oil. Journal of Medicinal Food, 9(4), 487490.

Budowski, P., \& Markley, K. S. (1951). The chemical and physiological properties of sesame oil. Chemical Reviews, 48(1), 125-151.

Carvalho, P. G. B. D., Borghetti, F., Buckeridge, M. S., Morhy, L., \& Ferreira Filho, E. X. (2001). Temperature-dependent germination and endo-beta-mannanase activity in sesame seeds. Revista Brasileira de Fisiologia Vegetal, 13, 139-148.

Chakraborthy, G. S., Sharma, G., \& Kaushik, K. N. (2008). Sesamum indicum: a review. Journal of Herbal Medicine and Toxicology, 2(2), 15-19.

Chavali, S. R., Zhong, W. W., \& Forse, R. A. (1998). Dietary a-linolenic acid increases TNF-a, and decreases IL-6, IL-10 in response to LPS: effects of sesamin on the $\Delta-5$ desaturation of $\omega 6$ and $\omega 3$ fatty acids in mice. Prostaglandins, Leukotrienes and Essential Fatty Acids, 58(3), 185-191.

Chen, P. R., Chien, K. L., Su, T. C., Chang, C. J., Liu, T. L., Cheng, H., \& Tsai, C. (2005). Dietary sesame reduces serum cholesterol and enhances antioxidant capacity in hypercholesterolemia. Nutrition Research, 25(6), 559-567.

Chen, Y. H., Leu, S. F., Jen, C. Y., \& Huang, B. M. (2011). Effects of sesamol on apoptosis and steroidogenesis in MA-10 mouse Leydig tumor cells. Journal of Agricultural and Food Chemistry, 59(18), 9885-9891.

Cheng, F. C., Jinn, T. R., Hou, R. C., \& Tzen, J. T. (2006). Neuroprotective effects of sesamin and sesamolin on gerbil brain in cerebral ischemia. International Journal of Biomedical Science: IJBS, 2(3), 284.

Cooney, R. V., Custer, L. J., Okinaka, L., \& Franke, A. A. (2001). Effects of dietary sesame seeds on plasma tocopherol levels. Nutrition and Cancer, 39(1), 66-71.

Deng, P., Wang, C., Chen, L., Wang, C., Du, Y., Yan, X., \& He, G. (2013). Sesamin induces cell cycle arrest and apoptosis through the inhibition of signal transducer and activator of transcription 3 signalling in human hepatocellular carcinoma cell line HepG2. Biological and Pharmaceutical Bulletin, 36(10), 1540-1548.

Dou, H., Yang, S., Hu, Y., Xu, D., Liu, L., \& Li, X. (2018). Sesamin induces ER stress-mediated apoptosis and activates autophagy in cervical cancer cells. Life sciences, 200, 87-93.

Fujimoto, A., Shingai, Y., Oyama, T. B., Kawanai, T., Hashimoto, E., Koizumi, K., ... \& Oyama, Y. (2010). Apoptosis-inducing action of two products from oxidation of sesamol, an antioxidative constituent of sesame oil: a possible cytotoxicity of oxidized antioxidant. Toxicology in Vitro, 24(6), 1720-1726.

Fukuda, Y., \& Nakata, S. (1999). Effects of roasting temperature in sliced almonds and sesame seeds on the antioxidative activities. Journal of the Japanese Society for Food Science and Technology (Japan). 
Fukuda, Y., Nagata, M., Osawa, T., \& Namiki, M. (1986). Contribution of lignan analogues to antioxidative activity of refined unroasted sesame seed oil. Journal of the American Oil Chemists' Society, 63(8), 1027-1031.

Geetha, T., Kapila, M., Prakash, O., Deol, P. K., Kakkar, V., \& Kaur, I. P. (2015). Sesamol-loaded solid lipid nanoparticles for treatment of skin cancer. Journal of drug targeting, 23(2), 159-169.

Harikumar, K. B., Sung, B., Tharakan, S. T., Pandey, M. K., Joy, B., Guha, S., ... \& Aggarwal, B. B. (2010). Sesamin manifests chemopreventive effects through the suppression of NF-kB-regulated cell survival, proliferation, invasion, and angiogenic gene products. Molecular Cancer Research, 8(5), 751-761.

Helli, B., Mowla, K., Mohammadshahi, M., \& Jalali, M. T. (2016). Effect of sesamin supplementation on cardiovascular risk factors in women with rheumatoid arthritis. Journal of the American College of Nutrition, 35(4), 300-307.

Hirata, F., Fujita, K., Ishikura, Y., Hosoda, K., \& Ishikawa, T. (1996). Hypocholesterolemic effect of sesame lignan in humans. Atherosclerosis, 122(1), 135-136.

Home Cooking. (1998). Sesame seeds. Available from Homecooking. about. com/library/weekly/aa060898.html (accessed May 15, 1998).

Hoopes, S. L., Garcia, V., Edin, M. L., Schwartzman, M. L., \& Zeldin, D. C. (2015). Vascular actions of 20HETE. Prostaglandins \& Other Lipid Mediators, 120, 9-16.

Hsu, D. Z., Su, S. B., Chien, S. P., Chiang, P. J., Li, Y. H., Lo, Y. J., \& Liu, M. Y. (2005). Effect of sesame oil on oxidative-stress-associated renal injury in endotoxemic rats: involvement of nitric oxide and proinflammatory cytokines. Shock, 24(3), 276-280.

Jacklin, A., Ratledge, C., Welham, K., Bilko, D., \& Newton, C. J. (2003). The sesame seed oil constituent, sesamol, induces growth arrest and apoptosis of cancer and cardiovascular cells. Annals of the New YorkAcademy of Sciences, 1010(1), 374-380.

Jeng, K. C. G., \& Hou, R. C. W. (2005). Sesamin and sesamolin: nature's therapeutic lignans. Current Enzyme Inhibition, 1(1), 11-20.

Jiang, Q., Christen, S., Shigenaga, M. K., \& Ames, B. N. (2001). Y-Tocopherol, the major form of vitamin E in the US diet, deserves more attention. The American Journal of Clinical Nutrition, 74(6), 714-722.

Kapadia, G. J., Azuine, M. A., Tokuda, H., Takasaki, M., Mukainaka, T., Konoshima, T., \& Nishino, H. (2002). Chemopreventive effect of resveratrol, sesamol, sesame oil and sunflower oil in the Epstein-Barr virus early antigen activation assay and the mouse skin two-stage carcinogenesis. Pharmacological Research, 45(6), 499-505.

Khamphio, M., Barusrux, S., \& Weerapreeyakul, N. (2016). Sesamol induces mitochondrial apoptosis pathway in HCT116 human colon cancer cells via prooxidant effect. Life sciences, 158, 46-56.

Kim, J. H., \& Lee, J. K. (2015). Sesamolin enhances NK cell lysis activity by increasing the expression of NKG2D ligands on Burkitt's lymphoma cells. International immunopharmacology, 28(2), 977-984.

Kiran, K., \& Asad, M. (2008). Wound healing activity of Sesamum indicum L seed and oil in rats.

Kumar, C. M., \& Singh, S. A. (2015). Bioactive lignans from sesame (Sesamum indicum L.): evaluation of their antioxidant and antibacterial effects for food applications. Journal of Food Science and Technology, 52(5), 2934-2941.

Kumar, C. M., Sathisha, U. V., Dharmesh, S., Rao, A. A., \& Singh, S. A. (2011). Interaction of sesamol (3, 4-methylenedioxyphenol) with tyrosinase and its effect on melanin synthesis. Biochimie, 93(3), 562569.

Latif, S., \& Anwar, F. (2011). Aqueous enzymatic sesame oil and protein extraction. Food Chemistry, 125(2), 679-684. 
Lee, C. C., Liu, K. J., Wu, Y. C., Lin, S. J., Chang, C. C., \& Huang, T. S. (2011). Sesamin inhibits macrophage-induced vascular endothelial growth factor and matrix metalloproteinase- 9 expression and proangiogenic activity in breast cancer cells. Inflammation, 34(3), 209-221.

Lemcke-Norojärvi, M., Kamal-Eldin, A., Appelqvist, L. A., Dimberg, L. H., Öhrvall, M., \& Vessby, B. (2001). Corn and sesame oils increase serum $y$-tocopherol concentrations in healthy Swedish women. The Journal of Nutrition, 131(4), 1195-1201.

Li, X., Gao, Y., Li, S., \& Yang, J. (2015). Effect of sesamin on pulmonary vascular remodeling in rats with monocrotaline-induced pulmonary hypertension. Zhongguo Zhong yao za zhi= Zhongguo zhongyao zazhi= China journal of Chinese materia medica, 40(7), 1355-1361.

Liang, Y. T., Chen, J., Jiao, R., Peng, C., Zuo, Y., Lei, L., ... \& Chen, Z. Y. (2015). Cholesterol-lowering activity of sesamin is associated with down-regulation on genes of sterol transporters involved in cholesterol absorption. Journal of Agricultural and Food Chemistry, 63(11), 2963-2969.

Liu, Z., Ren, B., Wang, Y., Zou, C., Qiao, Q., Diao, Z., ... \& Liu, X. (2017). Sesamol induces human hepatocellular carcinoma cells apoptosis by impairing mitochondrial function and suppressing autophagy. Scientific reports, 7(1), 1-12.

Liu, Z., Saarinen, N. M., \& Thompson, L. U. (2006). Sesamin is one of the major precursors of mammalian lignans in sesame seed (Sesamum indicum) as observed in vitro and in rats. The Journal of Nutrition, 136(4), 906-912.

Liu, Z., Xiang, Q., Du, L., Song, G., Wang, Y., \& Liu, X. (2013). The interaction of sesamol with DNA and cytotoxicity, apoptosis, and localization in HepG2 cells. Food chemistry, 141(1), 289-296.

Miyahara, Y., Hibasami, H., Katsuzaki, H., Imai, K., \& Komiya, T. (2000). Sesamol induces apoptosis in human lymphoid leukemia Molt 4B cells. Food Science and Technology Research, 6(3), 201-203.

Miyahara, Y., Hibasami, H., Katsuzaki, H., Imai, K., Osawa, T., Ina, K., \& Komiya, T. (2001). Sesaminol from sesame seed induces apoptosis in human lymphoid leukemia Molt 4B cells. International journal of molecular medicine, 7(5), 485-488.

Miyawaki, T., Aono, H., Toyoda-Ono, Y., Maeda, H., Kiso, Y., \& Moriyama, K. (2009). Antihypertensive effects of sesamin in humans. Journal of Nutritional Science and Vitaminology, 55(1), 87-91.

Morton, J. F. (1990). Mucilaginous plants and their uses in medicine. Journal of Ethnopharmacology, 29(3), 245-266.

Nakai, M., Harada, M., Nakahara, K., Akimoto, K., Shibata, H., Miki, W., \& Kiso, Y. (2003). Novel antioxidative metabolites in rat liver with ingested sesamin. Journal of Agricultural and Food Chemistry, 51(6), 1666-1670.

Nakano, D., Kurumazuka, D., Nagai, Y., Nishiyama, A., Kiso, Y., \& Matsumura, Y. (2007). Dietary sesamin suppresses aortic NADPH oxidase in DOCA salt hypertensive rats. Clinical and Experimental Pharmacology \& Physiology, 35(3), 324-326.

Namiki, M. (2007). Nutraceutical functions of sesame: a review. Critical reviews in food science and nutrition, 47(7), 651-673.

Pascoe, G. A., Fariss, M. W., Olafsdottir, K., \& Reed, D. J. (1987). A role of vitamin E in protection against cell injury: maintenance of intracellular glutathione precursors and biosynthesis. European Journal of Biochemistry, 166(1), 241-247.

Patel, M., Murugananthan, G., \& Gowda, K. P. S. (2012). In vivo animal models in preclinical evaluation of anti-inflammatory activity—A review. Int. J. Pharm. Res. Allied Sci, 1(2), 01-05.

Pathak, N., Bhaduri, A., \& Rai, A. K. (2019). Sesame: Bioactive compounds and health benefits. Bioactive molecules in food, 181-200.

Penalvo, J. L., Heinonen, S. M., Aura, A. M., \& Adlercreutz, H. (2005). Dietary sesamin is converted to 
Properties and Pharmaceutical uses of Bioactive Compounds from Sesame

enterolactone in humans. The Journal of Nutrition, 135(5), 1056-1062.

Saleem, T. M., Basha, S. D., Mahesh, G., Rani, P. S., Kumar, N. S., \& Chetty, C. M. (2011). Analgesic, antipyretic and anti-inflammatory activity of dietary sesame oil in experimental animal models. Pharmacologia, 2(6), 172-7.

Shimizu, S., Akimoto, K., Shinmen, Y., Kawashima, H., Sugano, M., \& Yamada, H. (1991). Sesamin is a potent and specific inhibitor of $\Delta 5$ desaturase in polyunsaturated fatty acid biosynthesis. Lipids, 26(7), 512-516.

Shimizu, S., Fujii, G., Takahashi, M., Nakanishi, R., Komiya, M., Shimura, M., ... \& Mutoh, M. (2014). Sesamol suppresses cyclooxygenase-2 transcriptional activity in colon cancer cells and modifies intestinal polyp development in ApcMin/+ mice. Journal of Clinical Biochemistry and Nutrition, 54(2), 95-101.

Sirato-Yasumoto, S., Katsuta, M., Okuyama, Y., Takahashi, Y., \& Ide, T. (2001). Effect of sesame seeds rich in sesamin and sesamolin on fatty acid oxidation in rat liver. Journal of Agricultural and Food Chemistry, 49(5), 2647-2651.

Siriwarin, B., \& Weerapreeyakul, N. (2016). Sesamol induced apoptotic effect in lung adenocarcinoma cells through both intrinsic and extrinsic pathways. Chemicobiological interactions, 254, 109-116.

Siriwarin, B., Weerapreeyakul, N., Tanthanuch, W., \& Thumanu, K. (2018). Biomolecular changes and DNA targeting effect of sesamol in human lung adenocarcinoma (SK-LU-1) cells by FTIR microscopy. Asian Pacific Journal of Tropical Biomedicine, 8(8), 377.

Smith, D. E., \& Salerno, J. W. (1992). Selective growth inhibition of a human malignant melanoma cell line by sesame oil in vitro. Prostaglandins, Leukotrienes and Essential Fatty Acids, 46(2), 145-150.

Srisayam, M., Weerapreeyakul, N., \& Kanokmedhakul, K. (2017). Inhibition of two stages of melanin synthesis by sesamol, sesamin and sesamolin. Asian Pacific journal of tropical biomedicine, 7(10), 886-895.

Truan, J. S., Chen, J. M., \& Thompson, L. U. (2012). Comparative effects of sesame seed lignan and flaxseed lignan in reducing the growth of human breast tumors (MCF-7) at high levels of circulating estrogen in athymic mice. Nutrition and cancer, 64(1), 65-71.

Utsunomiya, T., Chavali, S. R., Zhong, W. W., \& Forse, R. A. (2000). Effects of sesamin-supplemented dietary fat emulsions on the ex vivo production of lipopolysaccharide-induced prostanoids and tumor necrosis factor $\alpha$ in rats. The American Journal of Clinical Nutrition, 72(3), 804-808.

Visavadiya, N. P., \& Narasimhacharya, A. V. R. L. (2008). Sesame as a hypocholesteraemic and antioxidant dietary component. Food and Chemical Toxicology, 46(6), 1889-1895.

Watanabe, M., lizumi, Y., Sukeno, M., lizuka-Ohashi, M., Sowa, Y., \& Sakai, T. (2017). The pleiotropic regulation of cyclin D1 by newly identified sesaminol-binding protein ANT2. Oncogenesis, 6(4), e311e311.

Wu, M. S., Aquino, L. B. B., Barbaza, M. Y. U., Hsieh, C. L., Castro-Cruz, D., Kathlia, A., ... \& Tsai, P. W. (2019). Anti-inflammatory and anticancer properties of bioactive compounds from Sesamum indicum L.-A review. Molecules, 24(24), 4426.

Yen, G. C., \& Shyu, S. L. (1989). Oxidative stability of sesame oil prepared from sesame seed with different roasting temperatures. Food Chemistry, 31(3), 215-224.

Ying, Z., Kherada, N., Kampfrath, T., Mihai, G., Simonetti, O., Desikan, R., ... \& Rajagopalan, S. (2011). A modified sesamol derivative inhibits progression of atherosclerosis. Arteriosclerosis, Thrombosis, and Vascular Biology, 31(3), 536-542.

Yokota, T., Matsuzaki, Y., Koyama, M., Hitomi, T., Kawanaka, M., Enoki-Konishi, M., ... \& Sakai, T. (2007). Sesamin, a lignan of sesame, down-regulates cyclin D1 protein expression in human tumor cells. Cancer Science, 98(9), 1447-1453. 


\title{
A Synoptic Review on the Pharmacological Properties of Ocimum sanctum L.
}

\author{
Sayantika Roy, Swadhin Murmu, Swagata Mondal, Sonali Ray* \\ Department of Botany, Surendranath College, Kolkata, India \\ *Corresponding Authors Email: sonyyrr@gmail.com
}

\begin{abstract}
Ocimum sanctum $L$. (Synonym Ocimum tenuiflorum L.) belongs to the family Lamiaceae and is hailed to be very unique amongst the most sacred plants in India. It is a medicinally important plant as mentioned in traditional systems of treatment. This plant has been reported to possess antidiabetic, antifungal, antimicrobial, antioxidant, antifertility, anticancer, hepatoprotective, antispasmodic, and anti-inflammatory properties. This therapeutic potential of the plant is attributed mainly to the active ingredient, Eugenol, a phenolic compound along with other phytochemicals. Here, we attempt to present a synoptic compilation of the scientific reports of the pharmacological properties and significant pharmaceutical uses of the plant.
\end{abstract}

\section{Keywords: Ocimum Sanctum L.; Eugenol; Pharmacological Properties}

\section{INTRODUCTION}

Ocimum sanctum L. (Synonym Ocimum tenuiflorum L.) belongs to the family Lamiaceae, is the most prominent species of its genera (The Plant List, 2015). It is native to the Indian sub-continent and is cultivated in many countries of Southeast Asia. It is known worldwide for its medicinal, religious, ceremonial and ethnobotanical significance. This perennial herb ranging within a height of $30-60 \mathrm{~cm}$ has a distinctive aroma of its own. It has an upright, pubescent stem with branches. The herb has simple, petiolate leaves which are ovate in shape with slightly serrated margins and a subacute apex, arranged in a decussate phyllotaxy (Fig.1). Flowers are arranged in terminal spikes, with flowers having bilabiate corolla. It is popularly known as Holy Basil or Tulsi. Darrah (1974) identified two cultivars that are commonly found, namely - Rama Tulsi and Krishna Tulsi bearing green leaves and purple leaves respectively.

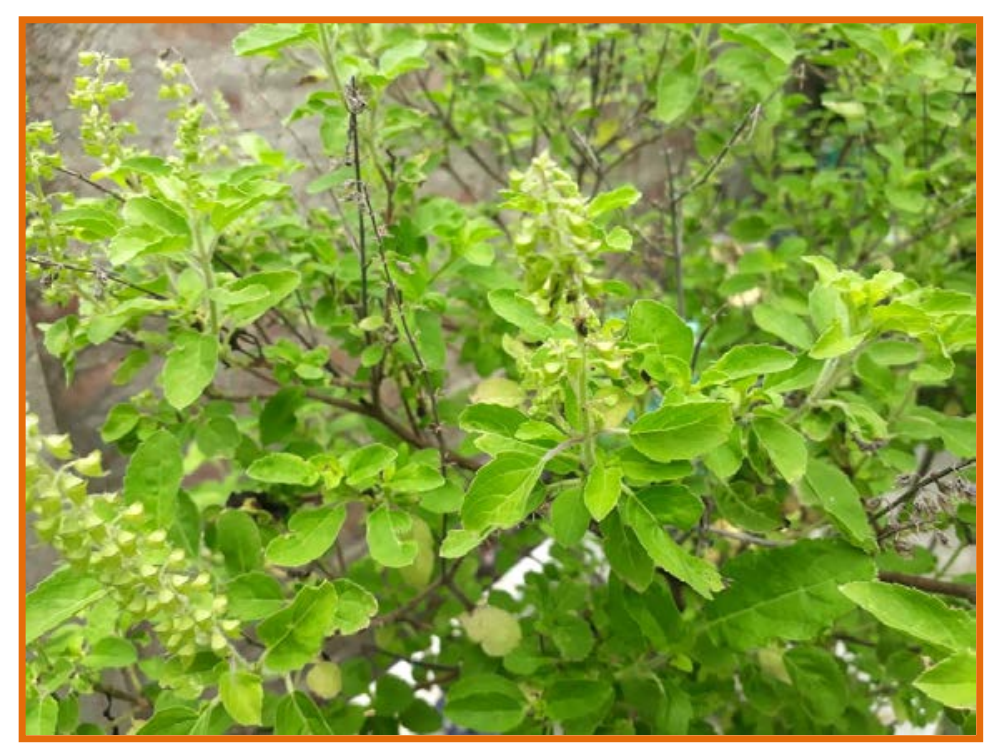

Figure 1: Ocimum Sanctum Plant

The whole plant with all its parts - leaves, stem, root, flower and seeds - have been used for curing a variety of ailments, by the practitioners following the traditional systems of medicine. According to the Ayurvedic Pharmacopeia of India (Government of India,1999), the powdered form of the leaves of this plant has been used in different dosages for the treatment of a variety of illnesses including the respiratory disorders, cough and cold, skin and taste disorders, and for treating problems related to worms in the gastrointestinal parts of the body (Singh \& Chaudhuri 2018). In order to establish the therapeutic values in modern medicine, several researches have been conducted to study the pharmacological effects of the various extracts of the plant and use them purposefully targeting specific ailments. 


\section{LITERATURE REVIEW AND DISCUSSION}

\section{Nutritional Value:}

$O$. sanctum contains many phytonutirents including vitamins $A$ and $C$, and minerals like calcium, zinc and iron. Pattanayak et al., (2010) investigated and reported about the contents of protein, carbohydrate, fats, phosphorous, calcium and iron. Among these, the protein content was found to be the highest at $4.2 \mathrm{gm}$ followed by carbohydrate at $2.3 \mathrm{gm}$ and fat $0.5 \mathrm{gm}$ of fat per $100 \mathrm{gm}$.

\section{Chemical composition:}

The leaves of $O$. sanctum consist of volatile oil $(0.7 \%)$ and shows the presence of various compounds like phenolics, flavonoids, neolignans, triterpenoids and derivatives of fatty acid. Eugenol, ursolic acid, carvacrol, linalool, caryophyllene, are some of the major components in the volatile oil extracted from the leaves. The flavanoids like orientin and vicenin and flavones like apigenin, isothymusin are isolated from the aerial parts of the plant. There is more than approximately $20 \%$ of fixed oil $(18-22 \%)$ along with carbohydrates in the form of polysaccharides, unsaponifiable $\beta$-sitosterol and mucilage in the seeds. Seeds of this plant are one of the chief sources of fixed oils such as oleic acid, stearic acid, palmitic acid and linolenic acid (Bano et al., 2017). However, the chemical constituency of the O. sanctum with the essential oils could depend on an array of factors like the origin, climatic conditions and also the nature of the cultivar from which the extract have been sourced (Beatovic et al., 2013).
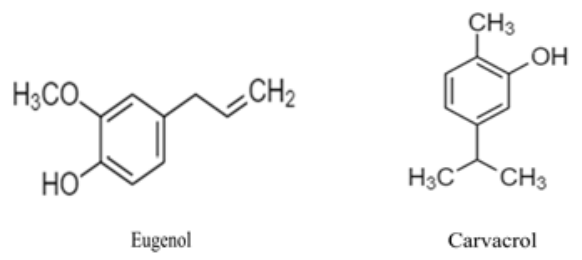<smiles>O=c1cc(-c2ccc(O)cc2)oc2cc(O)cc(O)c12</smiles><smiles>C=C1C=C(c2ccc(O)cc2)Oc2c1c(O)c([C@H]1O[C@H](O)[C@@H](O)[C@H](O)[C@H]1O)c(O)c2[C@@H]1O[C@H](O)[C@@H](O)[C@H](O)[C@H]1O</smiles><smiles></smiles>
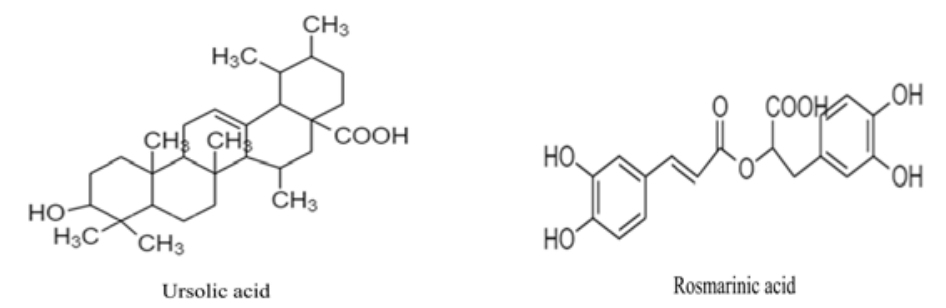

Figure 2: Chemical Structures of Some of the Important Phytochemicals Present

\section{Pharmacological properties of $O$. sanctum:}

\section{Antimicrobial activity:}

Alcoholic solvent extracts of $O$. sanctum showed wide spectrum inhibition against Escherichia coli, Shigella, Enterobacteria and species of Staphylococcus like S. aureus (Rahman et al., 2011). It has also been proved to act against Pseudomonas aeruginosa, Salmonella typhi, Klebsiella pneumoniae, Proteus, Candida albicans, Mycobacterium tuberculosis and Micrococcus pyogenes (Mishra \& Mishra, 2011). 
The flavanoids, orientin and vicenin, obtained from leaves of $O$. sanctum showed positive results against some bacteria that cause urinary tract infection in humans (Ali a \& Dixit, 2012).

The essential oil, obtained from the flower spikes and leaves of $O$. sanctum, at concentrations of $4.5 \%$ and $2.25 \%$ could have bacteriostatic effect on Staphylococcus aureus, methicillin resistant S. aureus (MRSA) and Escherichia coli, by inhibiting their growth (Yamani et al., 2016).

\section{Antioxidant \& Anti-inflammatory activity:}

Anti-inflammatory or cyclooxygenase inhibitory activity have been established using purified extracts of aerial parts of the plant, by the virtue of phytochemicals like eugenol, rosmarinic acid, apigenin, isothymusin, cirsilineol, etc (Kelm et al., 2000). Antioxidant potentiality of essential oils of the plant parts was observed by Salles Trevisan et al., (2006) and Gupta et al., (2006).

\section{Antidiabetic activity:}

Gholap and Kar (2004) suggested that the concentrations of the carbohydrate - glucose and cortisol could be decreased in the serum, as studied in male mice, by the usage of $O$. sanctum functioning to exhibit a hypoglycaemic and antiperoxidative effect.

Reports have been given by Hannan et al., (2006), that the chemical compounds present in the leaf extracts of $O$. sanctum affect the insulin secretory pathways and stimulate its production exhibiting insulinotropic effects, as examined with ethanolic extracts and five partition fractions on perfused rat pancreas, isolated rat islets and clonal rat BRIN-BD 11 cell line. Thus, from the study, the antihyperglycaemic potential of $O$. sanctum could be established.

Fractions of ethyl acetate derived from the alcoholic leaf extract of $O$. sanctum made with ethanol was reported to significantly reduce the level of fasting blood sugar, along with serum total cholesterol and triglyceride in diabetic rats induced with alloxan (AIDR). Petroleum ether and chloroform fractions too along with the fraction of extract made from the ethyl acetate were found to play a role in the elevation of liver glycogen levels, which otherwise are reduced in severely diabetic rats, thereby exhibiting an antidiabetic property with hepatoprotective effects (Khan et al., 2010).

The extract of the plants roots made with methanol, have been reported to exhibit antidiabetic potential on fasting blood glucose levels in rats which were induced to be diabetic with streptozotocin; in these rats the blood glucose levels were reduced to normal using the extract. Three new active constituents were characterized along with ursolic acid and palmityl glucoside (Ahmad et al., 2012).

$O$. sanctum have been reported to be a useful source of novel antidiabetic compounds and as a dietary supplement for managing the complications arising due to type-2 diabetes (Hannan et al., 2015).

\section{Antigenotoxic activity:}

The leaf extract exerts a protective effect against genetic damage induced with $\mathrm{Cr} \mathrm{Hg}-\mathrm{I}$ (Babu \& Maheswari, 2006). Siddique et al., (2007) reported the action of O. sanctum extract against any genotoxic damage in the in vitro mammalian cells subjected to cyproterone acetate.

\section{Radioprotective activity:}

Uma Devi et al., (2000) isolated the two flavonoids, orientin and vicenin, from the leaves of 0 . sanctum that are water-soluble and both the flavanoids were tested for their effect on the peroxidation of lipids caused by radiation and their antioxidant activity in adult mice. From the study, it was reported that the flavanoids provided significant protection against radiation lethality and chromosomal aberration, by inhibiting free radical formation.

\section{Anticarcinogenic activity:}

The extract of the leaves of $O$. sanctum made with ethanol have been found to regulate enzymes such as cytochrome P-450, cytochrome-b5 and aryl hydrocarbon hydroxylase, that metabolize carcinogens in the mice liver and elevate their activities, along with increasing the reduced glutathione levels (Banerjee 
et al., 1996).

The seed oil of this plant could delay tumor incidence and thereby enhance longer survival when administered on Swiss albino mice. The antioxidant property of the plant can be attributed to this chemopreventive potential (Prakash \& Gupta, 2000).

There are reports of both the aqueous and ethanolic extracts of $O$. sanctum being effective in reducing the volume of the tumour in Sarcoma-180 affected mice followed by an increase in their lifespan. It has also been found to have effects on human fibrosarcoma cells in the in vitro condition, clearly indicative of its anticancer activity (Karthikeyan et al., 2008).

The flavanoid, vicenin-2, present in $O$. sanctum was found to be very efficient as a novel compound to restrict the proliferation of prostate cancer when used in combination with docetaxel when administered in mice (Nagaprashantha et al., 2011).

In a similar study, Baliga et al., (2013) reported that the two flavanoids, vicenin and orientin were effective in protecting normal cells from the tumoricidal damage caused by gamma-radiation.

\section{Antifertility activity:}

The leaves of $O$. sanctum were reported to have abortifacient effect in women (Batta \& Santhakumari 1971). Ahmed et al., (2002) had observed a reversible antiandrogenic property of O. sanctum. The extract of $O$. sanctum leaves made with benzene were issued to the albino rats for 48 days and it was reported that the sperm count and mobility as well as their forward velocity remarkably decreased along with reduced fructose levels.

\section{Immunologic activity:}

The findings from the study of treatment of methanolic and aqueous extract of $O$. sanctum leaves extract on albino rats revealed its immunostimulatory potentiality, acting by increasing the antibody levels in response to Salmonella typhosa and sheep erythrocytes (Godhwani, Godhwani \& Was,1988). Similar immunomodulatory effects were reported by Mediratta, Sharma \& Singh (2002) with the treatment of seed oil of $O$. sanctum on rats while studying the humoral immune response.

\section{Antistress activity:}

O. sanctum have been reported to exhibit antistress properties and have the evidences of its usage in an extensive form in the Indian native system of medicine for various types of disorders related to anxiety. Administration of the $70 \%$ alcoholic extract of 0 . sanctum using ethanol controlled the alternation in neurotransmitter level and reduced the stress due to noise, as examined on Wistar strain albino rats (Ravindran et al., 2005).

Similar study on rats by Jothie Richard et al., (2016) had found O. sanctum to be effective in management of stress effects by inhibition of cortisol release.

Ocimumosides $A$ and $B$ and ocimarin, are the three compounds that were extracted and isolated from the leaves, by Gupta et al., (2007) along with other known compounds like apigenin. They reported the promising antistress effects of the first two compounds by normalizing hyperglycaemia, plasmacortisterone and adrenal hypertrophy.

\section{Memory enhancer activity:}

The efficacy of the extract of this plant as a neuro enhancer or cognitive memory enhancer agent have been studied in mice by Joshi and Parle (2006). The amnesic effect caused by scopolamine and memory deficit due to aging in mice could be mitigated by using the water-based extract of the whole dried plant. Alzheimer's disease and dementia among other disorders could also be treated similarly and have been found to show effective results. 


\section{Cardio-protective activity:}

Cardiac endogenous antioxidants have been augmented and myocardial infarction could be prevented by the leaf extract of $O$. sanctum, being issued orally in rats, as reported by Sharma et al., (2001) and Sood et al., (2005).

\section{Wound healing activity:}

Several studies showed wound healing property of $O$. sanctum. Alcoholic extract of the plant using ethanol was investigated for treating lesions and wounds, as examined in albino rats; epithelial cell formation and the recovery rate through contraction of the wound was significantly increased (Shetty, Udupa \& Udupa, 2008).

The consistent elevated production of tumour necrosis factor (TNF- $\alpha$ ) was achieved by 0 . sanctum treatment and thereby healing of wounds were much earlier than usual (Goel et al., 2010).

\section{Larvicidal activity:}

Eugenol and a triglyceride -1,3-dilinoleneoyl-2-palmitin, from $O$. sanctum had shown larvicidal activity on the larvae of Aedes aegypti (Kelm \& Nair 1998). The leaf extracts of $O$. sanctum were also found to induce larval mortality against Culex quinquefasciatus along with Aedes aegypti (Anees, 2008).

\section{CONCLUSION}

The tremendous pharmacological activities and a wealth of available literature make Ocimum sanctum one of the most valuable herbs in the plant kingdom. The pharmaceutical activities of the herb results from the amalgamated and synergistic interactions of the different phytochemicals present. This widespread herb is easily available in India and other neighboring countries, growing both in wild and cultivated forms. The extensive range of the properties of its chemical constituents makes it a potential entity for more detailed clinical research. More investigations will establish the prospects of using the plant and its active novel chemical constituents in a large scale in modern medicine.

\section{ACKNOWLEDGEMENT}

The authors express their sincere thanks to Department of Biotechnology, Government of India for the funding for DBT-STAR College grant, under which this review project was conducted. The authors are also grateful to the Principal and the DBT-STAR Coordinator, Surendranath College, for their support and encouragement in implementing this review project at undergraduate level.

\section{REFERENCES}

Ahmad, M. Z., Ali, M., \& Mir, S. R. (2012). Anti-diabetic activity of Ocimum sanctum L. roots and isolation of new phytoconstituents using two-dimensional nuclear magnetic resonance spectroscopy. Journal of Pharmacognosy and Phytotherapy, 4(6), 75-85.

Ahmed, M., Ahamed, R. N., Aladakatti, R. H., \& Ghosesawar, M. G. (2002). Reversible anti-fertility effect of benzene extract of Ocimum sanctum leaves on sperm parameters and fructose content in rats. Journal of Basic and Clinical Physiology and Pharmacology, 13(1), 51-60.

Ali, H., \& Dixit, S. (2012). In vitro antimicrobial activity of flavanoids of Ocimum sanctum with synergistic effect of their combined form. Asian Pacific Journal of Tropical Disease, 2, S396-S398.

Anees, A. M. (2008). Larvicidal activity of Ocimum sanctum Linn.(Labiatae) against Aedes aegypti (L.) and Culex quinquefasciatus (Say). Parasitology Research, 103(6), 1451-1453.

Babu, K., \& Maheswari, K. U. (2006). In vivo studies on the effect of Ocimum sanctum L. leaf extract in modifying the genotoxicity induced by chromium and mercury in Allium root meristems. Journal of Environmental Biology, 27(1), 93.

Baliga, M. S., Jimmy, R., Thilakchand, K. R., Sunitha, V., Bhat, N. R., Saldanha, E., ... \& Palatty, P. L. 
(2013). Ocimum sanctum L (Holy Basil or Tulsi) and its phytochemicals in the prevention and treatment of cancer. Nutrition and Cancer, 65(sup1), 26-35.

Banerjee, S., Prashar, R., Kumar, A., \& Rao, A. R. (1996). Modulatory influence of alcoholic extract of Ocimum leaves on carcinogen metabolizing enzyme activities and reduced glutathione levels in mouse.

Bano, N., Ahmed, A., Tanveer, M., Khan, G. M., \& Ansari, M. T. (2017). Pharmacological evaluation of Ocimum sanctum. J Bioequiv Availab, 9(3), 387-392.

Batta, S. K., \& Santhakumari, G. (1971). The antifertility effect of Ocimum sanctum and Hibiscus rosa sinensis. The Indian Journal of Medical Research, 59(5), 777-781.

Beatović, D. V., Jelačić, S. Ć., Oparnica, Č. D., Krstić-Milošević, D. B., Glamočlija, J. M., Ristić, M. S., \& Šiljegović, J. D. (2013). Hemijski sastav, antioksidativna i antimikrobna aktivnost etarskog ulja Ocimum sanctum L./Chemical composition, antioxidative and antimicrobial activity of essential oil Ocimum sanctum L. Hemijska Industrija/Chemical Industry.

Darrah, H. H. (1974). Investigation of the cultivars of the Basils (Ocimum). Economic Botany, 63-67.

Gholap, S., \& Kar, A. (2004). Hypoglycaemic effects of some plant extracts are possibly mediated through inhibition in corticosteroid concentration. Die Pharmazie-An International Journal of Pharmaceutical Sciences, 59(11), 876-878.

Godhwani, S., Godhwani, J. L., \& Was, D. S. (1988). Ocimum sanctum-a preliminary study evaluating its immunoregulatory profile in albino rats. Journal of Ethnopharmacology, 24(2-3), 193198.

Goel, A., Kumar, S., Singh, D. K., \& Bhatia, A. K. (2010). Wound healing potential of Ocimum sanctum linn. with induction of tumor necrosis factor.

Government of India. (1999). The Ayurvedic Pharmacopoeia of India (API). 1. http://www.ayurveda.hu/api/API-Vol-1.pdf

Gupta, P., Yadav, D. K., Siripurapu, K. B., Palit, G., \& Maurya, R. (2007). Constituents of Ocimum sanctum with antistress activity. Journal of Natural Products, 70(9), 1410-1416.

Gupta, S., Mediratta, P. K., Singh, S., Sharma, K. K., \& Shukla, R. (2006). Antidiabetic, antihypercholesterolaemic and antioxidant effect of Ocimum sanctum (Linn) seed oil. Indian Journal of Experimental Biology, 44(4):300-4.

Hannan, J. M. A., Marenah, L., Ali, L., Rokeya, B., Flatt, P. R., \& Abdel-Wahab, Y. H. A. (2006). Ocimum sanctum leaf extracts stimulate insulin secretion from perfused pancreas, isolated islets and clonal pancreatic $\beta$-cells. Journal of Endocrinology, 189(1), 127-136.

Hannan, J. M. A., Ojo, O. O., Ali, L., Rokeya, B., Khaleque, J., Akhter, M., ... \& Abdel-Wahab, Y. H. A. (2015). Actions underlying antidiabetic effects of Ocimum sanctum leaf extracts in animal models of type 1 and type 2 diabetes. European Journal of Medicinal Plants, 1-12.

Joshi, H., \& Parle, M. (2006). Evaluation of nootropic potential of Ocimum sanctum Linn. in mice.

Jothie Richard, E., Illuri, R., Bethapudi, B., Anandhakumar, S., Bhaskar, A., Chinampudur Velusami, C., ... \& Agarwal, A. (2016). Anti-stress Activity of Ocimum sanctum: Possible Effects on Hypothalamic-Pituitary-Adrenal Axis. Phytotherapy Research, 30(5), 805-814.

Karthikeyan, K., Gunasekaran, P., Ramamurthy, N., \& Govindasamy, S. (1999). Anticancer activity of Ocimum sanctum. Pharmaceutical biology, 37(4), 285-290.

Kelm, M. A., \& Nair, M. G. (1998). Mosquitocidal compounds and a triglyceride, 1, 3-dilinoleneoyl-2palmitin, from Ocimum sanctum. Journal of Agricultural and Food Chemistry, 46(8), 3092-3094.

Kelm, M. A., Nair, M. G., Strasburg, G. M., \& DeWitt, D. L. (2000). Antioxidant and cyclooxygenase inhibitory phenolic compounds from Ocimum sanctum Linn. Phytomedicine, 7(1), 7-13. 
Khan, M. R. I., Islam, M. A., Hossain, M. S., Asadujjaman, M., Wahed, M. I. I., Rahman, B. M., ... \& Ahmed, M. (2010). Antidiabetic effects of the different fractions of ethanolic extracts of Ocimum sanctum in normal and alloxan induced diabetic rats. Journal of Scientific Research, 2(1), 158-168.

Mediratta, P. K., Sharma, K. K., \& Singh, S. (2002). Evaluation of immunomodulatory potential of Ocimum sanctum seed oil and its possible mechanism of action. Journal of Ethnopharmacology, 80(1), 15-20.

Mishra, P., \& Mishra, S. (2011). Study of Antibacterial Activity of Ocimum Sanctum Extract Against Gram Positive and Gram Negative Bacteria (No. RESEARCH).

Nagaprashantha, L. D., Vatsyayan, R., Singhal, J., Fast, S., Roby, R., Awasthi, S., \& Singhal, S. S. (2011). Anti-cancer effects of novel flavonoid vicenin-2 as a single agent and in synergistic combination with docetaxel in prostate cancer. Biochemical Pharmacology, 82(9), 1100-1109.

Pattanayak, P., Behera, P., Das, D., \& Panda, S. K. (2010). Ocimum sanctum Linn. A reservoir plant for therapeutic applications: An overview. Pharmacognosy Reviews, 4(7), 95.

Prakash, J., \& Gupta, S. K. (2000). Chemopreventive activity of Ocimum sanctum seed oil. Journal of Ethnopharmacology, 72(1-2), 29-34.

Rahman, S., Islam, R., Kamruzzaman, M., Alam, K., \& Jamal, A. H. M. (2011). Ocimum sanctum L.: A review of phytochemical and pharmacological profile. American Journal of Drug Discovery and Development, 1, 1-15.

Ravindran, R., Devi, R. S., Samson, J., \& Senthilvelan, M. (2005). Noise-stress-induced brain neurotransmitter changes and the effect of Ocimum sanctum (Linn) treatment in albino rats. Journal of Pharmacological Sciences, 98(4), 354-360.

Salles Trevisan, M. T., Vasconcelos Silva, M. G., Pfundstein, B., Spiegelhalder, B., \& Owen, R. W. (2006). Characterization of the volatile pattern and antioxidant capacity of essential oils from different species of the genus Ocimum. Journal of Agricultural and Food Chemistry, 54(12), 43784382.

Sharma, M., Kishore, K., Gupta, S. K., Joshi, S., \& Arya, D. S. (2001). Cardioprotective potential of Ocimum sanctum in isoproterenol induced myocardial infarction in rats. Molecular and Cellular Biochemistry, 225(1), 75-83.

Shetty, S., Udupa, S., \& Udupa, L. (2008). Evaluation of antioxidant and wound healing effects of alcoholic and aqueous extract of Ocimum sanctum Linn in rats. Evidence-Based Complementary and Alternative Medicine, 5(1), 95-101.

Siddique, Y., Ara, G., Beg, T., \& Afzal, M. (2007). Anti-genotoxic effect of Ocimum sanctum L. extract against cyproterone acetate induced genotoxic damage in cultured mammalian cells. Acta Biologica Hungarica, 58(4), 397-409.

Singh, D., \& Chaudhuri, P. K. (2018). A review on phytochemical and pharmacological properties of Holy basil (Ocimum sanctum L.). Industrial Crops and Products, 118, 367-382.

Sood, S., Narang, D., Dinda, A. K., \& Maulik, S. K. (2005). Chronic oral administration of Ocimum sanctum Linn. augments cardiac endogenous antioxidants and prevents isoproterenol-induced myocardial necrosis in rats. Journal of Pharmacy and Pharmacology, 57(1), 127-133.

The Plant List. (2015). A Working List of All Plant Species. 13 ${ }^{\text {th }}$ January. http://www.theplantlist.org/

Uma Devi, P., Ganasoundari, A., Vrinda, B., Srinivasan, K. K., \& Unnikrishnan, M. K. (2000). Radiation protection by the ocimum flavonoids orientin and vicenin: mechanisms of action. Radiation Research, 154(4), 455-460.

Yamani, H. A., Pang, E. C., Mantri, N., \& Deighton, M. A. (2016). Antimicrobial activity of Tulsi (Ocimum tenuiflorum) essential oil and their major constituents against three species of bacteria. Frontiers in microbiology, 7, 681 . 


\title{
Investigational Treatment of Covid-19
}

\author{
Rudra Prasad Maiti, Abhik Kumar Manna, Ashish Ranjan, Lalita Das* \\ Department of Chemistry, Surendranath College, Kolkata, India \\ *Correspondening Author's Email: das.lalita1@gmail.com
}

\begin{abstract}
Coronaviruses are the primary cause of illnesses such acute viral nasopharyngitis, severe acute respiratory syndrome (SARS), in addition to Middle East respiratory syndrome (MERS). The world was introduced to a novel coronavirus in 2019, which caused an outburst in China's Wuhan area. This was identified as coronavirus 2 (SARS-CoV-2) which causes the infectivity known as COVID-19. This review is usually thought to be what medical pharmacists and therapists are most likely to encounter when considering experimental drugs in practise.
\end{abstract}

Keywords: Corona-virus; SARS CoV-2; COVID-19; Clinical Trials; Remdesivir; Favipiravir; Hydroxycholoroquine; Lopinavir; Corticosteroid; Interferon's

\section{INTRODUCTION}

SARS is a newly discovered coronavirus. CoV-2, also recognized as COVID-19, is a new coronavirus strain that causes illness. The WHO announced in March 2020 that a broader worldwide trial called 'Solidarity' should be conducted to evaluate local level of facilities and care with one of the subsequent treatments: remdesivir, favipiravir, hydroxychloroquine, lopinavir, corticosteroid, and interferon's ( Wang et al., 2020). This review is usually thought to be what medical pharmacists and therapists may meet in practise while considering these investigational drugs (Zumla et al., 2016).

\section{REVIEW LITERATURE AND DISCUSSION}

Medicines which are currently being accelerated through clinical trials

\section{Remdesivir:}

The first medicine licenced by the US Food as well as Drug management to deal the SARS-CoV-2 virus was Remdesivir. It has a strong link to the therapy of COVID-19 disease in hospitalised adults and children weighing more than $40 \mathrm{~kg}$ aged 12 and up (University of Liverpool). COVID-19 therapies: connections and experiments (2020).

\section{Mechanism of action:}

Remdesivir is an adenosine analogue that binds to nascent viral ribonucleic acid (RNA) chains, forcing them to terminate prematurely and put a stop to virus replication. It is extensively spread throughout the human body in addition to is primarily removed by the kidneys (Wang et al., 2020).

\section{Clinical trials and studies:}

In February 2020, Gilead Sciences started two stage three medical trials to ensure and analyse the security as well as efficiency of remdesivir in people with COVID-19. In a stage three randomised, double-blind, placebo-controlled, multicenter research, the efficiency and security of remdisivir in hospitalised patients along with very few to moderate COVID-19 respiratory syndrome were first assessed (US National Library of Medicine). COVID-19-2020). Remdesivir-based trial in patients with few to moderate COVID. The 2nd stage three trial will be a multi-center, randomised, double-blind, placebo-controlled test to ensure and assess the efficiency and security of remdesivir in

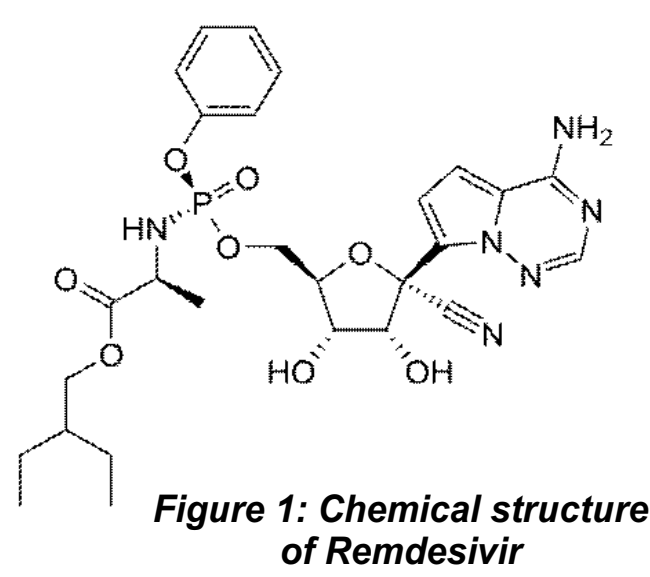


hospitalised patients alongwith severe COVID-19 respiratory disease (US National Library of Medicine). Adults with severe COVID-19-2020) are being tested with Remdesivir. Adults were the only ones who could participate in the trials. The patient received a well-continued standard of care and therapy (based on unspecified criteria) as well as remdesivir $200 \mathrm{mg}$ on day 1 , followed by a $100 \mathrm{mg}$ once daily dose for 9 days, depends on which support of the research the patient was allocated to. Despite the fact that the experiment's three-month completion target of early May 2020 was overly optimistic, the trial was cancelled in April 2020 due to a shortage of qualified patients.

Remdesivir is currently being used successfully in the United Kingdom, and it has been studied in clinical trials all in excess of the world and in Europe. The primary is the Adaptive COVID-19 Treatment Trial (ACTT), which has enrolled over 1000 patients internationally plus is run in the UK in addition to EU by the Medical Research Council Clinical Trials Unit and University College London (UCL). On April 19, 2020, the UCL-led section of the trial stopped to fresh enrolment after enrolling 79 patients, 46 of whom were from the United Kingdom. In COVID-19 patients, the high-level findings demonstrated a progressive decrease in recovery time. As a result, the US Food and Drug Administration (FDA) has approved remdesivir for patients with severe COVID-19 who are hospitalised (US Food and Drug Administration, 2020).

\section{Safety and practical consideration:}

Remdesivir showed no effect on renal function in patients with Ebola virus syndrome in a repeated dose study. Remdesivir should be utilised with concern in patients with renal injury since it contains sulfobutylether-cyclodextrin, a solubilizing agent. Both Gilead phase three trials exclude patients with brutal liver sickness (e.g., Child-Pugh score C, AST > five times upper limit) as well as/or extreme renal impairment (e.g., estimated glomerular filtration rate $30 \mathrm{ml} / \mathrm{min} / 1.73 \mathrm{~m} 2$ ), as well as those on continuous renal substitute therapy, hemodialysis, or peritoneal dialysis (Wang et al., 2020). Carbamazepine, phenobarbitone, phenytoin, primidone, or rifampicin should not be taken with Remdesivir since these medications are enzyme inducers and can lower the medicine's blood plasma concentration.

Gilead has increased supply and production of remdesivir on many occasions to meet the need for using COVID-19 trials.

\section{Favipiravir:}

In COVID-19 clinical studies, favipiravir cleared the virus faster than lopinavir/ritonavir. Favipiravir has shown promising consequences in medical trials in China, Russia, and Japan, and multiple trials in the United States, the United Kingdom, as well as India are presently underway. Treatment guidelines have recently been implemented in a number of nations, and several Indian states have already included favipiravir in their treatment regimens. The key principle of this analysis is to provide insight into the evidence and evolving role of favipiravir in the treatment of COVID-19 infection, with an emphasis on the benefits of starting antiviral therapy. Favipiravir, its pharmacodynamics, pharmacokinetics, in vitro, medical data, as well as enclosure in COVID-19 therapy practices will be the subject of this (Delang et al., 2018).

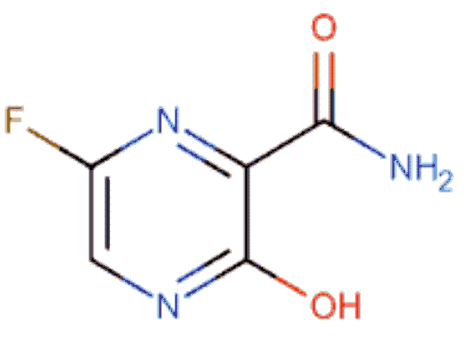

Figure 2: Chemical Structure of Favipiravir

\section{Machinery of Practice:}

Favipiravir (pro drug) is a purine analogue that is transformed into the active favipiravir ribofurabnosyl5B-triphosphate (favipiravir-RTP) by a process known as intracellular phosphoribosylation. Its role is to act as a discriminating and powerful inhibitor of RNA viruses' RNA-dependent RNA polymerase $(R d R p)$. Favipiravir is included into the embryonic viral RNA via the error-prone viral RdRp, resulting in chain extinction and viral mutagenesis. The mutagenic nature of favipiravir-RTP causes coronavirus repair machinery to flee, putting further strain on the Covid-19 nucleotide content. Because favipiravir 
has a high affinity for the RdRp complex, it is used to target SARS-Achilles CoV-2's heel (Furuta et al., 2017).

\section{Clinical Trials:}

Numerous open-label control studies and laboratory tests on various Chinese patients revealed that favipiravir had a shorter viral clearance time. It also demonstrated that the group with viral permission within 7 days of treatment had a good improvement rate on chest imaging (CT). Multivariate logistic regression revealed that the antiviral favipiravir is separately effective in improving chest imaging. Favipiravir was found to be responsible with quicker viral clearance using Multi Cox regression. Several other clinical trials have shown that favipiravir has a higher level of tolerance than Lopinavir/Ritonavir (Cai et al., 2020).

\section{Safety and practical consideration:}

Favipiravir has been tried and tested over $4000+$ patients showing positive results. The common adverse effects of favipiravir are downfall of neutrophil count, elevation of uric acid, elevation of SGOT and SGTP. Favipiravir is contradicted in expecting and lactating women because of its teratogenicity possible observed during animal reviews. In addition, favipiravir has been shown to be ineffective in patients with extreme Liver impairment, hypersensitivity, or severe kidney impairment. In patients with a history of gout, it should be given with caution. Favipiravir is the first antiviral oral medicine to be accepted for the mild and moderate treatment of Covid-19 patients. Favipiravir has been demonstrated to be a positive and potential cure for this disease in various studies conducted in China, Japan, and Russia (Zhao et al., 2015).

\section{Lopinavir and Ritonavir:}

\section{Mechanism of action:}

Lopinavir and ritonavir work by preventing HIV and coronaviruses from replicating by inhibiting the protease enzyme. Ribavirin, a artificial nucleoside analogue, was used in conjunction with lopinavir and ritonavir and was found to be effective against the viruses (Electronics Medicines Compedium, 2020).

\section{Clinical trials and studies:}

Young et al. employed Lopinavir/Ritonavir to treat 18 patients in Covid-19 in Singapore at diverse doses to better understand their medical course. Lopinavir/Ritonavir was used to treat five of the eighteen patients. The results were unsatisfactory due to the small number of patients that took part. (Young and colleagues, 2020)

\section{Safety and Practical consideration:}

The synergistic powers of Lopinavir-ritonavir and ribavirin are poorly understood. As a result, there is a scarcity of specific knowledge regarding the combined treatment's mechanism of action. Anemia, angioedema, diarrhoea, dry mouth, dizziness, increased infection rate, and some anomalies in menstrual cycle are among side effects of Lopinavir-ritonavir. (British National Formulary, Lopinavir, 2017; Cao et al., 2020).

\section{Hydroxychloroquine sulphate:}

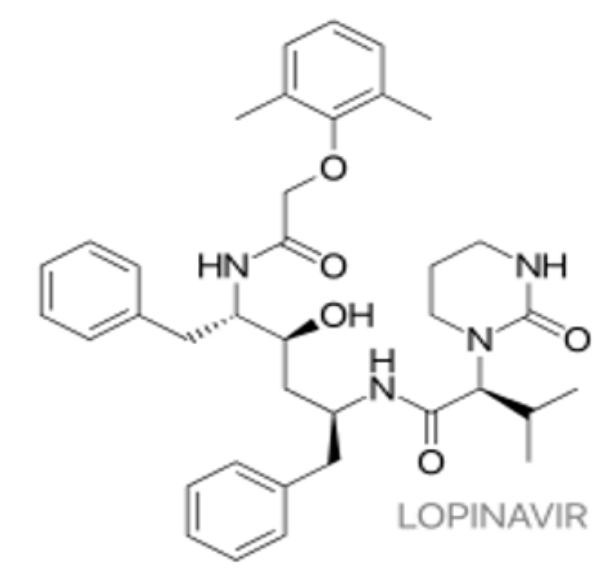

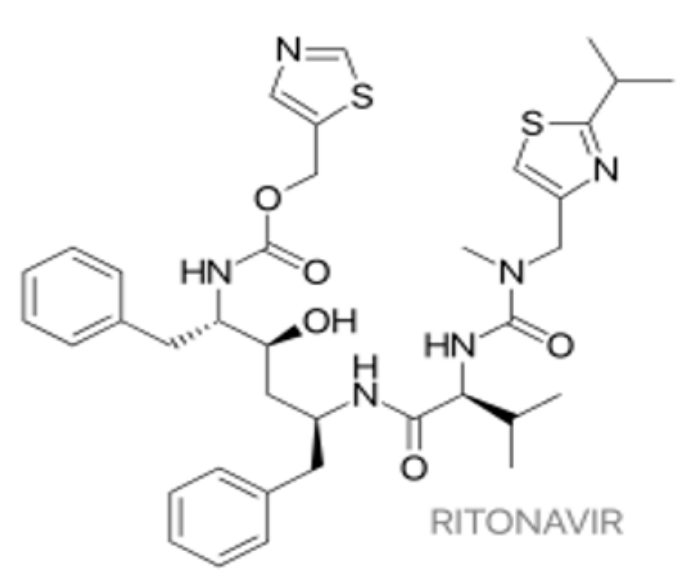

Figure 3: Chemical structure of Lopinavir-Ritonavir

The oral medication hydroxycholoroquine is used to treat malaria and other inflammatory diseases. Hydroxycholoroquine decreases the cytokine storm by decreasing $\mathrm{T}$ cell activation, and thereby 
reduces the severity of COVID-19 development. Hydroxycholoroquine has a lower side effects and can be utilised by pregnant women. In China, HCQ is less expensive and more readily accessible.

\section{Machinery of action:}

Hydroxycholoroquine helps to prevent virus infection by raising endosomal $\mathrm{pH}$, which is required for cell fusion, and thereby suppressing virus fusion (Owens, 2020). It also possesses immunostimulatory properties.

\section{Clinical Trials:}

Trials with hydroxycholoroquine were a failure since no advantages were identified (Robinson J. Recovery trial 2020). Those that were randomised got an oral dose of 800 mg every 6 hours, followed by a dose of $400 \mathrm{mg}$ every 12 hours. (Recovery trial at the University of Oxford, 2020).

Hydroxycholoroquine is also a part of Discovery trial.

\section{Safety and practical consideration:}

Nausea/vomiting, abdominal pain, frequent headaches, and rashes are all common hydroxycholoroquine adverse effects. Bruising or infection are two more possible side effects. (Hydrochloroquine sulphate, electronic pharmaceuticals compendium, 2020).

\section{Corticosteroid:}

Corticosteroids are hormones that are primarily steroid in origin and are chemically related compounds that are divided into mineralocorticoid and glucocorticoid actions. They are mostly used as an antiinflammatory and immunosuppressive agent. (Corticosteroid, British National Formulary, 2017).

\section{Machinery of action:}

Various inflammatory factors are effectively inhibited by corticosteroids. Pro-inflammatory genes that code for cytokines and chemokines are inhibited by glucocorticoids (Cruz-Topete D \& Cidlowski JA-2015). Because it targets inflammatory proteins, glucocorticoids, among other corticosteroids, are widely used to treat inflammation. They all work together to reduce the production of pro-inflammatory proteins.

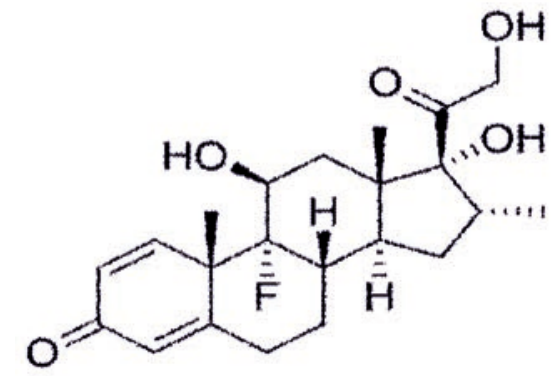

Figure 5: Chemical structure of Dexamethasone

\section{Clinical trials:}

Several corticoids have been exclusively used for clinical trials such asmethyl-prednisolone, dexamethasone and hydrocortisone. An open label, prospective, multi-center study was held in China to evaluate methyl-prednisolone improves the prognosis of patients recovering from COVID-19 infection (US national library of medicine-Glucocorticoid, 2020).

\section{Safety and practical consideration:}

Patients with severe Covid-19 should be treated with systemic corticosteroids, according to the World Health Organization. It's a recommendation with a caveat. Steroids are anti-inflammatory drugs that affect our body's immune system. It is not suggested for non-severe COVID-19 patients. (Dexamethasone, British National Formulary, Dexamethasone, British National Formulary, Dexamethasone, British National Formulary, British National Formulary, British. 


\section{CONCLUSION}

Several Covid-19 medicines are being used un-licensed due to pandemic; for that reason, a long term data were needed for a properevaluationin their efficiency and safety. So this review is about a detailed investigation of several possible treatment of covid-19, which can guide pharmacist and therapist in the time of pandemic.

\section{REFERENCES}

British National Formulary. Corticosteroids, generally use. 2017. https://bnf.nice.org.uk/treatmentsummary/corticosteroids-general-use.html

British National Formulary. Dexamethasone. 2020. //bnf.nice. org.uk/drug/dexamethasone.html

British National Formulary. Hydroxychloroquine sulfate. 2020. https://bnf.nice.org.uk/ drug/hydroxychloroquine-sulfate.html

Cai, Q., Yang, M., Liu, D., Chen, J., Shu, D., Xia, J., ... \& Liu, L. (2020). Experimental treatment with favipiravir for COVID-19: an open-label control study. Engineering, 6(10), 1192-1198.

Cao, B., Wang, Y., Wen, D., Liu, W., Wang, J., Fan, G., ... \& Wang, C. (2020). A trial of lopinavir-ritonavir in adults hospitalized with severe Covid-19. New England Journal of Medicine.

Cruz-Topete, D., \& Cidlowski, J. A. (2015). One hormone, two actions: anti-and pro-inflammatory effects of glucocorticoids. Neuroimmunomodulation, 22(1-2), 20-32.

Delang, L., Abdelnabi, R., \& Neyts, J. (2018). Favipiravir as a potential countermeasure against neglected and emerging RNA viruses. Antiviral research, 153, 85-94.

Electronic medicines compendium. Plaquenil-Hydroychloroquine sulfate $200 \mathrm{mg}$ film-coated tablets Summary of Product Characteristics. 2020. https://www.medicines. org.uk/emc/product/221/smpc

Furuta, Y., Komeno, T., \& Nakamura, T. (2017). Favipiravir (T-705), a broad spectrum inhibitor of viral RNA polymerase. Proceedings of the Japan Academy, Series B, 93(7), 449-463.

Owens, B. (2020). Excitement around hydroxychloroquine for treating COVID-19 causes challenges for rheumatology. The Lancet Rheumatology, 2(5), e257.

Robinson, J. (2020). RECOVERY trial to stop enrolling patients to 'ineffective'hydroxychloroquine arm. Pharm J.

US Food and Drug Administration. Coronavirus (COVID-19) update; FDA issues emergency use authorization for potential COVID-19 treatment. 2020. https://www.fda.gov/news-events/pressannouncements/coronavirus-covid-19-update-fda-issues-emergency-use-authorizationpotential-covid-19-treatment.

US Food and Drug Administration. Remdesivir EUALetter in adults with mild and moderate COVID-19. 2020. https://www.fda.gov/media/137564/download

Wang, Y., Zhang, D., Du, G., Du, R., Zhao, J., Jin, Y., ... \& Wang, C. (2020). Remdesivir in adults with severe COVID-19: a randomised, double-blind, placebo-controlled, multicentre trial. The lancet, 395(10236), 1569-1578.

Young, B. E., Ong, S. W. X., Kalimuddin, S., Low, J. G., Tan, S. Y., Loh, J., ... \& Singapore 2019 Novel Coronavirus Outbreak Research Team. (2020). Epidemiologic features and clinical course of patients infected with SARS-CoV-2 in Singapore. Jama, 323(15), 1488-1494.

Zhao, Y., Harmatz, J. S., Epstein, C. R., Nakagawa, Y., Kurosaki, C., Nakamura, T., ... \& Greenblatt, D. J. (2015). Favipiravir inhibits acetaminophen sulfate formation but minimally affects systemic pharmacokinetics of acetaminophen. British journal of clinical pharmacology, 80(5), 1076-1085.

Zumla, A., Chan, J. F., Azhar, E. I., Hui, D. S., \& Yuen, K. Y. (2016). Coronaviruses-drug discovery and therapeutic options. Nature reviews Drug discovery, 15(5), 327-347. 


\title{
The Story of Aspirin: - Journey From Willow to Wander Drug
}

Molla Jasimuddin, Souradeep Roy, Natasa Sultana, Suvankar Mallick, Hari Shankar Biswas* Department of Chemistry, Surendranath College, Kolkata, India

${ }^{*}$ Corresponding Author's Email: harishankarb7@gmail.com

\begin{abstract}
The cheapest and most frequently used drug in medicine is Aspirin. In the wide range of pharmacological area, it is a non-steroidal anti-inflammatory drug, including antipyretic, analgesic, and antiplatelet assets. Aspirin has lengthy been hooked up as a beneficial analgesic and antipyretic. Even in historical times, salicylate-containing flora inclusive of the willow had been typically used to alleviate ache and fever.
\end{abstract}

Keywords: Aspirin; NSAIDs; Efficacy; Adverse Effect; History of Aspirin

\section{INTRODUCTION}

The trade name of Aspirin is acetylsalicylic acid created by the Bayer laboratories. The registered trademarks of Bayer laboratories are using some countries and some countries are using generic name of this substance. The most cost-effective in low doses medicine is Aspirin uses for the remedy of secondary measures of thrombosis. The Aspirin has great history from the ancient era, $2500 \mathrm{BCE}$ it has used as herbal medicine, around 4000years ago Sumerian has used as medicine like clay tablets again Egyptians explain the use of willow leaves for inflammation or joint pain. Professor Johann Andreas Buchner purified salicin at the University of Munich from willow bark, in 1828. The chemical structure of salicylic acid was first worked out by Scientist Hermann Kolbe at Marburg University and a doctor, Thomas MacLagan recorded clinical trial of salicylate in 1876 to obtain complete decrease of joint inflammation and fever. Now the maximum commonly used drug around the Globe is Aspirin because it can prevent cardiovascular and cerebrovascular deasease also it is the most vital pharmaceutical fulfillment memories of the last Century. [PubMed review and texts: "Aspirin: The exceptional Story of a surprise Drug" (Jeffrey's 2005), and "The NSAID Wars: cash, Medicine, and 100 Years of Rampant Competition." (Mann \& Plummer 1991)].

\section{REVIEW LITERATURE AND DISCUSSION}

\section{Historical Improvements study of Salicylates}

Edwin Smith, in 1862, did one a few of the maximums traditionally critical acquisitions of his existence. Well regarded among his buddies for his keen supply and intricate know-how of Egyptology, he Smith obtained, for $£ 12,2$ worn paper rush scrolls throughout a close-by Luxor Avenue market1 that later grew to grow to be bent be a influential medical manual exposing ancient Egyptian's workout of medicine. Though authorless, the Ebers Paper rush is 110 pages and brought into attention the maximum whole medical paper rush ever improved; it dates come in to $1534 \mathrm{BC}$. It covers a giant type of medicinal situation and $\approx$ seven-hundred pharmaceutical and herbal remedies; however the maximum crucial plant species said is tjeret or Salix, regarded these days as willow tree. The Ebers Papyrus illustrates the using of this tree, which is grow in most additive of the primitive world, as each a general-motive tonic or an anti-inflammatory/pain reliever for nonspecific aches and pains. Via this trade by $216 \mathrm{AD}$, navy contacts, and neighboring coastal metropolis communications, willow had locate yourself a commonly used remedy in the course of the civilized world. Many years later, in 1758, Respected Edward Stone fed on the bark of an English willow.1 and try to discover an effective and a long way much less highly-priced remedy for "the agues" (now seemed to be malarial signs: 
fever, myalgias, and headache), Stone administered ground-up dehydrated willow to ague victims and showed that the substance modified into, in fact, effective in treating the ones signs. The dawn of the nineteenth century grows to be marked with significant exchange in terms of technological innovation, clinical inquiry, and economic prosperity. The first widespread discovery withinside the race to grow to be aware of and synthesize the energetic factor of willow came from Joseph Buchner, a professor of dispensing chemists at Munich University who, in 1828, sensitive willow into yellow crystals and labeled it salicin (after salix, Latin for willow). The French pharmacist Henri Leroux in addition sensitive the salicin extraction procedure in 1829 , handiest to be outdone via way of means of Raffaele Pieria who produced a more potent composite from the crystal that he aptly named 2hydroxybenzoic acid in 1838.

The use of salicylate medications a few years of the 19th century, which blanketed salicin, 2hydroxybenzoic acid, grew significantly, analgesic and physicians a developing wide variety of knew what to expect clinically from the ones medicines: markdown of ache, fever and inflammation. Inappropriately, the ugly component consequences, in particular gastric irritation, restrained their usefulness, and attempts to pass the ones untoward consequences were unsuccessful until Ferdinand Runge observed the compounds aniline and phenol withinside the residue left inside the returned of at the same time as burning coal (coal-tar). Runge's discovery, on the aspect of Henry Perkins' go after coal-tar-derived dyes, gave upward thrust push to the herbal chemical enterprise and might later play a huge function withinside the improvement of aspirin.

Charles Gerhart at Montpellier University, a professor of chemistry by 1852 , concluded that the molecular kind of 2-hydroxybenzoic acid contained of a treasured benzene components with 2 related hydroxyl and carboxyl components. By converting the hydroxyl affiliation with an acetyl organization, Gerhardt have emerged as the primary man to chemically manufacture aspirin. Inappropriately, Gerhardt's compound grew to become bent be adulterated and volatile and attracted no in addition importance. The first exact medical test regarding salicylates is accredited to John Maclagan. Maclagan managed salicin to sufferers with rheumatism., Maclagan's test out positioned that the one patients who acquired salicin experienced a remission of fever and joint inflammation which is published in The Lancet.

The first meticulous scientific trial regarding salicylates is accredited to John Maclagana. A Dundee Royal Infirmary physician, Maclagan, administered salicin to sufferers with rheumatism. Maclagan's look at located that the ones sufferers who obtained salicin skilled a remission of fever and joint inflammation which is also published in The Lancet.

Eichengrün did now not get hold of the refusal from the apex of the medicinal drug branch and forced earlier to run his very own scientific trials, alongside drug is taken by himself about the disagreement over the invention of aspirin. These types of trials passionate to modify it into a powerful anesthetic and had no evident harmful consequences on the heart. Dreser modified into now not stimulated and composed a legendary be conscious within side the boundary of Eichengrün's file: 'It is the identical antique Berlin boasting (Jeffreys, 2004). Still, after the involvement of the top of the part who prepared in addition experiments and the medicine can be manufacture expected by Dreser.

Aspirin modified into granted thru manner of approach of a team who had tested the drugs. The name modified into advanced from a combination of spiraea and acetyl. Even though the utility of aspirin withinside the clinical society modified into to begin with time-consuming, it fast took off and aspirin surprisingly have emerge as appeared international as one of the preliminary ache relievers. Even though Eichengrün and Hoffmann completed no fees for the improvement of aspirin, Dreser modified into rewarded credits on each treatment in his research laboratory and labored without delay to create a private wealth from the expansion of aspirin (Jeffreys, 2004). Even though Felix Hoffman is broadly recounted with the finding of aspirin, here may be various controversies around his announce (Sneader, 2000). Bayer modified into producing massive numbers of new pills at the time of discovery and no character changed into accredited with the innovation. In 1934, it is modified; files of discovery 
of aspirin were written by Schmidt after looking during the Bayer records (Schmidt, 1934). Particularly, Eichengrün's effect to the innovation modified into overlooked.

Eichengrün modified right into a Jew and the upward thrust of the Nazi can also moreover have restrained to make a announce to a function. He had, thru manner of approach of this period, went Bayer to build his very own enterprise agency but modified into challenged with sturdy policies on his artwork. In 1938 he modified into pressured to sell his commercial agency and in 1944 he modified into dispatched to the Theresienstadt awareness camp wherein he continued until the Russians launched it in 1945 (Sneader, 2000).

After 15 years, in 1949, the book of the file credit score to the invention to Arthur Eichengrün, Hoffmann, written a paper highlighting the artwork modified into executed beneath his route. He moved without delay to component out that he detected acetylsalicylic acid due to the fact the remarkable compound that they had separated and modified into primary name for scientific trials. $\mathrm{He}$ recommended he had experience it on himself and have begun out the primary trial run. These type of trials hooked up the anaesthetic consequences and antipyretic of acetylsalicylic acid further to its beneficial aspect impact report (Eichengrün, 1949).

\section{Higher push of aspirin}

The aspirin is release within 3 years into the marketplace; admiring the qualities of aspirin over 160 medical papers is published. It worked without delay to come to be relatively a achievement spherical the area. Following World War-I, in 1918, the area modified into strike through manner of approach of each different disastrous event, a universal outburst of infection. About 50 million humans passed from the epidemic: extra than passed from stopping within side the entire of World War-I (Shanks, 2014). There is no remedy is probably located, and vaccination end up unsuccessful. Aspirin have end up extensively used and modified into successful in alleviating the symptoms and symptoms of influenza, even though it modified into now now not effective in decreasing mortality. Its acceptance modified into sustained subsequently and aspirin went without delay to be considered through manner of approach of the overall community and the clinical occupation as a active febrifuge and analgesic, with limited issue results even as taken at present day doses (Lancet Editorial, 1935).

\section{Aspirin gradually plunges not in of benefit}

Aspirin professional some of barriers over the subsequent days. In 1932, at the back of the breakthrough of the gastroscope it speedy has become noticeable that aspirin advantage grow to be correlated with gastritis (Douthwaite \& Lintott, 1938, Douthwaite, 1938;). The improvement of recent anaesthetic entrepreneurs with out the ones issue effects, together with ibuprofen in 1962 and paracetamol in 1956, similarly dented aspirin's popularity. In addition, troubles had been recognized in 1962 even as aspirin end up advised to be correlated with Reye disorder in teenagers (Mortimer, 1962). This instance is said to a excessive brain disorder and fatty penetration of the intestines and need to be lethal. All over the subsequent years, there was increasing proof for this institution (Linnemann et al., 1975) and aspirin isn't exemptions for anyone beneath sixteenth years, however there are some exceptions, like remedy of Kawasaki disorder. Nobel Prize presented for records how aspirin struggled even as aspirin emerge as a reasonably a success product, little become into appeared in relation to its method of achievement. This began out out to come to be fairer later withinside the nineteenth century as systematic enhanced. maximum important manuscripts hypothesizing how aspirin struggled turn out to be posted in 1960 thru Collier \& Shorley (1970) and Harry Collier (1912-1983), a pharmaceutical business organisation modified into strolling with the resource of using a scientist for Allen and Hanburys. He managed the bradykinin to avoid bronchoconstriction of Aspirin in guinea pigs with the useful resource of the use of following element. Aspirin did presently now not exert an impact if it grow to be given even as bradykinin, critical him to hypothecate that Aspirin repressed bradykinin. Priscilla Piper, in 1963 (d. 1995), a PhD pupil from the London university, attached Harry Collier to artwork on the method in the lower again of the consequences of aspirin. They driven earlier with experiments for the following 5 years however 
struggled to shape similarly inroads. In this factor, Collier suggested that Piper want to be part of John Vane's laboratory as a postgraduate pupil to investigate fresh experimental techniques and to require the studies of the mechanism of aspirin additional. He (1927-2004) may be a solution decide withinside the facts of aspirin. In 1927, he have emerged as born in Birmingham, uk and went on to check out chemistry at the college of Birmingham in 1944, in advance than than shifting to the college of Oxford in 1946 to take a look at pharmacology. The university of Sheffield directly accept him and Yale withinside the us earlier than he another time to the UK to artwork withinside the college of London in 1955 in which he advanced the 'blood-bathed appendage cascade'. It becomes a way into a method wherein blood emerge as into handed over tissue strips. The number one 'upstream' strips become treated to line off it to launch of cytokines. He wishes to then take a glance on the results on the down easy strength to appear if it gotten smaller in return to the cytokine that turn out to be launched. He applies the method to vigorously diploma stages of blood hormones, which include angiotensin and bradykinin (Flower, 2005). Priscilla Piper labored with John Vane the use of this approach to take a look at how aspirin interacted with first-rate cytokines. They were the use of a version of the blood-bathed organ cascade wherein rabbit aorta changed into used because of the fact the 'downstream' tissue. They show off that aspirin antagonized an unidentified cytokine that they named 'rabbit aorta astringent component'. They went directly to repeat Collier's experiments as an example that injecting rabbit aorta contracting issue into the guinea pig induced anaphylaxis which modified into antagonized thru way of way of aspirin (Piper \& Vane, 1969). Vane emerge as capable of circulate on for example that rabbit aorta contracting aspect come to be a prostaglandin which inhibited its synthesis (Vane, 1971). The expression that the aspirin inhibited prostacyclin production covered the way for the prospect improvement of anti-inflammatory tablets (NSAIDs) and considered one of a kind cyclooxygenase (COX) enhancer and in 1982, gained John Vane the Nobel Prize for body structure or medicinal drug. In 1984, he also knighted and went devoid of delay.

\section{Application or uses of Aspirin}

\section{Treatment and Prevention of cardiovascular disorder: -}

\section{Primary prevention: -}

The advantages of aspirin remedy for the secondary prevention of cardiovascular disorder truly outweigh the dangers of bleeding, and coffee-dose aspirin is uniformly endorsed on this setting. However, no clean consensus exists approximately whether, and in that case in whom, aspirin remedy is suitable for the number one prevention of cardiovascular disorder. Three trials of low-dose aspirin as opposed to placebo in 3 populations at multiplied threat of myocardial infarction or ischemic stroke withinside the absence of hooked up cardiovascular disorder had been suggested in 2018 . The ASPREE trial in aged human beings changed into terminated early for futility due to the fact aspirin had no impact on disability-loose survival however appreciably multiplied the threat of most important haemorrhage and, unexpectedly, all-reason mortality. In the ASCEND trial in sufferers with diabetes mellitus and no proof of vascular disorder, aspirin appreciably decreased severe vascular occasions however multiplied most important bleeding. In the ARRIVE at trial in human beings with more than one threat elements for cardiovascular disorder, aspirin had no impact on most important cardiovascular occasions however multiplied gastrointestinal bleeding. The intention of this Review is to location those new effects withinside the context of preceding proof on aspirin for the number one prevention of cardiovascular disorder and to appraise whether or not the brand-new proof is probable to allow the greater focused use of aspirin specifically people for whom the internet gain is each clinically profitable and statistically definite.

\section{Secondary prevention: -}

Patients who be afflicted by one or greater CVD occasions, inclusive of myocardial infarct (MI) or ischaemic stroke, are at very excessive threat for each other CVD event. While rescue procedures, inclusive of percutaneous coronary intervention $(\mathrm{PCl})$, are geared toward stabilizing acute occasions, 
aspirin remedy may additionally in reality serve to save lots of you next CVD occasions. The position of aspirin in lowering CVD mortality and repeat occasions after acute MI become first established withinside the $2 \mathrm{~d}$ International Study of Infarct Survival (ISIS-2) trial.7 during this check out, 17,187 sufferers from 417 hospitals had been enrolled inside 24 hours after onset of suspected acute MI and randomized to receive: (i) one month of one hundred sixty mg/day enteric-lined aspirin; (ii) a 1-hour intravenous infusion of $1.5 \mathrm{MU}$ of streptokinase; (iii) each treatments; or (iv) neither. Aspirin use led to a large discount in non-deadly reinfarction, stroke, five-week vascular mortality, and all-reason mortality. Although different, smaller trials confirmed comparable advantages for sufferers with a record of preceding MI, the ISIS-2 trial become the first to supply proof of an instant impact of aspirin on acute $\mathrm{MI}$, demonstrating that one month of low-dose aspirin commenced directly after $\mathrm{MI}$ in one thousand sufferers might prevent 25 deaths and 10 to fifteen nonfatal infarcts and strokes. Additional mortality advantages had been located with longer length of aspirin remedy. Since the ISIS-2 trial, many various organizations have established comparable effects while aspirin is used for secondary prevention of CVD occasions. In 2002, the Antithrombotic Trialists' Collaboration analyzed sixteen trials of lengthy-time period aspirin use with doses ranging from $50-1500 \mathrm{mg} /$ day for secondary prevention of CVD occasions, alongside over 17,000 topics and three,306 severe vascular occasions. In those trials, aspirin use led to sizable discounts in severe vascular occasions alongside stroke and coronary occasions in each woman and men and coffee dose regimens ( $75-100 \mathrm{mg} /$ day) had been located to be as powerful as better doses. A 2020 booklet searching on the secondary prevention of cardiovascular disorder has proven that aspirin continues to be one among the good options.

\section{Aspirin in most cancers' prevention and management}

1988 Professor Gabriel Kune observed that human beings taking aspirin had a $40 \%$ decrease threat of growing most cancers of the huge. Other studies have similarly supported this locating and a time established decreased prevalence in colorectal most cancers has been located. In 2011, Sir John Burns confirmed the position of aspirin in supporting to save you most cancers in vendors of hereditary colorectal most cancers. Further research is ongoing to absolutely apprehend aspirins position in most cancers' prevention along with the position of aspirin in lowering the threat of meta static spread in hooked up most cancers.

\section{Primary disorder prevention: -}

Result from current number one prevention trials inclusive of ASCEND, ASPREE, ARRIVE, Aspect's seafood etc. have precipitated loads of dialogue and discussion26 and brought on refinement of similarly studies research. It is turning into obvious that an individualized technique is crucial in addition to cautious attention of age and all threat elements. Individualized dosing regimens may be had to absolutely take advantage of the probable lifesaving advantages of this captivating drug. Aone length suits all technique isn't always suitable and elements inclusive of multiplied platelet turnover in sure disorder situations e.g., diabetes leads to 'unblocked' platelets withinside the stream while a as soon as everyday aspirin regime is used, similarly frame weight can outcomes aspirin effectiveness.

\section{CONCLUSION}

Aspirin, and especially Low-dose Aspirin, has a therapeutically capability away from its previously regarded outcomes inside the anticipation of numerous sicknesses together with myocardial infarction, atherothrombotic events, strokes and colon cancer. Except the pharmacological outcomes that it shares with different NSAIDs can induce other lipid-derived mediators with effective stimulation and anti-inflammatory actions of the resolution of irritation places aspirin in a privileged function in the therapeutic arsenal. This review is a deep observe of the molecular mechanisms indirect inside the outcomes of aspirin and of AT mediators to suggest a extra lucid use of it based totally on the choice of sufferers who should gain from aspirin, when the remedy should begin, and the dose that need to be apply. 


\section{REFERENCES}

Douthwaite, A. H. (1938). Recent advances in medical diagnosis and treatment. British Medical Journal, 1(4038), 1143.

Douthwaite, A. H., \& Lintott, G. A. M. (1938). Gastroscopic observation of the effect of aspirin and certain other substances on the stomach. The Lancet, 232(6013), 1222-1225.

Eichengrün, A. (1949). Jahre Aspirin. Pharmazie, 4, 582-4.

Flower TR, Chesnokova LS, Froelich CA, Dixon C, Witt SN. Heat shock prevents alpha-synuclein-induced apoptosis in a yeast model of Parkinson's disease. Journal of molecular biology. 2005 Sep 2;351(5):1081-100.

Jeffrey, S. C., Torgov, M. Y., Andreyka, J. B., Boddington, L., Cerveny, C. G., Denny, W. A., ... \& Senter, P. D. (2005). Design, synthesis, and in vitro evaluation of dipeptide-based antibody minor groove binder conjugates. Journal of medicinal chemistry, 48(5), 1344-1358.

Jeffreys, A. J., \& May, C. A. (2004). Intense and highly localized gene conversion activity in human meiotic crossover hot spots. Nature genetics, 36(2), 151-156.

Laidlaw, P. P. (1935). Epidemic influenza: a virus disease. Lancet, 1118-24.

Linnemann Jr, C. C., Perlstein, P. H., Ramundo, N., Minton, S. D., Englender, G. S., McCormick, J. B., \& Hayes, P. S. (1975). Use of pertussis vaccine in an epidemic involving hospital staff. The Lancet, 306(7934), 540-543.

Mann, C. C., \& Plummer, M. L. (1991). The aspirin wars: money, medicine, and 100 years of rampant competition. Alfred a Knopf Incorporated.

Mortimer, P. H. (1963). The Experimental Intoxication of Sheep with Sporidesmin, a Metabolic Product of Pithomyces chartarum: IV.-Histological and Histochemical Examinations of Orally-dosed Sheep. Research in veterinary science, 4(1), 166-195.

Schmidt, H. (1995). The United States Occupation of Haiti, 1915-1934. Rutgers University Press.

Sneader, W. (2000). The discovery of aspirin: a reappraisal. Bmj, 321(7276), 1591-1594.

Sneader, W. (2000). The discovery of aspirin: a reappraisal. Bmj, 321(7276), 1591-1594.

Vane, J. R. (1971). Inhibition of prostaglandin synthesis as a mechanism of action for aspirin-like drugs. Nature new biology, 231(25), 232-235. 


\title{
Cisplatin: The Most Widely Used Anticancer Drug
}

\author{
Krishnendu Chatterjee, Tiasa Chatterjee, Apurba Biswas* \\ Department of Chemistry, Surendranath College, Kolkata, India \\ ${ }^{*}$ Corresponding Author's Email: apurbacu@yahoo.co.in
}

\begin{abstract}
Cisplatin or cis-diamminedichloridoplatinum(II) is one of the most successful and efficient chemotherapeutic drugs for the treatment of various types of malignancies, including bladder, testis, ovary, head and neck, lung cancer, germ cell tumors, lymphomas, sarcomas, and many others. Cisplatin molecules bind with DNA to form an adduct which finally transduces several signalling pathways, resulting in apoptosis and cell death. Unfortunately, neither cytotoxicity nor apoptosis are completely generated in cancer cells, therefore cisplatin may have a variety of side effects that limit its use and effectiveness. The restoration of cisplatin's efficiency is a difficult task for medical science. Combination therapies, in which other anticancer drugs containing platinum are used in combination with cisplatin in chemotherapy treatment, are being utilised to reduce cisplatin resistance and side effects, and have become successful in overcoming drug resistance and reducing toxicity. This article mainly highlights the brief description of cisplatin as an anticancer drug. This article briefly describes the first innovation of cisplatin, its synthesis method, molecular cellular mechanism of action, its activity as an anticancer drug, and its side effects and resistance. Special attention is given to cisplatin, transplatin, and any other platinum drugs that are not properly addressed.
\end{abstract}

Keywords : Cisplatin; Cancer Treatment; Drug Resistance; Side Effects

\section{INTRODUCTION}

Cancer is the most severe health problem and the second leading cause of death (Ghosh, 2019; Siegel, Miller \& Jemal, 2018). IRAC reported nearly 7.6 million cancer-related deaths worldwide, with 12.6 billion new cases reported each year (Baskar et al., 2012). Cancer arises when abnormal cells in the body proliferate uncontrollably. Old cells do not die when the body's usual regulatory mechanisms fail, but new cell growth continues, leading to the formation of aberrant cells. These cells form a mass of tissue called a tumor. Cancer may be treated depending on the type. The first one is surgery, which directly removes the tumor, but it is only possible if the cancer is localized. Radiation therapy using Xrays is a way to damage cancer cells. Chemotherapy is an efficient and widely used way to kill cancer cells (Baskar et al., 2012; Shewach \& Kuchta, 2009; Eastman, 2017). Cisplatin is one of the most potential and widely used first-generation metal-based chemotherapeutic agents (Siegel, Miller \& Jemal, 2018). It is reported that nearly 2 billion US dollars are invested in the platinum-based anticancer drug (Siafaca, 1999). From the studies, it is found that nearly $50 \%$ of patients are treated with cisplatin, which is effective at curing $90 \%$ of testicular cancer. It is more effective in the treatment of cancers like head and neck cancer, ovarian cancer, bladder cancer, cervical cancer, melanoma, and many more (Hambley, 1997). Though cisplatin is successful, it does not show its maximum efficiency due to its resistance and side effects, which are mainly due to protein binding (Ghosh, 2019). This is the reason that led researchers to develop a thousand cisplatin analogs, but only two have been approved (Wilson \& Lippard, 2014). But most of the platinum complexes are less effective compared to cisplatin (Zhanget al., 2010).

This review article is a brief overview of the drug cisplatin from its first to last. The synthesis method, its cellular mechanism, anticancer activity, side effects are also briefly encountered by this review. It should be noted that this review is only centred on cisplatin; the other platinum complexes and their 
properties are not incorporated into this article.

\section{LITERATURE REVIEW}

\section{First innovation of metal based anticancer drug}

Alfred Warner published 14 papers on platinum chemistry between 1896 and 1920 (Ghosh, 2019). In 1997, George B. Kauffman analysed Alfred Warner's platinum metals study, which disproved the Blomstrand-Josrgenses chain explanation for the formulation of the isomers cis and trans $\left[\mathrm{PtCl}_{2}\left(\mathrm{NH}_{3}\right)_{2}\right]$ (Wilson \& Lippard, 2014). Michele Peyrone initially described the cis isomer $\left[\mathrm{PtCl}_{2}\left(\mathrm{NH}_{3}\right)_{2}\right]$ in 1844 and termed it "Peyrone's salt" (Peyrone, 1844). In 1893, Warner deduced the structure of the cisplatin complex. Warner assumed that the isomers which result in two different colours are mainly due to the cis and trans position of the ammonia and chloride ligands and derived a square planar geometry of cis and trans $\left[\mathrm{PtCl}_{2} \mathrm{NH}_{3}\right]$ (Constable \& Housecroft, 2013). But the anticancer activity or inhabitation of cell division of cisplatin was accidentally discovered by biophysicists Rosenberg, Van Camp, and Krigas (1965). In a study of the effect of the electric field on the cell division in $\mathrm{NH}_{4} \mathrm{Cl}$ buffer, Mr. Barnett noticed that the cells of the $\mathrm{E}$ colai became long, and after a long study, he found that the phenomenon only occurred due to the inhibition of cellular division. Finally, it was proposed that cell division be restricted by a platinum compound released from the electrode. From these observations, the cisplatin $\mathrm{Pt}(\mathrm{II})$ complex was tested against sarcoma 180 tumours in Swiss white mice. The complex demonstrated potent activity in shrinking large solid tumors. After a successful journey with cisplatin, this drug is now the most potent in the field of cancer treatment.

\section{Synthesis of cisplatin}

In 1944, Michele Peyrone first synthesized cisplatin, though its structure was still unknown till that date. After 50 years, Alfred Warner proposed its square planar geometry and its isomers (Mellor, 1943). The early method of synthesis needed some improvements for better yield, purity, and reaction time. Dhara (1970) proposed a most important method for preparation of cisplatin. In 1970, Dhara described "A rapid method for the synthesis of cis- $\left[\mathrm{PtCl}_{2}\left(\mathrm{NH}_{3}\right)_{2}\right]$." In this method, the starting material $\mathrm{K}_{2}\left[\mathrm{PtCl}_{4}\right]$ is first treated with a saturated solution of $\mathrm{KI}$ to form the tetraiodo analogue $\mathrm{K}_{2}\left[\mathrm{Ptl} \mathrm{H}_{4}\right]$. Then $\mathrm{NH}_{3}$ is added to this tetraiodo analogue to form cis-[ $\left.\mathrm{Ptl}_{2}\left(\mathrm{NH}_{3}\right)\right]$, a yellow compound. This yellow compound is now dried and an aqueous solution of $\mathrm{AgNO}_{3}$ is added to it. After the addition of $\mathrm{AgNO}_{3}$, an insoluble precipitation is noticed which is nothing but the precipitation of Agl, which is filtered and discarded. After treating with $\mathrm{KCl}$ in the filtrate containing cis- $\left[\mathrm{Pt}(\mathrm{OH})_{2}\left(\mathrm{NH}_{3}\right)\right]^{2+}$, a yellow powder product cis-[ $\left[\mathrm{PtCl}_{2}\left(\mathrm{NH}_{3}\right)_{2}\right]$ is obtained.(Davies et al., 2008). Recrystalizaion with hot water containing $0.9 \% \mathrm{NaCl}$ produces more purified cisplatin. The efficiency of this process is mainly dependent on the trans effect, which was first introduced in 1926 by Chernyaev (Basolo \& Pearson, 1967). The incorporation of a second ammonia ligand into the intermidiate triiodo species $\mathrm{K}\left[\mathrm{Ptl}_{3}\left(\mathrm{NH}_{3}\right)\right]$ may result in the substitution of an iodo ligand that is trans to another iodo group or the iodo group that is trans to ammonia, but the final cis product is obtained due to the strong trans-directing iodo group to the ammonia. Actually, the earlier process does not contain the initial step, which is the conversion of $\mathrm{K}_{2}$ $\left[\mathrm{PtCl}_{4}\right]$ to $\mathrm{K}_{2}\left[\mathrm{Ptl}_{4}\right]$. But this step only ensures that the final product is mainly a cis-oriented product (Alderden, Hall \& Hambley, 2006).

\section{DISCUSSION}

\section{Mechanism of action}

It is beyond the scope of this article to elaborately explain the molecular cellular mechanism of cisplatin as an anticancer drug. This review presents a brief description, more particularly, an overview of the mechanism of cisplatin activity. Generally, cisplatin exposes its anticancer activity by binding to DNA (Ivanov et al., 1998). Cisplatin intravenously administered to a patient as a sterile saline solution (Ghosh, 2019). Many studies indicate that cisplatin primarily interacts with proteins 
that contain a thiol group, such as the amino acid cysteine, human serum, and albumin.It should be noted that protein binding accounts for 65 to 98 percent of the platinum found (Ivanov et al., 1998). This protein binding has been bound by its drug activity, and some serious side effects have developed from this binding. The unbound remaining cisplatin can enter the tumour cells by cell membrane diffusion (Gately \& Howell, 1993). But some studies suggest that Cu transporting proteins are factors for the transportation of cisplatin across the cell membrane (Ishida et al., 2002). Once the cisplatin enters the cell, its exit is restricted by forming a reactive, positively charged species. As the chloride concentration inside the cell is lower, one of the chloride ligands of cisplatin is replaced by water and hence the reactive species is formed (Davies, Berners-Price \& Hambley, 2000). This monoaquated reactive species can efficiently form platinum binding to DNA within the cell nucleus at least $98 \%$ of the platinum (Davies, Berners-Price \& Hambley, 2000). This monofunctional DNA adduct is mainly formed by binding with guanine, which is one of the DNA bases. To form a bifunctional adduct, the ring closure may occur either directly from the monofunctional DNA adduct or by aquation of the second chloride ligand present in cisplatin (Jamieson \& Lippard, 1999). At the primary stage, the bifunctional adducts are mainly guanine-guanine types or adenine-guanine types (Cohen et al., 1980). The bifunctional adducts result in a severe distortion of the DNA molecule, which can be easily acknowledged by DNA-binding proteins. These binding proteins may initiate DNA repair or they may be the cause of cell death (Guo \& Sadler, 1999).

\section{Use of cisplatin for cancer treatment}

\section{Use of cisplatin for treatment of lung cancer}

Lung cancer is one of the most common fatal diseases. Chemotherapy is the most effective treatment for small cell lung cancers (SCLC), as these tumours are generally widespread when diagnosed. The two most important drugs are cisplatin and carboplatin that are used in SCLC chemotherapy. Nevertheless, cisplatin is chosen over carboplatin due to its strong antitumor activity, though it can cause side effects including renal nausea and vomiting. Chemotherapy, along with radiation therapy, is most effective for patients with stage III and stage IV lung cancer that cannot be surgically removed (Zappa \& Mousa, 2016).

\section{Use of cisplatin for treatment of ovarian cancer}

Ovarian cancer is one of the most common forms of cancer in women, leading to highest death. Even though the exact cause of ovarian cancer is unclear, it can be expected in people with breast or colon cancer and because of inadequate screening strategies and specific symptoms of early-stage disease to detect it. Cisplatin is the most effective treatment of ovarian cancer as a chemotherapy agent although it has several side effects. Therefore combition therapy is used for better treatment as there is a chance to reapper in future (Kakar, Jala \& Fong, 2012).

\section{Use of cisplatin for treatment of testicular cancer}

Testicular cancer is a great concern for young men as seminoma and non-seminoma, two types of it, are generally seen among them. Cisplatin-based chemotherapy is the best for the treatment of seminoma testicular cancer. $85 \%$ of patients are cured with the help of cisplatin after three or four cycles. Non-seminomas are generally seen after their late teens. There are four main types of nonseminomas: embryonal carcinoma, yolk sac carcinoma, choriocarcinoma and teratoma. Cisplatin, along with other chemotherapic drugs such as bleomycin and etoposide, is used in combination therapy, which is the most competent method of treatment for patients with teratoma. Many mechanisms are planned so that they can be explained clearly. Gong et al. (2010) demonstrated that prostate cancer cells more express Kindlin-2, which regulates the death of cancer cells. Usanova et al. (2010) found that cisplatin sensitivity in tumour cells in the testes.

\section{Use of cisplatin for treatment of other cancers}

Cisplatin is also widely used as a treatment for brain tumours in children, stomach cancer, leukemia 
etc. It is very useful for the treatment of breast cancer patients as it makes hope to live long for patients. (Dentino et al., 1978). In the case of squamous cell carcinoma of the head and neck (CCSSN), this therapy may not be effective although overall liability is good for the patients. Cisplatin really a brilliant chemotherapy agent that can be used for the treatment of different types of cancers that is severe to the patients (Tsimberidou et al., 2009).

\section{Side effects of cisplatin}

Cisplatin is highly effective in treating testicular and ovarian cancer, although it has many side effects that may be seen by using an overdose of it. The main side effects of cisplatin have been mentioned below.

\section{Nephrotoxicity}

Nephrotoxicity is one of the most frequent kidney problems and happens when your body is exposed to a medication or toxin that causes damage to your kidneys. Renal toxicity has been noted when treated with cisplatin in the form of a single $50 \mathrm{mg} / \mathrm{m}^{2}$ agent in $28 \%$ to $36 \%$ paptients. This rental toxicity becomes severe when using drugs in a repeated manner. Nephrotoxicity is the cause of the increase in blood urea nitrogen (BUN) (Petrovic \& Todorović, 2016). The risk of nephrotoxicity can be decreased due to intravenous hydration of at least 3-6L per day (Tsang, Al-Fayea \&Au, 2009).

\section{Ototoxicity}

Ototoxicity is a major side effect for $31 \%$ of patients when they were treated with a single dose of 50 $\mathrm{mg} / \mathrm{m}^{2}$ cisplatin, and it also affects more children than adults (Petrovi \& Todorovi, 2016). Hearing loss is caused by excessive use of cisplatin and has become more severe for adults. It is not clear whether the reversibility of the cisplatin-induced ototoxicity is complete. Hearing loss is typically in the high frequency range, bilateral, and permanent (McKeage, 1995). Deafness has also been reported as a side effect. Antioxidants and anti-inflammatory medicines must be administered locally or in a systematic manner to treat cisplatin-induced ototoxicity (Rybak et al., 2007).

\section{Hepatotoxicity}

Hepatotoxicity can occur if you take too much cisplatin. This is mostly caused by oxidative stress, which is induced by an increase in transaminases and bilirubin in the bloodstream (İşeri et al., 2007). Cisplatin treatment has also been shown to increase cytochrome P450 levels, and the cytochromeP450-2E1 enzyme (Caro \& Cederbaum, 2004). Hepatotoxicity can be reduced by taking large amounts of selenium and vitamin E (Liao et al., 2008).

\section{Gastrointestinal toxicity}

Nausea and vomiting, abdominal pain, and a chemical hepatitis characterised by a disturbance of liver function enzymes are all symptoms of gastrointestinal poisoning. Despite routine preventive antiemetic therapy, almost all patients experience severe nausea and vomiting. There have also been reports of diarrhoea, loss of taste or metallic taste, pancreatitis, and mucositis (Tsang, Al-Fayea \& Au, 2009).

\section{CONCLUSION}

Cisplatin is one of the most potent and effective anticancer drugs. Cisplatin can treat many types of solid cancers, which are already mentioned in this article. The general mechanism of action of cisplatin, which causes apoptosis by damaging DNA and inhibiting replication, is not the only way to describe its cellular mechanism. There are a number of mechanisms of action of cisplatin that have been proposed with evidence, but none of them can completely describe its cellular action. So it is obvious that it is a great area of interest for chemists and biologists to find its complete mechanism. The major challenges for cisplatin are toxicity, side effects, and drug resistance. This resistance and side effects mainly arise due to the binding of cisplatin with proteins and changes in cellular uptake. These side effects and resistance can be overcome by the combination of cisplatin with certain platinum agents. Combination therapy has become an efficient way to restore the efficiency of 
cisplatin. Finally, combination techniques that reduce the uptake of cisplatin could offer the best clinical application of cisplatin.

\section{ACKNOWLEDGEMENT}

The authors express their sincere thanks to the Department of Biotechnology, Government of India, for the funding from the DBT-STAR College grant, under which this review project was conducted. We are also grateful to the Principal and the DBT-STAR Coordinator, Surendranath College, for their support and encouragement in implementing this review project at undergraduate level.

\section{REFERENCES}

Alderden, R. A., Hall, M. D., \& Hambley, T. W. (2006). The discovery and development of cisplatin. Journal of chemical education, 83(5), 728.

Baskar, R., Lee, K. A., Yeo, R., \& Yeoh, K. W. (2012). Cancer and radiation therapy: current advances and future directions. International journal of medical sciences, 9(3), 193.

Basolo, F., \& Pearson, R. G. (1967). Mechanisms of inorganic reactions; a study of metal complexes in solution.

Caro, A. A., \& Cederbaum, A. I. (2004). Oxidative stress, toxicology, and pharmacology of CYP2E1. Annu. Rev. Pharmacol. Toxicol., 44, 27-42.

Chernyaev, I. I. (1926). The mononitrites of bivalent platinum. Ann Inst Platine (USSR), 4, 243-275.

Cohen, G. L., Ledner, J. A., Bauer, W. R., Ushay, H. M., Caravana, C., \& Lippard, S. J. (1980). Sequence dependent binding of cis-dichlorodiammineplatinum (II) to DNA. Journal of the American Chemical Society, 102(7), 2487-2488.

Constable, E. C., \& Housecroft, C. E. (2013). Coordination chemistry: the scientific legacy of Alfred Werner. Chemical Society Reviews, 42(4), 1429-1439.

Davies, M. S., Berners-Price, S. J., \& Hambley, T. W. (2000). Slowing of cisplatin aquation in the presence of DNA but not in the presence of phosphate: improved understanding of sequence selectivity and the roles of monoaquated and diaquated species in the binding of cisplatin to DNA. Inorganic chemistry, 39(25), 5603-5613.

Davies, M. S., Hall, M. D., Berners-Price, S. J., \& Hambley, T. W. (2008). [1H, 15N] Heteronuclear single quantum coherence NMR study of the mechanism of aquation of platinum (IV) ammine complexes. Inorganic chemistry, 47(17), 7673-7680.

Dentino, M., Luft, F. C., Yum, M. N., Williams, S. D., \& Einhorn, L. H. (1978). Long term effect of Cis-Diamminedichloride platinum (CDDP) on renal function and structure in man. Cancer, 41(4), 1274-1281.

Dhara, S. C. (1970). A rapid method for the synthesis of cis-[Pt (NH3) 2Cl2]. Indian J Chem, 8(1), 193194.

Eastman, A. (2017). Improving anticancer drug development begins with cell culture: misinformation perpetrated by the misuse of cytotoxicity assays. Oncotarget, 8(5), 8854.

Gately, D. P., \& Gately, D. P., \& Howell, S. B. (1993). Cellular accumulation of the anticancer agent cisplatin: a review. British journal of cancer, 67(6), 1171-1176.

Ghosh, S. (2019). Cisplatin: The first metal based anticancer drug. Bioorganic chemistry, 88, 102925.

Gong, X., An, Z., Wang, Y., Guan, L., Fang, W., Strömblad, S., ... \& Zhang, H. (2010). Kindlin-2 controls sensitivity of prostate cancer cells to cisplatin-induced cell death. Cancer letters, 299(1), 54-62. 
Guo, Z., \& Sadler, P. J. (1999). Medicinal inorganic chemistry. Advances in inorganic chemistry, 49, 183-306.

Hambley, T. W. (1997). The influence of structure on the activity and toxicity of Pt anti-cancer drugs. Coordination Chemistry Reviews, 166, 181-223.

İşeri, S., Ercan, F., Gedik, N., Yüksel, M., \& Alican, I. (2007). Simvastatin attenuates cisplatin-induced kidney and liver damage in rats. Toxicology, 230(2-3), 256-264.

Ishida, S., Lee, J., Thiele, D. J., \& Herskowitz, I. (2002). Uptake of the anticancer drug cisplatin mediated by the copper transporter Ctr1 in yeast and mammals. Proceedings of the National Academy of Sciences, 99(22), 14298-14302.

Ivanov, A. I., Christodoulou, J., Parkinson, J. A., Barnham, K. J., Tucker, A., Woodrow, J., \& Sadler, P. J. (1998). Cisplatin binding sites on human albumin. Journal of Biological Chemistry, 273(24), 1472114730.

Jamieson, E. R., \& Lippard, S. J. (1999). Structure, recognition, and processing of cisplatin- DNA adducts. Chemical reviews, 99(9), 2467-2498.

Kakar, S. S., Jala, V. R., \& Fong, M. Y. (2012). Synergistic cytotoxic action of cisplatin and withaferin A on ovarian cancer cell lines. Biochemical and biophysical research communications, 423(4), 819825.

Kauffman, G. B. (1997). Alfred Werner's Research on the Platinum Metals. Platinum Metals Review, $41,34-40$

Liao, Y., Lu, X., Lu, C., Li, G., Jin, Y., \& Tang, H. (2008). Selection of agents for prevention of cisplatininduced hepatotoxicity. Pharmacological Research, 57(2), 125-131.

McKeage, M. J. (1995). Comparative adverse effect profiles of platinum drugs. Drug safety, 13(4), 228244.

Mellor, D. P. (1943). The Sterochemistry of Square Complexes. Chemical Reviews, 33(2), 137-183.

Petrović, M., \& Todorović, D. (2016). BIOCHEMICALAND MOLECULAR MECHANISMS OF ACTION OF CISPLATIN IN CANCER CELLS. Facta Universitatis, Series: Medicine \& Biology, 18(1).

Peyrone, M. (1844). Ueber die einwirkung des ammoniaks auf platinchlorür. Justus Liebigs Annalen der Chemie, 51(1), 1-29.

Rosenberg, B., Van Camp, L., \& Krigas, T. (1965). Inhibition of cell division in Escherichia coli by electrolysis products from a platinum electrode. Nature, 205(4972), 698-699.

Rybak, L. P., Whitworth, C. A., Mukherjea, D., \& Ramkumar, V. (2007). Mechanisms of cisplatininduced ototoxicity and prevention. Hearing research, 226(1-2), 157-167..

Shewach, D. S., \& Kuchta, R. D. (2009). Introduction to cancer chemotherapeutics. Chemical reviews, 109(7), 2859-2861.

Siafaca, K. (1999). Oncology trends products markets-Part 1. Future Oncology, 1045-1071.

Siegel, R. L., Miller, K. D., \& Jemal, A. (2015). Cancer Statistics, CA Cancer J Clin, 65(1), 5-29.

Tsang, R. Y., Al-Fayea, T., \& Au, H. J. (2009). Cisplatin overdose. Drug safety, 32(12), 1109-1122.

Tsimberidou, A. M., Braiteh, F., Stewart, D. J., \& Kurzrock, R. (2009). Ultimate fate of oncology drugs approved by the us food and drug administration without a randomized Trial. Journal of Clinical Oncology, 27(36), 6243-6250.

Usanova, S., Piée-Staffa, A., Sied, U., Thomale, J., Schneider, A., Kaina, B., \& Köberle, B. (2010). 
Cisplatin sensitivity of testis tumour cells is due to deficiency in interstrand-crosslink repair and low ERCC1-XPF expression. Molecular cancer, 9(1), 1-11.

Wilson, J. J., \& Lippard, S. J. (2014). Synthetic methods for the preparation of platinum anticancer complexes. Chemical reviews, 114(8), 4470-4495.

Zhang, J., Wang, L., Xing, Z., Liu, D., Sun, J., Li, X., \& Zhang, Y. (2010). Status of bi-and multi-nuclear platinum anticancer drug development. Anti-Cancer Agents in Medicinal Chemistry (Formerly Current Medicinal Chemistry-Anti-CancerAgents), 10(4), 272-282.

Zappa, C., \& Mousa, S. A. (2016). Non-small cell lung cancer: current treatment and future advances. Translational lung cancer research, 5(3), 288. 


\title{
Ethnomedicinal Uses in West Bengal, India
}

\author{
Pritha Manna, Nilufa Nasrin, Abontika Das, Jayanta Sikdar* \\ Department of Botany, Surendranath College, Kolkata, India \\ *Corresponding Author's Email: jayantabot@gmail.com
}

\begin{abstract}
This study was focus to find out some ethnomedicinal uses in West Bengal which are used to treatment various disease through this traditional knowledge. This indigenous knowledge can used for human being. Folk people or ethnic group of people are our main source of indigenous traditional ethnomedicine. They use locally medicinal plants for their treatments. In this review, we discuss some medicinally important plants which are used as ethnomedicine.
\end{abstract}

Keywords: Ethnomedicine; Medicinal Plants; Uses

\section{INTRODUCTION}

Ethnomedicine is commonly known as traditional indigenous medicinal plants which are used by folk people or by ethnic group. Ethnomedicinal studies (Jain, 2017) are important for the study of new crude drugs from different indigenous medicinal plants. Due to lack of modern medicinal facility, bad economic condition they adopt indigenous ethnomedicine. This practice mainly found in rural population especially tribal community (Mondal, Paul, Hoque, 2015; Das \& Ghosh 2017). They practice this ethnomedicine and inherit generation to generation. In India more than 3000 plant species are reported (Prakasha et al., 2010) medicinal properties.

The term Ethnobotany was first introduced by Harshberger in 1876 which means 'the study of plants used by ethnic or ancient people'. Now a days ethnobotany means direct relationship between plants and human population. Indian region is one of the greatest center of ethnobotanical wealth and a store house of traditional knowledge. Most of the tribal people still live far away from the influences of the modern world and maintain close association with the medicinal plants for all their needs. Indian region supports a large biodiversity of ancient lineage. It provided unique opportunities for study of ethnobotany. It is a science dealing with relationship between human and plants (Mukherjee, 2003). Ethnobotany is a mixture of different discipline like Botany, Anthropology, Sociology and Culture, Language and linguistics, Religion and Social customs, Medicine, Mythology, Geography, Economics and a many other subjects.

All tribes have their own names for plants in the different regions. It may be seen that a single plant has different local names in different regions. So local names/vernacular names help in verification of the uses with other persons at a later date.

Plants are used in the traditional medicines for several thousands of years. In the ancient age the people used the raw plants as food for their nutrition and used the crude drugs for remedies. Charak Samhita (1000 BC-100 AD) has reported more than 1000 herbal remedies. Not only that, the holy Vedas also remind us about the traditional medicinal uses of various plants. Atharvaveda (around 1200 BC), Charak Samhita and Shusrut Samhita (1000-500 BC) are the source of our indigenous traditional detailed description of different herbs and describes the uses (Tripathi et al., 2013). Ayurveda, Siddha and Unani are the evidence of the traditional medicines. During the last few decades, natural products are popular worldwide and known as herbal medicines. This practice of natural products actually is based on belief and experience of the ethnic people. However, this traditional knowledge doesn't have any written documents, they carry on orally generation-after generation and still accepted by around the world. In $77^{\text {th }}$ A.D great Greek surgeon Pedanius Dioscorides published "De Materia Medica" which is a book of information about many plants used by ancient Greeks in medicinal purpose. 


\section{LITERATURE REVIEW AND DISCUSSION}

Particular in human health care ethnomedicine has been playing very important role. In India ethnic people belief of their tradition and culture and they use as a health care practices (Ghosh, 2008; Chakraborty \& Bhattacharjee, 2006; Sahoo \& Sivaramakrishnan, 2014). These particular traditional medicines have no side effect as well as very effective, cheap and locally available. It also effects in international trade for its herbal drug demand and as a result ethnobotany is more importance for traditional medicinal knowledge like uses, preparations, doses and other important information regarding crude drugs. Now a days extensive research work done in the field of ethnobotany which help us to explore traditional knowledge. Folk traditional treatment procedure protocol, pharmacology, tribal medicine system is still not well known in different areas of West Bengal (Tripathi et al., 2013, Rahaman \& Karmakar, 2015).

Table 1: Some Important Ethnomedicinal Plants \& Uses

\begin{tabular}{|c|c|c|c|c|c|c|}
\hline $\begin{array}{l}\text { Sl. } \\
\text { No. }\end{array}$ & $\begin{array}{l}\text { Plant Name } \\
\text { (Local Name) }\end{array}$ & Scientific Name & Family & Habit & $\begin{array}{l}\text { Parts } \\
\text { Used }\end{array}$ & Uses \\
\hline 1. & Kalmegh & $\begin{array}{l}\text { Andrographis paniculata } \\
\text { (Burm. f.) Wall ex Nees }\end{array}$ & Acanthaceae & $\begin{array}{l}\text { Perennial } \\
\text { Herb }\end{array}$ & $\begin{array}{l}\text { Whole } \\
\text { plant, } \\
\text { mainly } \\
\text { leaves, } \\
\text { roots. }\end{array}$ & $\begin{array}{l}\text { Used loss of appetite; improve } \\
\text { liver function and digestion; } \\
\text { irregular stools. Used in fever, } \\
\text { general debility, dysentery, } \\
\text { dyspepsia. }\end{array}$ \\
\hline 2. & $\begin{array}{l}\text { Nayantara, } \\
\text { Chirabasanta }\end{array}$ & $\begin{array}{l}\text { Catharanthus roseus (L.) G. } \\
\text { Don }\end{array}$ & Apocynaceae & $\begin{array}{l}\text { Perennial } \\
\text { Herb }\end{array}$ & $\begin{array}{l}\text { Entire } \\
\text { plant }\end{array}$ & $\begin{array}{l}\text { Plant parts used to cure diabetes } \\
\text { diabetes mellitus), hypertension, } \\
\text { leucorrhoea, leukemia. Latex } \\
\text { also applied to cure cancerous } \\
\text { wounds. }\end{array}$ \\
\hline 3. & $\begin{array}{l}\text { Thankuni, } \\
\text { Manduki }\end{array}$ & Centella asiatica (L.) Urban. & $\begin{array}{l}\text { Apiaceae / } \\
\text { Umbelliferae }\end{array}$ & $\begin{array}{l}\text { Creeping } \\
\text { Herb }\end{array}$ & Leaves & $\begin{array}{l}\text { Used in constipation, cold and } \\
\text { cough, fever, jaundice fatigue, } \\
\text { weakness, indigestion, irregular } \\
\text { menstruation, mouth ulcers, } \\
\text { dysentery, leprosy and many } \\
\text { others. It is also used in cardiac } \\
\text { debility, asthma, epilepsy. }\end{array}$ \\
\hline 4. & Durba & Cynodon dactylon (L.) Pers. & $\begin{array}{l}\text { Poaceae / } \\
\text { Graminae }\end{array}$ & $\begin{array}{l}\text { Small } \\
\text { grass }\end{array}$ & $\begin{array}{l}\text { Whole } \\
\text { plant }\end{array}$ & $\begin{array}{l}\text { Used in diuretic, anti-catarrhal, } \\
\text { antipyretic, demulcent, leprosy, } \\
\text { cholera, dropsy, diarrhoea, } \\
\text { conjunctivitis. }\end{array}$ \\
\hline 5. & Mutha & Cyperus rotundus L. & Cyperaceae & $\begin{array}{l}\text { Perennial } \\
\text { Herb }\end{array}$ & $\begin{array}{l}\text { Roots, } \\
\text { Whole } \\
\text { plant }\end{array}$ & $\begin{array}{l}\text { Used in fever, different blood } \\
\text { disease, dyspepsia, urinary } \\
\text { disease. Plant juice used skin } \\
\text { burning sensation, root used to } \\
\text { fever with thirst. }\end{array}$ \\
\hline 6. & $\begin{array}{l}\text { Lalkeru, Dudhia, } \\
\text { Bara dudhe, } \\
\text { Dugdhika }\end{array}$ & Euphorbia hirta L. & Euphorbiaceae & Erect Herb & $\begin{array}{l}\text { Leaves, } \\
\text { Roots, } \\
\text { Enrtire } \\
\text { plant }\end{array}$ & $\begin{array}{l}\text { Plant extract used in diarrhoea, } \\
\text { bowel problems, colic, cold and } \\
\text { cough. Latex used on nail } \\
\text { corners infection, gonorrhoea, } \\
\text { ringworms, sores etc. }\end{array}$ \\
\hline 7. & Pudina, Mentha & Mentha piperita L. & $\begin{array}{l}\text { Lamiaceae } \\
\text { (Labiatae) }\end{array}$ & $\begin{array}{l}\text { Annual } \\
\text { Herb }\end{array}$ & Leaves & $\begin{array}{l}\text { Use to nausea, gastric stimulant, } \\
\text { antiseptic, cold, cough, vomiting, } \\
\text { sickness, local pains, , menstrual } \\
\text { colic etc. }\end{array}$ \\
\hline 8. & Tulsi & Ocimum sanctum $\mathrm{L}$. & Lamiaceae & $\begin{array}{l}\text { Aromatic } \\
\text { Herb }\end{array}$ & Leaves & $\begin{array}{l}\text { Plan juice used to cure cold and } \\
\text { cough, constipation, juice, cold } \\
\text { fever, on ringworm, remove } \\
\text { unwanted spot. }\end{array}$ \\
\hline 9. & Anantamul & $\begin{array}{l}\text { Hemidesmus indicus (L.) R. } \\
\mathrm{Br} \text {. }\end{array}$ & Asclepiadaceae & $\begin{array}{l}\text { Branched } \\
\text { Shrub }\end{array}$ & Roots & $\begin{array}{l}\text { Used kidney disorders, appetite, } \\
\text { indigestion fever, diarrhoea, skin, } \\
\text { piles, ulcers, stone kidney, } \\
\text { leucorrhoea, syphilis. }\end{array}$ \\
\hline
\end{tabular}




\section{Ethnomedicinal Uses}

\begin{tabular}{|l|l|l|l|l|l|l|}
\hline 10. & $\begin{array}{l}\text { Ayapan/Ayyapan } \\
\text { IAiapana }\end{array}$ & $\begin{array}{l}\text { Ayapana triplinervis (M. } \\
\text { Vahl.) R. King \& H. Robinson }\end{array}$ & $\begin{array}{l}\text { Asteraceae I } \\
\text { Compositae }\end{array}$ & $\begin{array}{l}\text { Perennial } \\
\text { Herb }\end{array}$ & Leaves & $\begin{array}{l}\text { Used to jaundice, intestine ulcer, } \\
\text { haemostatic foul ulcers low blood } \\
\text { pressure. Dried leaves used to } \\
\text { cardiac stimulant. }\end{array}$ \\
\hline 11. & Basak & Adhatoda zeylanica Medic. & Acanthaceae & $\begin{array}{l}\text { Perennial } \\
\text { Shrub }\end{array}$ & Leaves & $\begin{array}{l}\text { Used in catarrh, diarrhoea, } \\
\text { dysentery. Leaves extract used } \\
\text { in cold, cough and bronchitis } \\
\text { Flowers used in ophthalmia, bark } \\
\text { used for remove acidity, and } \\
\text { indigestion. }\end{array}$ \\
\hline
\end{tabular}

\begin{tabular}{|c|c|c|c|c|c|c|}
\hline 12. & Apang, Apamarg & Achyranthes aspera $\mathrm{L}$. & Amaranthaceae & $\begin{array}{l}\text { Perennial } \\
\text { Herb }\end{array}$ & $\begin{array}{l}\text { Entire } \\
\text { Plant }\end{array}$ & $\begin{array}{l}\text { Used in colic, piles, dropsy, } \\
\text { gonorrhoea pneumonia etc. }\end{array}$ \\
\hline 13. & $\begin{array}{l}\text { Aloe, } \\
\text { Ghritkumari, } \\
\text { Burn Plant }\end{array}$ & Aloe vera (L.) Burm.f. & Asphodelaceae & Shrub & $\begin{array}{l}\text { Whole } \\
\text { Plant }\end{array}$ & $\begin{array}{l}\text { Used as skin treatment. It helps } \\
\text { to heal wounds and burns. It } \\
\text { reduces dental plaque, } \\
\text { constipation, lowers blood sugar } \\
\text { level. }\end{array}$ \\
\hline 14. & Arjun / Arjuna & $\begin{array}{l}\text { Terminalia arjuna } \quad \text { (Roxb.) } \\
\text { Wight \& Arn. }\end{array}$ & Combretaceae & Tree & Bark & $\begin{array}{l}\text { Used in the treatment of wounds, } \\
\text { hemorrhages, ulcers, heart } \\
\text { diseases, \& relieves } \\
\text { hypertension }\end{array}$ \\
\hline 15. & $\begin{array}{l}\text { Cinnamon, } \\
\text { Daruchini }\end{array}$ & Cinnamon sp & Lauraceae & Tree & Bark & $\begin{array}{l}\text { Cough, bronchitis, common cold } \\
\text { problem. }\end{array}$ \\
\hline 16. & $\begin{array}{l}\text { Indian bay leaf, } \\
\text { tejpata }\end{array}$ & $\begin{array}{l}\text { Cinnamomum tamala } \\
\text { (Buch.- } \\
\text { Ham.) T.Nees \& C.H.Eberm. }\end{array}$ & Lauraceae & Tree & Leaves & Urinal problem, Blood urine \\
\hline 17. & Tentul & Tamarindus indica L. & Fabaceae & Tree & Bark & $\begin{array}{l}\text { Reduce pain in digestive track, } \\
\text { removes gases and effective in } \\
\text { dysentery. }\end{array}$ \\
\hline 18. & Jasthi madhu & Glycyrrhiza glabra L. & Fabaceae & $\begin{array}{l}\text { Perennial } \\
\text { Herb }\end{array}$ & $\begin{array}{l}\text { Root, } \\
\text { Leaves }\end{array}$ & $\begin{array}{l}\text { Cough, bronchitis , scalds of } \\
\text { head. }\end{array}$ \\
\hline 19. & Turmeric & Curcuma longa L. & Zingiberaceae & $\begin{array}{l}\text { Perennial } \\
\text { Herb }\end{array}$ & $\begin{array}{l}\text { Rhizome } \\
\mathrm{s}\end{array}$ & $\begin{array}{l}\text { Urinal problem, used to relieve } \\
\text { mild digestive problems, such as } \\
\text { feelings of fullness } \\
\text { and flatulence, skin diseases. }\end{array}$ \\
\hline 20. & Kalo Dhutra & Datura innoxia Mill. & Apocynaceae & Shrub & $\begin{array}{l}\text { Whole } \\
\text { Plant, } \\
\text { Root, } \\
\text { Leaves }\end{array}$ & $\begin{array}{l}\text { Used in dog bite, epilepsy, } \\
\text { dysentery. }\end{array}$ \\
\hline 21. & Akanda & Calotropis sp. & Apocynaceae & Shrub & $\begin{array}{l}\text { Root, } \\
\text { Leaves }\end{array}$ & $\begin{array}{l}\text { Used in cough, asthma, } \\
\text { dysentery. Cure leprosy, } \\
\text { leucoderma, ulcer, tumour. }\end{array}$ \\
\hline 22. & Sita-Ashok & $\begin{array}{ll}\text { Saraca asoka } & \text { (Roxb.) de } \\
\text { Wilde LN. } & \end{array}$ & Ceasalpiniaceae & Tree & $\begin{array}{l}\text { Leaf, } \\
\text { seed \& } \\
\text { roots }\end{array}$ & $\begin{array}{l}\text { It is best uterine tonic for strength } \\
\text { of uterus }\end{array}$ \\
\hline 23. & Cluster Fig, Gular & $\begin{array}{l}\text { Ficus racemosa L. Syb. F. } \\
\text { glomerata Roxb. LN. }\end{array}$ & Moraceae & Tree & $\begin{array}{l}\text { Root, } \\
\text { bark, fruit } \\
\text { \& latex }\end{array}$ & $\begin{array}{l}\text { Useful in measles, small pox and } \\
\text { chicken pox leaves juice in } \\
\text { jaundice }\end{array}$ \\
\hline 24. & $\begin{array}{l}\text { Arandi, Castor } \\
\text { Oil Plant }\end{array}$ & Ricinus communis L. LN. & Euphorbiaceae & Shrub & Leaves & $\begin{array}{l}\text { Used for headache. Keeps away } \\
\text { evil spirits, kajal prepared from } \\
\text { fruits is applied in eyes. }\end{array}$ \\
\hline 25. & Naagbal & Sida acuta Burm.f. LN. & Malvaceae & Weed & $\begin{array}{l}\text { Root, } \\
\text { seed \& } \\
\text { leaves }\end{array}$ & $\begin{array}{l}\text { Leaves in nervous \& urinary } \\
\text { disorders, in blood \& bile } \\
\text { disorders, in elephantiasis }\end{array}$ \\
\hline
\end{tabular}




\begin{tabular}{|c|c|c|c|c|c|c|}
\hline 26. & Bahera & $\begin{array}{l}\text { Terminalis belerica Roxb. } \\
\text { LN. }\end{array}$ & Combretaceae & Tree & Bark & $\begin{array}{l}\text { It is astringent tonic use, manage } \\
\text { loss of appetite, thirst, bloating } \\
\text { and flatulence }\end{array}$ \\
\hline 27. & Aswagandha & $\begin{array}{l}\text { Witnania coagulans Dunal } \\
\text { LN. }\end{array}$ & Solanaceae & Shrub & $\begin{array}{l}\text { Leaves, } \\
\text { roots }\end{array}$ & $\begin{array}{l}\text { Used in uterine disorders, it can } \\
\text { boost brain function, lower blood } \\
\text { sugar and cortisol levels, and } \\
\text { help fight symptoms of anxiety } \\
\text { and depression. }\end{array}$ \\
\hline 28. & Neem & Azadirachta indica LN. & Meliaceae & Tree & All parts & $\begin{array}{l}\text { Used for heart and blood } \\
\text { vessels, liver problems, skin } \\
\text { diseases, appetite, diabetes. }\end{array}$ \\
\hline 29. & Bel, Wood Apple & $\begin{array}{l}\text { Aegle marmelos } \quad \text { Corr. ex } \\
\text { Roxb. LN. }\end{array}$ & Rutaceae & Tree & $\begin{array}{l}\text { Leaves, } \\
\text { bark, } \\
\text { fruit, } \\
\text { seeds }\end{array}$ & $\begin{array}{l}\text { It is beneficial in treating } \\
\text { tuberculosis, hepatitis, ulcer and } \\
\text { digestive problems, \& in treating } \\
\text { cholera. }\end{array}$ \\
\hline 30. & Punarnaba & Boerhhavia sp. & Nyctaginaceae & Creeping & Root & $\begin{array}{l}\text { Used in cough, alcoholism } \\
\text { anaemia, jaundice, it } \\
\text { simulates rheumatoid arthritis , } \\
\text { intestinal colic, kidney disorders, } \\
\text { skin diseases, , insomnia, } \\
\text { asthma. }\end{array}$ \\
\hline
\end{tabular}

\section{CONCLUSION}

Ethnomedicine or indigenous medicine has its immense value and medicinal significance. But traditional medicinal knowledge or traditional practices of treatment needed to explore and popularized for vast uses specially for poor and economically less developed population. These practice not only safe, affordable for folk people but also helpful for conservation and protect our biodiversity from our modern-day urbanization and industrialization.

\section{ACKNOWLEDGEMENT}

The authors express their sincere thanks to Department of Biotechnology, Government of India for the funding from DBT-STAR College grant, under which this review project was conducted. We are also grateful to the Principal and the DBT-STAR Coordinator, Surendranath College, for their support and encouragement in implementing this review project at undergraduate level.

\section{REFERENCES}

Chakraborty, M. K., \& Bhattacharjee, A. (2006). Some common ethnomedicinal uses for various diseases in Purulia district, West Bengal. Indian Journal of Traditional Knowledge, 5(4), 554-558.

Das, D., \& Ghosh, P. (2017). Some important medicinal plants used widely in Southwest Bengal, India. International Journal of Engineering Science Invention, 6(6), 28-50.

Ghosh, A. (2008). Ethnomedicinal plants used in west Rarrh region of West Bengal. Natural Product Radiance 7(5), 461-465.

Jain, A. K. (2016). Indian Ethnobotany: Emerging Trends (Dr. S.K. Jain Felicitation Volume), 24, 64-68.

Mandal, P., \& Sivaramakrishnan, L. (2014). Vulnerability of flood prone communities in the lower reaches of Shilai river-Ghatal Block, Paschim Medinipur District, West Bengal, India. International Journal of Development Research, 4(7), 1393-1400.

Mondal, K., Paul, A., \& Haque, S. (2015). Ethnobiological and traditional medicine practices in Burdwan district, West Bengal, India. International Journal of Ethnobiology \& Ethnomedicine, 1(1), 1-8.

Mukherjee, P. K. (2003). GMP for Indian systems of Medicine. Business Horizons, New Delhi, 99, 112.

Prakasha, H. M., Krishnappa, M., Krishnamurthy, Y. L., \& Poornima, S. V. (2010). Folk medicine of NR 
Pura Taluk in Chikamaglur district of Karnatka. Indian Journal of Traditional Knowledge, 9(1), 55-60.

Rahaman, C. H., \& Karmakar, S. (2015). Ethnomedicine of Santal tribe living around Susunia hill of Bankura district, West Bengal, India: The quantitative approach. Journal of Applied Pharmaceutical Science, 5(02), 127-136.

Tripathi, S., Ray, S., Mondal, A. K., \& Verma, N. K. (2013). Rare Ethno-Medicinal Plants of South West Bengal, India with their Different Medicinal Uses: Needs Conservation; International Journal of Life Sciences Biotechnology and Pharma Research, 2(2), 114-122. 


\title{
Monoclonal Antibody in Cancer Therapy: Overview
}

\author{
Himadri Chakraborty, Mainak Mukherjee, Subhadra Roy* \\ Department of Zoology, Surendranath College, Kolkata, India \\ *Corresponding Author's Email: roysubhadra40@gmail.com
}

\begin{abstract}
The use of monoclonal antibodies in recent years has achieved a considerable success in cancer therapy. Presently, along with surgery, radiation and chemotherapy, monoclonal antibody (mAb) based immunotherapy is regarded as an important mode of cancer therapy. During the last few decades, many monoclonal antibodies have been approved for cancer treatment. Though ADCC (antibody dependent cellular cytotoxicity) is regarded as the main mechanism of monoclonal antibody action, several modifications and improvements were made to the monoclonal antibodies to eradicate their side effects. A wide range of modifications and improvements have been to optimize the already prevailing systems. The multifaceted properties of mAbs and their simultaneous induction of longlasting anti-tumor response as a therapeutic platform have given rise to newer strategies to fight cancer. The antigens and their receptors are overexpressed in cancer cells through various databases. Therefore, advanced studies using various techniques is the need of the hour for managing the disease. Our study focuses on categories, action mechanisms and clinical applications of the mAbs for cancer therapy. Cancer serology, resistance mechanism and tumor escape mechanism of mAbs have also been discussed here.
\end{abstract}

Keywords: Monoclonal Antibody; Cancer Serology; Therapy; ADCC

\section{INTRODUCTION}

Cancer treatment using monoclonal antibodies has reached a remarkable height of success in the past few years. Over the past two decades, antibody mediated therapy for treating the cancer has been considered as an important and most strategy strategies especially for the patients having hematological malignancies and solid tumors. Monoclonal antibodies are produced by fusing spleen cells from a rat which are immunized with a specific antigen and a mouse myeloma cell line. This is called Hybridoma technology.

However, trials with mouse mAbs had some drawbacks, they became more ineffective with repeated applications as the half-life of the antibody decreased during clinical trials. This happened due to the development of a human-anti-mouse antibody (HAMA) response in patients. In the late 1980s, "Fullyhuman" antibodies were derived from transgenic mice or yeast or phage systems. So, as a result of these innovations of antibody engineering, monoclonal antibodies proved effective in the treatment of cancer. In this paper we review the role of monoclonal antibodies in cancer therapy and its limitations.

\section{LITERATURE REVIEW AND DISCUSSION}

\section{Monoclonal antibodies and their types:}

Currently, various types of mAbs have been produced through antibody engineering. Although many of these antibodies share similar principles, they vary in targets and applications.

\section{Murine mAbs:}

Murine antibodies generally do not stimulate profound cytotoxicity but allergic reactions and anaphylactic shock may be induced by their repeated administration. Anti-CD3 mAb was initially approved for human treatment, but it was reported to be a great failure (Anasetti et al., 1990). Murine mAbs which contain some foreign protein molecules, stimulates unfavourable responses in human patients during clinical use. 


\section{Chimeric mAbs:}

Special type antibodies from humans and non-humans (mice) combinations were the chimeric antibodies. They were produced by manipulation of mouse variable regions and human constant regions (Mendelsohn, 2001). 65\% of human genetic components are used in these antibodies in order to minimize the unfavourable responses to foreign substances.

\section{Humanized mAbs:}

Humanized antibodies, are about $95 \%$ from human origin. Human mAbs have been recognized as natural drugs because of the safety in their usage (Marabelle \& Gray, 2015). Daclizumab, omalizumab etc. are some examples of humanized antibodies which are approved by FDA.

\section{Fully human mAb:}

It is difficult to produce fully human mAb by the conventional Hybridoma techniques. However, eventually techniques were developed to produce human mAbs. The most well- established and most commonly used technique for the development of new human antibodies is the phage display technique., The first fully human mAb drug, Humira, was launched for the treatment of rheumatoid arthritis in the year 2003 (Lang, 2007).

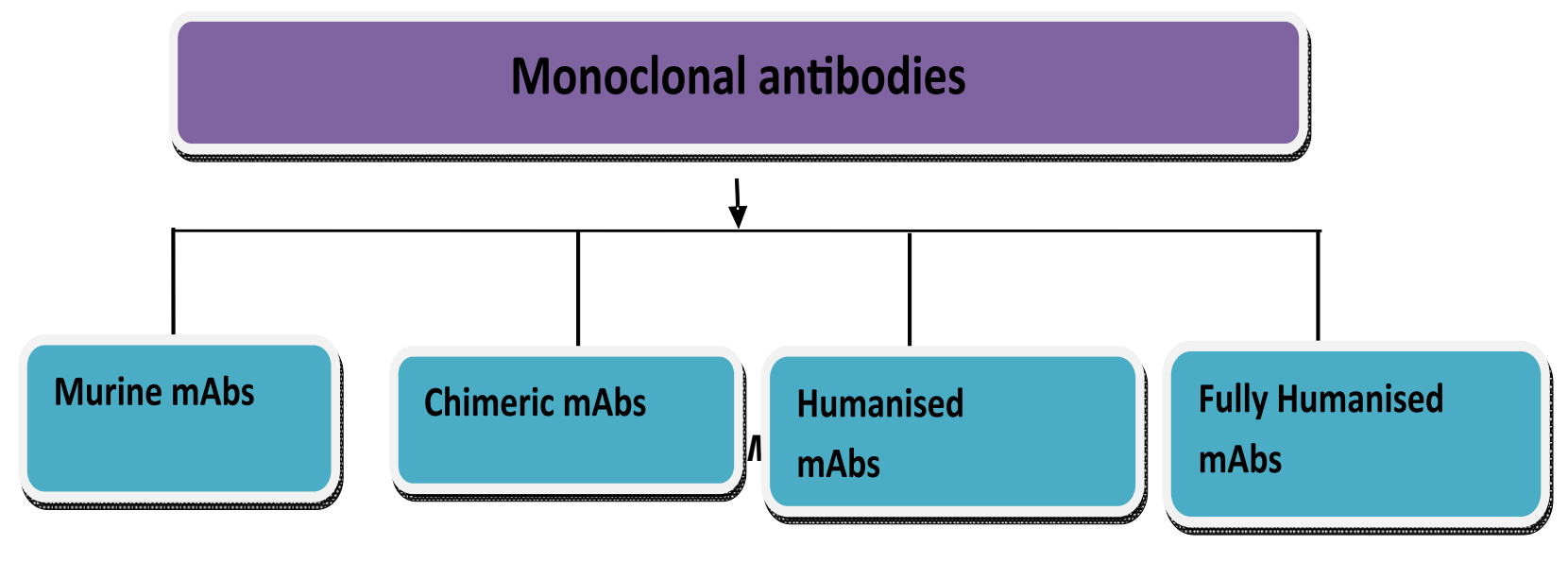

\section{Cancer serology:}

In the past, with the aim of producing cancer specific antisera, many animal species were immunized with human cancers (Leach, Krummel \& Allison, 1996). The discovery of the colon cancer markercarcinoembryonic antigen (CEA) and other markers like $\alpha$-fetoprotein had led to great progression in serological cancer investigation.

\section{Tumor antigens as antibody targets:}

The most important criteria of a tumor antigen to be the target antigen of monoclonal antibodies are that they must be accessible, expressed in high numbers and homogeneously, on the cancer cell surfaces. Also, the presence of the target antigen should be consistent and exclusive. Apart from the above-mentioned conditions, the Fc region should be easily available to immune effector cells and complement proteins. Some such tumour-associated antigens include CD20, CD30, CD33 and CD52. In some cases, mAbs target growth factors and growth factor receptors in patients. They include CEA2, ERBB2, ERBB, MET and insulin-like growth factor 1 receptor (Vermi et al., 2018).

\section{Clinical uses of monoclonal antibody:}

Many types of mAb-derived treatments are being used clinically over the last few years. CD-20, found specifically in abundance on cancerous B-cells was the first target utilized in mAb associated therapy (de Haij et al., 2010). A chimeric murine/human monoclonal lgGl antibody called Rituximab could target 
the CD20 B-cell surface antigen thereby mediating its lysis. Trastuzumab, a humanized IgG1 monoclonal antibody is used in treating breast cancer and gastric cancer. The mAbs like Bevacizumab (Printz, 2010), and Ranibzumab, are used to inhibit tumor-mediated angiogenesis. Other mAbs which are used in cancer immunotherapy are Pentuzumab, Ramucimumab, Olaratumab etc.

\section{Mechanisms of Tumor escaping:}

Tumor cells often escape the therapeutic effects of monoclonal antibodies. There are many reasons for such lack of tumor cell response to antibody treatment. Lack of therapeutic response in many cases may be due to mutation, heterogeneity in antigen or receptor size and affinity of antibody, permeability of blood vessels, low antibody-antigen ratio etc.

\section{Combination Therapies of mAbs:}

Success of monoclonal antibodies are seen when they are combined with chemotherapy or radiation. Few such approved combinations are combinations of Anti PD-1/PDL-1 with cetuximab In HNSCC patients (Giuliani \& Marzola, 2014) and combination of Ipilimumab and anti-PD1 in metastatic melanoma patients (Li, 2021).

\section{CONCLUSION}

Inspite of being ineffective and intolerable in the case of first mAb which was approved for humans, today monoclonal antibody therapy has occupied an important position in the treatment of malignant cancers. The evolution of modified mAbs have improved their effectiveness and made the antibodybased drugs biosafe. Trials for combination therapies have demonstrated the encouraging pathways and need to be optimized for maximizing the clinical efficiency of mAb therapy. Further studies are necessary to be made on the aspects of mutations of tumor-associated target antigens and antibodies through research. Thus, future studies may help to establish mAbs as therapeutics for treating cancer.

\section{ACKNOWLEDGEMENT}

The authors express their sincere thanks to Department of Biotechnology, Government of India for the funding from DBT-STAR College grant, under which this review project was conducted. We are also grateful to the Principal and the DBT-STAR Coordinator, Surendranath College, for their support and encouragement in implementing this review project at undergraduate level.

\section{REFERENCES}

Anasetti, C., Tan, P., Hansen, J. A., \& Martin, P. J. (1990). Induction of specific nonresponsiveness in unprimed human $\mathrm{T}$ cells by anti-CD3 antibody and alloantigen. The Journal of experimental medicine, 172(6), 1691-1700.https://doi.org/10.1084/jem.172.6.1691

de Haij, S., Jansen, J. H., Boross, P., Beurskens, F. J., Bakema, J. E., Bos, D. L., Martens, A., Verbeek, J. S., Parren, P. W., van de Winkel, J. G., \& Leusen, J. H. (2010). In vivo cytotoxicity of type I CD20 antibodies critically depends on Fc receptor ITAM signaling. Cancer research, 70(8), 3209-3217. https://doi.org/10.1158/0008-5472.CAN-09-4109

Giuliani, J., \& Marzola, M. (2014). Cetuximab/cisplatin and radiotherapy in HNSCC: is there a favorite choice? Open Medicine, 9(2), 279-284.

Lang, L. (2007). The food and drug administration approves Humira. Gastroenterology, 132(5), 16441645.https://doi.org/10.1053/j.gastro.2007.04.004

Leach, D., Krummel, M., \& Allison, J. (1996). Enhancement of Antitumor Immunity by CTLA-4 Blockade. Science, 271(5256), 1734-1736. https://doi.org/10.1126/science.271.5256.1734

$\mathrm{Li}, \mathrm{M}$. (2021). Ipilimumab versus ipilimumab plus anti-PD-1 for metastatic melanoma. The Lancet Oncology, 22(8), e342. https://doi.org/10.1016/s1470-2045(21)00326-0 
Marabelle, A., \& Gray, J. (2015). Tumor-targeted and immune-targeted monoclonal antibodies: Going from passive to active immunotherapy. Pediatric Blood \& Cancer, 62(8), 1317-1325. https:// doi.org/10.1002/pbc.25508

Mendelsohn, J. (2001). The epidermal growth factor receptor as a target for cancer therapy. EndocrineRelated Cancer, 8(1), 3-9. https://doi.org/10.1677/erc.0.0080003

Printz, C. (2010). Study comparing bevacizumab plus temsirolimus versus bevacizumab plus interferon$\alpha$ in advanced renal cell carcinoma subjects (INTORACT). Cancer, 116(14), 3309-3309. https://doi.org/10.1002/cncr.25497

Vermi, W., Micheletti, A., Finotti, G., Tecchio, C., Calzetti, F., Costa, S., Bugatti, M., Calza, S., Agostinelli, C., Pileri, S., Balzarini, P., Tucci, A., Rossi, G., Furlani, L., Todeschini, G., Zamò, A., Facchetti, F., Lorenzi, L., Lonardi, S., \& Cassatella, M. A. (2018). slan+ monocytes and macrophages mediate CD20-dependent B cell lymphoma elimination via ADCC and ADCP. Cancer Research, canres.2344.2017. https://doi.org/10.1158/0008-5472.can-17-2344 


\title{
Review on Ruthenium (II) Anticancer Complexes: Challenges and Expectation
}

\author{
Rajdeep Chakraborty, Arijit Banerjee, Lalita Das* \\ Department of Chemistry, Surendranath College, Kolkata, India \\ ${ }^{*}$ Corresponding Author's Email: das.lalita1@gmail.com
}

\begin{abstract}
"Once cancer happens it entirely changes the way of living for rest the life." This statement is sufficient to show how dreadful cancer is. Cancer one of the huge killers in the universe from years. Several FDA approved anticancer drugs are organic molecules, while metal containing drugs are very less. Platinum based drug cisplatin, first metal based therapeutic design, launched a new era in the application of transition metal complexes for therapeutic design. In recent times Ruthenium based compounds have emerged as a promising anticancer agent that serve as an alternative to cisplatin and its derivatives, due to its versatile and unique biochemical properties. Over the past few decades ruthenium (III) complexes have successfully been used in clinical research and their action of mechanisms of anticancer have been reported in large volumes. Ruthenium (II) complexes have lured many attentions as anticancer candidate; however, only one or two complexes have been reported comprehensively. This review mainly focuses to show the new approach towards the field of metal based anticancer drugs. This review will focus on a short discussion on platinum therapies, a brief history of ruthenium anticancer compounds, followed by a study on ruthenium-DMSO complexes and, in particular, on NAMI-A. Many challenges are faced in this field from how to develop new ruthenium anticancer compound to how to select new active compound with clear anticancer activity.
\end{abstract}

\section{Keywords: Antimetastatic; Anticancer DMSO; Medicinal Inorganic Chemistry; Ruthenium}

\section{INTRODUCTION}

Cancer could be a major health burden within the world. Although many breakthroughs in biological targeted approaches have occurred, there's a necessity for the event and innovation of potential anticancer agents. In this virtue, metal complexes hold potential as novel anticancer agents for a large number of cancer types (Shi et al., 2015; Benjamin Garbutcheon-Singh et al., 2011; Li, Collins \& Keene, 2015;Muhammad \& Guo, 2014; Suntharalingam, Song \& Lippard, 2014 \& Liu et al., 2016). This space is currently addressed with the utilization of platinum (II) coordination complexes, namely Cisplatin or cis-diamminedichloroplatinum (II) is the most generally known metal-based anticancer drug. Cisplatin is very effective against head, lung, ovarian, neck, and oesophageal cancers (Chu,1994 \& Cepeda et al., 2007). Such platinum agents lack cellular selectivity and particularly liable to off-target effects, like peripheral neuropathy, baldness and myelotoxicity in patients(Sledge et al., 1988; Arany \& Safirstein, 2003; Florea \& Büsselberg, 2011; Galluzzi et al., 2012; Suntharalingam, Song \& Lippard, 2014; Graf et al., 2014). The resistance of tumours to platinum reduces the effectiveness of platinum-based or perhaps renders them ineffective, causing treatment failure (Dhar et al., 2008a; Dhar et al., 2008b; Fong et al., 2016 \& Cao et al., 2016).Within the design of latest anticancer drugs, the interest in ruthenium (II/III) complexes has increased considerably (Abid, Shamsi, \& Azam, 2016; Schmid et al., 2007; Romero-Canelón, Salassa \& Sadler, 2013; Liu et al., 2010 \& Ye et al.,2014). Ruthenium complexes are tested against variety of neoplastic cell lines, and considered as the promising candidates for alternative drugs to cisplatin and its derivatives (Zhang \& Lippard, 2003; Kostova, 2006; Smith \& Therrien 2011; Liu et al., 2016; Furrer \& Süss-Fink, 2016; Levina, Mitra \& Lay, 2010 \& Hartinger et al., 2008). This review will provide its reader with a sway of the recent development of ruthenium complexes as a promising anticancer agent (particularly NAMI-A). 


\section{REVIEW LITERATURE AND DISCUSSION}

\section{Platinum Therapies}

From past few decades, within the field of metallo-anticancer therapies has been influenced by the dear metal Platinum. In the year 1965, at Michigan State University, Barnett Rosenberg during an experiment discovered the anticancer properties of Platinum. Rosenberg by employing a Platinum electrode applied an electrical field to a community of E. coli, which slow down their growth. An investigation was done, which concluded that the platinum electrode breaks all the way down to generate platinum (II) ion in place, which was inhibiting the cells from multiplying. These observations led to cis-diamminedichloroplatium (II), commonly referred to as cisplatin. In 1978, Cisplatin was approved by FDA (American Food and medicines Administration) for the treatment of cancer. Since then, it becomes a widely used anticancer drug. Approximately, $70 \%$ of world's cancer patients receive this compound as a part of their treatment (Dorcier et al., 2006).
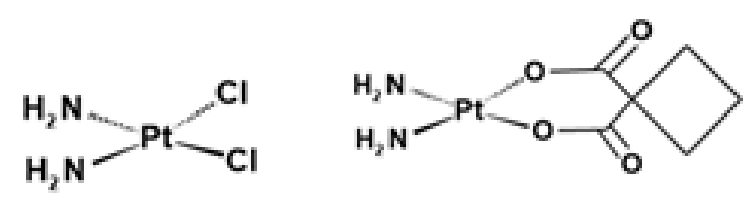<smiles>O=C1OC2(NC3CCCCC3N2)OC1=O</smiles>

Figure 1: The Structure of Cisplatin[a], Carboplatin[b], and Oxiplatin[c] Takahara, Frederick \& Lippard1996

\section{Cisplatin}

Cisplatin or cis-( $\mathrm{PtCl} 2(\mathrm{NH} 3) 2)$ was a unique kind of anticancer drug, and its discovery given a lead to a group of scientist and researchers to perform tests on other valuable metal-based therapies. However, after endless clinical candidates and diverse research work, disappointingly in the world of metal containing anticancer drugs, there are only two more world-wide drug approval. Analogues of cisplatin namely carboplatin and Oxiplatin were approved by FDA in the year of 1993 and 2003 respectively.

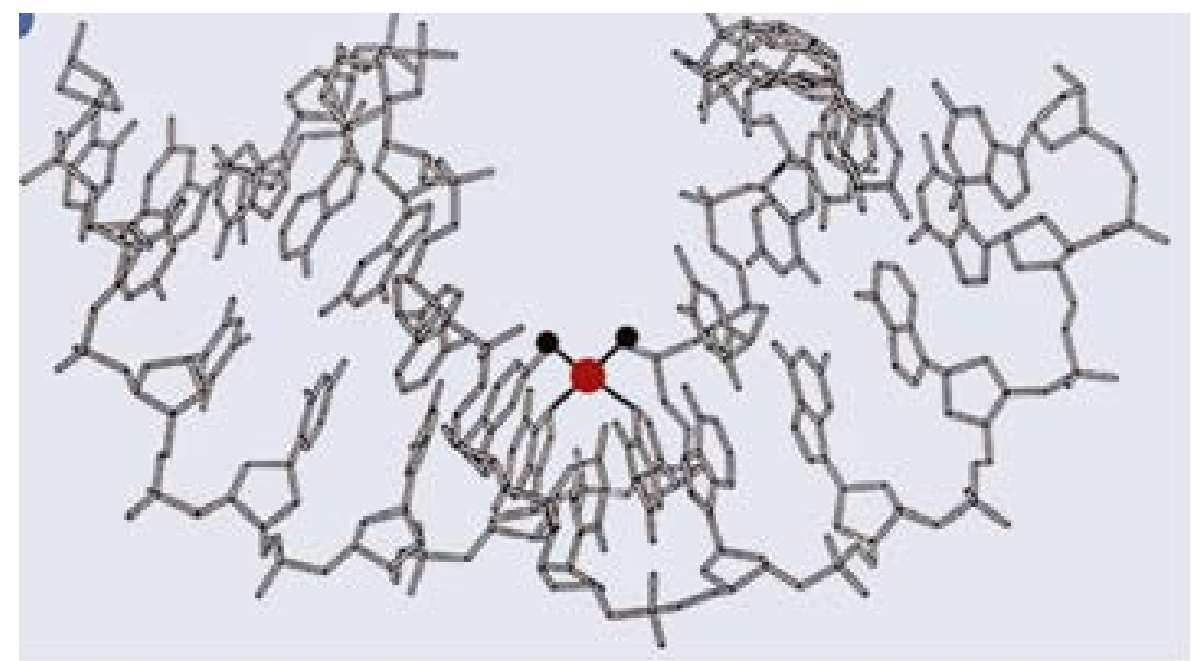

Figure 2: A Crystal Structure Showing Cisplatin (Red) Binding to DNA (Grey) (Takahara, Frederick \& Lippard1996) 
The mechanistic action of platinum-based anticancer drugs within the cell, a bis-aqua species is formed by the hydroxylation of the chloride or dicarboxylate ligands. The formation of bis-aqua species leads to the binding of two adjacent guanine bases of DNA irreversibly (Fig 2) (Takahara, Frederick \& Lippard 1996).

\section{From Platinum to Ruthenium}

Platinum complexes by no means could be a perfect drug, though its chemotherapeutic success is undeniable. it's not effective against several kinds of cancer. The resistance in effectiveness of the drug is common. It also features a big selection of aftereffects, that are nerve damage, hair loss and nausea.

To avoid these side effects, scientists have developed compounds supported ruthenium and tested against neoplastic cell. Result shows that this ruthenium-based compounds tend to causeless damage to body compared to platinum drugs.

In pharmacological application properties of ruthenium are similar temperament. It can avail a variety of oxidation states (II, III and IV) and also it has relatively low energy barriers to interconversion between these oxidation states, allowing smooth conversion of oxidation states in the cell. Ruthenium complexes shows relatively low ligand exchange rates in water (Fig 3), thanks to flexibility in oxidation states.

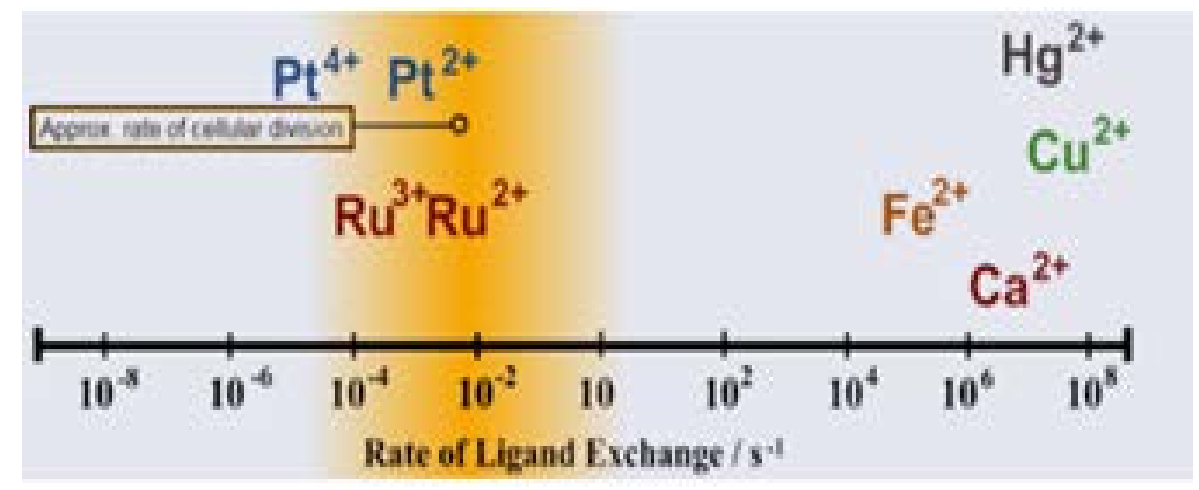

Figure 3: The Ligand Exchange Rates of Platinum Group Metals are Considerably

Ruthenium has the ability to make octahedral complexes, which allows the chemists to introduce more two ligands to take advantage. Whereas, platinum (II) complexes only adopt a square planar geometry. Ruthenium can bind to a spread of biomolecules, not only DNA. Ruthenium can form strong chemical bonds with many various elements of different chemical properties and electrone gativity (Schluga et al., 2006).

\section{Less Toxicity of Ruthenium}

Out of many assumptions, one assumption is that why platinum drugs are more toxic than ruthenium compounds are 'Activation by Reduction'. In keeping with this theory, ruthenium (II) complexes are less inert than ruthenium (III), which may be partially inherent due to its greater effective nuclear charge (Zeff). Chemically cancer cell needs a reduced environment than healthy cells, because their molecular oxygen concentration is low (due to unavailability from the blood supply). By considering the above two factors parallelly, ruthenium (III) (inert) causes a minimum damage to healthy cells, but when reduced to ruthenium (II) (active) causes heavy damage to the cancer cell lines (Vincent \& Love, 2012). At last, ruthenium has the ability to copy iron in binding with several biological molecules, such as proteins (e.g., albumin and transferrin) which contribute to the overall low toxicity of ruthenium drugs.

\section{Chemical Features of Ruthenium Compounds}

\section{Main chemical features of Ruthenium compounds are as follows}

II, III and IV are the oxidation states that can be achieved by ruthenium. But only two oxidation states are chemically accessible for ruthenium compounds, which are relevant for biological activities. The 
ruthenium (II) (diamagnetic, d6) and ruthenium (III) (paramagnetic, d5) are the oxidation states that are possible to access by ruthenium (Bergamo \& Sava, 2007). With both the oxidation states ruthenium ion have six-coordinate with octahedral geometry. It shows good affinity towards sulphur and nitrogen ligands. As mentioned earlier that due to higher nuclear effective charge Ru (II) species is less inert than $\mathrm{Ru}$ (III) species. When a good $\pi$-acceptor ligand is present in air, $\mathrm{Ru}$ (II) species will remain unoxidized. Elaborately, ruthenium and platinum (II) complexes have more or less similar kinetics for ligand exchange.

In order to exert the anticancer activity, active ruthenium compounds have to coordinate with some biological target. Platinum drugs (prodrugs) should undergo an activation process which leads to the metabolites which are real active species. To understand the activity of some inert ruthenium (III) chloroammine compounds (such as cis- $\left(\mathrm{RuCl}_{2}\left(\mathrm{NH}_{3}\right)_{4}\right)$ Clandfac- $\left(\mathrm{RuCl}_{3}\left(\mathrm{NH}_{3}\right) 3\right)$ ), scientists concluded that reduction takes place followed by hydrolysis (activation by reduction hypothesis) (Clarke, Zhu, F \& Frasca, 1999). This activation pathway is selective against solid tumours which are hypoxic, the reduction of ruthenium (III) to ruthenium (II) should facilitated by insufficient circulation and having more reducing environments compared to normal tissues. Other source to tumour selectivity for $\mathrm{Ru}$ compounds is derived by their capability to bind with transferrin (serum protein). Compared to normal tissues, the tumour cell often express transferrin receptors excessively, due to their excessive iron uptake and a transferrin-mediated uptake have been evidenced for some ruthenium species (Clarke, 2002; Giaccone, 2000; Lippard et al., 2003; Habtemarium et al., 2005).

\section{History}

Historically, the chloro-ammine-ruthenium (III) compounds are primary ruthenium complexes to be studied for its anticancer activity. It is the ruthenium analogues of chloro-ammine-platinum compounds. In the year of 1980 Clarke along with his co-workers reported anticancer behaviour for fac- $\left(\mathrm{RuCl}_{3}\right.$ $\left.\left(\mathrm{NH}_{3}\right)_{3}\right)$ in mice models (Fig 4). fac- $\left(\mathrm{RuCl}_{3}\left(\mathrm{NH}_{3}\right)_{3}\right)$ was not proceeded further, due to its negligible solubility which prevents it from adequate formulation as a drug (Clarke, Zhu \& Frasca 1999).

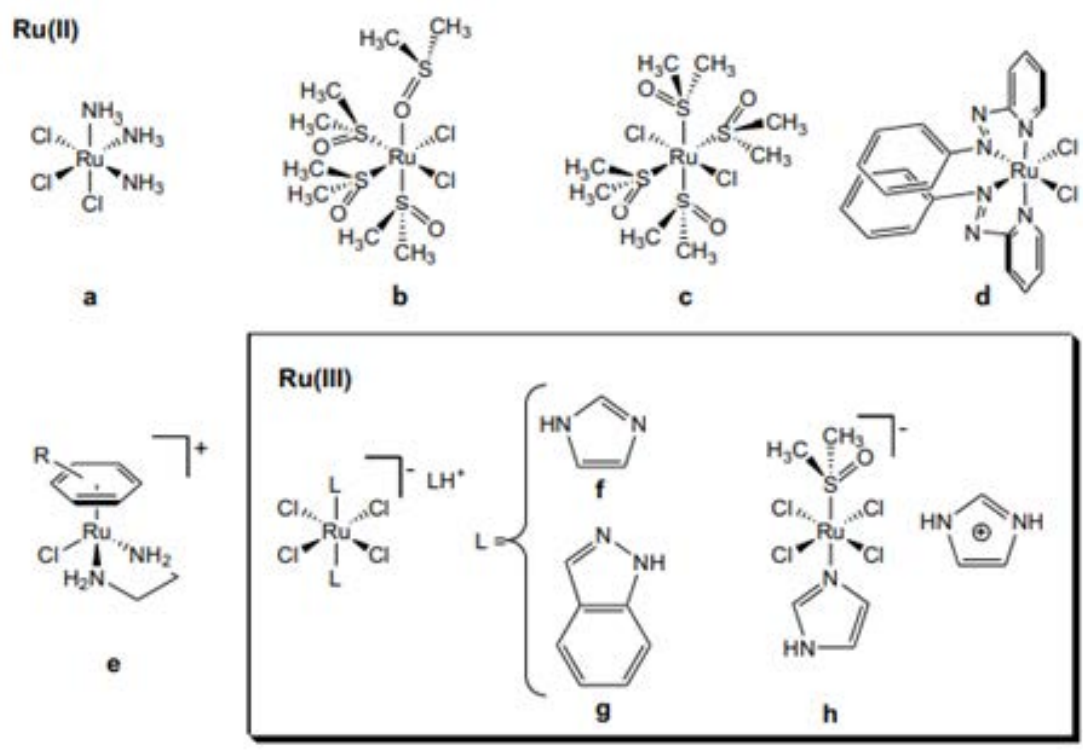

Figure 4 Structures of some ruthenium(II) and ruthenium(III)(inset) complexes that shows anticancer activity: [a] fac [RuCl $\left.3\left(\mathrm{NH}_{3}\right)_{3}\right] ;$ [b] cis-[RuCl (dmso) $\left._{4}\right]$; [c] trans-[RuCl (dmso) $\left._{4}\right]$; [d] cis-[RuCl (azpy) $_{2}$ ]; [e] organometallic compounds of

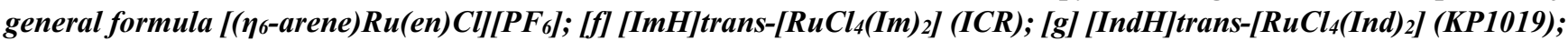
[h] [ImH]trans-[RuCl $4(\mathrm{Im})($ dmso-S)] (NAMI-A) (Keppler, 1993; Sava, Alessio \& Bergamo 1999; Alessio et al. , 2004; Groessl et al., 2007) 
4 years passed after the studies of fac- $\left(\mathrm{RuCl}_{3}\left(\mathrm{NH}_{3}\right)_{3}\right)$ was done, Mestroni and his team studied for the anticancer behaviour of a most commonly known ruthenium (II) complex, cis- $\left(\mathrm{RuCl}_{2}(\mathrm{dmso}) 4\right)(1, \mathrm{dmso}$ = dimethyl sulfoxide, Fig 4) (Mestroni et al., 1994.). When compared to cisplatin, compound 1 is noncytotoxic invitro and moreover, it possesses toxicity a minimum of three order of magnitude below that of platinum-based drug cisplatin. In mice bearing solid metastasing tumours, 1 showed activity against the first tumour and also in the metastases, when given at a most tolerated dose. Several studies show that the activity of ruthenium complex was similar to that of cisplatin but have an overall less host toxicity. The above results showed us a way to carry out scientific investigation of the anticancer activities of ruthenium-dmso complexes (Mestroni et al., 1994.). In the year of 1989 the trans isomer of ruthenium (II) complex $\left(\mathrm{RuCl}_{2}(\mathrm{dmso})_{4}\right)$ (2, Fig 4) was more active than the former cis isomer 1 against lung carcinoma, a tumour with metastases. On molecular basis the cis isomer is less toxic than the trans isomer. Although trans isomer is more toxic, it is more practical in reducing the mass and amount of the ongoing metastases which is caused from the first tumour. Many experiments were carried out in which the tumour was removed surgically. Experimental studies showed us that when treated in mice the postsurgical survival time was more effective for compound 2 than platinum-based drug cisplatin. In other words, trans- $\left(\mathrm{RuCl}_{2}(\mathrm{dmso})_{4}\right)$ have more selective activity against metastases, while in reducing the first tumour, cisplatin was more active (Mestroni et al.,1994). Later on, other ruthenium-dmso complexes also showed this feature.

The 80s showed a primary breakthrough in field of anticancer drug containing ruthenium: Keppler and his co-workers revealed (IndH)trans- (Ind)RuCl $\mathrm{R}_{4}$ (Ind) (KP1019, Ind = indazole)and (ImH)trans(Im)RuCl 4 (Im) (ICR, Im=imidazole) (Fig 4) were two isostructural ruthenium (III) complexes that are active against variety of tumour model(Alessio et al., 2004.). These results supported the essential premise of this field, i.e., that active complexes which does not have platinum centre, will be effective against platinum-resistant tumours, and further researches were proceeded. In the same year, while working on the preparation of the ruthenium (II) isomers 1and 2, we isolated and characterized thedmso analogue of Keppler's compounds, (dmso) $\mathrm{H}(\mathrm{dmso}))$ trans-( $\left.\mathrm{RuCl}_{4}(\mathrm{dmso}-\mathrm{S})_{2}\right)$. This compound, is not suitable for biological testing because of its very rapid hydrolysis at physiological $\mathrm{pH}$, proved to be an excellent successor for ruthenium (III) compounds bearing both dmso and heterocyclic $\mathrm{N}$-ligands (L).

In early 90s scientists and researchers reported that $(\mathrm{Na})$ trans- $((\mathrm{Im}) \mathrm{RuCl} 4$ (dmso-S) (NAMI), which is structurally just like ICR having admso with $S$ ligand that replaces an imidazole, is active against solid metastasizing tumours in mice (Keppler, 1993).Further, NAMI was replaced in pre-clinical trials by its imidazolium salt, (ImH)trans- (Im) $\mathrm{RuCl}_{4}(\mathrm{dmso}-\mathrm{S})$, called NAMI-A (Fig 4), which is an asset with the identical antimetastatic properties butis a more reproducible and stable solid and consequently is more fitted to further development in clinical phase. NAMI-A is capable of effectively restricting the development and growth of pulmonary metastases. Within the mouse which includes the non-small cell carcinoma in human tumour is xenografted in all mentioned experimental models of solid tumour were tested in vivo. Conversely, its activity towards the first tumour and cytotoxicity are negligible when compared to those of platinum-based anticancer drug. For instance, cisplatin is toxic against cellcultures at micro molar $(\mu \mathrm{M})$ concentrations, while NAMI-A is void of toxicity up to milli molar (mM)concentrations.

After many preclinical tests, in the year of 1998 NAMI-A began clinical trials in European countries. Cancer Institute of Amsterdam became the first to begin clinical trials of NAMI-A. NAMI-A cleared this evaluation with great result. 24 patients were tested, all showed good tolerance over a good range of sub-toxic dose with no unexpected toxicity. Although there is no side effect but there form painful blisters, which was considered as to limit the dose of drug. $300 \mathrm{mg} / \mathrm{m}^{2} /$ day was determined to be advised dose for further testing (Sava, Alessio \& Bergamo, 1999.). Currently NAMI-A will begin phase 12 clinical trials.

In early $21^{\text {st }}$ century, KP1019, developed by Keppler and his colleagues, entered inti phase 1 clinical 
trials (Alessio et al., 2004). This compound is barely moderately toxic in I cell culture tests, similar to NAMI-A. Presently, a pure new category of ruthenium (II) compounds was developed. Associates of Reedijk showed us that complexes with bidentate heterocyclic $\mathrm{N}$-ligands like cis- $\left(\mathrm{RuCl}_{2}(\mathrm{azpy})_{2}\right)$ (azpy $=$ 2-phenylazopyridine (Fig 4) possess significant toxicity (Alessio et al., 2004.). Groups of Sadler (Sadler et al., 1999; Sadler et al., 2007.) and Dyson (Ang et al., 2006 \& Vock et al.,2007.) developed Organometallic ruthenium (II)-arene compounds, which were found to possess in vivo activity. Particularly compounds with general formula (RuCl(n6-arene) (en)) ( $\left.\mathrm{PF}_{6}\right)$ (en =ethylenediamine) developed by the team of Sadler (Fig 4) showed faithful anti-cancer activity, both in vivo against animal tumour models and in vitro against human cancer cell lines.

\section{NAMI-A}

NAMI-A is a ruthenium anticancer complex that has entered clinical trials (Kostova, 2006; Lentz et al., 2009). The trivial name NAMI is not considered as the abbreviation of "New Anticancer Metastasis Inhibitor", but it bears a reasonable origin. It was formed as an acronym of the chemical formula of the complex: "NA" originated from the symbol of sodium and "MI" from the word imidazole. NAMI-A is the corresponding imidazolium salt. NAMI-A is nothing but are formed version of the prototype NAMI (Gou et al., 2017) (Fig 5).
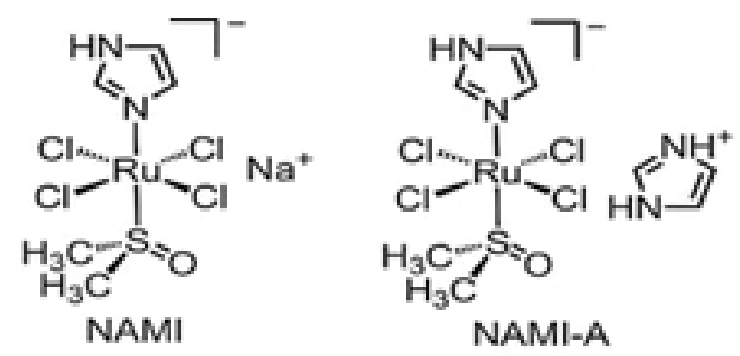

Figure 5: NAMI and NAMI-A

NAMI-A is primarily based for the use of the ruthenium metal. Ruthenium is not known to the living ecosystem; it has an ability to form strong complexes with numerous ligands (Gopal, Jayaraju \& Kondapi,1999). The ability to form complexes by NAMI-A is due to its partially filled $4 \mathrm{~d}$ sub-shell. This complex forming ability makes it useful for a vast range of applications including electronics, photochemistry, catalysis, biosensor and anticancer drugs (Kostova, 2006 and Antonarakis \& Emadi, 2010). Ruthenium has a greater resistance to hydrolysis, unlike traditional platinum complexes. It has also more selective action on tumours than platinum-based drugs.

The mechanistic action of NAMI-A (mostly unknown), is not related to direct tumour cell toxicity, hence it is responsible for decreased toxicity in host cell of this drug. NAMI-A in cell free medium is able to interact with DNA (similar to any d-block metal which is not fully inert). Nuclear DNA is not the obvious target of this drug. Thus, the working mechanism of action of this ruthenium (III) drug is readily distinguishable from platinum-based anticancer drug. Several features of NAMI-A are relevant for its metastasis's inhibition, including: (Keppler, 1993; Sava, Alessio \& Bergamo,1999; Alessio et al., 2004; Groessl et al., 2007).

- Inhibition of matrix metallo proteinases and tumour cell invasion;

- Adhesion upregulation;

- Angiogenic activity downregulation;

- $\quad$ Caspase activation and inhibition of ERK1/2;

- The interaction with proteins and integrins is efficient.

\section{Activation and Chemical Behaviour of NAMI-A}

In the coordination sphere of NAMI-A, there a dmso group is present. It controls the chemical behaviour 
of NAMI-A. The dmso group is involved in two step hydrolytic reactions whose nature and rate are strongly dependent on pH (Scheme 1) (Keppler, 1993; Sava, Alessio \& Bergamo, 1999; Alessio et al., 2004; Redemaker-Lakhai, et al., 2004). The complex isn't inert, because it undergoes stepwise hydrolysis of two chlorides, under $37.0^{\circ} \mathrm{C}$ and $7.4 \mathrm{pH}$ (phosphate buffer) within couple of minutes. the primary hydrolytic step is catalysed by ruthenium (II) species, of course the speed is influenced by addition of trace number of biological reductants, like antioxidant or cysteine. In between the partial dissociation of the dmso, there lies the second hydrolytic step.

At any temperature NAMI-A is inert. In slightly acidic medium, dissociation of dmso occurs slowly and the hydrolysis of chloride is suppressed (Alessio et al., 1993 \& Groessl et al., 2007).

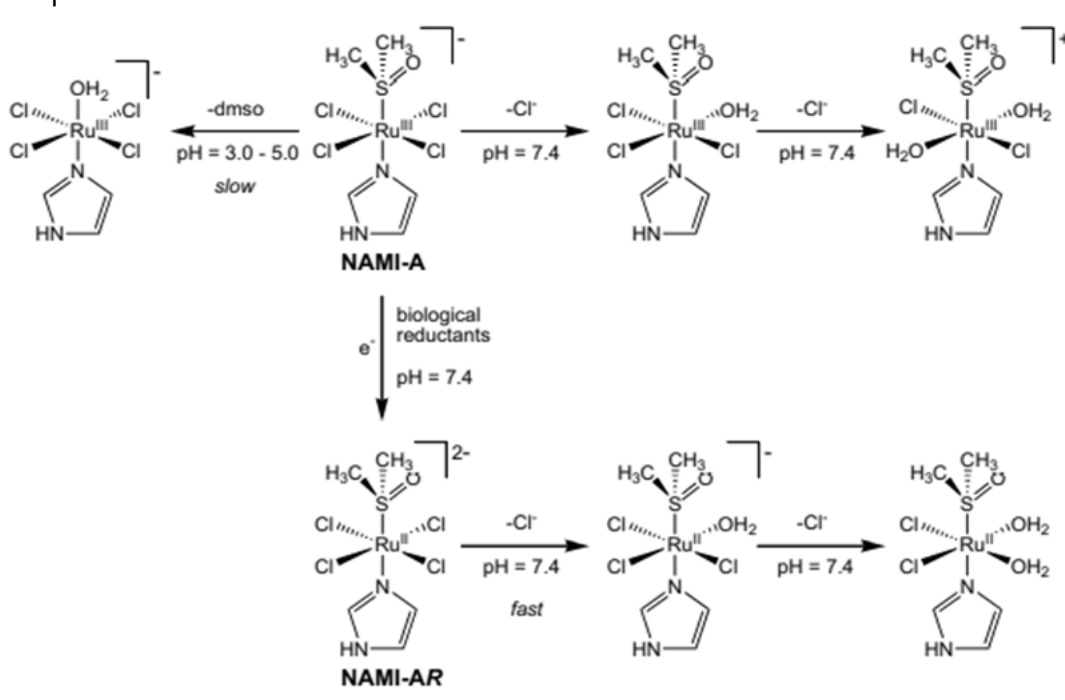

\section{Scheme 1: Representation of the chemistry of NAMI-A under various conditions. (Keppler, 1993;} Sava, Alessio \&Bergamo ,1999; Alessio et al,. 2004)

NAMI-A rapidly reduces to its corresponding dianion ruthenium (II) species trans- $\left(\mathrm{RuCl}_{4}(\mathrm{Im})\right.$ (dmso$S)^{2}$-, NAMI-AR, using catalytic amounts of commonly used biological electron donor or reducing agents (e.g., vitamin $\mathrm{C}$, cysteine or glutathione) at physiological $\mathrm{pH}$. Two chloride ligands of NAMI-AR undergo rapid stepwise hydrolysis (Scheme 1). Within the coordination sphere of NAMI-AR there is no loss of dmso/imidazole or reoxidation by oxygen present in atmosphere is observed. Metabolites of NAMI-A that can bear the dmso-S have reduction potentials almost like the parent compound and thus it is reduced easily (Ravera et al., 2006).

Remarkably, ruthenium (III) and ruthenium (II) species with identical net charge, i.e., in mer$\left(\mathrm{RuCl}_{3}(\mathrm{H} 2 \mathrm{O})(\mathrm{dmso}-\mathrm{S})(\mathrm{Im})\right.$ )-and NAMI-A the chloride dissociation has similar rates (Ravera et al., 2006 \& Schluga et al., 2006).

To conclude, even NAMI-A is reduced to ruthenium (II) in vivo, the employment of biological reductants isn't needed for reduction. NAMI-A activation may occur easily through aquation, attributable to its relative lability at physiological $\mathrm{pH}$. In other words, to elucidate the activity for NAMI-A the activation-byreduction hypothesis is a concrete evidence. Contrastingly, anti-metastatic activity of NAMI-A is presumably associated with the presence of dmso within the coordination sphere of its active metabolite(s).

\section{Structure-Activity Relationships}

As time pasts, to determine the structure activity relationship for NAMI-A, scientist have researched on every unit of the NAMI-A frame (Keppler, 1993; Sava, Alessio \& Bergamo,1999; Alessio et al., 2004). A short conclusion on the results is given below (Scheme 2). 


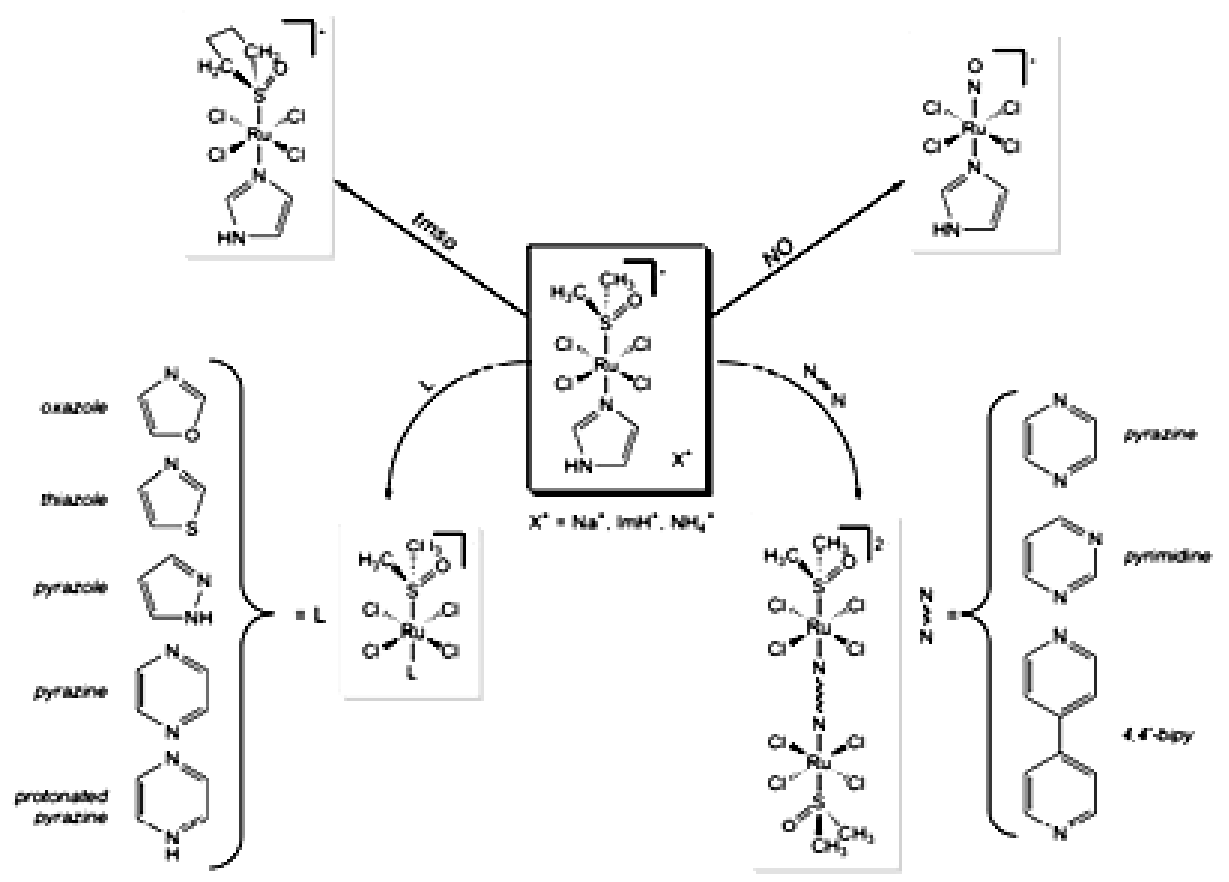

Scheme 2 Representation of the NAMHA type compounds [Keppler et al. 1993;Sava, Alessio \& Bergamo,1999; Alessio et al, 2004; Alessio et al, 1993; Groessl et al, 2007; Ravera et al,, 2006; Schluga et al, 2006; Hartmann et al., 1998; Sava et al., 2002.]

Many sulfoxides were tested, but scientist and researchers concluded that only tmso (tetramethylenesulfoxide) is incredibly just like dmso. This results in identical kind of ruthenium complexes. From biological and chemical point of view the $(\mathrm{Na})$ trans- $\left(\mathrm{RuCl}_{4}(\mathrm{Im})(\mathrm{tmso}-\mathrm{S})\right)$ complex is almost similar toNAMI-A. A robust m-acceptor ligand NO may also successfully replace dmso, which bind as $\mathrm{NO}+$. It results in the reduction of ruthenium (III) to ruthenium (II). If we replace dmso-S with NO+ in NAMI-A ends up in the formation of its derivative, diamagnetic complex $\left((\mathrm{Im})_{2} \mathrm{H}\right)$ trans$\left(\mathrm{RuCl}_{4}(\mathrm{Im})(\mathrm{NO})\right)$. It is slightly toxic to living cells in vitro but is barren of antimetastatic activity against in vivo models. (Alessio et al., 1993; Groessl et al., 2007\& Hartmann et al., 1998).

\section{N-ligand}

This unit in NAMI-A framework may be effortlessly varied in an organised way (Scheme 2). In ruthenium (III) prototype $((\mathrm{dmso}) \mathrm{H}(\mathrm{dmso}))$ trans-( $\mathrm{RuCl}_{4}(\mathrm{dmso}-\mathrm{S})$ (dmso-S $\left.)\right)$, under mild conditions one among the 2 trans S-bonded sulfoxides are often replaced by an outsized number of heterocyclic $\mathrm{N}$-ligands ( $\mathrm{L}$ ), and also by NH3 (ammonia), which leads to a series of NAMI-A types compounds with general formula $(\mathrm{HL})$ trans- $\left(\mathrm{RuCl}_{4}(\mathrm{~L})(\mathrm{dmso}-\mathrm{S})\right)$ (Alessio et al., 2004). Researchers studied those compounds with increased lipophilicity and large aromatic ligands ( $\mathrm{L}=$ quinoline and indazole), are less active than NAMI-A but are highly toxic, so they were not proceeded further. In slightly acidic medium (due to slower dissociation of dmso) these compounds are more stable than NAMI-A. At physiological pH they act similarly to NAMI-A, which is useful for the purpose in view of the drug administration (Keppler, 1993). N-ligand of similar size and low basicity than imidazole ( $L=$ thiazole) having an in vivo effectiveness better than NAMI-A. If we use bridging ligands ( $L=$ pyrimidine, pyrazine or 4,4'-bipyridine) researchers developed binuclear compounds of formula $(\mathrm{Na})_{2}$. Each ruthenium centre contains a coordination environment same as NAMI-A type complex. The antimetastatic activity of these compound is reminiscent of that of NAMI-A (Keppler 1993; Sava, Alessio \& Bergamo ,1999; Alessio et al., 2004; Alessio et al., 1993 \& Groessl et al., 2007). 


\section{Charge}

In the time period of NAMI, chargeless ruthenium (III) complex mer-( $\left.\mathrm{RuCl}_{4}(\mathrm{Im})(\mathrm{dmso}-\mathrm{O})(\mathrm{dmso}-\mathrm{S})\right)$, is derived from NAMI-A by replacing chloride ion with a dmso with an $\mathrm{O}$ atom. It has an antimetastatic activity almost similar to that of NAMI-A. Thanks to poor solubility in water, this complex and similar neutral NAMI-A derivative were not proceeded further.

\section{Chlorides}

As mentioned earlier, chemical behaviour of NAMI-A and all NAMI-A type complexes showed a stepwise hydrolysis of minimum two chloride ions in physiological solution. After reduction of NAMI-A in vivo, dissociation of chloride is the main natural process that happens (Sava, Alessio \& Bergamo, 1999). Thus, the strategy within the 80 s in which platinum-based drugs from cisplatin to Oxiplatin to carboplatin may be worth to be pursues for active ruthenium-chloride-dmso compounds. Significant differences in hydrolytic behaviour and its activity are predicted when the chloride in NAMI-A is replaced with chelating dicarboxylates. Despite, several efforts it is impossible to segregate any ruthenium (III) compound having both a chelating dicarboxylate and dmso in the coordination sphere. Previously derived NAMI-A derivatives, either it failed to have dmso any more or often it is ruthenium (II) species (Keppler, 1993; Sava, Alessio \& Bergamo ,1999; Alessio et al., 2004).

\section{Oxidation State}

It is discussed earlier, by using biological reductants NAMI-A is effectively reduced. Reduction of NAMIA with water soluble vitamin gives NAMI-AR, in vial before administration. It is more practical than NAMIA itself against metastasis growth. (Keppler, 1993; Sava, Alessio \& Bergamo ,1999 \& Alessio et al., 2004).

\section{Mechanism of Action}

In recent times, the mechanistic action of NAMI-A results in a large number of concurrent mechanisms that will not involve nuclear DNA (Levina, Mitra \& Lay, 2009). Sava et al. and his team members has done research work many years ago that NAMI-A will affect the tumour cells within the primary tumour (Sava et al., 2003.) having metastatic ability. But it will sparsely affect the first tumour itself. The group of Sava (Gava et al., 2006; Pelillo et al., 2016; Casarsa et al., 2004.) and Lay (Liu et al., 2010.) investigated on different neoplastic cell lines that NAMI-A has the capability to significantly affect tumour cell with the ability of metastasis. It affects the tumour cell by interfering at sub-cytotoxic and physiological relevant ruthenium concentrations with tumour metastatic progression. More modern observations are there associated with this theorem. Remarkably, due to fast ligand exchange kinetics of NAMI-A, it is not internalised by cells. Compared to other ruthenium anticancer agents, there is a huge difference in mechanism, which are internalised by cells in large amounts. Studies performed by Aitken et al. that supported the difference in ruthenium uptake .

The binding of ruthenium to collagens of cell surface integrins and extracellular matrix, leads to the development of adhesion and also the invasiveness of cancer cell is reduced. The action of NAMI-A against fully grown metastases is perhaps more reasonably, because of its anti-angiogenic properties. It was confirmed within the chick chorioallantois and within rabbit eye cornea model (Vacca et al., 2002; Morbidelli et al., 2003).

\section{CONCLUSION}

The growth of NAMI-A is an impressive case study in the field of medicinal chemistry. Three decades of vigorous studies and research have produced huge amount of data on this compound, and this data helped NAMI-A to its introduction in clinical studies. There is success in the clinal trial, but it teaches us quite a few things. 
Although NAMI-A has low stability and it undergoes facile chemical transformation, it is suitable for pharmacological testing and pharmacological testing. Like cisplatin and related platinum drugs, NAMI-A also behaves as a typical classical prodrug. Additionally, the toxicity of this compound is restricted and tolerable moreover it manifests a suitable solubility in biological fluids.

Investigated compound in clinical trials produce sparce evidence of systemic toxicity, which increases the chance of NAMI-A in clinical use. Though the anticancer activity is a limited once, used as a standalone factor, there is still many options to explore a bigger number of cancer models and it can be used in combination therapies.

Many scientific publications have been generated in this field of ruthenium drugs. However, a critical evaluation must be done, more and more attention should be given in separate ideas and concepts that are not been validated or myths from people who have found a solid experimental support or facts.

The mechanisms were not fully understood. Yet it seems like ruthenium complexes shows a multitargeted mode of action. There are still lots of space for new studies and there is a whole new understanding on taking advantages of latest technologies.

Finally, this review ends up by making it very useful for scientist and researchers for planning and preparation of higher ruthenium anticancer agents.

\section{ACKNOWLEDGEMENT}

The authors express their sincere thanks to Department of Biotechnology, Government of India for the funding from DBT-STAR College grant, under which this review project was conducted. The authors are also grateful to the Principal and the DBT-STAR Coordinator, Surendranath College, for their support and encouragement in implementing this review project at undergraduate level.

\section{REFERENCES}

Abid, M., Shamsi, F., \& Azam, A. (2016). Ruthenium complexes: an emerging ground to the development of metallopharmaceuticals for cancer therapy. Mini Reviews in Medicinal Chemistry, 16(10), 772-786.

Alessio, E., Mestroni, G., Bergamo, A., \& Sava, G. (2004). Ruthenium antimetastatic agents. Current Topics in Medicinal Chemistry, 4(15), 1525-1535.

Ang, W. H., Daldini, E., Scolaro, C., Scopelliti, R., Juillerat-Jeannerat, L., \& Dyson, P. J. (2006). Development of organometallic ruthenium- arene anticancer drugs that resist hydrolysis. Inorganic Chemistry, 45(22), 9006-9013.

Antonarakis, E. S., \&Emadi, A. (2010). Ruthenium-based chemotherapeutics: are they ready for prime time?. Cancer Chemotherapy and Pharmacology, 66(1), 1-9.

Arany, I., \& Safirstein, R. L. (2003, September). Cisplatin nephrotoxicity. In Seminars in Nephrology (Vol. 23, No. 5, pp. 460-464). WB Saunders.

Aitken, J. B., Antony, S., Weekley, C. M., Lai, B., Spiccia, L., \& Harris, H. H. (2012). Distinct cellular fates for KP1019 and NAMI-A determined by X-ray fluorescence imaging of single cells. Metallomics, 4(10), 1051-1056.

Benjamin Garbutcheon-Singh, K., P Grant, M., W Harper, B., M Krause-Heuer, A., Manohar, M., Orkey, N., \& R Aldrich-Wright, J. (2011). Transition metal based anticancer drugs. Current Topics in Medicinal Chemistry, 11(5), 521-542.

Bergamo, A., \& Sava, G. (2007). Ruthenium complexes can target determinants of tumour malignancy. Dalton Transactions, (13), 1267-1272.

Cao, Z. T., Chen, Z. Y., Sun, C. Y., Li, H. J., Wang, H. X., Cheng, Q. Q., ... \& Wang, J. (2016). Overcoming 
tumor resistance to cisplatin by cationic lipid-assisted prodrug nanoparticles. Biomaterials, 94, 9-19.

Casarsa, S., Puglisi, F., Baudi, F., De Paola, L., Venuta, S., Piga, A., ... \& Damante, G. (2004). BRCA2 germline mutations in primary cancer of the fallopian tube. Oncology Reports, 12(2), 313-316.

Cepeda, V., Fuertes, M. A., Castilla, J., Alonso, C., Quevedo, C., \& Pérez, J. M. (2007). Biochemical mechanisms of cisplatin cytotoxicity. Anti-Cancer Agents in Medicinal Chemistry (Formerly Current Medicinal Chemistry-Anti-CancerAgents), 7(1), 3-18.

Chu, G. (1994). Minireview Cellular responses to cisplatin. J Biol Chem, 269, 787-790.

Clarke, M. J. (2002). Ruthenium metallopharmaceuticals. Coordination Chemistry Reviews, 232(1-2), 6993.

Clarke, M. J., Zhu, F., \&Frasca, D. R. (1999). Non-platinum chemotherapeutic metallopharmaceuticals. Chemical Reviews, 99(9), 2511-2534.

Dhar, S., Gu, F. X., Langer, R., Farokhzad, O. C., \& Lippard, S. J. (2008a). Targeted delivery of cisplatin to prostate cancer cells by aptamer functionalized Pt (IV) prodrug-PLGA-PEG nanoparticles. Proceedings of the National Academy of Sciences, 105(45), 17356-17361.

Dhar, S., Liu, Z., Thomale, J., Dai, H., \& Lippard, S. J. (2008b). Targeted single-wall carbon nanotubemediated $\mathrm{Pt}(\mathrm{IV})$ prodrug delivery using folate as a homing device. Journal of the American Chemical Society, 130(34), 11467-11476.

Dorcier, A., Ang, W. H., Bolano, S., Gonsalvi, L., Juillerat-Jeannerat, L., Laurenczy, G., ... \& Dyson, P. J. (2006). In vitro evaluation of rhodium and osmium RAPTA analogues: The case for organometallic anticancer drugs not based on ruthenium. Organometallics, 25(17), 4090-4096.

Florea, A. M., \& Büsselberg, D. (2011). Cisplatin as an anti-tumor drug: cellular mechanisms of activity, drug resistance and induced side effects. Cancers 3: 1351-1371.

Fong, T. T. H., Lok, C. N., Chung, C. Y. S., Fung, Y. M. E., Chow, P. K., Wan, P. K., \& Che, C. M. (2016). Cyclometalated Palladium (II) N-Heterocyclic Carbene Complexes: Anticancer Agents for Potent In Vitro Cytotoxicity and In Vivo Tumor Growth Suppression. Angewandte Chemie International Edition, 55(39), 11935-11939.

Furrer, J., \& Süss-Fink, G. (2016). Thiolato-bridged dinuclear arene ruthenium complexes and their potential as anticancer drugs. Coordination Chemistry Reviews, 309, 36-50.

Galluzzi, L., Senovilla, L., Vitale, I., Michels, J., Martins, I., Kepp, O., ... \& Kroemer, G. (2012). Molecular mechanisms of cisplatin resistance. Oncogene, 31(15), 1869-1883.

Giaccone, G. (2000). Clinical perspectives on platinum resistance. Drugs, 59(4), 9-17.

Gopal, Y. V., Jayaraju, D., \& Kondapi, A. K. (1999). Inhibition of topoisomerase Il catalytic activity by two ruthenium compounds: a ligand-dependent mode of action. Biochemistry, 38(14), 4382-4388.

Graf, N., Bielenberg, D. R., Kolishetti, N., Muus, C., Banyard, J., Farokhzad, O. C., \& Lippard, S. J. (2014). ACS Nano, 2012, 6, 4530-4539;(b) Y. Yuan, RTK Kwok, BZ Tang and B. Liu. J. Am. Chem. Soc, 136, 2546-2554.

Groessl, M., Reisner, E., Hartinger, C. G., Eichinger, R., Semenova, O., Timerbaev, A. R., ... \& Keppler, B. K. (2007). Structure- activity relationships for NAMI-A-type complexes (HL)[trans-RuCl4L (S-dmso) ruthenate $(\mathrm{III})](\mathrm{L}=$ imidazole, indazole, 1, 2, 4-triazole, 4-amino-1, 2, 4-triazole, and 1-methyl-1, 2, 4triazole): Aquation, redox properties, protein binding, and antiproliferative activity. Journal of Medicinal Chemistry, 50(9), 2185-2193.

Hartinger, C. G., Jakupec, M. A., Zorbas-Seifried, S., Groessl, M., Egger, A., Berger, W., ... \& Keppler, B. K. (2008). KP1019, a new redox-active anticancer agent-Preclinical development and results of a clinical phase I study in tumor patients. Chemistry \& Biodiversity, 5(10), 2140-2155.

Keppler, B. K. (Ed.). (1993). Metal complexes in cancer chemotherapy. wiley-VCH. 
Kostova I. (2006). Ruthenium complexes as anticancer agents. Current Medicinal Chemistry, 13(9), 1085-1107.

Levina, A., Mitra, A., \& Lay, P. A. (2009). Recent developments in ruthenium anticancer drugs. Metallomics, 1(6), 458-470.

Morbidelli, L., Donnini, S., Filippi, S., Messori, L., Piccioli, F., Orioli, P., ... \&Ziche, M. (2003). Antiangiogenic properties of selected ruthenium (III) complexes that are nitric oxide scavengers. British Journal of Cancer, 88(9), 1484-1491.

Levina, A., Mitra, A., \& Lay, P. A. (2010). Metallomics 2009, 1, 458-470; c) G. Süss-Fink. Dalton Trans, 39 , 1673-1688.

Li, F., Collins, J. G., \& Keene, F.R. (2015). Ruthenium complexes as antimicrobial agents. Chemical Society Reviews, 44(8), 2529-2542. (a)

Liu, M., Lim, Z. J., Gwee, Y. Y., Levina, A., \& Lay, P. A. (2010). Characterization of a ruthenium (III)/NAMI-A adduct with bovine serum albumin that exhibits a high anti-metastatic activity. Angewandte Chemie, 122(9), 1705-1708.

Liu, P., Jia, J., Zhao, Y., \& Wang, K. Z. (2016). Recent advances on dark and light-activated cytotoxity of imidazole-containing ruthenium complexes. Mini Reviews in Medicinal Chemistry, 16(4), 272-289.

Mestroni, G., Alessio, E., Sava, G., Pacor, S., Coluccia, M., \& Boccarelli, A. (1994). Water-soluble ruthenium (III)-dimethyl sulfoxide complexes: chemical behaviour and pharmaceutical properties. Metal-Based Drugs, 1(1), 41-63.

Muhammad, N., \& Guo, Z. (2014). Metal-based anticancer chemotherapeutic agents. Current Opinion in Chemical Biology, 19, 144-153.

Pelillo, C., Mollica, H., Eble, J. A., Grosche, J., Herzog, L., Codan, B., ... \& Bergamo, A. (2016). Inhibition of adhesion, migration and of a5 $\beta 1$ integrin in the HCT-116 colorectal cancer cells treated with the ruthenium drug NAMI-A. Journal of Inorganic Biochemistry, 160, 225-235.

Ravera, M., Cassino, C., Baracco, S., \& Osella, D. (2006). New Insights into the Redox Chemistry of Ruthenium Metallopharmaceuticals: The Electrochemical Behaviour of [LH][trans-RullICl4L2](L= imidazole or indazole) Complexes.

Romero-Canelón, I., Salassa, L., \& Sadler, P. J. (2013). The contrasting activity of iodido versus chlorido ruthenium and osmium arene azo-and imino-pyridine anticancer complexes: control of cell selectivity, cross-resistance, p53 dependence, and apoptosis pathway. Journal of Medicinal Chemistry, 56(3), 1291-1300.

Sava, G., Alessio, E., \& Bergamo, A. (1999). G. Mestroni in Topics in Biological Inorganic Chemistry, Vol. 1 "Metallo-pharmaceuticals".

Schluga, P., Hartinger, C. G., Egger, A., Reisner, E., Galanski, M., Jakupec, M. A., \& Keppler, B. K. (2006). Redox behavior of tumor-inhibiting ruthenium (III) complexes and effects of physiological reductants on their binding to GMP. Dalton Transactions, (14), 1796-1802.

Schmid, W. F., John, R. O., Arion, V. B., Jakupec, M. A., \& Keppler, B. K. (2007). Highly antiproliferative ruthenium (II) and osmium (II) arene complexes with paullone-derived ligands. Organometallics, 26(26), 6643-6652.

Shi, G., Monro, S., Hennigar, R., Colpitts, J., Fong, J., Kasimova, K., .. \& McFarland, S. A. (2015). Ru (II) dyads derived from a-oligothiophenes: a new class of potent and versatile photosensitizers for PDT. Coordination Chemistry Reviews, 282, 127-138.

Sledge Jr, G. W., Loehrer Sr, P. J., Roth, B. J., \& Einhorn, L. H. (1988). Cisplatin as first-line therapy for metastatic breast cancer. Journal of Clinical Oncology, 6(12), 1811-1814.

Smith, G. S., \& Therrien, B. (2011). Targeted and multifunctional arene ruthenium chemotherapeutics. 
Dalton transactions, 40(41), 10793-10800.

Suntharalingam, K., Song, Y., \& Lippard, S. J. (2014). Conjugation of vitamin E analog a-TOS to Pt (IV) complexes for dual-targeting anticancer therapy. Chemical Communications, 50(19), 2465-2468.

Takahara, P. M., Frederick, C. A., \& Lippard, S. J. (1996). Crystal structure of the anticancer drug cisplatin bound to duplex DNA. Journal of the American Chemical Society, 118(49), 12309-12321.

Vacca, A., Bruno, M., Boccarelli, A., Coluccia, M., Ribatti, D., Bergamo, A., ... \& Sava, G. (2002). Inhibition of endothelial cell functions and of angiogenesis by the metastasis inhibitor NAMI-A. British Journal of Cancer, 86(6), 993-998.

Vincent, J. B., \& Love, S. T. (2012). The need for combined inorganic, biochemical, and nutritional studies of chromium (III). Chemistry \& Biodiversity, 9(9), 1923-1941.

Vock, C. A., Ang, W. H., Scolaro, C., Phillips, A. D., Lagopoulos, L., Juillerat-Jeanneret, L., ... \& Dyson, P. J. (2007). Development of ruthenium antitumor drugs that overcome multidrug resistance mechanisms. Journal of Medicinal Chemistry, 50(9), 2166-2175.

Ye, R. R., Tan, C. P., He, L., Chen, M. H., Ji, L. N., \& Mao, Z. W. (2014). CyclometalatedIr (III) complexes as targeted theranostic anticancer therapeutics: combining HDAC inhibition with photodynamic therapy. Chemical Communications, 50(75), 10945-10948.

Zhang, C. X., \& Lippard, S. J. (2003). New metal complexes as potential therapeutics. Current Opinion in Chemical Biology, 7(4), 481-489. 


\title{
Investigating the Pathomechanisms of Diabetic Retinopathy: The Cost of Diabetes
}

\author{
Abhijit Senapati, Anwesha Banerjee, Supritam Pandey, Souvik Khanra, Subhadipa Majumder* \\ Department of Zoology, Surendranath College, Kolkata, India \\ ${ }^{*}$ Corresponding Author's Email: subhadipa@gmail.com
}

\begin{abstract}
Diabetic retinopathy is a major complication of diabetes that progressively damage the retinal blood vessels of people who have diabetes. It is the primary cause of blindness which has a significant effect on the world's health system. It is a disease which effects both type I and II diabetic patients at any stage of life. Diabetic Retinopathy is also one of the principal cause of blindness in adults in India. In some patients with Diabetic Retinopathy, blood vessels swell and leak fluid. In severe cases, new blood vessels are formed and abnormally grow on the surface of the retina. DR is the multi-factorial and a complex disease which effect the vasculature and photoreceptor functions of retina. Multiple biological, chemical, physiological and molecular alterations help to initiate and progress the diabetic retinopathy. A number of physiological pathways are changed in a pathological mode in the high sugar environment. These include blood retinal barrier dysfunction, capillary regeneration, glial cell dysfunctions and inflammation. This review aims to explore the pathomechanisms of diabetic retinopathy for easy understanding the disease.
\end{abstract}

Keywords: Diabetic Retinopathy; PDR; NPDR; Retina

\section{INTRODUCTION}

Diabetic retinopathy (DR) is a vascular disease mostly affects the structure and function of the microscopic vessels of retina which affects patients with diabetes mellitus (Figure 1). DR can be characterized into two clinical stages: non-proliferative diabetic retinopathy (NPDR) and proliferative diabetic retinopathy (PDR) (Sivakumar et al., 2005). During early NPDR, the retina is damageddue to abnormal permeability and/or non-perfusion of capillaries which forms microaneurysms that is dilation of retinal blood vessels, absolute glaucoma and deposition of lipoprotein exudates. All the cellular components of retinal blood vessels are lost and results acellular capillaries. So, the main features of non-proliferative retinopathy are occlusion and abnormal dilation of retinal capillaries surrounding the zoneswhere blood flow is absent and the zones surrounding the ischemia (Usman, 2018). Once the condition becomes more complex and severe, it transits first to pre-proliferative and lastly to proliferative retinopathy (Priya, Srinivasarao \& Sharma, 2013).

\section{LITERATURE REVIEW AND DISCUSSION}

Neovascularization is the hallmark of pre-proliferative retinopathy.It leads to retinal ischemia and hypoxia. Leaking of fluid occurs from the abnormal capillary permeability; this is clinically known as macular oedema (MO) which impedes visual acuity (Ting et al., 2002). Retinal capillaries are occluded which leads retinal ischemia.Ischemiastimulates the neovascularization by which new fragile and hemorrhagic blood vessels proliferate on the surface of retina. Blood is accumulated in the vitreous cavity from these hemorrhaging vessels and impairs the vision. Eventually it leads to retinal detachment and blindness. This visual impairment and associated complications have a negative impact on the quality of life and overall life expectancy of the patient. 


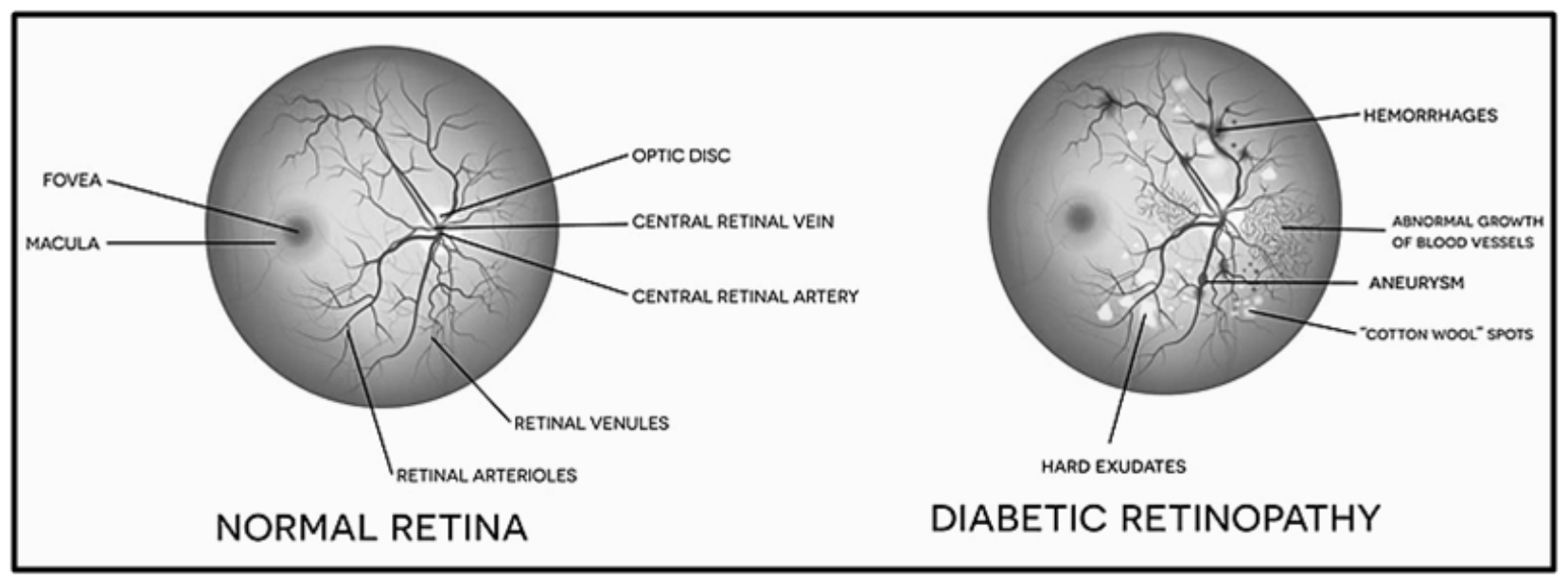

Figure 1: Normal vs diabetic eye. (source: www.eye7.in/retina/diabetic-retinopathy/)

\section{Statistics of DR}

Diabetic retinopathy leads to major cause of vision loss due to microvascular complications. The main causes are increased urbanization, consumption of less-nutritious foods, sedentary lifestyles and obesity. Globally, 422 million adults were estimated with diabetes in 2014, compared to 108 million in 1980. In adult population, the global prevalence of diabetes has almost doubled since 1980. In the United States, the people between the ages of $20-64$ is suffered from blindness due to diabetic retinopathy (Wilkinson et al., 2003).

Over the past decade, the diabetes prevalence has increased in high-income countries. Presently, South East Asia and the Western Pacific account for more than half of adults with diabetes world-wide (Figure 2).

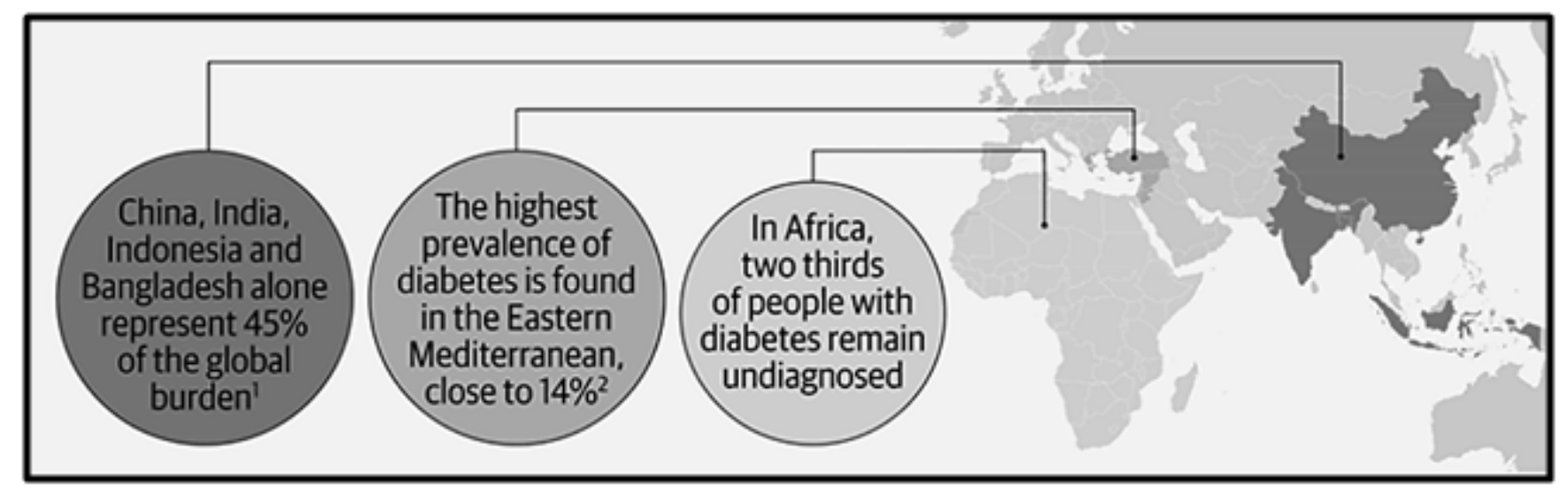

Figure 2: World-wide distribution of Diabetic. (source: atlas.iapb.org/vision-trends/diabeticretinopathy).

The prevalence of diabetes mellitus is growing and complications are becoming major health issues which requires effective and active health interventions for disease control and treatment (Lang, 2007).

\section{Epidemiology of DR}

Vision Loss Expert Group of the Global Burden of Disease Study reported that in between 1990 and 2015 , the crude prevalence of visual impairment and blindness due to diabetic retinopathy (DR) increased significantly in all age groups. In 2013, there were 382 million diabetic people and this number is estimated to rise to 592 million by 2035 . 
In an urban Chennai population, the age- and gender-adjusted prevalence rate of diabetes was $28.2 \%$ (95\% confidence interval [Cl], 27.0-29.3), and the prevalence of diabetic retinopathy in general population was $3.5 \%(95 \% \mathrm{Cl}, 3.49-3.54)$. Some factors are significantly associated with increased risk of diabetic retinopathy which includes gender (men at greater risk; odds ratio [OR], $1.41 ; 95 \% \mathrm{Cl}, 1.04-1.91)$; use of insulin (OR, 3.52; $95 \% \mathrm{Cl}, 2.05-6.02)$; duration of diabetes (>15 years; OR, 6.43; $95 \% \mathrm{Cl}, 3.18-12.90)$ and people with known diabetes mellitus (OR, $2.98 ; 95 \% \mathrm{Cl}$, 1.72-5.17) (Raman et al.,2008).

\section{Current studies regarding the disease (International and National aspect)}

Around 463 million adults (20-79 years) were diabetic in 2019 and by 2045 this will rise to 700 million (Saeedi et al., 2019). The following Table 1 updates the recent international studies on DR.

Table 1: Descriptions of the international studies on DR.

\begin{tabular}{|l|l|c|}
\hline \multicolumn{1}{|c|}{ SI No. } & \multicolumn{1}{c|}{ Topic } & References with year \\
\hline 1 & $\begin{array}{l}\text { Prevalence of retinopathy in prediabetic } \\
\text { patients. }\end{array}$ & Kirthi et al., 2021 \\
\hline 2 & Vitreous metabolomics profiling. & Tomita et al., 2021 \\
\hline 3 & Oxidative stress in DR. & Ortega et al., 2021 \\
\hline 4 & Diabetic retinopathy screening. & Vujosevic et al., 2020 \\
\hline 5 & micro RNA expression. & Zarcia-Medina et al., 2020 2020 \\
\hline 6 & Role of antioxidants on diabetic retinopathy. & \\
\hline
\end{tabular}

India, the contemplated diabetic capital of the world was predicted to hit 69.9 million of diabetic population by 2025. The main goal of this study was to evaluate prevalence as well as to explore the risk factors for developing DR among familiar diabetes. Figure 1.3 represents the prevalence of DR as reported by Gadkari. Prevalence of DR in respect of duration of diabetes, distribution of patients according to their age and prevalence of DR in patients with other end organ disease are also mentioned in the Table 2,3 and 4. Table 5 shows the recent studies on DR in India (Gadkari, Maskati \& Nayak, 2016).

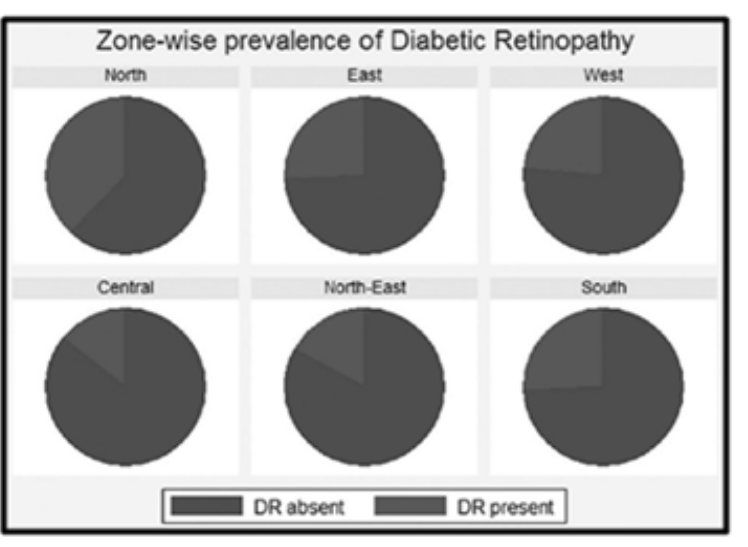

Figure 3: Zone-wise prevalence of diabetic retinopathy in India. (source: Gadkari, Maskati, \& Nayak, 2016)

Table 2: Relation between duration of diabetes mellitus and prevalence of diabetic retinopathy. (source: Gadkari, Maskati, \& Nayak, 2016)

\begin{tabular}{|lc|}
\hline Duration of DM & Prevalence of DR \\
\hline$<6$ months & 9.23 \\
6 months-5 years & 15.12 \\
$>5$ years & 35.12 \\
\hline DM: Diabetes mellitus, DR: Diabetic retinopathy \\
\hline
\end{tabular}


Table 3: Relation between age and the prevalence of diabetic retinopathy. (source: Gadkari, 2016) in the last sent manuscript

\begin{tabular}{|lcccc|}
\hline \multirow{2}{*}{ Age in years } & \multicolumn{3}{c}{ Diabetic retinopathy } & Prevalence (\%) \\
\cline { 2 - 4 } & Present & Absent & Total & \\
\hline $0-20$ & 2 & 59 & 61 & 3.28 \\
$21-40$ & 57 & 458 & 515 & 11.07 \\
$41-60$ & 581 & 2079 & 2660 & 21.84 \\
$61-80$ & 448 & 1341 & 1789 & 25.04 \\
$>80$ & 13 & 43 & 56 & 23.21 \\
\hline
\end{tabular}

Table 4: Relation between age and the prevalence of diabetic retinopathy. (source: Gadkari, Maskati \& Nayak, 2016)

\begin{tabular}{|lc|}
\hline Relation to other end-organ disease & Prevalence (\%) \\
\hline Renal & 42.86 \\
Gardiac & 29.34 \\
Stroke & 31.82 \\
Others & 22.47 \\
No complications & 21.06 \\
Multiple & 48.72 \\
\hline
\end{tabular}

Table 5: Descriptions of the studies on DR in India

\begin{tabular}{|c|l|l|}
\hline SI No. & Topic & References with year \\
\hline 1. & $\begin{array}{l}\text { Single injection of intravitreal dexamethasone and } \\
\text { diabetic muscular edema. }\end{array}$ & Verghese, Ranjan, \& Manayath, 2021 \\
\hline 2. & $\begin{array}{l}\text { Detection of DR using intuitionistic fuzzy digital convex } \\
\text { envelope segmentation algorithm. }\end{array}$ & Meenakshi et al., 2021 \\
\hline 3. & $\begin{array}{l}\text { Correlation between markers of renal function and } \\
\text { diabetic retinopathy in type 2 diabetes. }\end{array}$ & Rajalakshmi et al., 2020 \\
\hline 4. & Tackling diabetic retinopathy from the grassroots. & Sivaprasad, 2020 \\
\hline
\end{tabular}

The survey conducted by Rajendra Prasad Centre for Ophthalmic Sciences, AIIMS, New Delhi during the year of $2015-2019$ showed $8.0 \%$ prevalence of familiar diabetic cases and $3.8 \%$ redesigned diabetic cases. The survey also studied the prevalence of DR in different age groups and it was found to have $18.6 \%$ prevalence in the $60-69$ years' age group, $18.3 \%$ in the age group of $70-79$ years and $18.4 \%$ in above 80 age group, while 50-59 years' age group showing a lower prevalence of $14.3 \%$ (Figure 4).

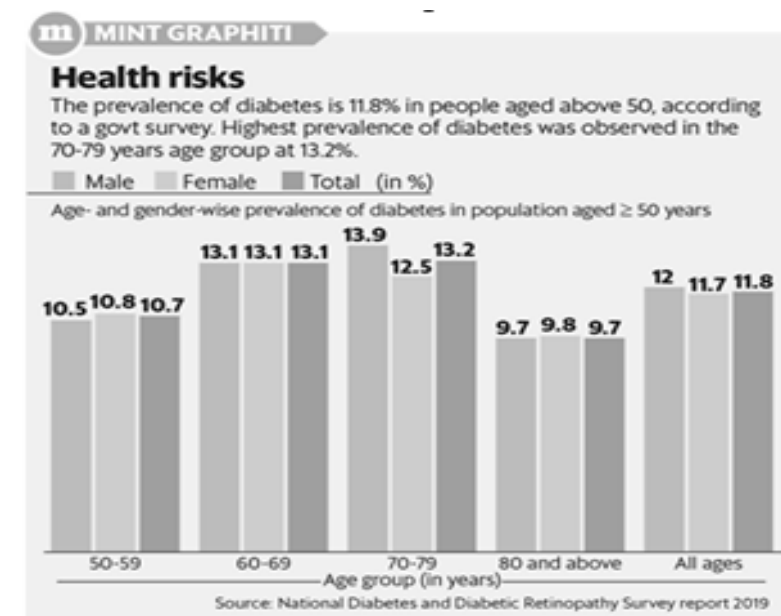

Figure 4: Government survey on diabetes in India. (source: https://www.livemint.com/science/ health/government-survey-found-11-8-prevalence-of-diabetes-in-india-11570702665713.html) 


\section{Stages of diabetic retinopathy}

Patients with type 1 or type 2 diabetes are at risk of developing diabetic retinopathy as well as diabetic macular edema (DME). Diabetic retinopathy may progress through four stages (Wilkinson et al., 2003) (Figure 5).

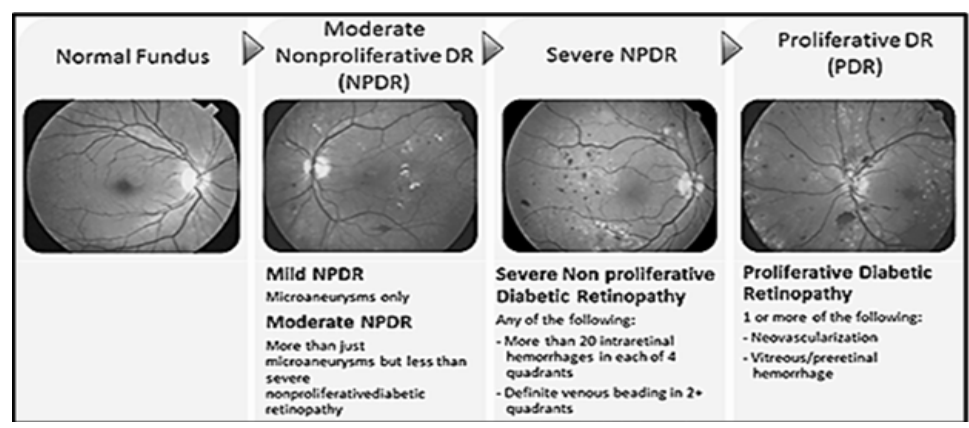

Figure 5: Stages of DR. (source: www.medscape.org/viewarticle/812590_2)

\section{Mild non-proliferative retinopathy}

At the early stages, balloon like swellings are found in the retinal blood vessels, this structures are called microaneurysms. These microaneurysms cause fluid leakage into the retina.

\section{Moderate non-proliferative retinopathy}

In this stage, the blood vessels of retina swells. It may also distort and cannot transport the blood. These conditions ultimately contribute to DME.

\section{Severe non-proliferative retinopathy}

In this stage, blood supply to retina is totally stopped because more blood vessels are blocked. Growth factors are secreted from these areas and induce the retina to form new blood vessels.

\section{Proliferative diabetic retinopathy (PDR)}

At advanced stage of diabetes, growth factors are secreted by the retina and help to proliferate the new blood vessels that grow on the inner surface of retina and then into the vitreous gel. But the new blood vessels are fragile, which continues them to leak and bleed. Scar tissues contract and cause retinal detachment from underlying tissue which leads to permanent vision loss.

\section{Histopathological changes in retina}

NPDR represents the early stage of DR. In this stage,two main observations are increased vascular permeability and capillary occlusion. Fundus photography can detect retinal pathologies including micro aneurysms, hemorrhages and hard exudatesal though the patient is asymptomatic. Neovascularization is a characteristic feature of PDR which is the most advanced stage of DR.

\section{Blood-Retinal Barrier Dysfunction}

During diabetic retinopathy, blood contents leak into the retinal neuropil because the inner blood-retinal barrier is compromised. Breakdown of the barrier results diabetic macular edema which ultimately leads to blindness (Chang et al., 2006).

\section{Basement membrane thickening of retinal endothelial cells}

In human and experimental diabetes, the first histopathological change is vascular basement membrane thickening (Figure 6). It is found that thickening of basement results cell death and instability of blood vessels in the retina (Cai, 2002).

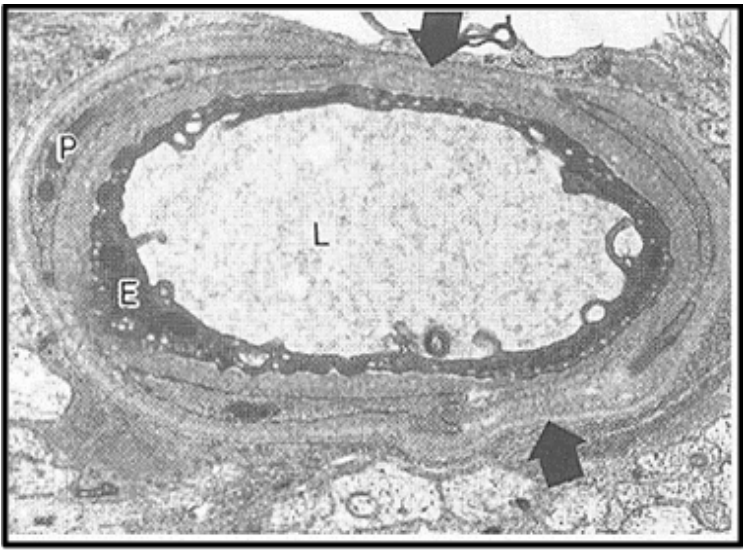

Figure 6: The thickened basement membrane (arrows). E=endothelial cell; $P=$ pericyte; $L=$ Iumen (source: Anderson, 1995) 


\section{Capillary degeneration}

Acellular capillary is a very common feature of DR. Smooth muscle cells of capillary are also lost and this capillary degeneration leads toischemia in diabetic retinopathy which can be found in postmortem retinas from long-term diabetic patients (Curtis et al., 2009) (Figure 7).

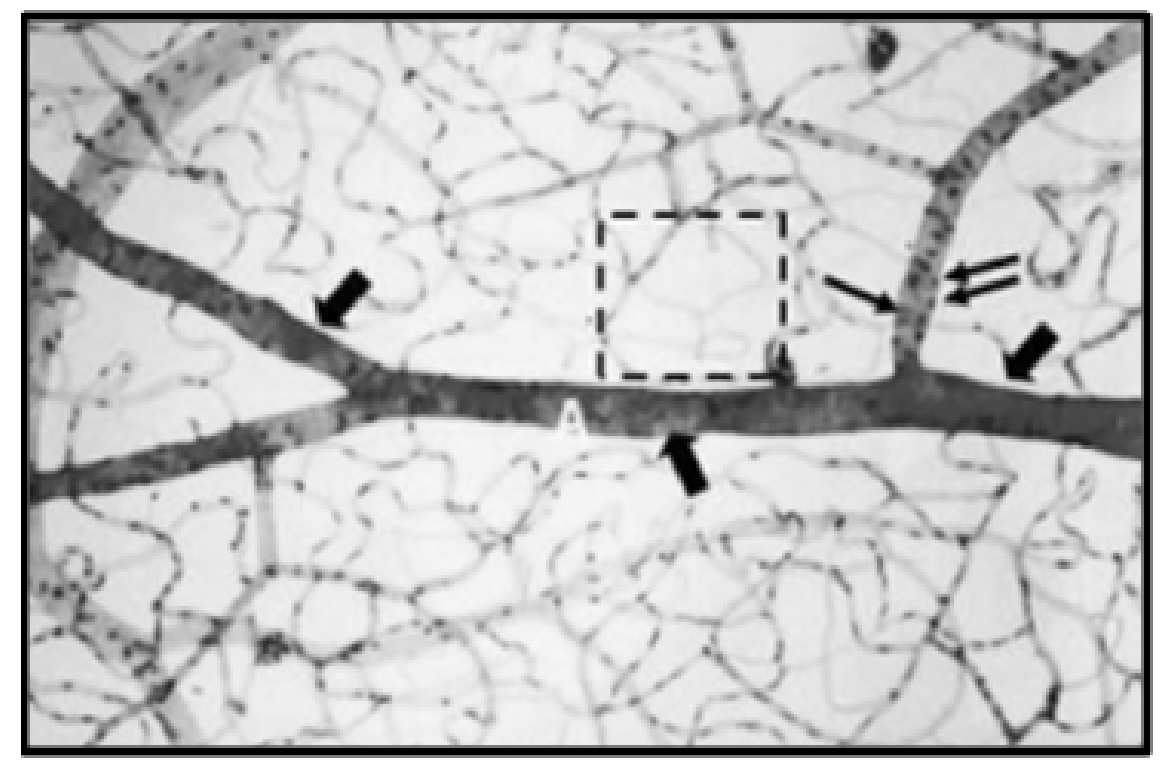

Figure 7: Absence of arterial smooth muscle cells (arrows) and capillary acellularity (dashed box). (Source: Curtis, Gardiner \& Stitt, 2009)

\section{Microaneursyms}

Typical clinical feature of diabetic retinopathy is capillary microaneurysms. The capillary wall is outpouching like a balloon and associated with capillary degeneration (Kelaini, Cochrane, \& Margariti, 2015) (Figure 8).

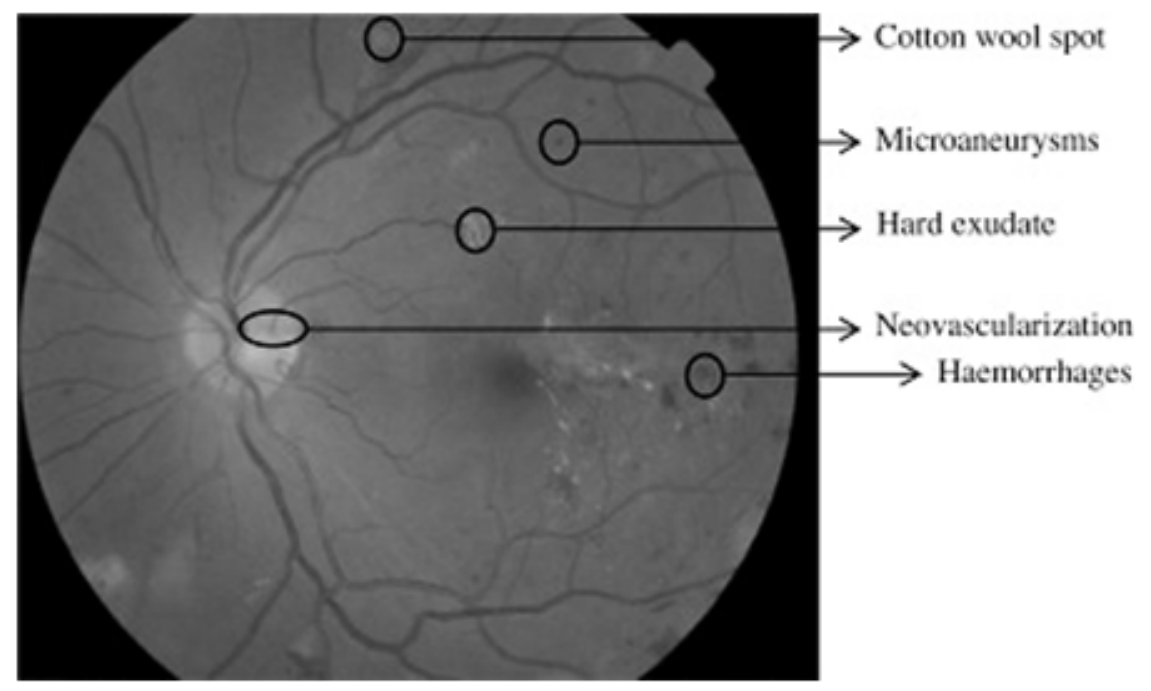

Figure 8: Micro aneurysms of diabetic eye. (Zaki et al., 2013)

\section{Risk factors}

Generally, a person with diabetes mellitus may develop diabetic retinopathy. However, the main risk factors are (Figure 9), 


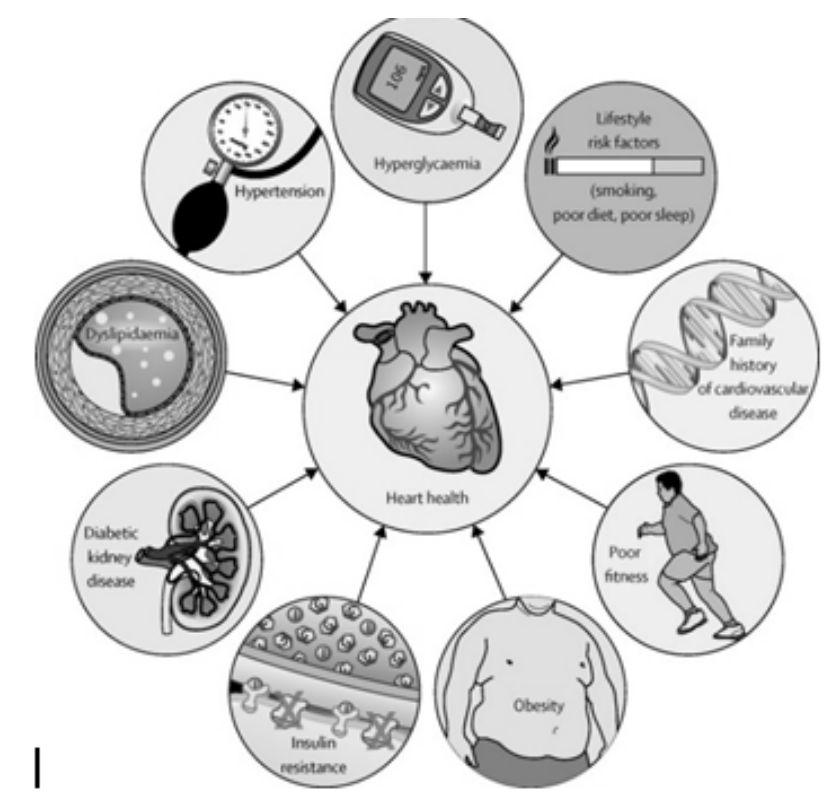

Figure 9: Risk factors with type 1 diabetes. (source: Bjornstad, Donaghue \& Maahs, 2018)

Duration of diabetes: If the patient has diabetes for a long period.

Hypertension: Persons with high blood pressure and/or high cholesterol are also at greater risk (Schrier, 2000)

Poorly controlled blood sugar level: If sugar levels are poorly controlled and no medical steps have been taken to improve it, then DR can set in earlier. (Hardin et al.,1956)

Hyperlipidaemia: Many studies have stated that lipid values have an effect on the initiation and progression of DR.

Smoking: Smoking is also a risk factor for development of DR.

Race: Hispanics and African Americans are at greater risk for developing diabetic retinopathy (Emanuele et al., 2005).

Puberty and Pregnancy:Puberty and pregnancy exacerbate DR rapidly. Pregnant women face higher risk for diabetes as well as diabetic retinopathy. With a gestational diabetes, woman has a high risk of developing diabetes (Correa, Freitas \& Marcon, 2003).

Body mass index: There are some positive correlation shown by some studies between the higher risk of DR and BMI and waist to hip ratio (WHR) (Seddon et al. , 2003).

Cataract surgery: Sometimes, intra-capsular extraction and extra-capsular cataract extraction surgery lead to DR progression (Xu et al., 2011).

Inflammation: Chronic and/or low-grade inflammation play a role in the pathogenesis of DR (Joussen et al., 2004). Various studies reported that the increased concentrations of chemokines like prostaglandins (PgE1, PgE2), stromal cell-derived factor (SDF-1 $\alpha$ ), high-sensitivity C-reactive protein (hsCRP), intercellular adhesion molecule 1 (ICAM1) and vascular cell adhesion molecule 1 (VCAM1)and tumor necrosis factor alpha (TNF- $\alpha$ ) are responsible for DR progression (Costagliala et al., 2013).

Genetic factors: The onset of DR and its severity and rapidity islinked with several genetic factors including chromosome $1 \mathrm{p}$, chromosomes 3 and 9, aldose reductase gene (ALR2), receptor for 
advance glycation end products (RAGE) gene, transforming growth factor beta 1 (TGF-beta1) gene, vascular endothelial growth factor (VEGF) gene, endothelial nitric oxide synthase (eNOS) gene, vitamin $D$ receptor and insulin-like growth factor 1 (IGF-I) gene.

Nephropathy: Kidney problem is more common in diabetic patients. It was predicted that nephropathy may be an early risk factor for type 1 diabetic patients. In 2010, this finding was published on the basis of the 15-year Beaver Dam Eye Study over 3,000 people. They concluded that nephropathy was a risk factor for new cases of severe retinopathy (Lindholm et al., 2006).

\section{Molecular and biochemical aspect of occurring DR}

Diabetes induced complications can be elucidated by a number of cellular pathways and potential molecular mechanisms. It was found that all pathways end with increased oxidative stress, inflammation and vascular occlusion. These factors help to upregulate various factors that plays a pathogenic role in diabetic retinopathy (Figure 10 and 11).

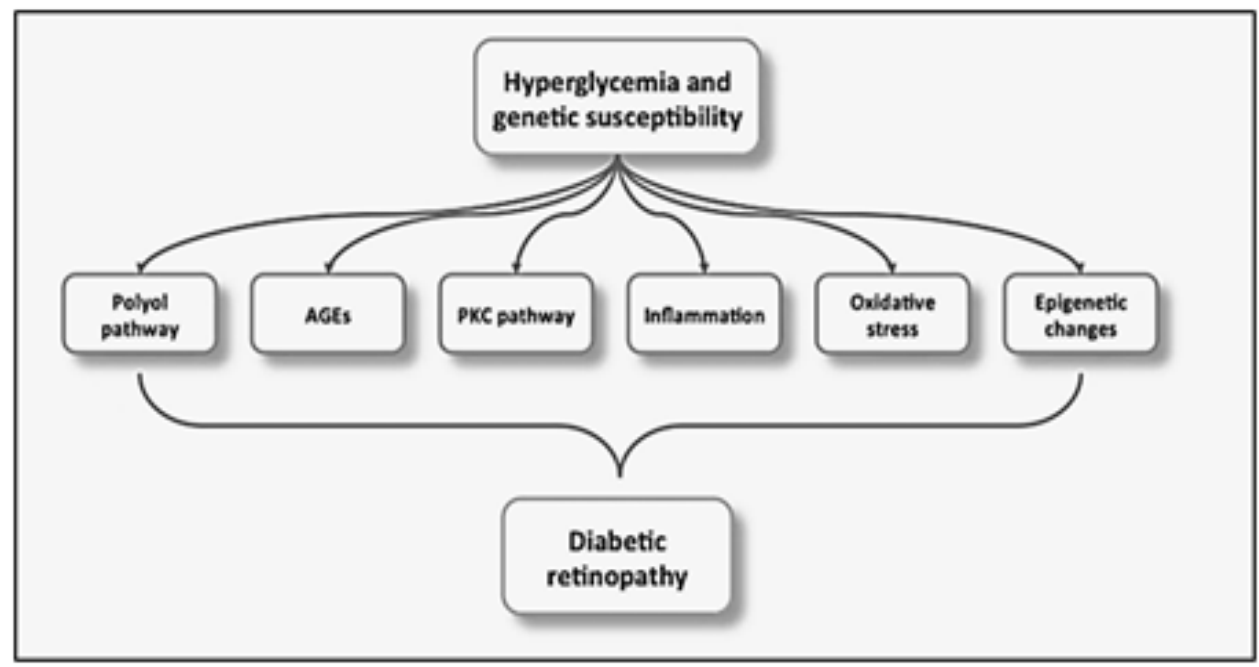

Figure 10: Altered molecular pathways lead to the development of DR. (source: Eshaq et al., 2017).

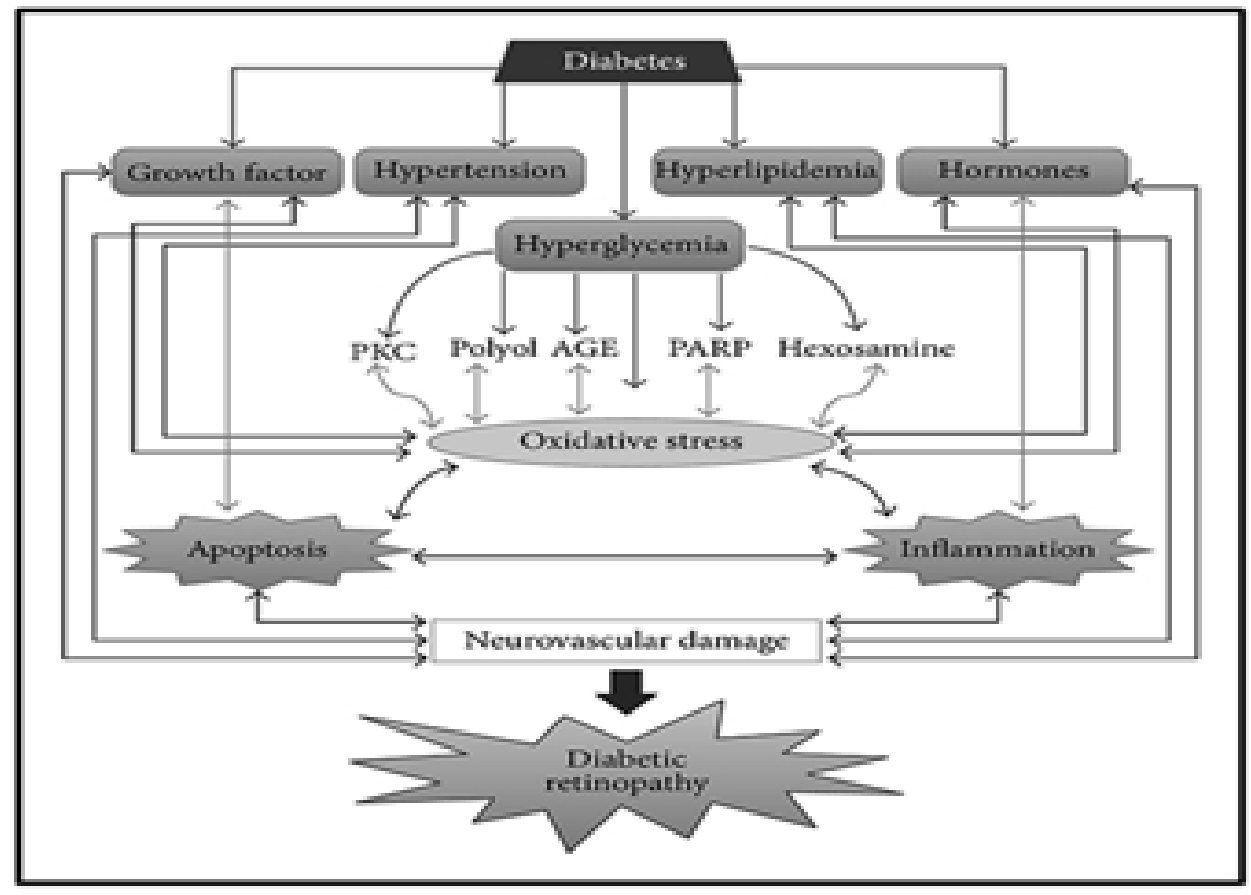

Figure 11: Hyperglycemia-induced diabetes related complications. (source: Safi et al., 2014) 


\section{Increased Polyol Pathway Flux}

In the polyol pathway, enzyme aldose reductase reduces glucose into sorbitol using NADPH as a cofactor. Sorbitol then converted into fructose by sorbitol dehydrogenase (Figure 12). Multiple damaging effects are found in retinal cells due to upregulation of sorbitol. Fructose produced by the polyol pathway is phosphorylated to fructose-3-phosphate. Itbreaks down then into3deoxyglucosone. Both are strong glycating agents and produceadvanced glycation end products (AGEs) (Dagher et al., 2004)

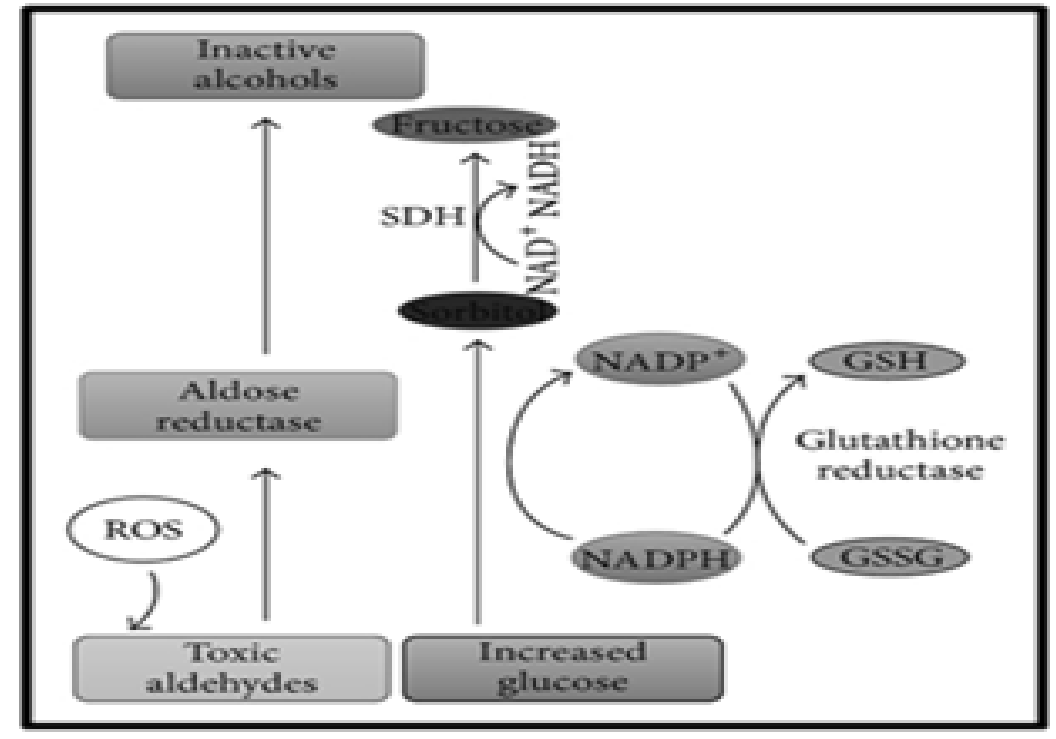

Figure 12: Aldose reductase and the polyol pathway. (source: Eshaq et al., 2017)

\section{Advanced Glycation products accumulation}

Traditionally the chronic exposure of the retina to hyperglycaemia causes building up of advanced glycation end products (Figure 13) which have an important role in retinopathy (Zong, Ward \& Stitt, 2011). Accumulation of AGEs gives rise to variety of vascular complications (Goldin et al., 2006).

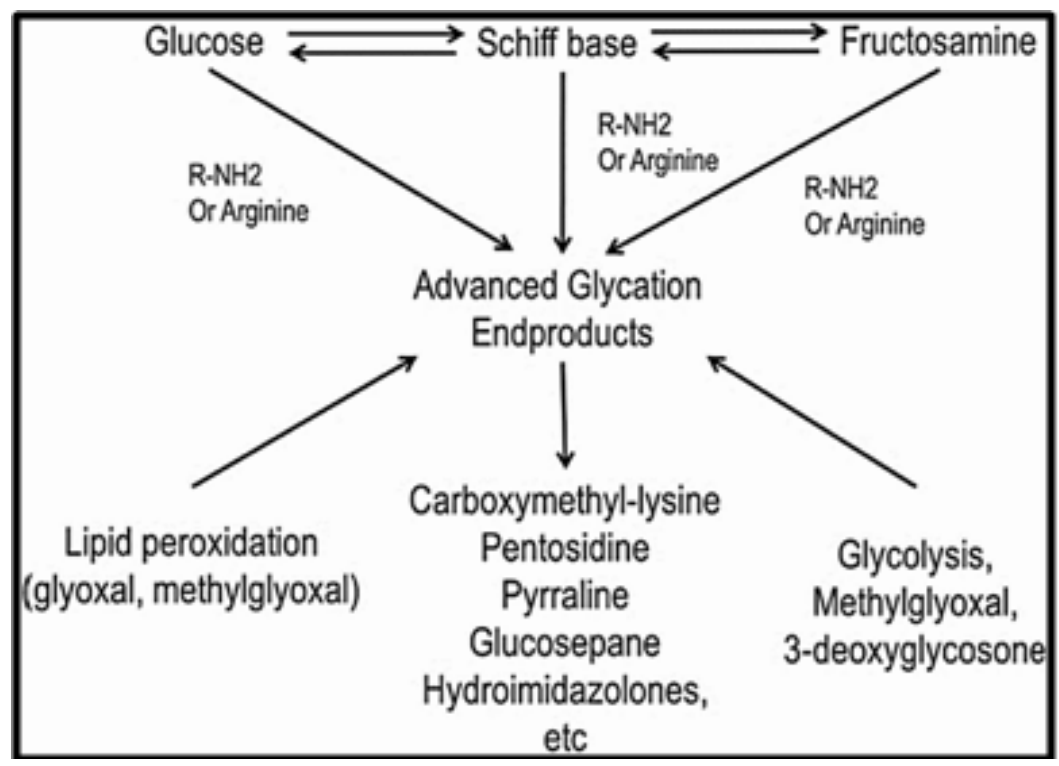

Figure 13: Formation of AGEs. (Gugliucci \& Menini, 2014)

\section{Hexosamine Pathway}

It has found thatdiabetes causes increasement of hexosamine content in retinal tissues of humans as 
well as in rats. Studies showed that insulin resistance is established due to the increased flux of glucose via the hexosamine pathway which result vascular complications and stimulation growth factor systhesis (Yang et al.,1994) (Figure 14).

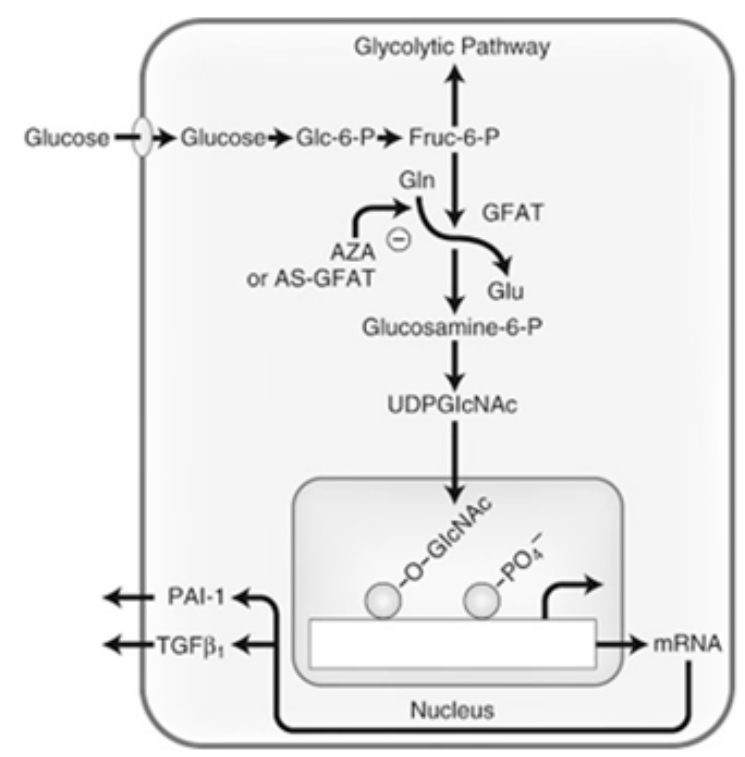

Figure 14: The hexosamine pathway. (source: Brownlee, 2016, Williams Textbook of Endocrinology, Thirteenth Edition)

\section{Protein kinase C Pathway}

It is reported thatin diabetes hyperglycemia induced activation of protein kinase $C$ cause many microvascular alterations in the retina of diabetic patients (Studer, Craven \& DeRubertis, 1993) (Figure 15).

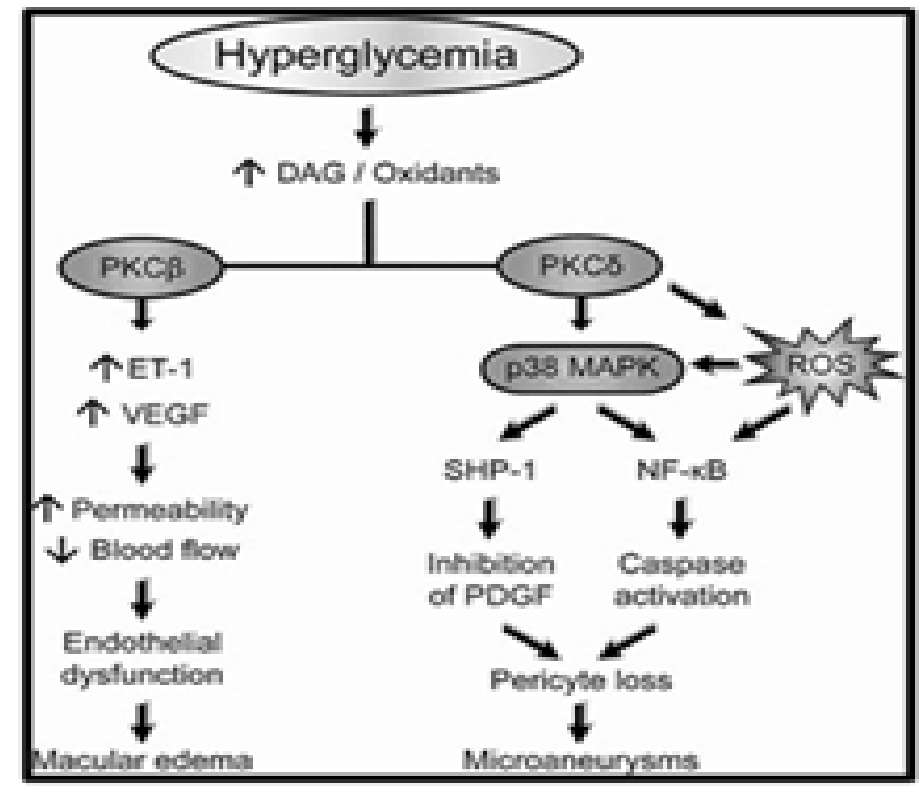

Figure 15: Target protein activation by PKC causing diabetic retinopathy. (source: Geraldes \& King, 2010)

\section{Inflammation}

Hyperglycemia creates a pro-inflammatory environment where help to overexpressed the inducible nitric oxide synthase (iNOS), leukotrienes, and cyclooxygenase -2 (COX-2).Hypoxia is the another 
important factor in the diabetic retina which develop retinopathy because of capillary blockage or dropout. (Hammes et al., 2003) (Figure 16).

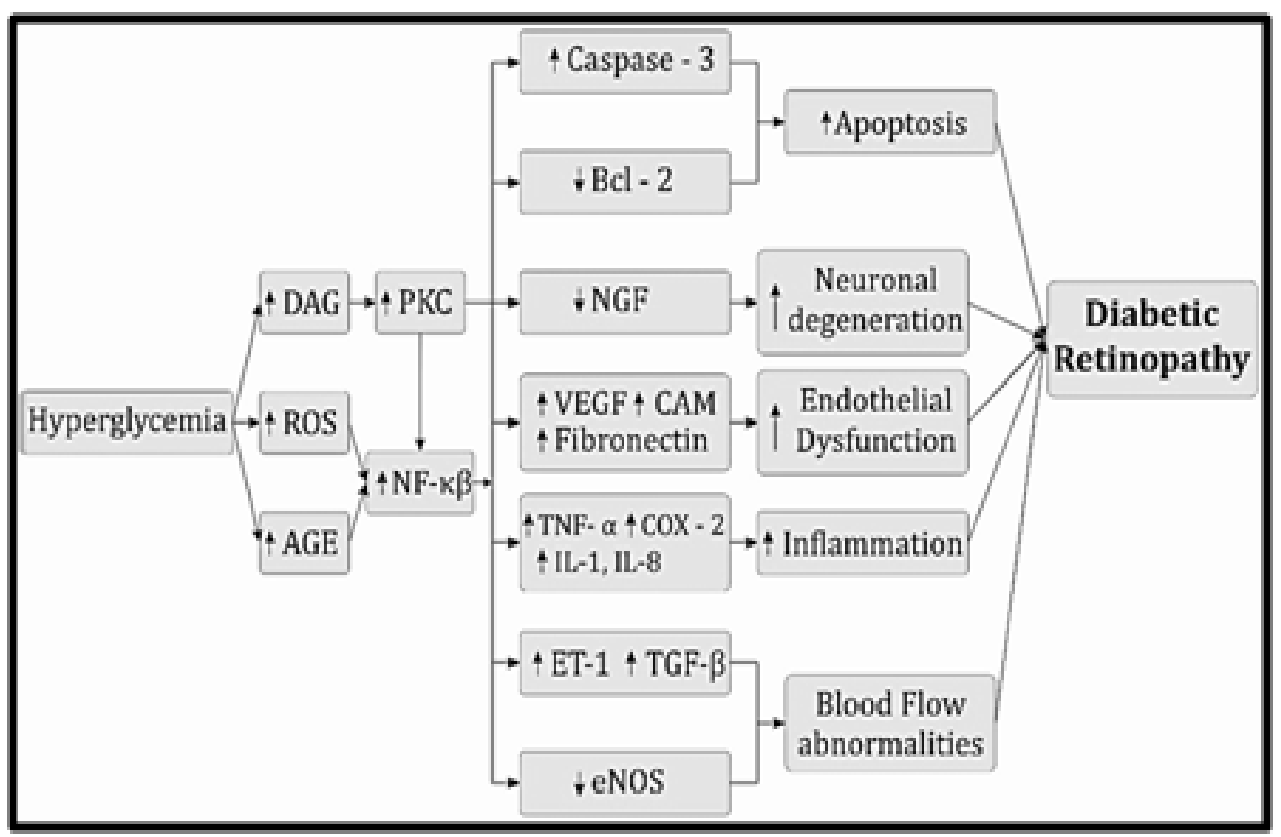

Figure 16: Role of inflammatory mediators in DR. (source: Suryavanshi \& Kulkarni et al., 2017)

\section{Oxidative stress}

In ordinary physiological conditions, reactive oxygen species (ROS) aids the body to kill the foreign materials that can leads to damage of the retinal cells. Hyperglycemia induces the formation of ROS, increased level of which activates many other pathways which help to initiate DR pathogenesis via up regulation of the poly-ADPribose polymerase (PARP) pathway as well as the down regulation of glyceraldehyde 3-phosphate dehydrogenase (GAPDH) activity (Chaturvedi et al.,1998).

\section{Symptoms of diabetic retinopathy}

Early stages of diabetic retinopathy usually are without of any symptoms. The disease often progresses unnoticed till it affects vision. "Floating" spots appears in the visual field due tobleeding from abnormal retinal blood vessels (Figure 17). Sometimes, the spots are clear on their own. But, sometimes, if left untreated, bleeding recurs which leads to permanent vision loss (Colucciello, 2004).

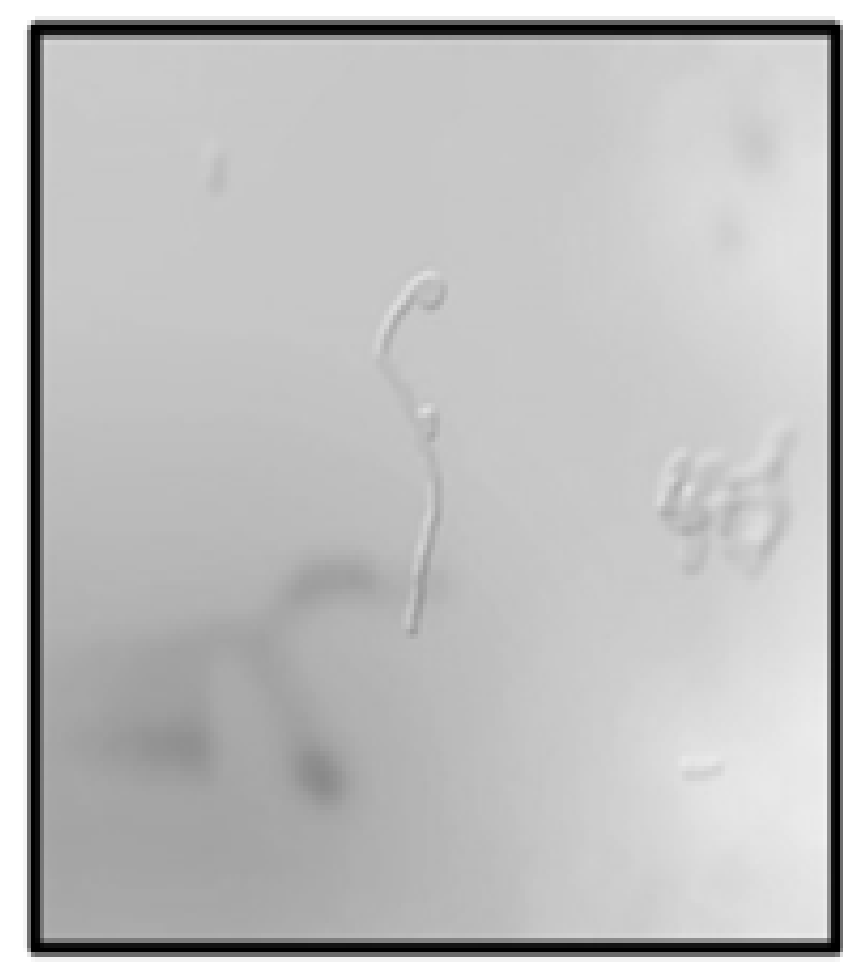

Figure 17: Eye floaters. (source: www. eyecareconcepts.com.au/eye-floatersspots.html). 
In case of diabetic macular edema (DME), it can cause blurred vision (Maheshwary et al., 2010) (Figure 18). Blurriness is a common sign of retinopathy.

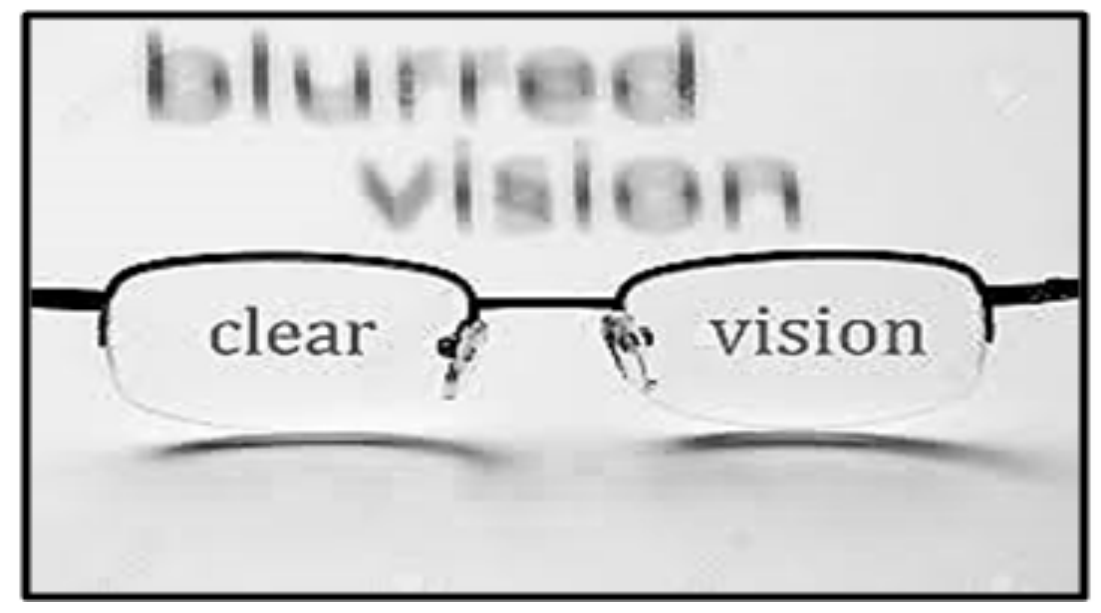

Figure 18: Blurred vision in DR. (source: www.justreversediabetes.com/diabetes-and-blurryvision.html).

This disease can give a form of colour blindness. The reason for this is the same as the blurriness. The macula, the center part of the retina can become inflamed as well as the nerve fibres located there. It mainly causes blurry vision but also causing some people to have a hard time differentiating between colours. (Falkenstein, 2008).

Another symptom of this retinopathy is darkened areas within field of vision (Figure 19). This is most commonly reported in the center of visual field. However, it can be anywhere, and it can last for anywhere from a few minutes to days on end.

\section{What It's Like}

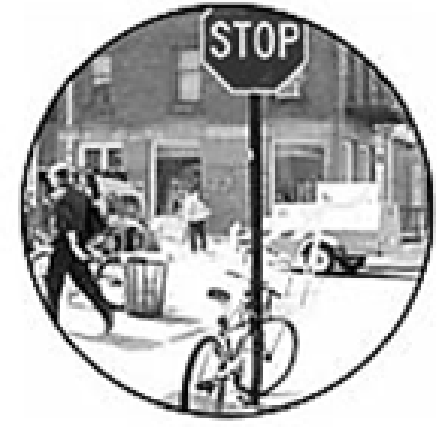

This is how a street scene looks with normal vision.

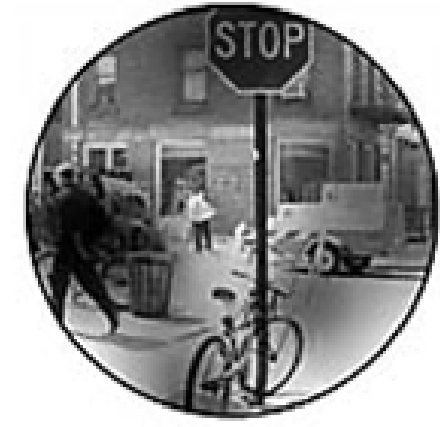

The same scene with diabetic retinopathy.

Figure 19: Darkened area at visual field. (source: li129-107.members.linode.com/about-lowvision-blindness/vision-disorders/diabetic-retinopathy/diabetic-retinopathy-overview/)

\section{Diagnosis methods of DR}

The present diagnosis methods for detection of DR are based on the following tests (Falkenstein et al., 2008) 


\section{Detection of visual acuity}

Trained ophthalmic technicians measured the best corrected visual acuity and calculated the minimum angle of resolution (MAR). I early treatment, Diabetic Retinopathy Study chart is used (Falkenstein et al., 2008) (Figure 20).

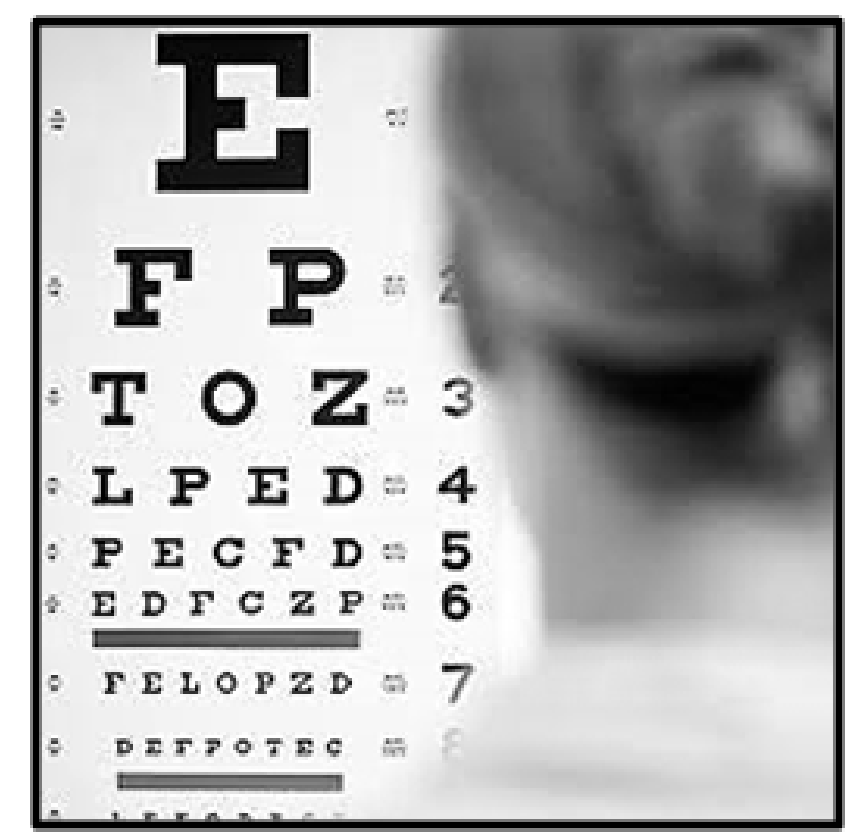

Figure 20: Visual acuity test. (source: understandingyoureyeexam.weebly.com/visual-acuitytest.html) This test determines how well a patient can see shapes and letters at a specific distance.

\section{Measurement of intraocular pressure}

Ophthalmologists use the Tonometer for detection of intraocular pressure.

\section{Examine the 'red reflex'}

This is done with the ophthalmoscope held about $50 \mathrm{~cm}$ from the patient by examining the red reflection of light emerging from the eye. Both eyes are examined and compared.

\section{Dilated funduscopic evaluation}

To assess the severity of DR the stereoscopic fund us photograph is taken for detecting the retinal thickening, hard exudates etc. Presently the grading is done on the basis of having NPDR or PDR which is determined by the presence or absence of newly formed capillaries on the surface of the retina and into the vitreous.

\section{Fluorescein angiogram}

A fluoresce in angiogram can be used to test the damaged or leaky blood vessel by using a fluorescent dye which is injected into an arm vein (Spaide, Lancins \& Cooney, 2015)

\section{Control measures of Diabetes}

Risk factors of diabetic retinopathy includes hypertension, hyperglycemia, duration of diabetes etc. A study was coordinated by the diabetes control and complications trial (DCCT) in and according to their report, the acute treatment and improved glucose control slow down its progression compared to traditional treatment methods (Duh, Sun \& Stitt, 2017).

Progression of diabetic retinopathy can be reduced by intensive glucose and blood pressure control 
but it could be difficult to manage long-term management of these risk factors (Figure 21).

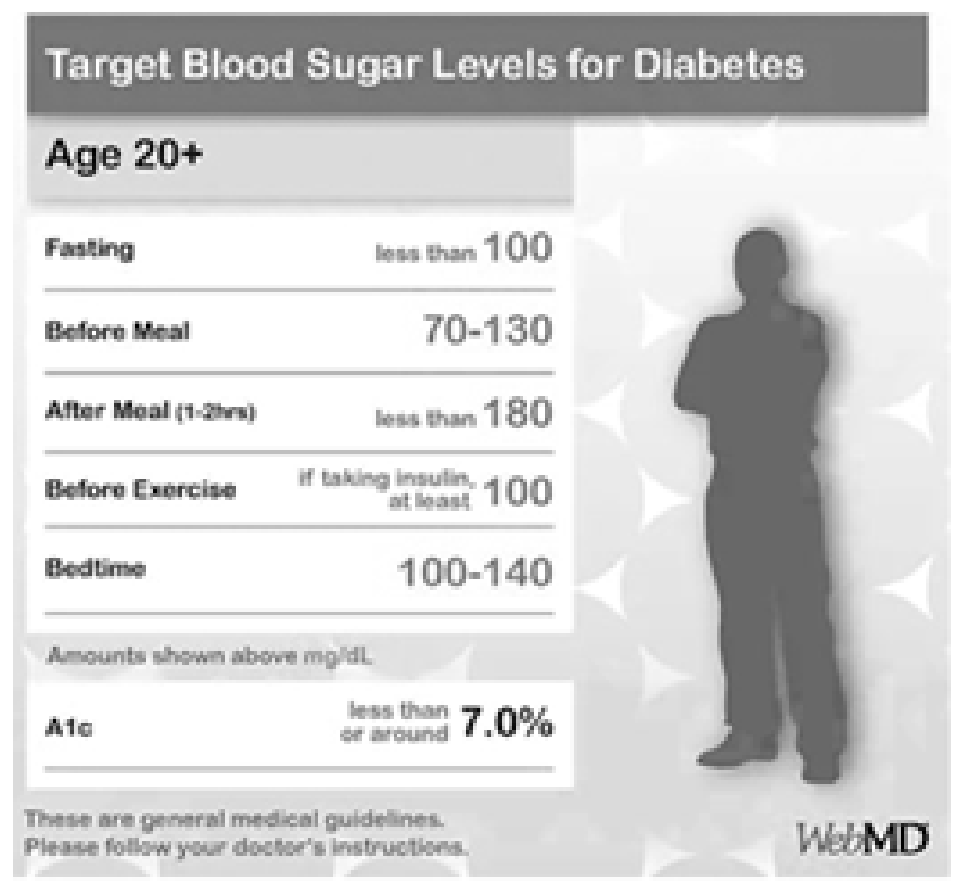

Figure 21: Target Blood Sugar Levels (adults)in diabetic patients. (source: https://www. webmd.com/diabetes/guide/normal-blood-sugar-levels-chart-adults)

\section{Treatment}

Both a doctor and an ophthalmologistare essential for the treatment of DR. Medical doctor helps to control blood sugar and can treat other diabetic related complications like kidney or heart malfunctions. Ophthalmologist uses vitrectomy (laser or a surgical procedure) which can treat directly diabetic retinopathy to stopadditional vascular damages and try to preserve vision.

\section{Photocoagulation}

Photocoagulation is a laser treatment for diabetic retinopathy. It can create a burn in the target tissue and destroy the abnormal structures in the retina (Figure 22).

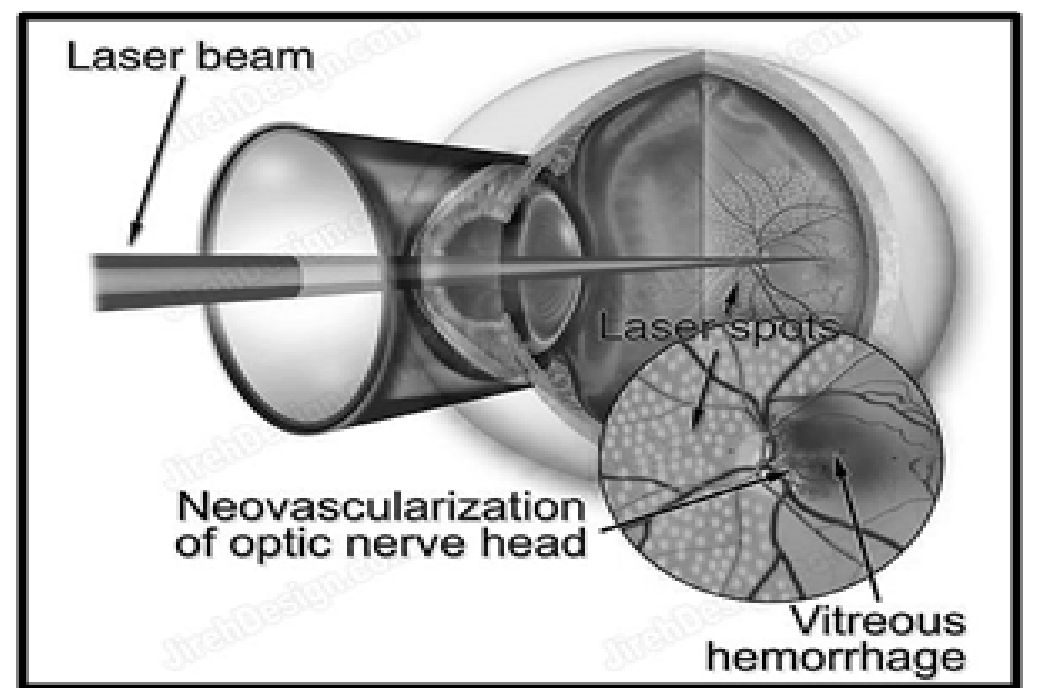

Figure 22: Photocoagulation method. (source: jirehdesign.com/stock-eye-illustrations/eyesurgery/retina-surgery-illustrations/argon-laser-diabetic-retinopathy-suvr0006/) 


\section{Vitrectomy}

If patient has a hemorrhage may recommend vitrectomy surgery. During vitrectomy, ophthalmologist drains the fluid inside the eye, clear any lingering blood and remove scar tissue that causing poor vision. The vitreous is then restored with a substitute fluid (Figure 23).

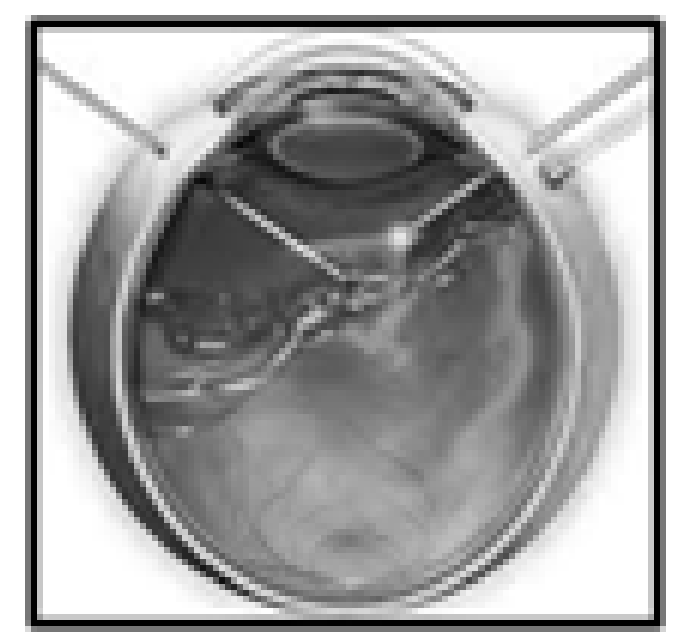

Figure 23: Procedure of vitrectomy. (source: svaretina.com/for-patients/common-disorderstreatments/vitrectomy-surgery/)

\section{Anti-inflammatory treatment}

In spitea vascular disease, many data suggest that inflammation is a potential risk factor for DR so the anti-inflammatory therapies may also veryeffective for treatment of DR. (Joussen et al., 2002; Boyer et al., 2014)

\section{CONCLUSION}

Diabetic retinopathy $(\mathrm{DR})$ is the most common problem that causes progressively damage of retina of eye leading to vision impairment and blindness. From the $90 \mathrm{~s}$, occurrence of this complication has increased. In this review article, we interpret current statistics, different stages and medical aspects of DR. The review article illustrates the comparative study of prevalence, epidemiology current statics and current studies (National and International aspects) of disease which provides information on different stages of DR and histopathological changes of retina and elucidate symptoms, risk factors, different diagnosis methods of DR. It also manifests molecular and biochemical aspects of DR which includes multiple cellular pathways and potential molecular mechanisms. The review article unravels current image of DR and set forth different treatments of the disease which includes Photocoagulation, Vitrectomy, Anti-inflammatory treatment, VEGF inhibition, Erythropoietin inhibition and retinal microvascular surgery.

DR is one of the major causes of blindness in India and treatments can help. But this condition can't be cured completely so we need to improve awareness and provide proper care is indeed present. The aim of the review article is to reduce blindness due to diabetes by informing people and make them aware about the disease.

\section{ACKNOWLEDGEMENT}

Our sincere thanks to the department of biotechnology (Government of India) who give us an opportunity by writing a review article to strengthen the basic science at undergraduate (UG) level which encourages knowledge. We are also grateful to the Principal and the DBT-STAR Coordinator, Surendranath College, for their support and encouragement in implementing this review project. 


\section{REFERENCES}

Anderson, P. W. (1995). Through the glass lightly. Science, 267(5204), 1615-1616.

Bjornstad, P., Donaghue, K. C., \& Maahs, D. M. (2018). Macrovascular disease and risk factors in youth with type 1 diabetes: time to be more attentive to treatment? The Lancet Diabetes \& Endocrinology, 6(10), 809-820.

Boyer, D. S., Yoon, Y. H., Belfort Jr, R., Bandello, F., Maturi, R. K., Augustin, A. J., ... \& Ozurdex MEAD Study Group. (2014). Three-year, randomized, sham-controlled trial of dexamethasone intravitreal implant in patients with diabetic macular edema. Ophthalmology, 121(10), 1904-1914.

Brownlee, W. E. (2016). Federal Taxation in America. Cambridge University Press.

Cai, J., \& Boulton, M. (2002). The pathogenesis of diabetic retinopathy: old concepts and new questions. Eye, 16(3), 242-260.

Chang, Y. H., Chen, P. L., Tai, M. C., Chen, C. H., Lu, D. W., \& Chen, J. T. (2006). Hyperbaric oxygen therapy ameliorates the blood-retinal barrier breakdown in diabetic retinopathy. Clinical \& Experimental Ophthalmology, 34(6), 584-589.

Chaturvedi, N., Sjolie, A. K., Stephenson, J. M., Abrahamian, H., Keipes, M., Castellarin, A., ... \& EUCLID Study Group. (1998). Effect of lisinopril on progression of retinopathy in normotensive people with type 1 diabetes. The Lancet, 351(9095), 28-31.

Colucciello, M. (2004). Diabetic retinopathy: control of systemic factors preserves vision. Postgraduate Medicine, 116(1), 57-64.

Corrêa, Z.M.D.S., Freitas, A.M. and Marcon, I.M., 2003. Risk factors related to the severity of diabetic retinopathy. Arquivos Brasileiros de Oftalmologia, 66(6), pp.739-743.

Costagliola, C., Romano, V., De Tollis, M., Aceto, F., Romano, M. R., Pedicino, C., \& Semeraro, F. (2013). TNF-alpha levels in tears: a novel biomarker to assess the degree of diabetic retinopathy. Mediators of Inflammation, 2013.

Curtis, T. M., Gardiner, T. A., \& Stitt, A. W. (2009). Microvascular lesions of diabetic retinopathy: clues towards understanding pathogenesis? Eye, 23(7), 1496-1508.

Dagher, Z., Park, Y. S., Asnaghi, V., Hoehn, T., Gerhardinger, C., \& Lorenzi, M. (2004). Studies of rat and human retinas predict a role for the polyol pathway in human diabetic retinopathy. Diabetes, 53(9), 2404-2411.

Duh, E. J., Sun, J. K., \& Stitt, A. W. (2017). Diabetic retinopathy: current understanding, mechanisms, and treatment strategies. JCl insight, 2(14).

Emanuele, N., Sacks, J., Klein, R., Reda, D., Anderson, R., Duckworth, W., \& Abraira, C. (2005). Ethnicity, race, and baseline retinopathy correlates in the veterans affairs diabetes trial. Diabetes care, 28(8), 1954-1958.

Eshaq, R. S., Aldalati, A. M., Alexander, J. S., \& Harris, N. R. (2017). Diabetic retinopathy: breaking the barrier. Pathophysiology, 24(4), 229-241.

Falkenstein, I. A., Cochran, D. E., Azen, S. P., Dustin, L., Tammewar, A. M., Kozak, I., \& Freeman, W. R. (2008). Comparison of visual acuity in macular degeneration patients measured with snellen and early treatment diabetic retinopathy study charts. Ophthalmology, 115(2), 319-323.

Gadkari, S. S., Maskati, Q. B., \& Nayak, B. K. (2016). Prevalence of diabetic retinopathy in India: The allIndia ophthalmological society diabetic retinopathy eye screening study 2014. Indian Journal of Ophthalmology, 64(1), 38.

Geraldes, P., \& King, G. L. (2010). Activation of protein kinase C isoforms and its impact on diabetic 
complications. Circulation research, 106(8), 1319-1331.

Goldin, A., Beckman, J. A., Schmidt, A. M., \& Creager, M. A. (2006). Advanced glycation end products: sparking the development of diabetic vascular injury. Circulation, 114(6), 597-605.

Hammes, H. P., Du, X., Edelstein, D., Taguchi, T., Matsumura, T., Ju, Q., .. \& Brownlee, M. (2003). Benfotiamine blocks three major pathways of hyperglycemic damage and prevents experimental diabetic retinopathy. Nature Medicine, 9(3), 294-299.

Hardin, R. C., Jackson, R. L., Johnston, T. L., \& Kelly, H. G. (1956). The development of diabetic retinopathy: effects of duration and control of diabetes. Diabetes, 5(5), 397-405.

Joussen, A. M., Poulaki, V., Le, M. L., Koizumi, K., Esser, C., Janicki, H., ... \& Adamis, A. P. (2004). A central role for inflammation in the pathogenesis of diabetic retinopathy. The FASEB Journal, 18(12), 14501452.

Kelaini, S., Cochrane, A., \& Margariti, A. (2015). Induced Pluripotent Stem Cells and Vascular Disease. In Stem Cells in Modeling Human Genetic Diseases (pp. 63-81). Springer, Cham.

Lang, G. E. (2007). Laser treatment of diabetic retinopathy. Diabetic Retinopathy, 39, 48-68

Lindholm, E., Bakhtadze, E., Sjögren, M., Cilio, C. M., Agardh, E., Groop, L., \& Agardh, C. D. (2006). The374 T/A polymorphism in the gene encoding RAGE is associated with diabetic nephropathy and retinopathy in type 1 diabetic patients. Diabetologia, 49(11), 2745-2755.

Maheshwary, A. S., Oster, S. F., Yuson, R. M., Cheng, L., Mojana, F., \& Freeman, W. R. (2010). The association between percent disruption of the photoreceptor inner segment-outer segment junction and visual acuity in diabetic macular edema. American Journal of Ophthalmology, 150(1), 63-67.

Meenakshi, S., Amsonia, P., Rani, R. U., \& Amsaveni, D. (2021). Automated Detection of Diabetic Retinopathy Using Intuitionistic Fuzzy Digital Convex Envelope Segmentation Algorithm. In IOP Conference Series: Materials Science and Engineering (Vol. 1012, No. 1, p. 012068). IOP Publishing.

Priya, P. V., Srinivasarao, A., \& Sharma, J. V. C. (2013). Diabetic Retinopathy-Can Lead To Complete Blindness. Int. J. Sci. Invent. Today, 2(4), 254-265.

Rajalakshmi, R., Rani, C. S. S., Venkatesan, U., Unnikrishnan, R., Anjana, R. M., Rani, S. J., ... \& Mohan, V. (2020). Correlation between markers of renal function and sight-threatening diabetic retinopathy in type 2 diabetes: a longitudinal study in an Indian clinic population. BMJ Open Diabetes Research and Care, 8(1), e001325.

Raman, R., Rani, P. K., Rachepalle, S. R., Gnanamoorthy, P., Uthra, S., Kumaramanickavel, G., \& Sharma, T. (2009). Prevalence of diabetic retinopathy in India: Sankara Nethralaya diabetic retinopathy epidemiology and molecular genetics study report 2. Ophthalmology, 116(2), 311-318.

Saeedi, P., Petersohn, I., Salpea, P., Malanda, B., Karuranga, S., Unwin, N., ... \& IDF Diabetes Atlas Committee. (2019). Global and regional diabetes prevalence estimates for 2019 and projections for 2030 and 2045: Results from the International Diabetes Federation Diabetes Atlas. Diabetes Research and Clinical Practice, 157, 107843.

Safi, S. Z., Qvist, R., Kumar, S., Batumalaie, K., \& Ismail, I. S. B. (2014). Molecular mechanisms of diabetic retinopathy, general preventive strategies, and novel therapeutic targets. BioMed Research International, 2014.

Schrier, R. (2000). Effect of blood pressure control on diabetic microvascular complications in patients with hypertension and type 2 diabetes. Diab Care2000, 23, 54-64.

Seddon, J. M., Cote, J., Davis, N., \& Rosner, B. (2003). Progression of age-related macular degeneration: association with body mass index, waist circumference, and waist-hip ratio. Archives of Ophthalmology, 121(6), 785-792. 
Sivakumar, R., Ravindran, G., Muthayya, M., Lakshminarayanan, S. and Velmurughendran, C.U. (2005). Diabetic retinopathy analysis. BioMed Research International, 2005(1), 20-27.

Sivaprasad, S. (2020). Tackling diabetic retinopathy from the grassroots. Indian Journal of Ophthalmology, 68(Suppl 1), S8.

Spaide, R.F., Lancins, J.M. and Cooney, M.J., 2015. Retinal vascular layers imaged by fluorescein angiography and optical coherence tomography angiography. JAMA Ophthalmology, 133(1), pp.45-50.

Studer, R. K., Craven, P. A., \& DeRubertis, F. R. (1993). Role for protein kinase C in the mediation of increased fibronectin accumulation by mesangial cells grown in high-glucose medium. Diabetes, 42(1), 118-126.

Suryavanshi, S. V., \& Kulkarni, Y. A. (2017). NF-кß: a potential target in the management of vascular complications of diabetes. Frontiers in Pharmacology, 8, 798.

Ting, T. D., Oh, M., Cox, T. A., Meyer, C. H., \& Toth, C. A. (2002). Decreased visual acuity associated with cystoid macular edema in neovascular age-related macular degeneration. Archives of Ophthalmology, 120(6), 731-737.

Usman, M. (2018). An overview of our current understanding of diabetic macular ischemia (DMI). Cureus, $10(7)$.

Verghese, S., Ranjan, R. \& Manayath, G.J. (2021). Comments on: Long-term results of a single injection of intravitreal dexamethasone as initial therapy in diabetic macular edema. Indian Journal of Ophthalmology, 69(1), p.186.

Wilkinson, C. P., Ferris III, F. L., Klein, R. E., Lee, P. P., Agardh, C. D., Davis, M., ... \& Group, G. D. R. P. (2003). Proposed international clinical diabetic retinopathy and diabetic macular edema disease severity scales. Ophthalmology, 110(9), 1677-1682.

Xu, H., Chen, M., Forrester, J. V., \& Lois, N. (2011). Cataract surgery induces retinal pro-inflammatory gene expression and protein secretion. Investigative Ophthalmology \& Visual Science, 52(1), 249-255.

Yang, C. W., Vlassara, H., Peten, E. P., He, C. J., Striker, G. E., \& Striker, L. J. (1994). Advanced glycation end products up-regulate gene expression found in diabetic glomerular disease. Proceedings of the National Academy of Sciences, 91(20), 9436-9440.

Zaki, W. M. D. W., Zulkifley, M. A., Hussain, A., Halim, W. H. W., Mustafa, N. B. A., \& Ting, L. S. (2016). Diabetic retinopathy assessment: Towards an automated system. Biomedical Signal Processing and Control, 24, 72-82.

Zong, H., Ward, M., \& Stitt, A. W. (2011). AGEs, RAGE, and diabetic retinopathy. Current Diabetes Reports, 11(4), 244-252. 


\title{
Diversity of Poisonous Snakes in India
}

\author{
Tania Das, Ramij Uddin Sardar, Arijit Das, Manish Kanti Biswas* \\ Department of Zoology, Surendranath College, Kolkata, India \\ *Corresponding Author's Email: mankbc@gmail.com
}

\begin{abstract}
Snakes are the integral part of the ecosystem. They are probably most misunderstood and universally disliked creature in world since time immemorial. Indian govt. implemented ban on trade of snake skins as they control rodents in agricultural fields. Some poisonous snake bite is may be fatal, but most of the bite is dry bite i.e. harmless to us. Among 285 species of snakes found in India, only four- spectacled cobra (Najanaja), Russell's viper (Daboia russelii), Common krait (Bungarus caerules), and sawscaled viper (Echis carinatus), called Big Four are responsible for the majority of life-threatening bites. In India about one million people bitten by snakes annually and just one in twenty dies. Venomous snakebite can create various symptoms which includes swelling and restricted pain and might become extended up to convulsions, vomiting, and even paralysis. After snake bite the biting are should be clean up, with minimal body movement and immobilizing the affected part.
\end{abstract}

Keywords: Snake; Bite; Venom; Management

\section{INTRODUCTION}

Snakes play significant role in ecosystem food chains. Snakes are found in different habitats from grasslands to wetlands, from agriculture fields toforests, and also around residential areas to deserts and sea. The snakes are predator ofrodents, birds, amphibians and mammals. Most snake species are found in the dry zones. Maybe it's due to their capability to stay alive withoutfood for a long time (Whitaker, 1978). Snakes are used to be predators of harmful insects and rodents in agriculture areas, but in India, due to lack of awareness hundreds of snakes are killed by the people. The venom machinery in the mouth of venomous snakes comprise a pair of fangs useful for the snakes to paralyze and kill the prey. Due to human fault of careless working in the agriculturalareas without protection measures, the snake bite happens. Both venomous and nonvenomous snakes are killed without knowing the snake species. Across the globe people fear the snakes forinsufficient knowledge resulting killing whenever and wherever they are seen (Kumar, 1991). All over the world, near about 3783 species of snakes are found, while in India among 518 species of reptiles 279 species are snakes within 28 families (Janani et al., 2016). They constitute approximately 10 per cent of the total snake species found in the world and $80 \%$ of them are non-poisonous (Kale, Vairale \& Ghait, 2019). The Venomous snakes comprise about 58 Species and there are only 4 species of snakes very dangerous to man, namely, Krait, Cobra, Saw-scaled viper and Russell's viper (Jadhav, Chavan \&Trimukhe, 2018).

\section{REVIEW LITERATURE AND DISCUSSION}

\section{Fang:}

Snake fangs are dedicated, gracefully modified teeth. Some are like hypodermic needles; others are more like water slides (Table: 1). But all helping the same function: to inject venom into the snake's prey. Rarely, the fangs are used in defenses, but studies show that snakes striking in defense are far less prone to insert venom than when they're striking at a prey item. 
Table 1: Types of fangs in snakes

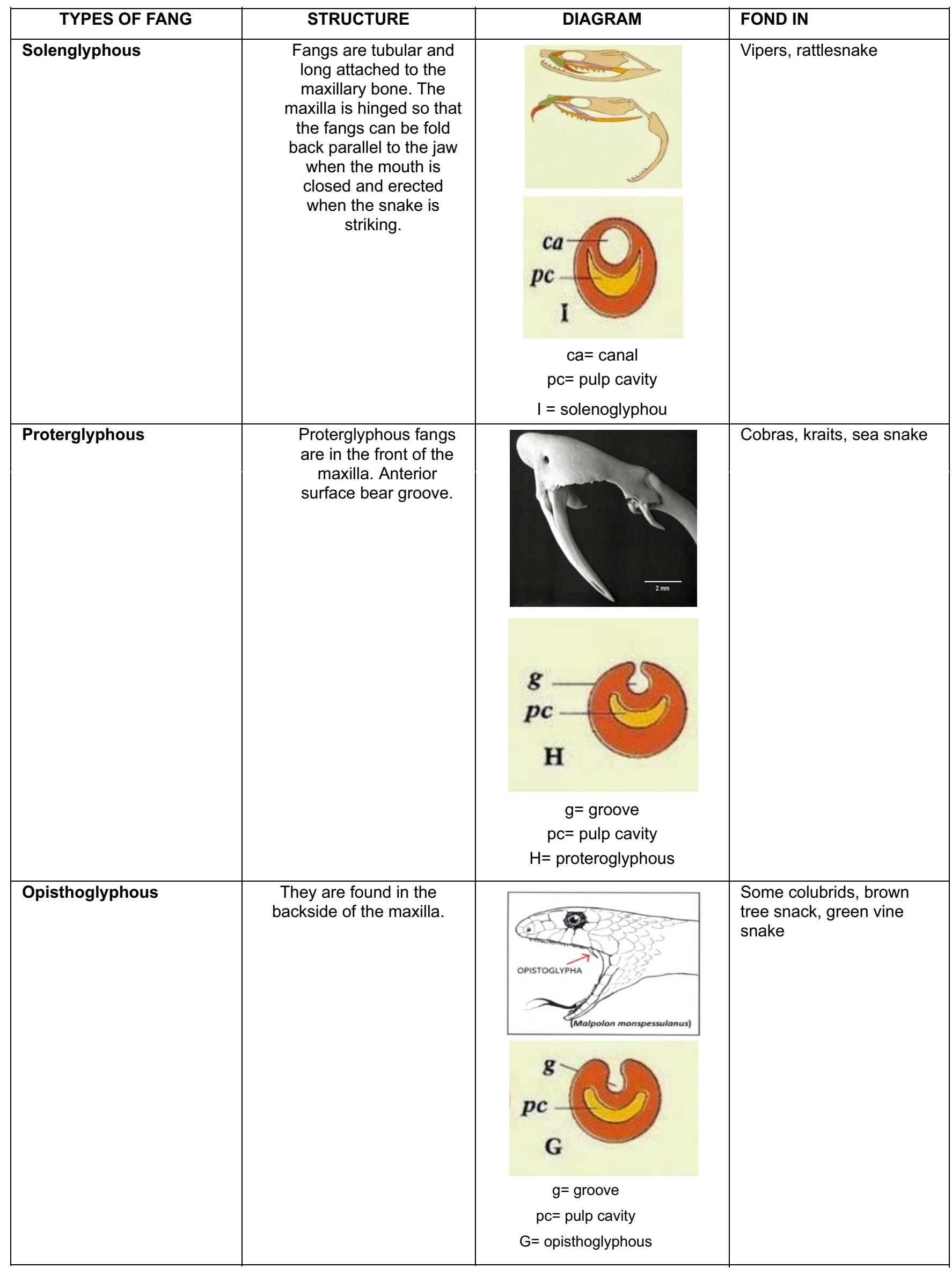




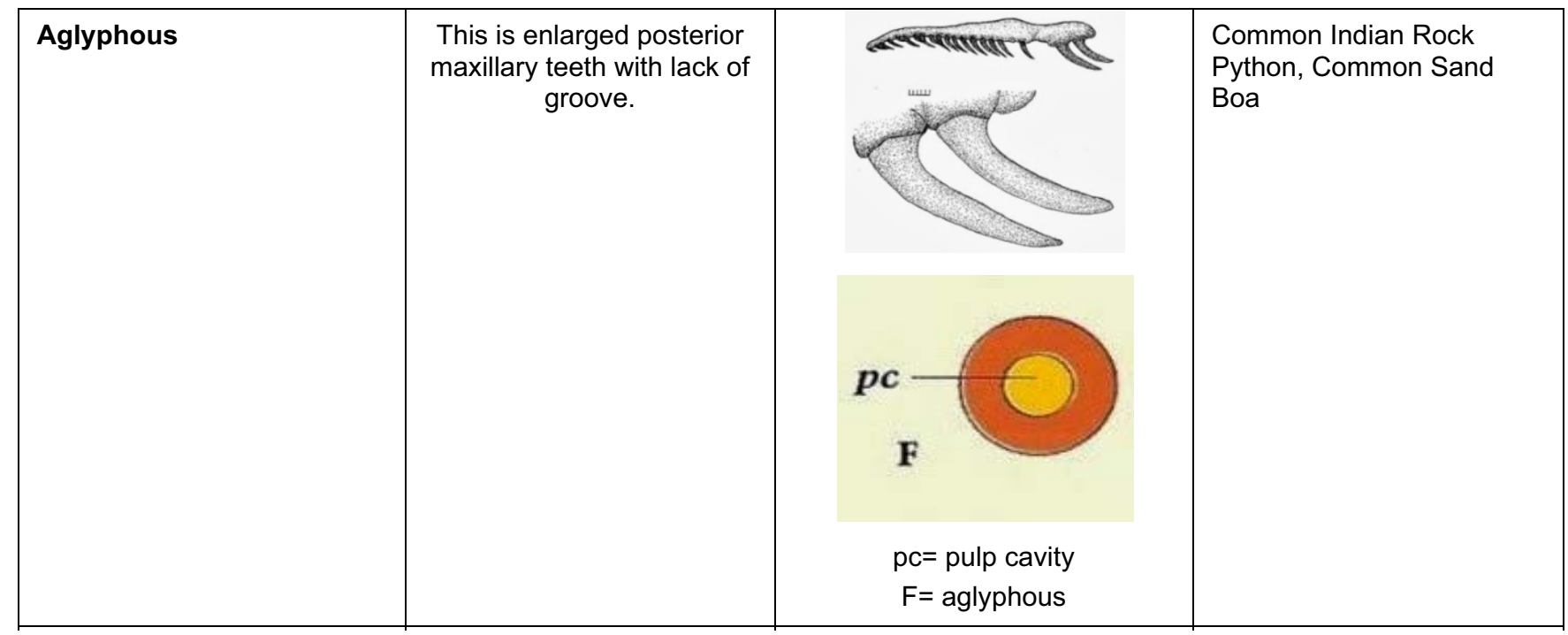

\section{Venom apparatus:}

The structure of venom apparatus in snakes varied, but some featuresremainsame. The venom releasemachinerycomprising set of fangs, venom ducts, a pair of accessory glands, and a pair of venom forming postorbital glands. These venom glands include three major cell types: conical mitochondria-rich cells, secretory cells, and basal cells which turn out venom (Figure 1).

\section{Poison gland:}

- In a venomous snake the poison gland at locaten one on either side of the apartment.

- Superior labial gland of the parotid gland modified into poison gland.

- Each venom gland is a satellite and provided with a narrow dark at its anterior end.

\section{Venom duct:}

- The duct passes forward along the side of the upper jaw and loops over itself just in front of the fang and opens either at the base of the fans or the base of the tunnel on the fangs.

- $\quad$ From the gland venom flows to the fang through the accessory gland.

\section{Accessory gland:}

- The accessory gland is the site of activation of venom components.

\section{Fangs:}

- There is one pair of fangs, located in various positions on the upper jaw.

- The fangs are used for bothvenom release during biting or spit venom.

- Maxillary teeth are transformed into enlarged and sharppoison fangs.

- $\quad$ There is the power of regeneration (when lost for some reason).

In viper, the maxilla is rotatable, which enables the fang to be erected during a bite or remain parallel to the jaw in a calm condition.

Inspite of various positions on upper jaw fangs are always located in maxilla. Moreover, in venomous elapids andcolubrid the venom fang is mounted in stable maxillary bone, and so that it is always remain erected. In viper the maxilla is rotatable, which enables the fang to be erected during a bite or remain parallel to jaw in relaxed condition. Superior snakes use venom for prey capture (Viperidae, colubrid,Actraspidae, Elapidae), are frequently referred to by the arrangement of their fangs may befront- or rear-fanged snakes. Majority of the medically important snakes are front-fanged (Viperidae and Elapidae) (Kumar, 2012). 

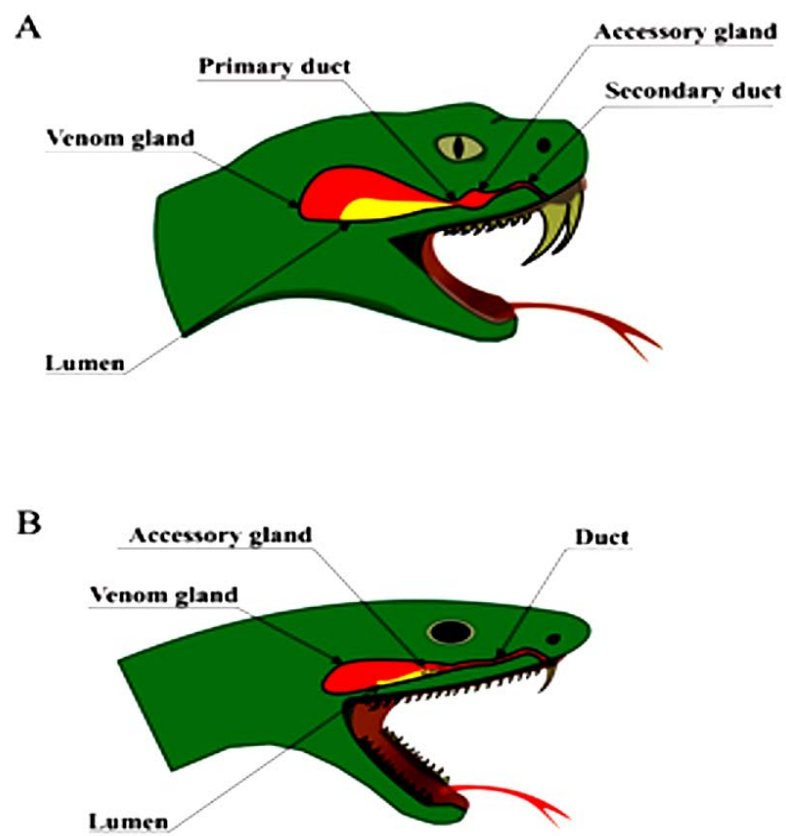

Figure 1: Snake Venom Delivery Apparatus. Schematic Anatomy of Snake Venom Delivery Systems (Jadhav, Chavan \& Trimukhe, 2018)

\section{Clinical features of snakebite:}

Due to 'fear-factor' some people may develop strange signs and symptoms, even when no venom has been injected. Some develop numbness sensation in the extremities, ripple of their hands and feet, and vertigo. Shock may develop after the bite or assumed bite, with faintness and collapse with reflective slowing of the heart (Maheshwari \& Mittal, 2004). Puzzling symptoms may appear with restlessness. With different age and size of snakebite victim the clinical appearance varies, the snake-species, the number and location of the bites, and the quantity and toxicity of the venom. Other factors of severity and outcome are listed in Table 1(Janani et al., 2016). The most common poisonous snakes in India are listed with their pictures, venom type and distribution in Table 3.

Table 2: Factors Effectingthe Severity in Snakebite

\begin{tabular}{|l|l|}
\hline \multicolumn{1}{|c|}{ Factor } & \multicolumn{1}{c|}{ Effect on Outcome } \\
\hline Mass of the victim & Greater body mass has less amount of poison per kg of body weight. \\
\hline Comorbidity & Older patients with comorbidity give up more easily to snake veom. \\
\hline Part bitten & Patients bitten on the body, face, and straight into the blood have a bad predict. \\
\hline $\begin{array}{l}\text { Bite } \\
\text { characteristics }\end{array}$ & $\begin{array}{l}\text { Bite quantity, depth of bite, bite through clothing, or other guards, the quantity of } \\
\text { poison inserted, condition of fangs, all involve the outcome. }\end{array}$ \\
\hline $\begin{array}{l}\text { Individual } \\
\text { sensitivity }\end{array}$ & The compassion to venom varies from individual to individual. \\
\hline Snake species & The effect of snake venom in victim varies from species to species. \\
\hline $\begin{array}{l}\text { Secondary } \\
\text { infection }\end{array}$ & Presence or absence of microbes or pathogens in the mouth of the snake. \\
\hline Treatment & Way of treatment using both first aid and antivenom dose. \\
\hline
\end{tabular}


Table 3: Commonpoisonous Snakes of India

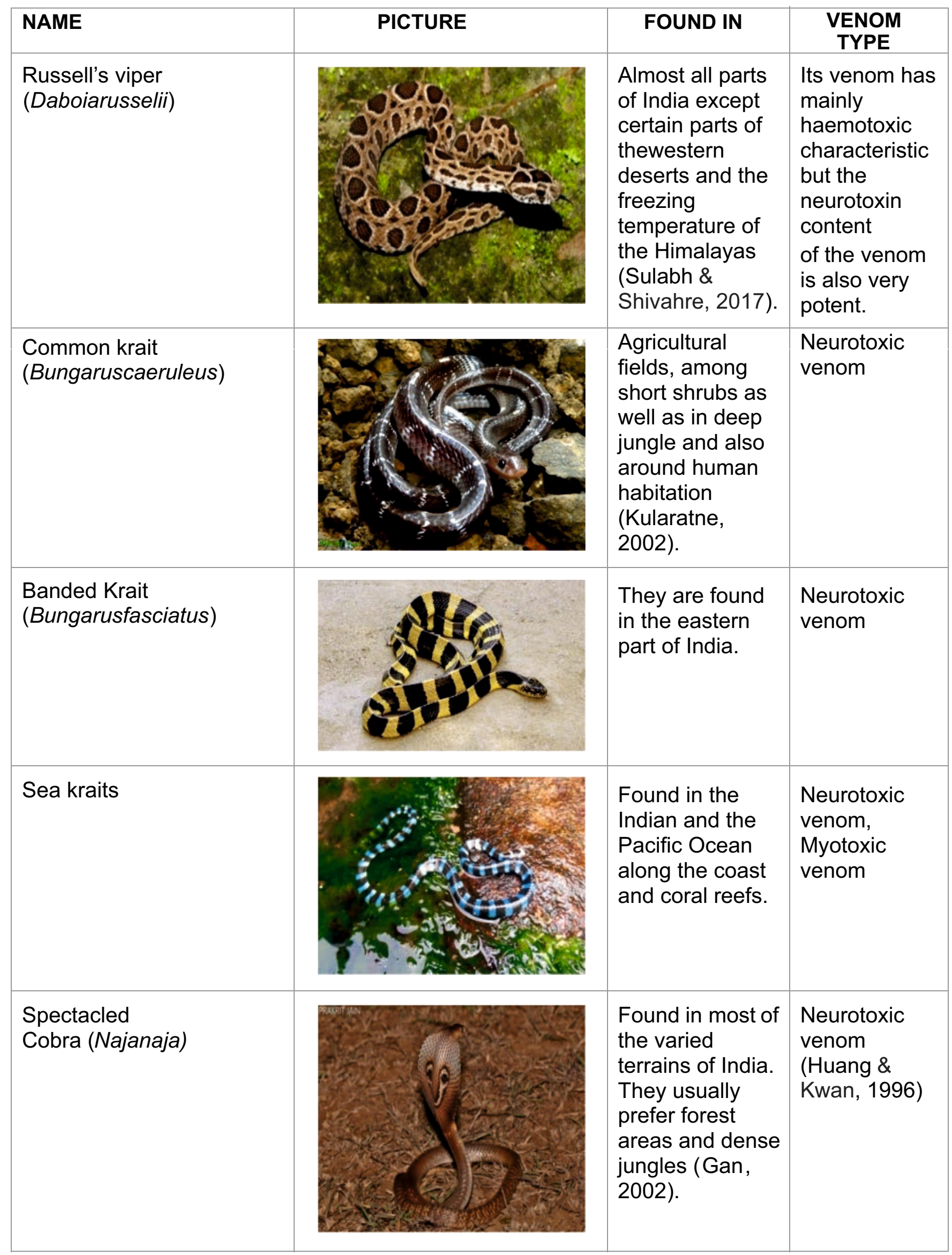




\begin{tabular}{|c|c|c|c|}
\hline $\begin{array}{l}\text { Saw-scaled viper } \\
\text { (Echiscarinatus) }\end{array}$ & 5 & $\begin{array}{l}\text { Found in northern and } \\
\text { southern India. }\end{array}$ & $\begin{array}{l}\text { haemotoxic venom } \\
\text { neurotoxic venom }\end{array}$ \\
\hline $\begin{array}{l}\text { King Cobra } \\
\text { (Ophiophagushannah) }\end{array}$ & & $\begin{array}{l}\text { Found in India all along } \\
\text { the Western Ghats, the } \\
\text { eastern coasts of } \\
\text { Andhra Pradesh and } \\
\text { Orissa, the northeastern } \\
\text { jungles and tea gardens } \\
\text { as well as the lower } \\
\text { Foothills of Himalayas. }\end{array}$ & $\begin{array}{l}\text { Neurotoxic venom, } \\
\text { cytotoxic venom. } \\
\text { (Kumar et al., } \\
\text { 1999). }\end{array}$ \\
\hline $\begin{array}{l}\text { Malabar pit viper } \\
\text { (Trimeresurusmalabaricus) }\end{array}$ & & $\begin{array}{l}\text { Found along the coastal } \\
\text { areas ofWestern Ghats } \\
\text { comprising mostly of } \\
\text { Kerala and covers the } \\
\text { majority of Maharashtra }\end{array}$ & Haemotoxic venom \\
\hline $\begin{array}{l}\text { Bamboo pit viper } \\
\text { (Trimeresurusgramineusi) }\end{array}$ & & $\begin{array}{l}\text { Found only in southern } \\
\text { India, these snakes } \\
\mathrm{m} \text { a k e p e } \mathrm{f} \mathrm{e} \mathrm{c} \mathrm{t} \\
\text { camouflage for the } \\
\text { green shades of } \\
\text { bamboo and other trees } \\
\text { (Kale, Vairale \& Ghait, } \\
\text { 2019). }\end{array}$ & Haemotoxic venom \\
\hline
\end{tabular}

\section{CONCLUSION}

Snake and the mildly venomous vine snake. Though many different kinds of poisonous snakes are found in India the snakes most commonly found to cause death. Polyvalent anti-venom containing anti-venom of all the big four poisonous snakes has been developed. However, it is not sufficiently potent to completely eradicate deaths caused due to the bite of any of the big four. Every species of snake has different constituents in its venom and require specific anti-venom preparation, to make anti-venom more efficient and potent. The anti-venom should be prepared specifically according to the species of the snake delivering the poison. This is also the reason for less potency of the polyvalent anti-venoms prepared against the big four snakes, which is used when the identification of the species to which the snake belongs is not possible. So, a much specific approach towards the development of anti-venoms exactly according to the type of snake would be a better alternative. General teaching and education of the common people about the identification of the common snakes will also help in resolving the matter more discretely. 


\section{ACKNOWLEDGEMENT}

The authors express their sincere thanks to Department of Biotechnology, Government of India for the funding from DBT-STAR College grant, under which this review project was conducted. The authors are also grateful to the Principal and the DBT-STAR Coordinator, Surendranath College, for their support and encouragement in implementing this review project at undergraduate level.

\section{REFERENCE}

Gan, G. (2002). Snake venoms. The Singapore Family Physisian, 28, 40-54.

Huang, S. J., \& Kwan, C. Y. (1996). Inhibition by multivalent cations of contraction induced by Chinese cobra venom cardiotoxin in guinea pig papillary muscle. Life Sciences, 59(4), PL55-PL60.

Jadhav, P. L., Chavan, S. P., \&Trimukhe, H. S. (2018). Snake species diversity and their distribution in and around Nanded city, Maharashtra, India. Journal of Entomology and Zoology Studies, 6(4), 18551860.

Janani, S., Maheshwaran, E. G., Leenu, J., Samuel, T., \&Raveen, R. (2016). Diversity of snakes rescued at Chennai, Tamil Nadu, India. International Journal of Fauna and Biological Studies, 3(5), 81-86.

Kale, G. B., Vairale, S., \&Ghait, S. N. (2019). Study of snake species diversity in rural and semi urban areas of Buldhana district of Maharashtra, India. International Journal of Life Sciences (Amravati), (Special Issue A13), 219-225.

Kularatne, S. A. M. (2002). Common krait (Bungarus caeruleus) bite in Anuradhapura, Sri Lanka: a prospective clinical study, 1996-98. Postgraduate Medical Journal, 78(919), 276-280.

Kumar, S.R. (1991). Snakebite: an experience. Journal of Bombay Natural Hisory Society, 88, 460. https://www.biodiversitylibrary.org/page/48673890\#page/8/mode/1up

Kumar, T. K. S., Pandian, S. T. K., Jayaraman, G., Peng, H. J., \& Yu, C. (1999). Understanding the structure, function and folding of cobra toxins. Proceedings-National Science Council Republic of China Part a Physical Science and Engineering, 23, 1-19.

Kumar, V. M. S. (2012). The conservation of Indian Reptiles: An approach with molecular aspects. Reptile Rap.

Maheshwari, M., \& Mittal, S. R. (2004). Acute myocardial infarction complicating snake bite. The Journal of the Association of Physicians of India, 52, 63-64.

Sulabh, S., \& Shivahre, P. R. (2017). Common poisonous snakes of india-A review. World Journal of Pharmaceutical Research.

Whitaker, R. (1978). Common Indian Snakes: aField Guide. Macmillan, New Delhi. 


\section{Published by :}

Lincoln Research and Publications Limited, Australia in collaboration with

Lincoln University College, Malaysia

ISBN: 978-0-6488798-4-8

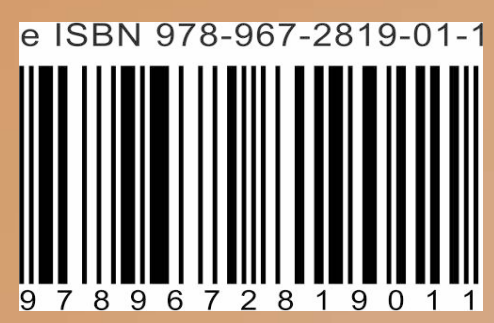

\section{www.lincolnrpl.org o www.lucp.net}

